\title{
Determinants of Pricing in the EU Fresh Fruit and Vegetable Markets: The EU Entry Price System and Spatial and Vertical Price Transmission
}

\author{
Dissertation \\ zur Erlangung des Doktorgrades \\ der Fakultät für Agrarwissenschaften \\ der Georg-August-Universität Göttingen \\ vorgelegt von \\ Linde Johanna Götz \\ geboren in Neustadt an der Weinstraße
}

Göttingen, Mai 2008 
D 7

1. Referentin/Referent: Prof. Dr. Stephan von Cramon-Taubadel

2. Korreferentin/Korreferent: PD Dr. Harald Grethe

Tag der mündlichen Prüfung: 20. Juni 2008 


\section{Contents}

Acknowledgements....................................................................................................................... 2

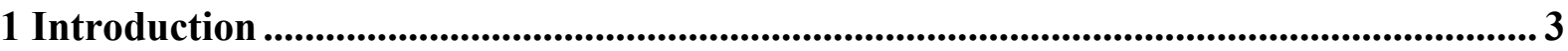

2 Overview of the Research Papers .......................................................................................... 6

3 The EU Import Regime for Oranges-Much Ado about Nothing? ................................ 19

4 The EU Entry Price System for Fresh Fruits and Vegetables - Paper Tiger or

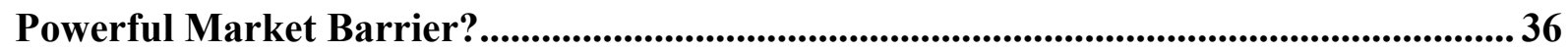

5 Does the Entry Price System Restrict Fresh Fruit and Vegetable Exports from China

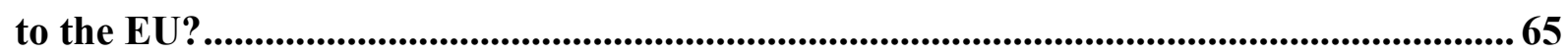

6 Vertical Price Transmission in the International Fresh Fruit and Vegetable Supply

Chain: Israeli Grapefruit Exports to the EU after Export Market Liberalization

7 Threshold Adjustment and/or Threshold Cointegration? An Application to the

8 Discussion of Results and Ideas for Future Research ................................................... 124

9 Unresolved Issues in Price Transmission Analysis.................................................... 132 


\section{Acknowledgements}

This $\mathrm{PhD}$ thesis is part of the research project "Deregulation of Agricultural Trade in Israel and its Influence on Agricultural Product Trade with the European Union”, a cooperation of the Department of Agricultural Economics and Rural Development, University of Göttingen, Germany, and the Department of Agricultural Economics and Management, The Hebrew University, Israel.

I am indebted to my advisor Prof. Stephan von Cramon-Taubadel for his continuous guidance, motivating support, and valuable comments on my research papers. Many insightful and encouraging discussions with him at all stages of this project provided me with helpful feedback and kept my work going.

I am very grateful to PD Dr. Harald Grethe for his extensive support and for giving me a jump-start to the analysis of EU import policy for fresh fruits and vegetables. His encouragement and enthusiasm motivated me very much.

Many thanks to Prof. Bernhard Brümmer for his excellent support and his patience with my frequent questions.

Furthermore, I am thankful to Dr. Yael Kachel for the field excursions to Israeli fresh fruit and vegetable businesses, which provided me with a much better understanding of the market institutions and processes behind the data. Also, I appreciate the generosity of experts and traders in the fresh fruit and vegetable business to share their knowledge and insight in many telephone interviews and discussions during the Fruit Logistica fair.

Markus Fahlbusch provided excellent research assistance. I am grateful to my colleague Rico Ihle for many helpful discussions.

I am much obliged to Edgar Preugschat, particularly for sharing the ups and downs of writing a $\mathrm{PhD}$ thesis.

Finally, I am very grateful to my parents for all their support.

I gratefully acknowledge funding of my research by the Volkswagen Stiftung including a research stay at the Department of Agricultural Economics and Management, The Hebrew University, Israel, in February 2006. I appreciate additional funds provided by the Schaumann-Stiftung to extend my research. Further, I am thankful to Prof. Thomas Glauben for giving me the time to complete my work at the Leibniz-Institute for Agricultural Development in Middle and Eastern Europe. 


\section{Introduction}

This $\mathrm{PhD}$ thesis comprises five papers which are related to price determination in the $\mathrm{EU}$ markets for fresh fruits and vegetables (FFV). This market is of particular relevance since the $\mathrm{EU}$ is the largest importer of FFV in the world, accounting for $27 \%$ of the value of world fruits and vegetable imports (intra-EU trade excluded, EU-27) in 2007 (UN, 2008). Global trade in FFV has increased by 16\% from 2003 to 2007. The share of EU imports of world imports increased from $26 \%$ to $35 \%$ for fruits and from $10 \%$ to $15 \%$ for vegetables in 2007 compared to 2003.

The analysis conducted in each of the five studies is based on data of FFV prices which is characterized by several particularities. Typical for FFV price data is the high volatility and the incidence of extreme values. This may be caused by high variability of market supply resulting from irregular size and timing of harvest caused by changing weather conditions, and seasonality of supply. Also, the short-run supply elasticity is low and can be balanced out only to a low degree by storage due to the high perishability of the products. Further, seasonally changing composition of the supply of differing origin may imply changing price regimes prevailing in a market throughout a year. These particularities may pose an extra challenge to analysis of FFV markets. For example, seasonally restricted supply implies that the time-series data is discontinuous.

In addition, EU import prices of some kinds of FFV are influenced by the EU entry price system (EPS). In combination with ad valorem tariffs of up to $20 \%$ the EPS aims to protect EU growers of 15 kinds of selected fruits and vegetables against international competition. Analogously to a minimum import price, the EPS is designed to restrict imports below the product-specific, politically chosen entry price. In some cases a lower, preferential entry price, which is granted within trade preferences, applies (a detailed explanation of the functioning of the EPS is given in chapter 4, section 2).

The EPS is the topic of three research papers aiming to fill the knowledge gap on its effects on EU import prices. In the paper "The EU Import Regime for Oranges -Much Ado about Nothing?" we focus on the relevance of the EU import system, comprising the EU entry price system (EPS) and trade preferences, for EU imports of oranges from the Mediterranean (MED) countries ${ }^{1}$. We comprehensively investigate the effectiveness of the EPS for all relevant kinds of fruits and vegetables and countries of origin in the paper "The EU Entry Price System for Fresh Fruits and Vegetables - Paper Tiger or Powerful Market Barrier?”. Based on results gained in the latter paper we deepen the analysis of the relevance of the EPS

\footnotetext{
${ }^{1}$ The MED countries comprise Algeria, Cyprus, Egypt, Israel, Jordan, Lebanon, Malta, Morocco, Palestine Authority, Syria, Tunisia, and Turkey, the countries covered by the Euro-Mediterranean Partnership. Cyprus and Malta became EU members in 2004.
} 
for EU imports originating in China in the paper "Does the Entry Price System restrict Fresh Fruit and Vegetable Exports from China to the EU?".

The indicators developed as measures for the relevance of the EPS explicitly take into account that the fresh fruit and vegetable price data often contain extreme values which may influence the value of an indicator more than proportionally and therefore may distort results.

The next two papers empirically investigate price transmission. Basically, price transmission describes the relationship of prices at different stages of the marketing process (vertical price transmission) or in spatially segmented markets (horizontal or spatial price transmission). The degree of price transmission is an indicator for market integration and efficiency ${ }^{2}$. In a perfectly integrated market price shocks are transmitted completely from one marketing stage to the next or between spatially separated markets. On the other extreme, markets are not integrated and separated if no price shocks are transmitted between markets (FACKLER AND GoodwIN, 2001).

In both studies, price transmission is analyzed by a model based on a cointegration approach. It is assumed that although both price data series evolve in parallel in the long-run and thus a long-run equilibrium exists, these prices might deviate in the short-run. Thus, the higher the degree of market integration and efficiency, the more do prices move in parallel in the longrun. Further, the higher the degree of market integration, the faster are short-run deviations from the long-run equilibrium corrected, and the more complete and faster are price shocks transmitted.

In the paper titled "Vertical Price Transmission in the International Fresh Fruit and Vegetable Supply Chain: Israeli Grapefruit Exports to the EU after Export Market Liberalization” we measure vertical price transmission in the Israeli citrus export sector. We analyze if price changes in the EU market for Israeli grapefruits are transmitted asymmetrically by Israeli exporters to Israeli grapefruit growers.

Price transmission is asymmetric (symmetric) if price increases are transmitted with different (identical) speed than price decreases to the next stage of the marketing chain. Price transmission is supposed to be symmetric in a competitive market environment. Asymmetry in price transmission may be induced by a bundle of different factors. In the majority of price transmission studies, asymmetry is linked with non competitive market structure, such as monopoly and oligopoly (MEYER AND VON CRAMON-TAUBADEL, 2004).

A challenging problem in this study is the discontinuity in the price data due to the seasonality of grapefruit production. To the best of our knowledge, price transmission analysis based on discontinuous data has been conducted only once before by WARD (1982).

\footnotetext{
${ }^{2}$ Market integration and efficiency are defined and distinguished in chapter 9.
} 
In the paper "Threshold adjustment and/or threshold cointegration? An application to the German apple market" we focus on horizontal (i.e. spatial) price transmission.

Spatial markets are in equilibrium and thus are efficient if the prices of a homogeneous good in two spatially separated markets differ exactly in the transaction costs, primarily transport costs, of moving a good from one to the other market (Law of one Price). Prices might diverge from this equilibrium in the short-run, but arbitrage activities drive the price difference between the markets back towards this equilibrium. Thus, in spatially efficient markets there are no opportunities for spatial arbitrage profits that can be exploited by spatial traders (FACKLER AND GOODWIN, 2001).

In this paper we develop a method which allows analyzing price transmission in a setting characterized by irregular seasonal threshold effects in price transmission regimes induced by changing market conditions (e.g. trade volume, price) and which seems to be typical for fresh fruits and vegetables.

The following chapters are structured as follows. Chapter 2 first provides an overview on all research papers whereas the research papers themselves are presented in Chapters 3 to 7 . Chapter 8 discusses results and develops ideas for further research. Chapter 9 outlines some unresolved issues prevailing in price transmission analysis.

\section{References}

FACKLER, P. AND B. GoOdwIN (2001): Spatial Price Analysis, in: Gardner, B. and G. Rausser (eds.): Handbook of Agricultural Economics, Vol. 1B: 971-1024.

Meyer, J. AND S. von Cramon-Taubadel (2004): Asymmetric Price Transmission: A Survey, Journal of Agricultural Economics, Vol. 55: 581-611.

WARD, R.W. (1982): Asymmetry in Retail, Wholesale, and Shipping Point Pricing for Fresh Vegetables, in: American Journal of Agricultural Economics, Vol. 64(2): 205-212.

UN (2008): UN Comtrade Database, www.comtrade.un.org, accessed May 18, 2008. 


\section{Overview of the Research Papers}

This chapter provides an overview of each of the five research studies by highlighting the research question addressed, the motivation for the study, the research method, the data basis, and the results.

A) The EU Import Regime for Oranges-Much Ado about Nothing? (jointly with Harald Grethe)

The paper was published in the Journal of International Agricultural Trade and Development 3(1) in 2007. Earlier versions of this paper were presented as Poster paper at the IAAE Annual Conference, August 12-18, 2006, Gold Coast, Australia, as Contributed paper at the $98^{\text {th }}$ EAAE Seminar "Marketing Dynamics within the Global Trading System: New Perspectives", June 29 - July 2, 2006, Chania, Crete, Greece, and at the workshop "Trade of Agricultural Products", The Hebrew University of Jerusalem, Februar 13, 2006, Rehovot, Israel.

This paper focuses on the influence of the EU import system on fresh orange exports from the MED countries. In particular, we analyze whether the EU import system contributed to the substantial decline of orange exports from Morocco and Israel, the primary MED countries supplying oranges to the EU market, concurrently with the increase of supply of oranges by Spain since the eighties. We take into account possible effects induced by the transition of the EU reference price to the entry price system in 1995 and the improvement of Spain's access to the EU market in the course of Spain joining the EU in 1986.

The EU import system for fresh oranges follows two contrary goals. First, it aims to protect $\mathrm{EU}$ orange growers. To this end it calls for an ad valorem tariff that varies seasonally between $3.2 \%$ and $16 \%$, and an entry price that applies from December to the end of May. Analogous to a minimum import price, the entry price system seeks to restrict EU imports below the orange entry price level of $354 € /$ ton.

Second, the EU intends to induce orange imports from preferred trading partners by granting trade preferences using three kinds of instruments. A general tariff reduction lowers the mostfavoured-nation (MFN) ad valorem tariff by a certain percentage for any amount of orange exports. In contrast, a tariff rate quota (TRQ) and an entry price quota (EPQ) are both limited quantitatively, where the respective preference is applicable only up to a certain export quantity as given by the size of the quota. The TRQ specifies a MFN tariff reduction of a 
particular size. The EPQ is the most comprehensive trade preference since it includes a tariff elimination as well as a preferential entry price, which is lower than the MFN entry price.

Thus, the EU import system for fresh oranges is highly complex and evolved in a multitude of separate agreements and regulations. It causes considerable transaction costs in policy design and administration as well as in its effects on trading companies.

We evaluate whether the entry price affects the EU import price level for oranges and if the MED actually utilize the EU trade preferences for oranges based on two indicators, following the approach in CHEMNITZ AND GRETHE (2005). The effectiveness of the entry price is analyzed by comparing the observed EU import price, measured by the standard import value (SIV), with the entry price for oranges. The utilization of the preferential quotas, comprising TRQ and EPQ, is investigated by comparing the development of the orange export quantity to the evolution of the total preferential quota for oranges (quota fill rates). In addition, based on legal documents we analyze in detail how EU orange market access conditions for the MED have developed and compare this to Spain, particularly during the transition phase (March 1986 to December 1995) over which Spain became a member of the EU.

Regarding the entry price, results suggest that the import price of oranges originating in the MED countries is about $40 \%$ higher than the MFN entry price on average (1995-2005). EU import prices for oranges originating in Morocco and Israel are on average $71 \%$ and $112 \%$ higher than the preferential entry price level respectively, implying that these countries do not utilize the preferential entry price. Egypt is the only MED country benefiting to some degree from the preferential entry price.

With respect to preferential quotas, we find that about $70 \%$ of EU orange imports during the EU orange harvest season originate in the MED countries, and enter the EU tariff-free since 1993 due to preferential tariff elimination within a quota. The analysis also reveals that although orange quotas increased from 1991 to 2004 for the MED countries as a whole, actual exports declined concurrently. Therefore, the quota fill rate fell for most MED and the unweighted average quota fill rate is $60 \%$ or less since 1997.

Additionally, it becomes evident that the improvement of the EU market access for Spain due to EU accession occurred almost parallel to the enhancement of preferences for the MED countries until 1993. Further, since orange exports from Morocco and Israel enter the EU tariff free since 1993, and both countries do not utilize the preferential entry price, any erosion of orange trade preferences compared to Spain, which is suggested by CIOFFI AND DELL'AQUILA (2004, p. 175), can not originate from the EU import system for oranges.

Moreover, our results do not confirm the finding by CIOFFI AND DELL'AQUILA (2004, p. 178) that the introduction of the entry price for oranges in 1995 , which was about $34 \%$ higher than 
the former reference price, fostered the decline of the Israeli and Moroccan orange exports to the EU. Instead, we show that a preferential entry price for oranges originating in Israel and Morocco, which was equal to the former reference price, was introduced concurrently with the implementation of the EPS in December 1995. Thus, Morocco and Israel were not subject to the MFN entry price for oranges at any time.

In conclusion, our results suggest that the EU import system for oranges, which was changed substantially since the eighties, is not decisive for the decline of orange exports to the EU by MED countries, particularly Morocco and Israel. Further, the contribution of the external market regulation to the protection of EU growers is small. Even EU trade preferences for oranges seem not to have triggered additional exports by the MED countries.

Thus, a policy recommendation following from our analysis (which could be implemented as a part of the ongoing Barcelona Process) would be to abolish the EU import restrictions for oranges from the MED countries to avoid transaction costs involved in the administration and further development of the EPS.

\section{B) The EU Entry Price System for Fresh Fruits and Vegetables - Paper Tiger or Powerful Market Barrier? (jointly with Harald Grethe)}

This paper is accepted for publication in the Food Policy. An earlier version of this paper was published under the title "The Relevance of the EU Entry Price System for Imports of Fresh Fruits and Vegetables”, as an IATRC Working Paper 07-03 in 2007. Also, the paper is accepted as Contributed paper to the EAAE 2008 Congress, August 26-29, 2008, Gent, Belgium.

We investigate the effectiveness of the EU entry price system (EPS) on import prices of each of the 15 fruits and vegetables to which the EPS applies and for all major countries of origin. The central question is whether the EPS influences EU import prices and if EU import prices would change if the EPS was abolished.

This comprehensive study of the EPS aims to fill the knowledge gap on the impact of the EPS on EU import prices. This information is required for the quantitative analysis of the effects of a liberalisation of FFV trade between the EU and MED countries within the ongoing Barcelona process, as GARCÍA ÁlvAREZ-COQUE AND JORDÁN GALDUF (2007) point out. Further, our analysis intends to shed light on the question if the EPS is relevant for FFV exports by developing countries. It is claimed that the EPS hinders developing countries to utilize their competitive cost advantage in horticultural production by exporting fruits and 
vegetables at low prices to the EU market (DIOP AND JAFFE (2005)). Also, in the context of the ongoing Doha negotiations of the World Trade Organization (WTO), knowledge about the effectiveness of the EPS could serve as a basis for deciding how much negotiation effort to put into its maintenance (from an EU perspective) or its dismantling (from a third-country perspective).

We use a unique data set comprising about 60,000 observations of the standard import value (SIV), a synthetic import price calculated by the European Commission based on wholesale price notations, for the period 1995 to 2005.

The effectiveness of the EPS is measured by two indicators. One indicator is the percentage share of observations for which the SIV is lower than the entry price. A drawback of this indicator, which was used in the previous study (GOETZ AND GRETHE, 2007a), is that it is confined to the effects of the EPS on import prices which are lower than the entry price. Thus, this indicator does not cover the influence of the EPS on import prices which are higher than the entry price. Therefore, we construct a second indicator. We assume that exporters might supply their product at the lowest possible price while complying with the entry price, thereby utilising their competitive cost advantage only to such a degree that additional specific tariffs are avoided. This implies a concentration of observations of import prices higher than the entry price slightly above the entry price. The degree of accumulation of observations of import prices around the entry price is measured by the 0.05 -quantile of the distribution of import prices which are higher than the entry price. Since the variance of this distribution varies by product and country of origin, the 0.05 quantiles with differing variance are not exactly comparable. Also, we find the effectiveness of the EPS to be proportional to the 0.05 quantile within a certain interval only. Therefore, we standardize the 0.05 quantile by dividing it by the standard deviation and taking logarithm.

We do not consider the skewness coefficient of the import price distribution as a further indicator since skewness, which is correlated to the effectiveness to the EPS, is also strongly influenced by accidental extreme values, which are typical for fresh fruit and vegetable price data (see chapter 1), and prevail in several of the data series. Further, our indicators are not based on the assumption that import prices are normally distributed since we find truncated or two-peaked price distributions of import prices in several cases.

These two indicators serve as variables in a cluster analysis that attributes 81 product-specific and country-specific imports of fresh fruits and vegetables into four clusters which differ in the degree they are affected by the EPS.

We find that the relevance of the EPS differs across products and across countries of origin for most kinds of fruits and vegetables. For example, our results suggest that the relevance of 
the EPS for cucumbers and tomatoes depends on the country of origin, which is in contrast to LÓPEZ AND MUÑIZ (2007).

Further, our findings suggest that for any simulation modelling of trade liberalisation for fruits and vegetables between the MED and the EU, it is essential to take into account the EPS in modelling exports of courgettes, cucumbers and tomatoes by Morocco, apples, clementines, lemons and tomatoes by Turkey and artichokes by Egypt for which the EPS is a powerful market barrier. On the other hand, there is little value in modelling the effects of the EPS for exports of apricots, cherries, mandarins, nectarines and peaches and table grapes by Turkey, mandarins and oranges by Morocco, mandarins, oranges, plums and table grapes by Israel, and table grapes by Egypt, for which the EPS is indeed a "paper tiger".

We find that the EPS is of little relevance for developing countries other than the EU's direct southern neighbours. Since the least developed countries are exempted from the EPS as part of the Everything-But-Arms initiative, the EPS is of no relevance for Sub Saharan Africa except for South Africa. The EPS is also of minor importance for Latin American countries (Brazil, Argentina, Chile and Uruguay) since they face substantial transport costs implying that they have to export to the EU market at relatively high prices.

Regarding the Doha negotiations, EU producers would be most interested in the maintenance of the EPS for artichokes, courgettes, cucumbers, lemons, plums and tomatoes. However, they might not at all be affected by the dismantling of the EPS for apricots, mandarins, oranges, peaches and nectarines and table grapes. Since our results suggest that the EPS is most relevant for Morocco, Turkey and countries of Eastern Europe as Bosnia-Herzegovina and Serbia-Montenegro, as well as China and South Africa, these countries might benefit most if the EPS was abolished.

As a conclusion, since the EPS is in contradiction with the WTO rules, causes substantial administrative and transaction costs, and is redundant in 64 of the 81 analyzed product and country specific cases, the EPS should be abolished.

\section{C) Does the Entry Price System Restrict Fresh Fruit and Vegetable Exports from China to the EU? (jointly with Harald Grethe)}

This paper was presented as Contributed paper at the International Agricultural Trade Research Consortium (IATRC) Summer Symposium, July 8-9, 2007, Bejing, China. 
The objective of this paper is to analyze if the relevance of the EPS for Chinese fruit exports to the EU has changed in the time period 1997-2005 and to explore the factors which might have influenced this development.

This paper is motivated by the results of the analysis of the overall effectiveness of the EPS (Goetz And Grethe, 2007b), which show that China was besides Poland, Turkey and Uruguay one of the few countries for which the EPS matters regarding apples. With respect to pears China was even the only country for which our results suggested that the EPS is highly relevant. In this paper we analyze the question why the EPS is particularly relevant for Chinese apple and pear exports to the EU in spite of the far distance to the EU market.

China is a relatively new supplier of fresh fruits and vegetables to international markets, and has increased its share rapidly. Specifically, China started to deliver significant amounts of apples to the EU market not before 1995. In 2005, China exported one million tons of apples, of which about 5\% were imported by the EU. Regarding pears, China's net exports amounted to 300,000 tons in 2005 , of which about $4 \%$ were exported to the EU.

In this paper we supplement our results of the study on the overall relevance of the EPS (GOETZ AND GRETHE, 2007b) for apples and pears originating in China by calculating the two indicators for the efficiency of the EPS on a yearly basis. In addition, we test if skewness could serve as a further possible indicator for measuring the effectiveness of the EPS.

For apples we find that the share of negative observations rises up to $27 \%$ and the 0.05 quantile decreases to 1.93 in 2005, indicating that the relevance of the EPS has increased in the time period 1997-2005. In addition, the mean of the SIV distribution decreases to about $20 \%$ above the entry price in 2005 . Yet, the concurrent increase of skewness of the SIV distribution cannot be observed. Instead, the skewness coefficient decreases in this time period.

For pears, the share of negative observations rises up to $46 \%$ and the 0.05 quantile is in most years relatively low throughout the time period 1998-2005. Also, we find skewness clearly increasing since 2000 and highly negatively correlated with the mean of the distribution, indicating that the lower the mean, the more right-skewed is the distribution.

These results confirm that skewness may serve as an indicator for the relevance of the EPS in some cases only and therefore is problematic to utilize as a general indicator.

One factor explaining why the EPS is particularly relevant for China is that it has relatively low transportation costs compared to other apple producing countries supplying to the EU market. Traders report that the cost to ship a 20 ton container from China to the EU is about $2500 €$, in contrast to a container from Chile that costs $4500 €$. This results in a significant 
price difference, equivalent to about $17 \%$ of the average Chinese SIVs for apples and pears in 2005.

For the future, traders expect that Chinese traders to ship less quantity to the EU in the future as low selling prices on the EU market, together with specific tariffs, have resulted in occasional losses for Chinese traders in recent years.

Also, the future development of Chinese apple and pear exports to the EU will depend strongly on domestic market conditions in China. Chinese net exports of apples accounted for only $2.4 \%$ of total production-for pears this share was $2.8 \%$ (FAOSTAT, 2007). Thus, small relative changes in the Chinese consumption pattern could affect exports significantly. If the share of disposable income in Chinese GDP increases, this may induce much higher domestic consumption of fresh fruits and vegetables and thus may reduce the export potential. Such a development would make the EPS less relevant in protecting the EU market.

\section{D) Vertical Price Transmission in the International Fresh Fruit and Vegetable Supply}

\section{Chain: Israeli Grapefruit Exports to the EU after Export Market Liberalization}

(jointly with Stephan von Cramon-Taubadel and Yael Kachel)

An earlier version of this paper is forthcoming in Heißenhuber, A., L. Kirner, S. Pöchtrager and K. Salhofer, (2008): Conference proceedings of the GeWiSoLa 47 Annual Conference “Agrar- und Ernährungswirtschaft im Umbruch”, September 26-28, 2007, Munich, Germany. It was presented as Contributed paper at the "1. Mediterranean Conference of Agro-Food Social Scientists", April 23-25, 2007, Barcelona, Spain, and at the GeWiSoLa $47^{\text {th }}$ Annual Conference “Agrar- und Ernährungswirtschaft im Umbruch”, September 26-28, 2007, Munich, Germany.

The motivation for this study is that international FFV trade is especially susceptible to the abuse of market power. FFV export sectors are often characterized by low competition. Also, transparency how the grower price is determined is extremely low due to the consignment system. For small farmers, particularly in developing countries, to profit from the increasing international trade in FFV it is decisive that they are well integrated into the supply chain and benefit adequately from the profits achieved from international FFV trade.

This study is unique in investigating vertical price transmission in the international supply chain for fresh fruits and vegetables (FFV). To cast light on the issue of market power we study vertical price transmission between Israel and France in the imperfectly competitive 
Israeli citrus export sector, which emerged after the former parastatal marketing board was liberalised in 1991.

It is often hypothesised that imperfect competition will manifest itself in asymmetric price transmission (MEYER AND VON CRAMON-TAUBADEL, 2004; RAPSOMANIKIS ET AL., 2006). In most cases, it is predicted that market power will lead to positive asymmetric price transmission meaning that e.g. margin-squeezing decreases in output prices will be transmitted faster and more completely than margin-stretching price changes.

Israeli grapefruit exports provide a case study that is well suited to isolating the link between market power and APT. First, the Israeli citrus export sector is dominated by 4 export companies so imperfect competition is possible and might be reflected in APT. Second, due to the consignment system the grower price of the Israeli grapefruits exported to the EU is determined ex-post only after the products are sold in the export market, and FFV products are highly perishable, several other factors that might cause APT such as adjustment and menu costs, caused by adjusting a firm's prices to a change in the price or quantity of inputs or outputs and inflation, can be disregarded. Furthermore, asymmetry in price transmission can not result from market intervention by the EU since the EU entry price system does not apply to grapefruits. Third, the post-liberalisation period that we study includes two important developments that may have changed exporters' pricing behaviour. These developments are the enforcement of the minimum price agreement in 1994/95, and the decrease of the EU import price by $30 \%$ in the time period underlying this analysis.

Our empirical model explicitly accounts for the hypothesis that the exporters' pricing behaviour may have changed by allowing for a structural break in the cointegration regression. The unknown timing of the break-point in the cointegration regression is determined by the GREGORY AND HANSEN (1996) test. In addition, we distinguish a heterogeneous, volatile phase directly after liberalization from a more homogeneous, calm phase some years later, and estimate the error correction model for those two regimes separately.

The estimation is based on firm-specific grower prices of the three largest exporters and French import price data as a proxy for the EU import price in the time period 1991-2000.

Our results suggest that price transmission behaviour of Israeli citrus exporters changed in the post-liberalization period after 1991. In particular, we find that Agrexco and Tnuport, two of the three largest exporters, transmitted grapefruit price changes in the EU import market asymmetrically to Israeli citrus growers in the phase with heterogeneous pricing in the first years after liberalization. Though, price transmission of all three exporters became more 
symmetric in the subsequent phase (second half of the 1990s) which was characterized by more homogeneous pricing.

The identified asymmetry was beneficial to exporters and damaging to growers by increasing and decreasing profits, respectively. This supports the assumption that the detected asymmetry in price transmission is caused by the abuse of market power by the exporters. Mehadrin might have less motivation for exerting market power over the citrus growers since it partially retains the citrus produce form its own citrus plantations.

We also find that the specified asymmetry in price transmission is economically significant providing further evidence that the observed asymmetry in price transmission was caused by Israeli exporters exerting market power over Israeli citrus growers. Our results indicate that growers' seasonal losses resulting from asymmetric price transmission amounted to as much as $4.0 \%$ and $3.9 \%$ of citrus growers' total revenues delivering to Agrexco and Tnuport, respectively, and hence presumably a much larger share of their profits.

The findings of this study are in line with the results of former studies on the effects of a market liberalization confirming that there is a high risk that market power is exerted by the newly established export companies. Yet, our results suggest that the governmental intervention in the liberalized market has induced the exporters to cease transmitting prices asymmetrically so that the efficiency of the Israeli citrus international marketing channel improved in the long-run.

\section{E) Threshold adjustment and/or threshold cointegration? An application to the German} apple market (jointly with Stephan von Cramon-Taubadel and Emma Stephens)

It is accepted for presentation as Contributed paper at the IAMO Forum 2008 "Agri-Food Business: Global Challenges - Innovative Solutions”, 25-27 June 2008, Halle (Saale), Germany, the 2008 CAES/NAREA Joint Conference, June 30 to July 1, 2008, Quebec, Canada and the EAAE 2008 Congress, August 26-29, 2008, Gent, Belgium.

We propose a three-step procedure to estimate a regime-specific vector error correction model (VECM) to analyze price transmission and market integration. In our model, not only the short-run adjustment process towards equilibrium is non-linear, as in threshold VECM and Markov switching VECM frameworks, but also the long-run equilibrium relationship itself can display non-linearity, as a function of the size of a stationary threshold variable with respect to a threshold value. 
This paper is motivated by the fact that applications of the VECM to analyze price transmission are based on the assumption that prices are linked by a constant long-run equilibrium relationship while allowing for threshold or switching effects in the short-run adjustment process towards this equilibrium. In particular, the threshold VECM (e.g. Goodwin And Piggott, 2001; Balcombe, Bailey AND BrooKs, 2007) distinguishes between regimes depending on whether the deviation of prices from their long-run equilibrium, in other words the error correction term (ECT), is above or below a threshold value. In the Markov-switching VECM (e.g. BRUEMMER ET AL., forthcoming), shifts between different adjustment regimes are triggered by unobservable state variables. Though, both models maintain the hypothesis of a linear long-run equilibrium relationship. This may not always be justifiable. Failing to account for non-linearity in the long-run relationship can lead to misleading estimates of this relationship and the adjustment processes that lead to it.

Our VECM model approach is unique in explicitly testing the null hypothesis of linear cointegration against the alternative of threshold cointegration based on a test proposed by GONZALO AND PITARAKIS (2006). In this test, a supLM test is conducted based on a LagrangeMultiplier test statistic for a model which compares a linear with a threshold cointegration regression for all possible threshold points determined by the value of the observed threshold variable.

Our approach differs from other approaches allowing for a structural break in the long-run price transmission relationship since it enables the long-run relationship to move back and forth between regimes as a function of a threshold variable, rather than hypothesizing a oneoff break in this relationship. This is an appealing model in settings, in which price transmission is hypothesised to be seasonal, but the seasonal pattern in question is irregular from year to year, depending on e.g. weather and harvests in different regions that are linked by trade.

We apply this procedure to 942 observations of daily apple prices on wholesale markets in Hamburg and Munich. Due to substantial seasonal variation in supply quantities, prices and price differences, we hypothesize that the equilibrium relationship between prices in Hamburg and Munich is subject to threshold effects, with the share of German as opposed to imported apples in total wholesale trade acting as the threshold variable. This is substantiated by the results of the Chow break point test on the estimated VECM. The p-values drop into the critical range cyclically, indicating that the price relationship is not stable but changes seasonally. Utilizing a smoothed threshold variable we determine two significant thresholds and distinguish four different regimes. We estimate an unrestricted ECM distinguishing 4 regimes by including corresponding dummy variables. The unrestricted model has the 
advantage to test within an F-test not only if the short-run adjustment parameters but also the cointegration vectors of the regimes are significantly different. The four regimes can be characterized as follows:

In summer, when the regime "Season Beginning" prevails, the remainder of the stored apples of the previous harvest and the first apples of the new harvest are supplied to the market and the share of German apples traded is below $12 \%$. The rapid error correcting behaviour of the Hamburg price can be attributed to the substantial amounts of apples sold from Munich to Hamburg in this time period, since the harvest season starts earlier in the southern parts of Germany. Since the Munich price does not error correct thus it dominates the Hamburg price. The fast contemporaneous price adjustment on both markets might result from the strong influence of the actual quantity of apples supplied on the market price since the supply of fresh German apples is heavily restricted in this time period.

In the regime "Harvest" in fall, the daily traded share of newly harvested apples grown in Germany increases, implying that prices of German apples and the apple price level in general declines, inducing apple supply of southern hemisphere countries to vanish. Then, the share of German apples traded lies between $12 \%$ and 34\%. The intense integration of markets with the relatively highest speed of adjustment to the long-run equilibrium can be traced back to the large amounts of apples traded between northern and southern Germany in this time period.

During the regime "Main Season" in winter, when almost exclusively German and Italian apples stored in the regional warehouses are supplied to the wholesale markets, the share of German apples traded is above $34 \%$. The low speed of adjustment to the long-run equilibrium of prices in both markets might be attributed to the relatively low mean wholesale price level in this time period limiting profitable interregional trade and implying a low degree of market integration.

The regime "Storage Clearing" prevails in spring, when the share of stored German apples sold declines and apple warehouses are cleared, whereas the share of newly harvested apples grown in southern hemisphere countries increases. Then, the share of German apples traded lies between $12 \%$ and $34 \%$. Similarly to the previous regime, the relatively low price level reduces the margin for profits resulting from interregional trade. In addition, since apples have been stored for quite some time at this point of time, once they are taken out of the warehouse, the apples perish very fast which is a further factor restricting interregional trade implying low market integration. This explains why cointegration can not be identified unambiguously in this regime implying that if prices on the Hamburg and Munich market drift apart their long-run equilibrium level, the deviation is not corrected. 
As a conclusion, the consideration of threshold-type non-linearity not only in adjustment but also in equilibrium represents a useful addition to the methodological toolbox for price transmission and market integration analysis. Further, our suggested approach appears particularly suitable to capture irregular seasonal threshold effects in price transmission typical for fresh fruits and vegetables.

\section{References}

BAlcombe, K., BAiley, A. And J. BRoOKS (2007): Threshold Effects in Price Transmission: The Case of Brazilian Wheat, Maize and Soya Prices, American Journal of Agricultural Economics 89(2): 308-323.

Bruemmer, B., S. von Cramon-Taubadel, S. AND S. Zorya (forthcoming): A Markovswitching vector error correction model of vertical price transmission between wheat and flour in Ukraine, European Review of Agricultural Economics.

Chemnitz, C. And H. Grethe (2005): EU Trade Preferences for Moroccan Tomato Exports Who Benefits? Contributed paper, $\mathrm{XI}^{\text {th }}$ Congress of European Association of Agricultural Economists, Copenhagen. August, 24-27.

Cioffi, A. AND C. DELl'Aquila (2004): The Effects of Trade Policies for Fresh Fruit and Vegetables of the European Union, Food Policy, Vol. 29: 169-185.

von CRAmon-TAubadel, S., J.P. Loy And J. MeYer (2006): The Impact of Cross-Sectional Data Aggregation on the Measurement of Vertical Price Transmission: An Experiment with German Food Prices, in: Agribusiness, Vol. 22 (4): 1-18.

Diop, N. AND S. M. JAFFEE (2005): Fruits and Vegetables: Global Trade and Competition in Fresh and Processed Product Markets. In: Aksoy. M. A. and J. C. Beghin. Global Agricultural Trade and Developing Countries. World Bank, 237-257.

García Álvarez-Coque, J. M. And J. M. Jordán Galduf (2007): Agro-food Trade and the Euro-Mediterranean Agreements, Contributed paper, 1. Mediterranean Conference on Agrofood Social Scientists (103rd EAAE Seminar), Barcelona, Spain, April 23-25.

Goetz, L. AND H. Grethe (2007a): The EU Import System for Oranges: Much Ado about Nothing? Journal of International Agricultural Trade and Development 3(1).

Goetz, L. AND H. Grethe (2007b): The Relevance of the EU Entry Price System for Imports of Fresh Fruits and Vegetables, IATRC Working Paper 07-0. 
Gonzalo, J. And J. Pitarakis (2006): Threshold Effects in Cointegrating Relationships, Oxford Bulletin of Economics and Statistics, 68 (Supplement): 813-833.

Goodwin, B.K. AND N. Piggott (2001): Spatial market integration in the presence of threshold effects, American Journal of Agricultural Economics 83: 302-317.

Gregory, A.W. and B.E. HANSEN (1996): Residual-based tests for cointegration in models with regime shifts, in: Journal of Econometrics, Vol. 70: 99-126.

LÓPEZ, J. A. AND I. A. MUÑIZ (2007): Measuring Domestic Implications of Tariff Cuts under EU Entry Price Regime, Contributed paper, 1. Mediterranean Conference on Agro-food Social Scientists (103rd EAAE Seminar), Barcelona, Spain, April 23-25.

Meyer, J. AND von S. CRAmon-TAubadel (2004): Asymmetric price transmission: A survey, in: Journal of Agricultural Economics, Vol. 55: 581-611.

Rapsomanikis, G., D. Hallam AND P. CONFORTI (2006): Market integration and price transmission in selected food and cash crop markets of developing countries: review and applications, in: SARRIS, A. AND D. HALlAM: Agricultural Commodity Markets and Trade, Edward Elgar, Cheltenham, UK: 187-217.

TIFFIN, R. AND P.J. DAWSON (2000): Structural breaks, cointegration and the farm-retail price spread for lamb, Applied Economics, Vol. 32: 1281-1286.

WARD, R.W. (1982): Asymmetry in Retail, Wholesale, and Shipping Point Pricing for Fresh Vegetables, in: American Journal of Agricultural Economics, Vol. 64(2): 205-212. 
3 The EU Import Regime for Oranges-Much Ado about Nothing?

jointly with Harald Grethe 


\title{
THE EU IMPORT REGIME FOR ORANGES - MUCH Ado ABOUt Nothing?
}

\author{
Linde Götz ${ }^{1}$ and Harald Grethe ${ }^{2}$ \\ ${ }^{1} \mathrm{PhD}$ Student, Institute of Agricultural Economics and Rural Development, \\ Georg-August-University Göttingen, Germany \\ ${ }^{2}$ Assistant Professor, Institute of Agricultural Economics and Social Sciences, \\ Humboldt-University of Berlin, Germany
}

\begin{abstract}
EU orange imports are restricted by ad valorem tariffs and an entry-price system establishing a minimum import price. In addition, the EU applies a comprehensive system of trade preferences. Despite its complexity, the effectiveness of the EU import system for oranges is low. Import prices for oranges from extra-EU countries are $40 \%$ higher than the EU entry price on average. Also, at least $72 \%$ of extra-EU orange imports during the EU harvest season enter the EU tariff free. Concordantly, the preferential entry price is not utilized by eligible orange exporters, and quota fill rates have decreased over time. The analysis suggests that EU trade preferences for oranges were not decisive for the development of Mediterranean countries' orange exports to the EU. In the light of the low effectiveness of the entry-price system for oranges and high transaction costs involved, the system's abolishment should be considered.
\end{abstract}

Keywords: trade preferences, oranges, tariff rate quota, entry price, Mediterranean countries JEL code: F13, Q17, Q18.

\section{Introduction}

The EU import system for oranges is designed to follow two contrasting goals. On the one hand, it intends to protect EU orange growers by the means of an ad valorem tariff and a de facto minimum import price established by the EU entry-price system. This allows creating an EU market price, which is higher than the world market price. On the other hand, the EU aims to induce orange imports from preferred trading partners by a comprehensive system of trade preferences. Countries that are granted trade preferences have superior EU orange market access compared to countries that are not covered by trade preferences, the so-called mostfavored-nation (MFN) suppliers. Preferential market access is established by a preferential ad valorem tariff, which is lower than the MFN ad valorem tariff, and is in some cases supplemented by a preferential entry price, which is lower than the MFN entry price.

This article investigates the effectiveness of the EU import system for oranges. In particular, it addresses the following questions. Does the EU entry price indeed affect the EU import price level for oranges? Do the preferred trading partners actually utilize the trade preferences for oranges? Is the origin of EU orange imports determined by the development of trade 
preferences? We show that the EU market price for oranges is substantially higher than the entry price and hence, the entry-price system for this product has little effect. In addition, it becomes evident that EU trade preferences for oranges are complex. They are specified, negotiated and repeatedly revised for each preferred trading partner individually.

The results of this study demonstrate that, in contrast to its complexity, the effectiveness of the EU import system for oranges is low with respect to its goals, i.e. protecting EU orange growers on the one hand and creating orange imports from the preference receiving countries on the other. The low effectiveness of trade preferences for oranges in contrast to their high complexity is in line with findings from other authors for trade preferences in general (e.g., Brenton and Ikezuki, 2005), as well as for the Mediterranean countries (Grethe, Nolte, and Tangermann, 2005).

This article is organized as follows. Section 2 describes in detail EU orange imports and import policies for oranges, including trade preferences. Section 3 explains the methodology and presents the results of the analysis of the entry-price system and the preferential orange quotas. Section 4 draws summarizing conclusions and puts results in perspective.

\section{EU Imports of Oranges}

The EU is the largest orange importer in the world. In 2003, EU orange imports amounted to about 805,000 metric tons (mt), equivalent to $23 \%$ of world orange imports (FAO, 2005). In addition, EU intra-trade of oranges, originating in the southern EU member countries Spain, Italy, Greece, and Portugal, accounted for about 1.6 million tons, of which 74\% originated in Spain. The non-EU countries exporting oranges to the EU can be divided into northern and southern-hemisphere suppliers, characterized by distinct orange export seasons. The major northern-hemisphere suppliers are the Mediterranean countries (MED), ${ }^{3}$ which accounted for $88.4 \%$ of total EU orange imports from January to June in the period 1988-2004, and Cuba (Eurostat). In contrast, the orange export season of the primary southern-hemisphere suppliers, including South Africa, Brazil, Argentina, Uruguay, Zimbabwe, and Swaziland lasts from June to November (figure 1).

The most important MED countries exporting oranges to the EU are Morocco and Israel. Both countries' orange exports decreased markedly between 1988 and 2004 (figure 2). Additional MED countries exporting oranges to the EU are Egypt, Cyprus, Tunisia, and Turkey. Cypriot

\footnotetext{
${ }^{3}$ The MED countries comprise Algeria, Cyprus, Egypt, Israel, Jordan, Lebanon, Malta, Morocco, Palestine Authority, Syria, Tunisia, and Turkey, the countries covered by the Euro-Mediterranean Partnership. Cyprus and Malta became EU members in 2004.
} 
orange exports to the EU have decreased while Egyptian orange exports have recently increased. MED orange exports to the EU represented $72 \%$ of EU imports from non-EU countries during the EU harvest season lasting from November 1 to May 31 in the period 1988 to 2004.

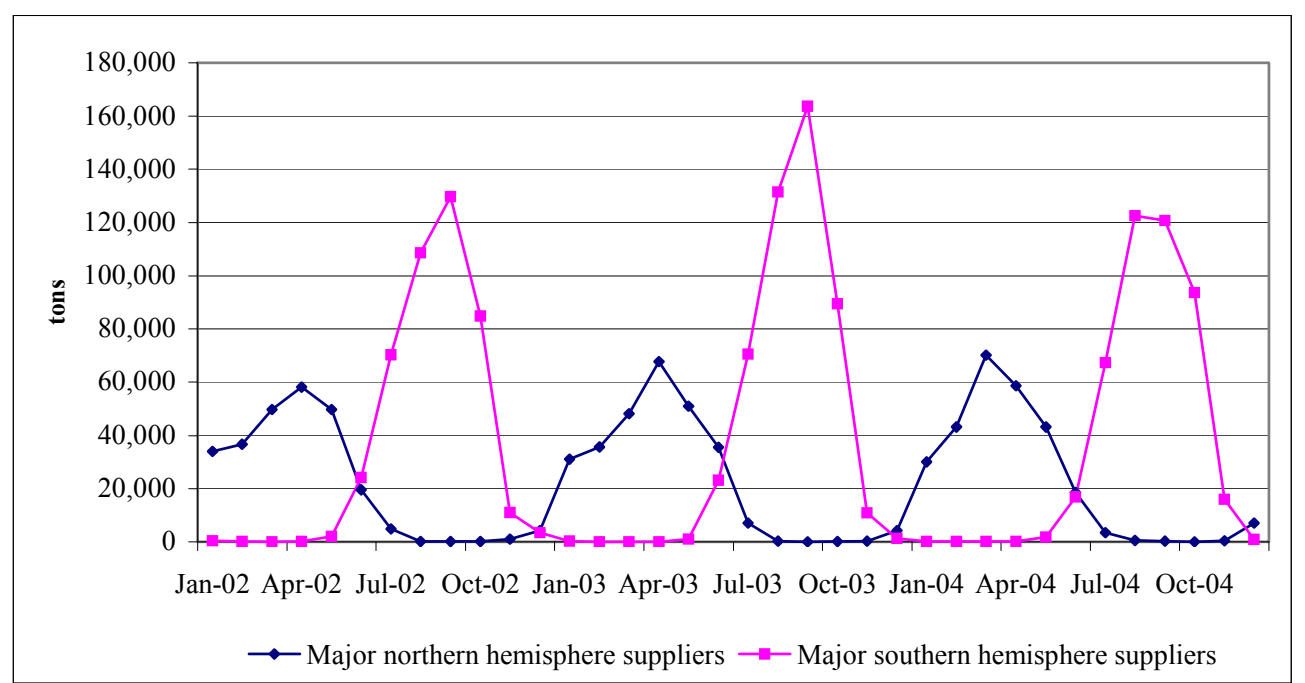

Major northern-hemisphere suppliers: Morocco, Israel, Tunisia, Turkey, Cyprus, Egypt, and Cuba; Major southernhemisphere suppliers: South Africa, Brazil, Argentina, Uruguay, Zimbabwe, and Swaziland. Source: Eurostat.

Figure 1. Seasonal pattern of extra-EU orange imports, 2002-2004.

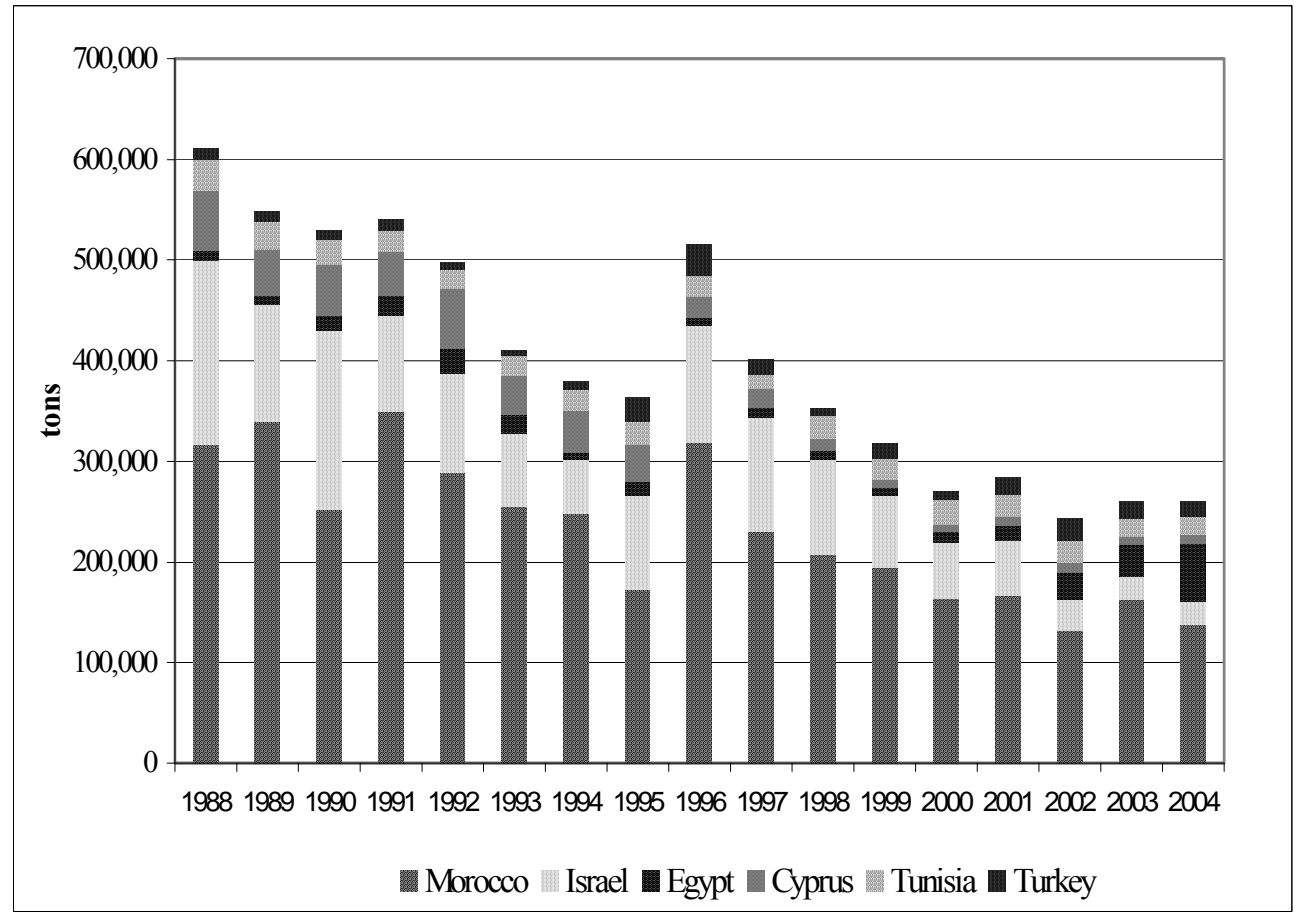

Source: Eurostat.

Figure 2. EU orange imports from major northern-hemisphere suppliers, 1988-2004. 


\section{EU Orange Import Policy}

The EU MFN external-market regulation for oranges includes a seasonally varying ad valorem tariff, with the highest tariff (16\%) applied from October 16 to March 31 during the EU orange harvest season (see table 1). In addition, an entry-price system is in effect from December 1 to May 31. In the event that the entry price is undercut, an additional specific tariff is levied; its size varies proportionately to the difference between the product's actual import price and the entry price. The maximum tariff equivalent (MTE) is the maximum specific tariff of 71 Euro that is levied if the minimum entry price is undercut by $8 \%$ or more.

\section{Table 1. EU MFN Import Regime for Oranges}

\begin{tabular}{|l|l|l|l|}
\hline Time period & $\begin{array}{l}\text { MFN ad valorem tariff } \\
(\%)\end{array}$ & $\begin{array}{l}\text { MFN entry price } \\
\text { (Euro/ton) }\end{array}$ & $\begin{array}{l}\text { Specific tariff } \\
\text { (Euro/ton) }\end{array}$ \\
\hline $01.01 .-31.03$. & 16.0 & 354 & $\leq 71$ \\
\hline $01.04 .-30.04$. & 10.4 & 354 & $\leq 71$ \\
\hline $01.05 .-15.05$. & 4.8 & 354 & $\leq 71$ \\
\hline $16.05 .-31.05$. & 3.2 & 354 & $\leq 71$ \\
\hline $01.06 .-30.09$. & 3.2 & NA & NA \\
\hline $01.10 .-15.10$. & 3.2 & NA & NA \\
\hline $16.10 .-30.11$. & 16.0 & NA & NA \\
\hline $01.12 .-31.12$. & 16.0 & 354 & $\leq 71$ \\
\hline
\end{tabular}

Sources: European Commission (2005a), own calculations.

The EU orange import system has been changed substantially in the course of the implementation of the results of the Uruguay Round. Applied ad valorem tariffs for oranges were reduced by $20 \%$ between 1995 and 2001, and the former reference-price system was replaced by the entry-price system as of December 1995. The MFN entry price for oranges, introduced on December 1995, was 34.3\% higher than the former reference price, which was kept constant since 1975. This rise in the de facto minimum import price was designed to compensate EU orange growers, mainly in Italy, for the abolition of the market penetration premium $^{4}$ in the course of the EU accession of Spain and Portugal. Following its introduction in 1995 , the MFN entry price for oranges was reduced slightly by $4 \%$ until 2001 , due to the way in which the EU implemented its market access commitments resulting from the Uruguay Round Agreement.

\footnotetext{
${ }^{4}$ Market penetration premiums, a policy instrument to subsidize orange production, were paid to orange growers on class I orange exports to other EU member countries prior to December 1995 (Swinbank and Ritson, 1995).
} 
The substantial seasonal differences of the external market regulation for oranges imply that northern-hemisphere suppliers are confronted with stronger import restrictions than southernhemisphere suppliers. Since 2001, northern-hemisphere suppliers are charged an average ad valorem tariff of $10.9 \%$ during their main export season from January to June, which is significantly higher than the average ad valorem tariff of $4.3 \%$ southern-hemisphere suppliers are confronted with throughout their export season from June to November. Southernhemisphere suppliers are subject to a substantial ad valorem tariff only from October 16 to November 31, amounting to $16 \%$ since 2001. Also, northern-hemisphere suppliers have to comply with the entry-price system from January to May, thus during almost their complete export season, whereas the entry-price system is not at all effective during the southernhemisphere suppliers' season.

EU trade preferences for oranges are mainly granted to the MED countries, the major northern-hemisphere orange suppliers to the EU. The primary southern-hemisphere suppliers, such as South Africa and Brazil, do not enjoy preferential orange market access. The only exception among the southern-hemisphere suppliers are Zimbabwe and Swaziland, which are offered an $80 \%$ reduction in ad valorem tariff since 2000 .

The EU grants trade preferences for oranges using three kinds of instruments. A general tariff reduction lowers the MFN ad valorem tariff by a certain percentage for any amount of orange exports. A tariff rate quota (TRQ) and an entry price quota (EPQ) are both quantitative limits, i.e. the respective preference is applicable only up to a certain export quantity. Similarly to the general tariff reduction, the TRQ specifies a particular percentage of MFN tariff reduction. The EPQ includes a lowered entry price in addition to a $100 \%$ ad valorem tariff reduction (elimination).

In general, preferential access to the EU orange market might induce a competitive advantage for the preference receiving country's exporters against non-preference receiving countries' exporters. Also, trade preferences might diminish the competitive advantage of the protected EU domestic producers vis-à-vis non-EU suppliers in preference receiving countries. In particular, a preferential tariff may increase the non-EU exporters' profits by raising the export price. A preferential entry price might allow utilizing a cost advantage if the produce can profitably be supplied to the EU market at a price below the MFN entry price.

TRQs for oranges were first introduced for Morocco, Israel, Egypt, and Tunisia in 1991 to quantitatively limit the ad valorem tariff reductions granted analogously to the tariff reduction for Spain and Portugal in the context of EU market accession (table 2). In the ensuing years, TRQs increased slightly, and in January 1993 the ad valorem tariff within the TRQ was 
abolished completely to coincide with the tariff cancellation for Spanish and Portuguese orange exports. EPQs were introduced for Morocco and Israel concurrently with the transformation of the reference price into the entry-price system in December 1995. Thus, Morocco and Israel were not concerned by the large increase in the MFN entry price compared to the former reference price. Instead, the preferential entry price for oranges in $1995 / 96$ was set equal to the former reference price, amounting to $74.6 \%$ of the MFN entry price. It was successively diminished by $4 \%$ until 2001 , parallel to the reduction of the MFN entry price. For Egypt, an EPQ was established in December 1996.

Table 2. Development of EU Preferences for Primary Northern-hemisphere Orange Exporters, 1991-2004

\begin{tabular}{|c|c|c|c|c|c|c|c|}
\hline & Morocco & Israel & Egypt & Tunisia & Cyprus & Turkey & MED \\
\hline \multicolumn{8}{|c|}{ Thousand metric tons } \\
\hline \multicolumn{8}{|c|}{ Preferential tariff-rate quota (TRQ) } \\
\hline 1991 & 265.0 & 293.0 & 7.0 & 28.0 & 0.0 & 0.0 & 593.0 \\
\hline 1992 & 273.0 & 301.8 & 7.2 & 28.0 & 0.0 & 0.0 & 610.0 \\
\hline 1993 & 280.9 & 310.6 & 7.4 & 28.0 & 0.0 & 0.0 & 626.9 \\
\hline 1994 & 288.9 & 323.7 & 7.6 & 28.0 & 0.0 & 0.0 & 648.2 \\
\hline 1995 & 292.8 & 328.1 & 7.7 & 30.9 & 0.0 & 0.0 & 659.5 \\
\hline 1996 & 296.8 & 0.0 & 7.8 & 31.4 & 0.0 & 0.0 & 336.0 \\
\hline 1997 & 296.8 & 0.0 & 7.8 & 32.3 & 0.0 & 0.0 & 336.9 \\
\hline 1998 & 296.8 & 0.0 & 7.8 & 33.2 & 0.0 & 0.0 & 337.8 \\
\hline 1999 & 296.8 & 0.0 & 7.8 & 34.2 & 0.0 & 0.0 & 338.8 \\
\hline 2000 & 340.0 & 0.0 & 7.8 & 35.1 & 0.0 & 0.0 & 382.9 \\
\hline 2001 & 340.0 & 0.0 & 7.8 & 35.1 & 0.0 & 0.0 & 382.9 \\
\hline 2002 & 340.0 & 0.0 & 7.8 & 35.1 & 0.0 & 0.0 & 382.9 \\
\hline 2003 & 340.0 & 0.0 & 7.8 & 35.1 & 0.0 & 0.0 & 382.9 \\
\hline 2004 & 0.0 & 0.0 & 0.0 & 35.1 & 0.0 & 0.0 & 35.1 \\
\hline \multicolumn{8}{|c|}{ Entry price quota (EPQ) } \\
\hline 1996 & 300.0 & 200.0 & 0.0 & 0.0 & 0.0 & 0.0 & 500.0 \\
\hline 1997 & 300.0 & 200.0 & 8.0 & 0.0 & 48.2 & 0.0 & 556.2 \\
\hline 1998 & 300.0 & 200.0 & 8.0 & 0.0 & 48.2 & 0.0 & 556.2 \\
\hline 1999 & 300.0 & 200.0 & 8.0 & 0.0 & 48.2 & 0.0 & 556.2 \\
\hline 2000 & 300.0 & 200.0 & 8.0 & 0.0 & 48.2 & 0.0 & 556.2 \\
\hline 2001 & 300.0 & 200.0 & 8.0 & 0.0 & 48.2 & 0.0 & 556.2 \\
\hline 2002 & 300.0 & 200.0 & 8.0 & 0.0 & 48.2 & 0.0 & 556.2 \\
\hline 2003 & 300.0 & 200.0 & 8.0 & 0.0 & 48.2 & 0.0 & 556.2 \\
\hline 2004 & 300.0 & 201.5 & 50.0 & 0.0 & 48.2 & 0.0 & 599.7 \\
\hline \multicolumn{8}{|c|}{ Preferential intra-quota tariffs (\% of MFN duty) } \\
\hline 1989-1992 & $20.0^{*}$ & $40.0^{*}$ & $40.0^{*}$ & $20.0 *$ & $60.0^{*}$ & 0.0 & \\
\hline 1993-2004 & 0.0 & 0.0 & 0.0 & 0.0 & $24.0^{*}$ & 0.0 & \\
\hline \multicolumn{8}{|c|}{ Preferential extra-quota tariffs ( $\%$ of MFN duty) } \\
\hline 1989-1992 & 20.0 & 40.0 & 40.0 & 20.0 & 0.0 & 0.0 & \\
\hline 1993-2004 & 20.0 & 40.0 & 40.0 & 20.0 & 0.0 & 0.0 & \\
\hline
\end{tabular}

Notes: *Further reduction of intra-quota tariffs in line with reductions for imports from Spain and Portugal. Malta, Algeria, Jordan, Lebanon, Syria and Palestine are no relevant orange exporters to the EU and are therefore not included in the table.

Source: European Union. 
Spain and Portugal had to comply with the reference price until December 1993. In the second phase of EU accession transition (January 1990 to December 1993), oranges exported from Spain to the EU had to adhere with the reference price indirectly due to a compensation mechanism. In the event that the market price of Spanish oranges fell below the average EU supply price, which could not be lower than the reference price, Spanish exporters had to pay a compensation, equivalent to the difference between the reference price and the EU market price (see European Union, OJ L302, 15.11.1985, Article 152).

Between 1996 and 2004, TRQs were first increased for Morocco, Egypt, and Tunisia and were finally abolished for Morocco, Egypt, and Israel, which were granted EPQs in the meantime. In addition, the EPQ increased significantly for Egypt in 2004. For Cyprus, the tariff reduction rate gradually increased until the tariff was fully removed in December 1997. The tariff preference was supplemented by a preferential entry price, levied within an EPQ of 48,200 mt. With Cyprus' EU accession in 2004, trade barriers were completely eliminated. For Turkey, the ad valorem tariff for orange exports to the EU was removed completely in 1987. Overall, total orange quotas, including the TRQ and EPQ, granted by the EU to the MED orange suppliers amounted to 593,000 $\mathrm{mt}$ in 1991, increasing to about 939,000 $\mathrm{mt}$ in 2000, and contracting to about $635,000 \mathrm{mt}$ in 2004, when the TRQ for Morocco was eliminated.

To sum up, the EU import regime for oranges is highly complex and evolved in a multitude of separate agreements and regulations. All MED countries may export oranges to the EU within the respective quotas tariff free since 1993. Also, orange exports enter the EU at preferential entry prices for Morocco and Israel since December 1995, Egypt since December 1996 and Cyprus since December 1997. Thus, the relatively high MFN entry price was at no time applied to Morocco and Israel, the largest MED orange exporters. Further, the MED trade preferences for oranges did not erode relative to those of Spain and Portugal until December 1993.

\section{Analysis of the Effectiveness of the EU Import System for Oranges}

To analyze whether and how the EU entry price impacts the EU import price for oranges, and thus the domestic orange market price, the standard import value (SIV) of oranges, an indicator for the import price, is compared to the entry price. The European Commission calculates the SIV daily as the weighted average of wholesale market prices surveyed by origin of the produce in all EU countries and less marketing and transportation margins and 
custom duties (for further details see European Union, OJ 1994, L337/66, Regulation $3223 / 94)$.

Our analysis is based on about 5,500 observations of the SIV for the orange exporting MED, including Morocco, Israel, Tunisia, Egypt, Cyprus, and Turkey, with about 600 to 1,100 observations for each individual country (figure 3). Each single dot corresponds to the SIV of oranges originating in a particular country at a given date. The data set includes SIV observations from December 1, 1995, when the entry-price system was first introduced, until May 31, 2005. The gaps in the data correspond to the SIVs surveyed exclusively when the entry-price system is in effect, i.e., from December 1 until May 31.

Figure 3 reveals directly that the vast majority of observations lies distinctively above the MFN entry price. Few SIV observations lie below the MFN entry price and even less are lower than the preferential entry price. In particular, the share of SIV observations that exceed the MFN entry price is highest for Israel with $99.9 \%$, followed by Cyprus with $98.7 \%$, Tunisia with 97.2\%, and Morocco with 93\% (table 3).

For Morocco and Israel, none of those observations lies below the applied entry price, which is the preferential entry price introduced on December 1, 1995. This means that the specific tariff was not at all imposed on Moroccan or Israeli oranges in this time period. Two observations for Cyprus and 24 observations for Tunisia lie below the respective entry price. The SIV was below the applied entry price most frequently for Egyptian oranges with 31 and Turkey with 90 observations, corresponding to $4.2 \%$ and $8.0 \%$ of all observations respectively. The average difference between the SIV and the MFN entry price is highest for Israel with the SIV amounting to $158.1 \%$ of the MFN entry price and $212 \%$ of the preferential entry price on average, followed by Turkey, Cyprus, and Tunisia. The differences are lowest for Egypt, with $124.1 \%$ and $166.5 \%$, respectively. On average, the EU import price for oranges originating in the MEDs is $40 \%$ higher than the MFN entry price and about $90 \%$ higher than the preferential entry price. This indicates that the entry-price system for oranges is largely redundant. 


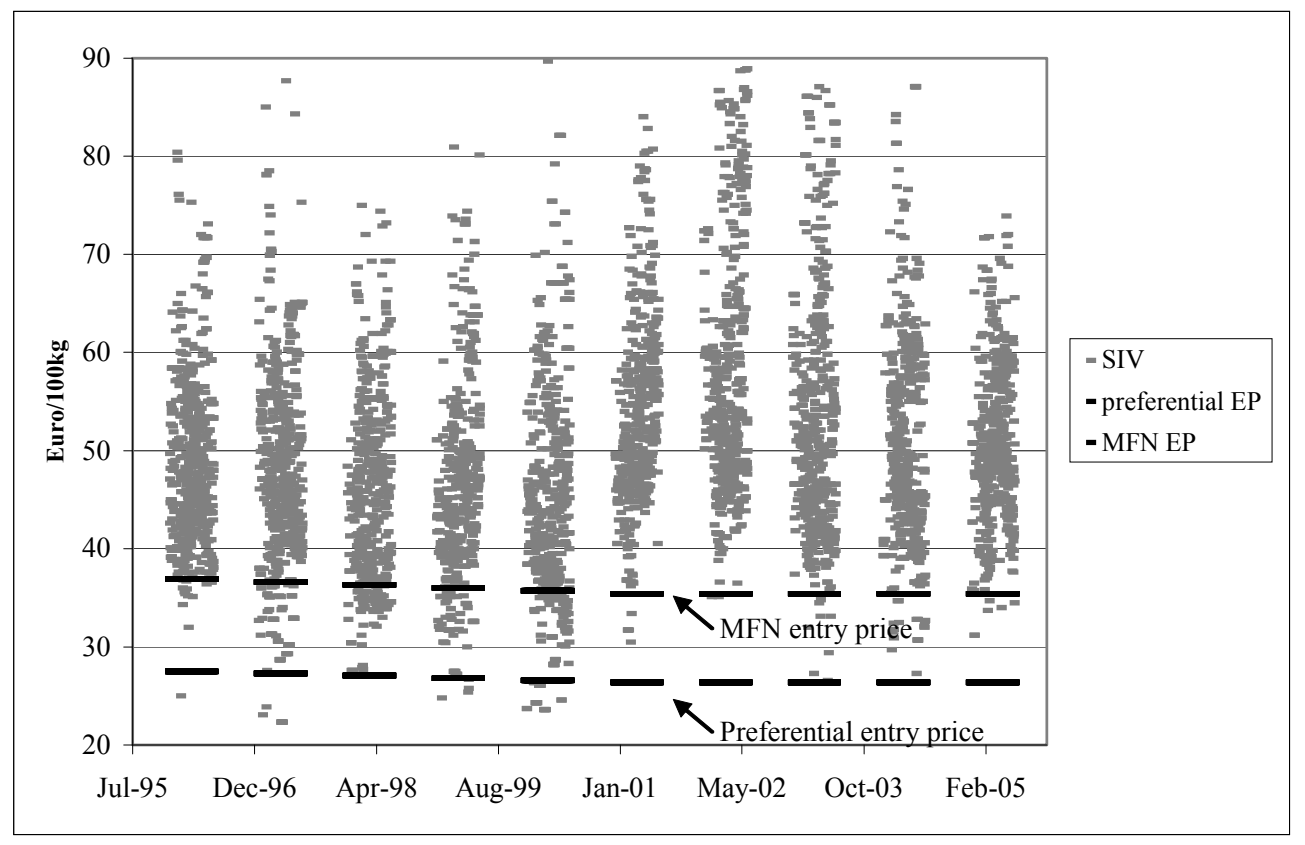

Sources: European Commission (2005a, 2005b).

Figure 3. SIV, MFN entry price and preferential entry price of MED orange exports to the EU, December 1995 to May 2005.

Table 3. SIV in Relation to MFN Entry Price and Preferential Entry Price of MED Exports of Oranges to the EU, December 1995to May 2005

\begin{tabular}{|c|c|c|c|c|c|c|}
\hline & \multirow[t]{2}{*}{$\begin{array}{l}\text { Number } \\
\text { of observations }\end{array}$} & \multirow{2}{*}{$\begin{array}{l}\text { SIV > } \\
\text { MFN EP } \\
\% \quad \text { of } \\
\text { observations }\end{array}$} & \multicolumn{2}{|l|}{$\begin{array}{l}\text { SIV }< \\
\text { Applied EP* }\end{array}$} & \multirow{2}{*}{$\begin{array}{l}\text { SIV as \% of } \\
\text { MFN EP } \\
\text { average }\end{array}$} & \multirow{2}{*}{$\begin{array}{l}\text { SIV as \% of } \\
\text { pref. EP } \\
\text { average }\end{array}$} \\
\hline & & & $\begin{array}{l}\text { number of } \\
\text { observations }\end{array}$ & $\begin{array}{l}\% \text { of } \\
\text { observations }\end{array}$ & & \\
\hline Israel & 961 & $99.9 \%$ & 0 & $0 \%$ & $158.3 \%$ & $212.4 \%$ \\
\hline Tunisia & 854 & $97.2 \%$ & 24 & $2.8 \%$ & $141.5 \%$ & $185.8 \%$ \\
\hline Turkey & 1,132 & $92.0 \%$ & 90 & $8.0 \%$ & $144.5 \%$ & $193.8 \%$ \\
\hline Morocco & 1,133 & $93.0 \%$ & 0 & $0.0 \%$ & $127.6 \%$ & $171.1 \%$ \\
\hline Egypt & 746 & $79.1 \%$ & 31 & $4.2 \%$ & $124.1 \%$ & $166.5 \%$ \\
\hline Cyprus & 613 & $98.7 \%$ & 2 & $0.3 \%$ & $144.4 \%$ & $193.7 \%$ \\
\hline Total & 5439 & $93.3 \%$ & 147 & $2.7 \%$ & $140.1 \%$ & $187.9 \%$ \\
\hline
\end{tabular}

Note: for Morocco and Israel: applied EP = pref. EP; for Turkey and Tunisia: applied EP = MFN EP; for Egypt: applied EP = MFN EP before Dec. 96 and pref. EP afterwards; for Cyprus: applied EP = MFN EP before Dec. 97; pref. EP afterwards.

Sources: European Commission (2005a, 2005b), own calculations.

\section{Evidence from other Fruit Markets}

To check whether this result can be generalized, two other fruits are investigated. The size of the difference between the import price and the MFN entry price for oranges is exceeded by the corresponding difference for table grape exports from the MED countries to the EU (figure 4). On average, the SIV for table grapes amounts to $199.1 \%$ of the MFN entry price effective July 21 to November 20. 


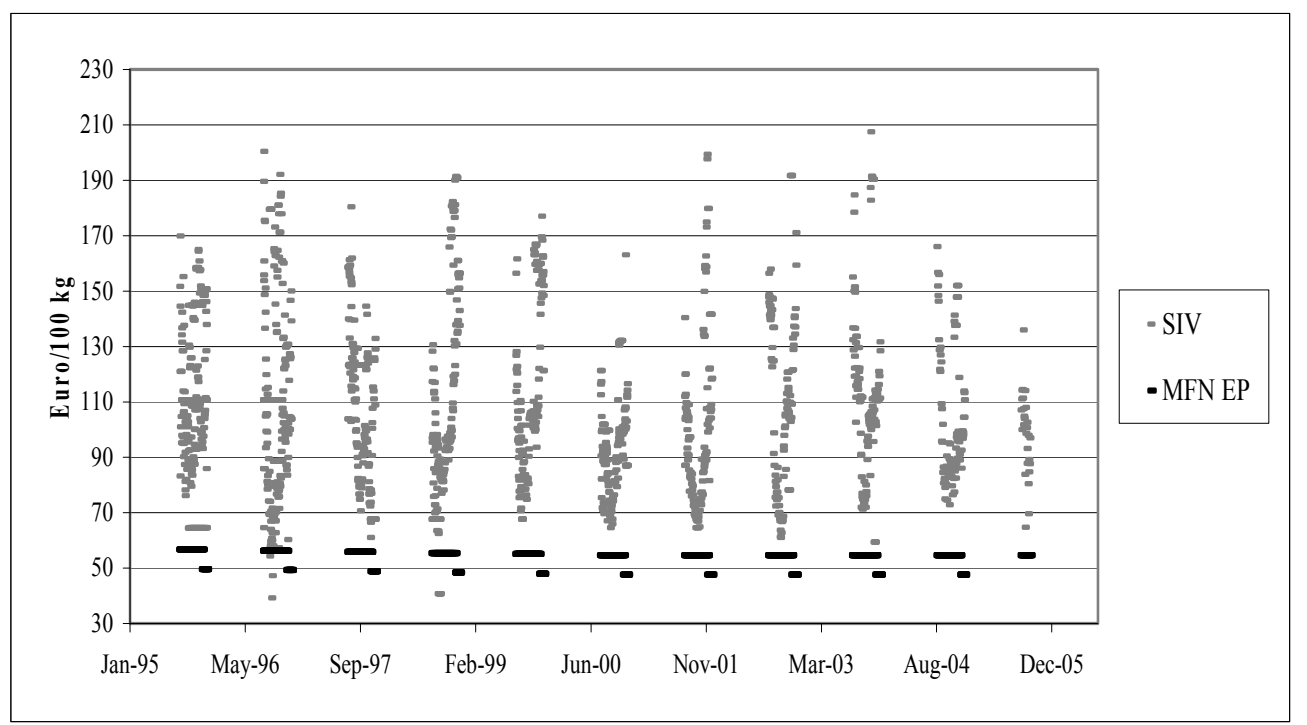

Sources: European Commission (2005a, 2005b).

Figure 4. SIV and MFN entry price of MED exports of table grapes to the EU, December 1995 to May 2005.

The situation for EU clementine imports from the MED countries differs considerably. The SIV is below the MFN entry price (operative November 1 to the end of February) for Turkey in $44 \%$, Morocco in $31 \%$ and Israel in $23 \%$ of the surveyed cases for clementines, although a preferential entry price is granted to Morocco exclusively (figure 5). Morocco also benefits

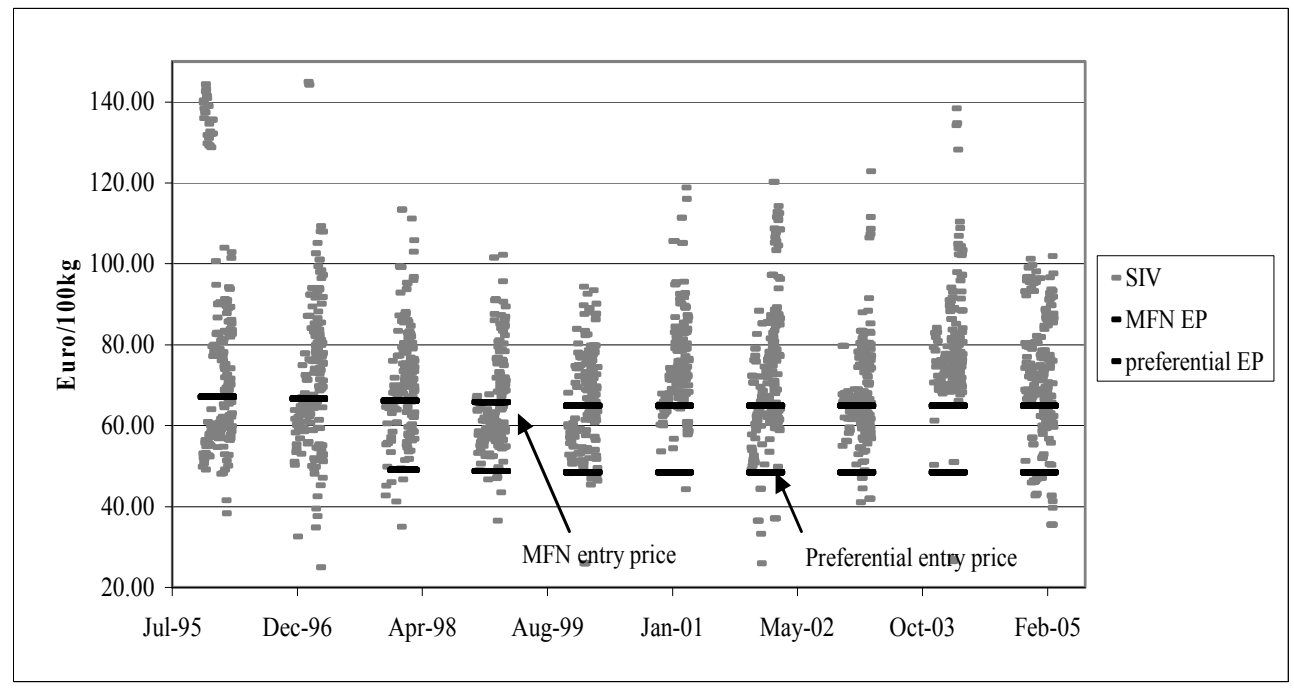

Sources: European Commission (2005a, 2005b).

Figure 5. SIV, MFN and preferential EP of MED exports of clementines to the EU, December 1995 to May 2005.

heavily from an EPQ granted by the EU for Moroccan tomatoes. For the period 2000 to 2003 about $58 \%$ of Moroccan tomato exports enter the EU at a price between the MFN and the preferential entry price (Chemnitz and Grethe, 2005). Thus, the EU entry-price system for oranges and grapes is by and large redundant for MED country exports. For clementines and 
tomatoes, however, import prices are much closer to entry prices, and the entry-price system seems to have an import restricting effect.

\section{Development of Quota Fill Rates}

The utilization of the preferential quotas for oranges is investigated by comparing the development of orange exports to the evolution of the total orange quota, comprising TRQ and EPQ. The corresponding quota fill rates, equal to the orange exports in percentage of the total orange quota, are given in Table 4 for the period 1991 to 2004 . The only countries for which exports exceed the respective quota in some years are Morocco and Egypt. Morocco's orange exports exceed quotas in 1991 and 1992, but fall below afterwards. Since 1997, Morocco's fill rate has been below 50\%. The removal of the TRQ in 2004 caused an increase in the fill rate in that year. Egypt exceeds its quota from 2002 to 2004 due to the rise of Egyptian orange exports to the EU in this period. Tunisia's quota fill rate varies between $48 \%$ and $75 \%$. The rate for Cyprus is always below 50\%. Israel exhibits the lowest fill rates, declining from $32 \%$ in 1991 to $12 \%$ in 2004 . The unweighted average fill rate fell from more than $100 \%$ in 1991 to $39 \%$ in 1999 , but rose again to over $50 \%$ in 2002 .

Table 4. Orange Quota Fill Rates (Orange Exports in \% of Quota)

\begin{tabular}{|l|l|l|l|l|l|l|}
\hline & Morocco & Israel & Cyprus & Egypt & Tunisia & Average \\
\hline $\mathbf{1 9 9 1}$ & 132 & 32 & - & 279 & 75 & 130 \\
\hline $\mathbf{1 9 9 2}$ & 106 & 33 & - & 347 & 69 & 139 \\
\hline $\mathbf{1 9 9 3}$ & 91 & 23 & - & 264 & 72 & 113 \\
\hline $\mathbf{1 9 9 4}$ & 86 & 17 & - & 92 & 73 & 67 \\
\hline $\mathbf{1 9 9 5}$ & 59 & 28 & - & 184 & 73 & 86 \\
\hline $\mathbf{1 9 9 6}$ & 54 & 58 & - & 105 & 64 & 70 \\
\hline $\mathbf{1 9 9 7}$ & 39 & 57 & 38 & 61 & 45 & 48 \\
\hline $\mathbf{1 9 9 8}$ & 35 & 47 & 25 & 54 & 69 & 46 \\
\hline $\mathbf{1 9 9 9}$ & 33 & 35 & 18 & 50 & 61 & 39 \\
\hline $\mathbf{2 0 0 0}$ & 26 & 27 & 16 & 68 & 69 & 41 \\
\hline $\mathbf{2 0 0 1}$ & 26 & 27 & 19 & 95 & 61 & 46 \\
\hline $\mathbf{2 0 0 2}$ & 21 & 15 & 21 & 170 & 61 & 58 \\
\hline $\mathbf{2 0 0 3}$ & 25 & 12 & 19 & 195 & 48 & 60 \\
\hline $\mathbf{2 0 0 4}$ & 46 & 12 & 19 & 114 & 53 & 49 \\
\hline
\end{tabular}

Sources: Eurostat, European Union, own calculations.

Overall, while TRQs and EPQs for oranges originating in the MED countries were increasing, the MED countries' orange exports to the EU were decreasing. Therefore, the quota fill rate has fallen for most MED countries, and the unweighted average quota fill rate has been $60 \%$ or less for all years since 1997. 


\section{Discussion of Results and Implications}

Our analysis reveals that the import price of oranges originating in the MED countries is about $40 \%$ higher than the MFN entry price on average. In addition, the investigation on the EU trade preferences for oranges shows that about $70 \%$ of EU orange imports during the EU orange harvest season originate in the MED countries, and have entered the EU tariff-free since 1993 due to preferential tariff reductions. This suggests that the contribution of the external market regulation to the protection of EU orange growers is low. In particular, the entry-price system for oranges is of little effectiveness.

Low protectiveness of the EU reference-price system for oranges, the predecessor of the entry-price system until the implementation of the Uruguay Round results, was already detected by Swinbank and Ritson (1995). They find (p. 348) that countervailing charges were applied 500 times for all fruits and vegetables in the period August 1988 to August 1994, due to the shortfall of the import price under the reference price. For oranges, countervailing charges were induced altogether only 7 times, which may be interpreted as an indicator for a low protectiveness of the reference-price system for oranges or alternatively for a successful organization of the exporters concerned (Swinbank and Ritson 1995, p. 356). These results are in line with an earlier analysis of the EU external market regulations for oranges by Williams (1986).

Concordantly, Morocco, Israel, and Cyprus do not utilize the preferential entry price for oranges. Thus, MED countries do not compete with EU producers in this lower-price segment. Indeed, EU importers report that prices of Moroccan and Israeli orange imports are significantly higher than the import price of Spanish oranges. Egypt is the only MED country benefiting from the preferential entry price to some degree.

The analysis also reveals that although orange quotas increased from 1991 to 2004 for the MED countries as a whole, actual exports declined concurrently, and thus quota fill rates have decreased. A quota underfill can result from the method of quota administration and especially the red tape involved in importing under the quota (Skully, 2001). This, however, seems not to be relevant for the TRQs and EPQs granted by the EU for fresh fruit and vegetable imports. These quotas are administered according to the first-come-first-serve principle, and EU importers report that they do not involve significant red tape. Thus, the underfill reflects a market equilibrium, in which third country exporters' marginal cost equal 
the EU price. ${ }^{5}$ As a conclusion, the quantitative limitations of tariff and entry price reductions within TRQs and EPQs are largely redundant.

Additionally, it is evident that the improvement of market access for Spain and Portugal due to their EU accession occurred almost parallel to the enhancement of preferences for the MED countries until 1993. This supports the conclusion that the development of trade preferences for the MED countries compared to market access conditions for Spain and Portugal was not decisive for the development of the MED's orange exports to the EU up to 1993. Furthermore, our results indicate that the erosion of orange trade preferences of Israel and Morocco relative to those of Spain and Portugal in the aftermath of 1993 did not cause the decline of orange exports from those countries. Both countries' orange exports enter the EU tariff free since 1993. Also, the preferential entry price is not utilized by the orange exporters in Israel and Morocco. Even, the average import price of oranges originating in Israel and Morocco is about $58 \%$ and $28 \%$ higher than the MFN entry price, respectively. Hence, any erosion of trade preferences compared to Spain, which is suggested by Cioffi and dell'Aquila (2004, p. 175), could not originate from EU trade policies. Also, we cannot find evidence for the assumption of Cioffi and dell'Aquila (2004, p. 178) that the large increase in the MFN entry price relative to the former reference price may have contributed to the decline of Moroccan and Israeli orange exports to the EU. Instead, we show that a preferential entry price for oranges originating in Israel and Morocco, which was equal to the former reference price, was introduced concurrently with the implementation of the entry-price system in December 1995. Thus, Morocco and Israel were never subject to the MFN entry price for oranges.

Hence, factors beyond EU trade policy would appear to have caused the decline of the MED's orange exports to the EU. For example, market distance and product variety are of particular importance for the decline of Israeli orange exports to Germany. German importers appreciate the high flexibility with orange imports from Spain. Due to Spain's proximity to the market, Spanish produce is packed directly in nets in Spain and transported by truck to retailers' distribution centers in Germany within 2 days. In contrast, Israeli produce is first packed in cardboard boxes in Israel, which are transported by ship within 4 days to Marseille (France). The produce is then carried by truck to packing stations in Germany where it is repacked in nets before it is brought to supermarkets. Of course, the resulting transportation costs are lower for Spanish produce. Besides, Shamouti is the orange variety which still dominates Israeli orange production. In Spain, new orange varieties were introduced, e.g. the Navel

\footnotetext{
${ }^{5}$ See de Gorter and Kliauga (2005) for a detailed analysis of the economics of TRQs.
} 
varieties. German consumers prefer Navel over Shamouti oranges, but Israeli orange producers have not adapted to this change in consumer preferences.

It remains to determine the influence of EU internal agricultural policy as well as structural policy on the large increase in EU orange market share of Spanish produce. EU orange production is protected internally by processing aid and withdrawal compensation. Also, operational programs of producer organizations for improvement of product quality and market promotion activities are financially supported. Restructuring aids are granted to modernize marketing structure and to grub up old orange groves. Additional funds are provided by the EU Cohesion Fund, e.g. for enhancement of transport infrastructure.

Finally, all this implies that the liberalization of orange trade between the EU and the MED countries, which could be realized in the course of the ongoing Barcelona Process, would induce few, if any, trade effects. Theoretically, the entry-price system would prevent especially low qualities from entering the EU market. For oranges, however, interviews with trading companies did not reveal evidence of potential low-quality orange market segments below the entry price level. Existing regulatory standards for citrus fruits laid down in EC regulation 2200/96 specify minimum quality requirements regarding e.g. fruit size, external appearance and uniformity. Citrus produce which does not comply with those standards is not allowed to enter the EU market. Thus, inexpensive, low-quality produce is barred from the EU market, even if the EU entry-price system were removed. Recently, public standards are supplemented by even more restrictive private standards, in particular EUREPGAP, which evolves quickly and becomes a quasi-mandatory private sector quality assurance scheme for fresh fruits and vegetables in the EU (Codron, Giraud-Héraud, Soler, 2005).

Yet, as demonstrated for clementines, these results cannot be generalized, not even for citrus imported from the MED countries. It is highly probable that the removal of the entry price for clementines would result in a decrease of the average EU import price level. Table grapes, however, provide a second example for which the SIV of imports from the MED is far above the EU entry price, and thus the entry-price system is of little effect.

The conclusion that large parts of the EU external trade regime for oranges are redundant will potentially be amplified by the current round of trade negotiations in the WTO. Negotiations on market access will probably result in significant tariff reduction rates which would also apply to the specific tariffs which are part of the EU entry-price system. In implementing the results of the Uruguay Round, the EU reduced entry prices by the same monetary amount as specific tariffs - an approach which could be repeated and would thus further diminish the relevance of the EU entry-price system (Grethe 2005, p. 28-29). 
In the light of the low effectiveness of the EU import regime for oranges along with high transaction costs involved in its administration and further development, the unlimited and free access by MED countries to the EU orange market could be considered as an alternative. This may be extended to grapes and possibly to other fruits and vegetables. In addition, the abolition of the entry-price system for some products would reduce the incidence of a clear non tariff barrier to market access which survived the Uruguay Round process of tariffication, but which is in clear conflict at least with its spirit.

\section{Acknowledgements}

Helpful comments made by Stephan von Cramon-Taubadel, John Beghin and Frank Fuller on a draft version and financial support by the Volkswagen foundation are gratefully acknowledged.

\section{References}

Brenton, P., and T. Ikezuki. 2005. "The Impact of Agricultural Trade Preferences, with Particular Attention to the Least Developed Countries." In A. Aksoy, and J. Beghin, eds., Global Agricultural Trade and Developing Countries. Washington DC: World Bank, pp. 55-73.

Chemnitz, C., and H. Grethe. 2005. "EU Trade Preferences for Moroccan Tomato Exports - Who Benefits?" In XI ${ }^{\text {th }}$ Congress, European Association of Agricultural Economists, "The Future of Rural Europe in the Global Agri-Food System", Copenhagen, 24-27 August (CD).

Cioffi, A., and C. dell' Aquila. 2004. "The Effects of Trade Policies for Fresh Fruit and Vegetables of the European Union.” Food Policy. 29:169-185.

Codron, J.-M., E. Giraud-Héraud, and L.-G. Soler. 2005. "Minimum Quality Standards, Premium Private Labels, and European Meat and Fresh Produce Retailing." Food Policy. 30:270-283.

de Gorter, H., and E. Kliauga. 2005. "Reducing Tariffs versus Expanding Tariff Rate Quotas." In Anderson, K. and Martin, W., eds., Agricultural Trade Reform and the Doha Development Agenda. New York: Macmillan and the World Bank.

European Commission. 2005a. TARIC. 2005b. Standard Import Values. Unpublished.

European Union. Various issues. Official Journal of the European Communities (OJ).

Eurostat. Various issues. External Trade Data.

Food and Agriculture Organization. 2005. FAOSTAT Agricultural data. http://www.fao.org. (Accessed at 30 July 2005).

Grethe, H. 2005. "EU Agricultural Trade Preferences for North Africa and the Near East and the EU Import Regime for Fresh Fruit and Vegetables." Paper prepared for the FAO Regional Trade Workshop Recent Development in the WTO Negotiations on Agriculture and in Regional Trade Agreements and their Implications for Trade, Agriculture and Food Security in the Near East Countries", Cairo 15 th to 17 th November.

Grethe, H., S. Nolte, and S. Tangermann. 2005. "Evolution, Current State and Future of EU Trade Preferences for Agricultural Products from North-African and Near-East Countries." Journal of International Agricultural Trade and Development. 2:109-133.

Skully, D. 2001. Economics of Tariff-Rate Quota Administration. Technical Bulletin No. 1893, Washington DC: U.S. Department of Agriculture, Economic Research Service. 
Swinbank, A., and C. Ritson. 1995. "The Impact of the GATT Agreement on EU Fruit and Vegetable Policy." Food Policy. 20:339-357.

Williams, H. 1986. "Future Prospects of Cyprus Citrus Exports to the E.E.C." Discussion Paper 16, University of Newcastle upon Tyne, Department of Agricultural Economics. 
4 The EU Entry Price System for Fresh Fruits and Vegetables - Paper Tiger or Powerful Market Barrier?

jointly with Harald Grethe 


\title{
The EU Entry Price System for Fresh Fruits and Vegetables - Paper Tiger or Powerful Market Barrier? Linde Goetz ${ }^{a}$ and Harald Grethe ${ }^{b}$
}

\author{
${ }^{a}$ Department of Agricultural Economics and Rural Development, University of Goettingen, Germany \\ ${ }^{\mathrm{b}}$ Institute for Agricultural Policy and Agricultural Markets, University of Hohenheim, Germany \\ The authors are grateful to the European Commission, DG Agriculture and DG Taxation and Customs Union for \\ making data available, and appreciate financial support from the Volkswagen Foundation. In addition, we would \\ like to thank staff members of the European Commission and German importers for answering our questions and \\ discussing our results. Finally, we thank Stephan von Cramon-Taubadel, Nana Kuenkel, Holger Schulze and \\ Walter Zucchini as well as two anonymous reviewers for helpful comments on a draft version.
}

\section{Summary:}

The EU protects EU growers of 15 kinds of fresh fruits and vegetables against international competition by the entry-price system (EPS), which is designed to restrict imports below the product-specific, politically designated entry price level. This study investigates the relevance of the EPS per product and country of origin. We develop two indicators for the effectiveness of the EPS, which serve as variables in a cluster analysis identifying four classes differing in the relevance of the EPS. The relevance of the EPS is found to be heterogeneous among products as well as countries of origin. It is highest for artichokes, courgettes, cucumbers, lemons, plums and tomatoes. The influence of the EPS on apples, clementines and pears is significantly lower, and of least relevance for apricots, mandarins, oranges, peaches and nectarines and table grapes. The EPS has the greatest effect on countries which neighbour the EU, whereas it is of minor importance for exports from far-away countries with the exception of China and South Africa.

\section{$1 \quad$ Introduction}

The EU is the largest importer of fresh fruits and vegetables in the world, in 2005 accounting for $47 \%$ of world fresh fruits and vegetable imports (intra-EU trade excluded, EU-27) (FAO, 2007). It has established a comprehensive import system for fresh fruits and vegetables, which protects EU growers of 15 kinds of selected fruits and vegetables against international competition not only by the means of ad valorem tariffs of up to $20 \%$, but also by the EU entry-price system (EPS). Analogous to a minimum import price, the EPS aims to restrict imports below the product-specific, politically designated entry price (EP) level. This system was established in 1995, replacing the former reference price system (RPS).

Various authors have analysed the functioning and effects of this highly complex system and have compared it to the former reference price system (see Williams and Ritson, 1987; Swinbank and Ritson, 1995; Grethe and Tangermann, 1999; Martin and de Gorter, 1999; Cioffi and del' Aquila, 2004; Chemnitz and Grethe, 2005; Goetz and Grethe, 2007; GarcíaÁlvarez-Coque et al 2007; Martinez-Gomez 2007; López and Muñiz, 2007). As a general conclusion, the effects of the EPS appear relatively difficult to assess and differ strongly between countries of origin and products. 
This study is unique in that it comprehensively analyses the effectiveness of the EPS for all products and countries of origin based on a uniform approach. The central question is whether the EPS influences EU import prices. In particular, we investigate the relevance of the EPS on a disaggregated level, i.e. for each of the 15 fruits and vegetables and all major exporting countries individually. We utilise a unique data set comprising about 60,000 observations of the standard import value (SIV), a synthetic import price calculated by the European Commission (EC) based on wholesale price quotations, for the period 1995 to 2005 (European Commission, 2005a). We derive two indicators to measure the influence of the EPS. One indicator is taken from previous studies, supplemented by a newly developed indicator. These indicators serve as variables in a cluster analysis that identifies four clusters of product-specific and country-specific imports of fresh fruits and vegetables which differ according to the degree they are affected by the EPS.

The effectiveness of the EPS is particularly topical for four main reasons. First, from an EU producer's perspective it is interesting to see how policy-dependent the sector is. Any liberalisation of trade in fresh fruits and vegetables between the EU and Southern Mediterranean countries ${ }^{6}$ (SMC) within the Barcelona Process is strongly resisted by EU producers, as SMC exports of fresh fruit and vegetables to the EU directly compete with southern EU production due to overlapping production and marketing campaigns (García Álvarez-Coque and Jordán Galduf, 2007). ${ }^{7}$

Second, for any quantitative analysis of liberalisation of trade in fresh fruits and vegetables especially between the EU and SMC, knowledge of the impact of the EPS on the EU import price is required, as García Álvarez-Coque and Jordán Galduf (2007) point out. Some applied studies which analyse the liberalisation of EU fruit and vegetable trade disregard the EPS (e.g. Bunte, 2005). Our paper provides a basis for deciding for which products it is important to take the EPS into account in simulation analyses.

Third, the EPS is criticised from a development policy perspective. This is based on the assumption that the EPS restricts fruit and vegetable exports especially from developing countries, which have a clear comparative cost advantage in the labour-intensive production of fruits and vegetables compared with developed countries (Diop and Jaffe, 2005). Our analysis sheds light on the question for which countries the EPS is of particular relevance.

\footnotetext{
${ }^{6}$ The SMC comprise the following ten Mediterranean countries: Algeria, Egypt, Israel, Jordan, Lebanon, Morocco, the Palestinian Authority, Syria, Tunisia and Turkey.

${ }^{7}$ In some EU regions, fruit and vegetable production plays an important role for agricultural incomes. There are $35 \mathrm{EU}$ regions in which fruits and vegetables represent more than $45 \%$ of the gross added value of the region's agricultural sector (García Álvarez-Coque and Jordán Galduf, 2007). These regions are in Spain, Greece and Italy (8 each), the Netherlands (5), Belgium (4), and Portugal and France (1 each).
} 
Fourth, in the context of the ongoing Doha negotiations of the World Trade Organization (WTO), knowledge about the effectiveness of the EPS could serve as a basis for deciding how much negotiation effort to put into its maintenance (from an EU perspective) or its dismantling (from a third-country perspective).

This article is structured as follows. Section 2 describes the functioning of the EPS and Section 3 presents a literature review. The indicators used to analyse the effectiveness of the EPS are derived and discussed in Section 4. Empirical results of the cluster analysis are presented in Section 5, while an outlook on the further development of the effectiveness of the EPS is given in Section 6. Section 7 concludes.

\section{Structure of the EU entry-price system}

The EU protects growers of 15 kinds of selected fruits and vegetables against international competition not only by the means of ad valorem tariffs of up to $20 \%$, but also by the EPS. The EPS came into effect on July 1, 1995, replacing the former RPS. Analogous to a minimum import price, the EPS is designed to restrict imports below the product-specific, politically designated EP plus ad valorem tariff (Table 1). If the EP is undercut, an additional specific tariff is levied, which proportionally varies depending on the gap between the product's actual import price and the EP. When the EP is undercut by $8 \%$ or more, the maximum specific tariff, referred to as the maximum tariff equivalent (MTE) ${ }^{8}$, of up to $80 \%$ of the EP is charged. For example, the EPS is applied to oranges during the EU orange harvest season in the time period December 1 to May 31. The MFN tariff for oranges seasonally varies between $3.2 \%$ and $16.0 \%$ whereas the MFN EP remains constant at a level of $354 € / \mathrm{t}$. If oranges are exported to the $\mathrm{EU}$ at a price of $336.3 € / \mathrm{t}$, the $\mathrm{EP}$ is undercut by $5 \%$. This implies that the exporter has to pay an additional specific tariff of $17.7 € / t$ which is equal to the gap between the import price and the EP. If the entry price for oranges is undercut by $8 \%$ or more, an additional specific tariff at the level of the MTE of $71 € / t$ is charged.

Concurrently to protecting EU growers, the EU aims to foster exports to the EU of these fruits and vegetables from preferred trading partners by granting preferential market access. In most cases, preferential market access to the EU market for fresh fruits and vegetables is restricted to ad valorem tariff reductions, and thus the EPS still applies. Exceptions are market access under the Everything-but-Arms Initiative, and preferential market access for the Balkan countries, for which the EPS does not apply. In addition, in some cases EU trade preferences

\footnotetext{
${ }^{8}$ The designation "maximum tariff equivalent" stems from the Uruguay Round, in which the MTE was established as the tariffied equivalent of the former RPS.
} 
Table 1: Basic elements of the EPS

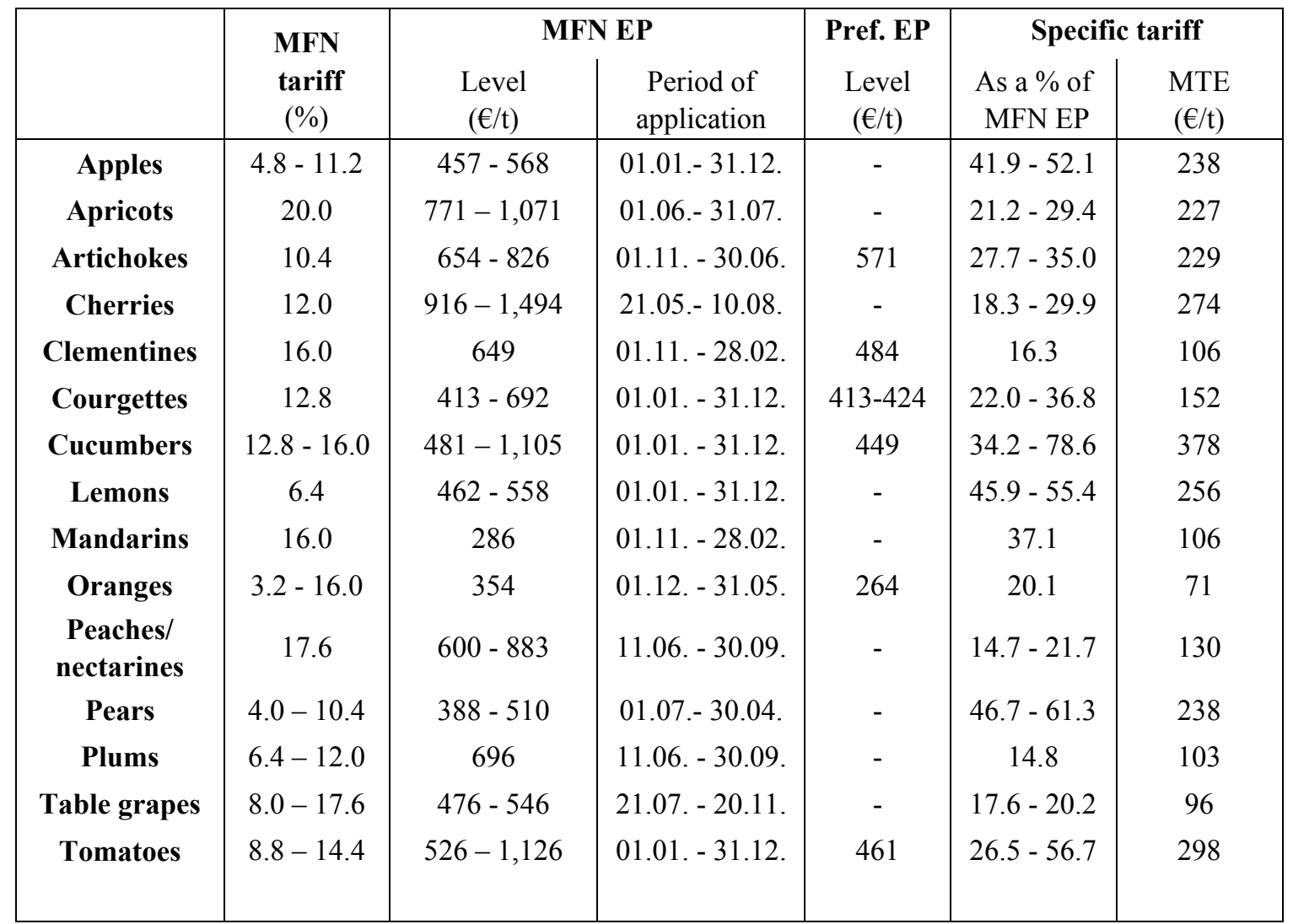

Sources: European Commission (2007), own calculations.

for fresh fruits and vegetables include a preferential EP, which is lower than the most favoured nation (MFN) EP. Preferential EPs, which are limited quantitatively up to a certain export amount by entry price quotas (EPQs), are granted exclusively to Morocco ${ }^{9}$ for artichokes, courgettes, cucumbers, clementines and tomatoes, while a preferential EP for oranges is also granted to Cyprus (pre-EU), Egypt and Israel. As an example, Figure 1 compares the EU orange market access conditions for MFN countries to those for Israel, a preferred trading partner in the time period January, 1 to March, 31. A MFN country has to comply with an EP of $354 € / \mathrm{t}$ and is subject to a tariff amounting $16 \%$. In contrast, Israel may export oranges to the EU tariff free and has to comply with a lower EP of $264 € / t$ within an EPQ of up to 201,500 t. If Israel's exports exceed the quota, the MFN entry price applies and an ad valorem tariff amounting $40 \%$ of the MFN tariff (6.4\%) is charged.

Monitoring compliance with the EPS faces the difficulty that a large share of fruit and vegetable imports in the EU is on commission, implying that the import price is not determined until the product is sold in the EU market. Therefore, the EC calculates a synthetic import price, the standard import value (SIV). Fruit and vegetable prices, surveyed for each product and export country individually, are collected on representative fruit and vegetable

\footnotetext{
${ }^{9}$ Since January 2006, Jordan has enjoyed preferential EPs similar to Morocco; however, this period is not covered in this analysis.
} 


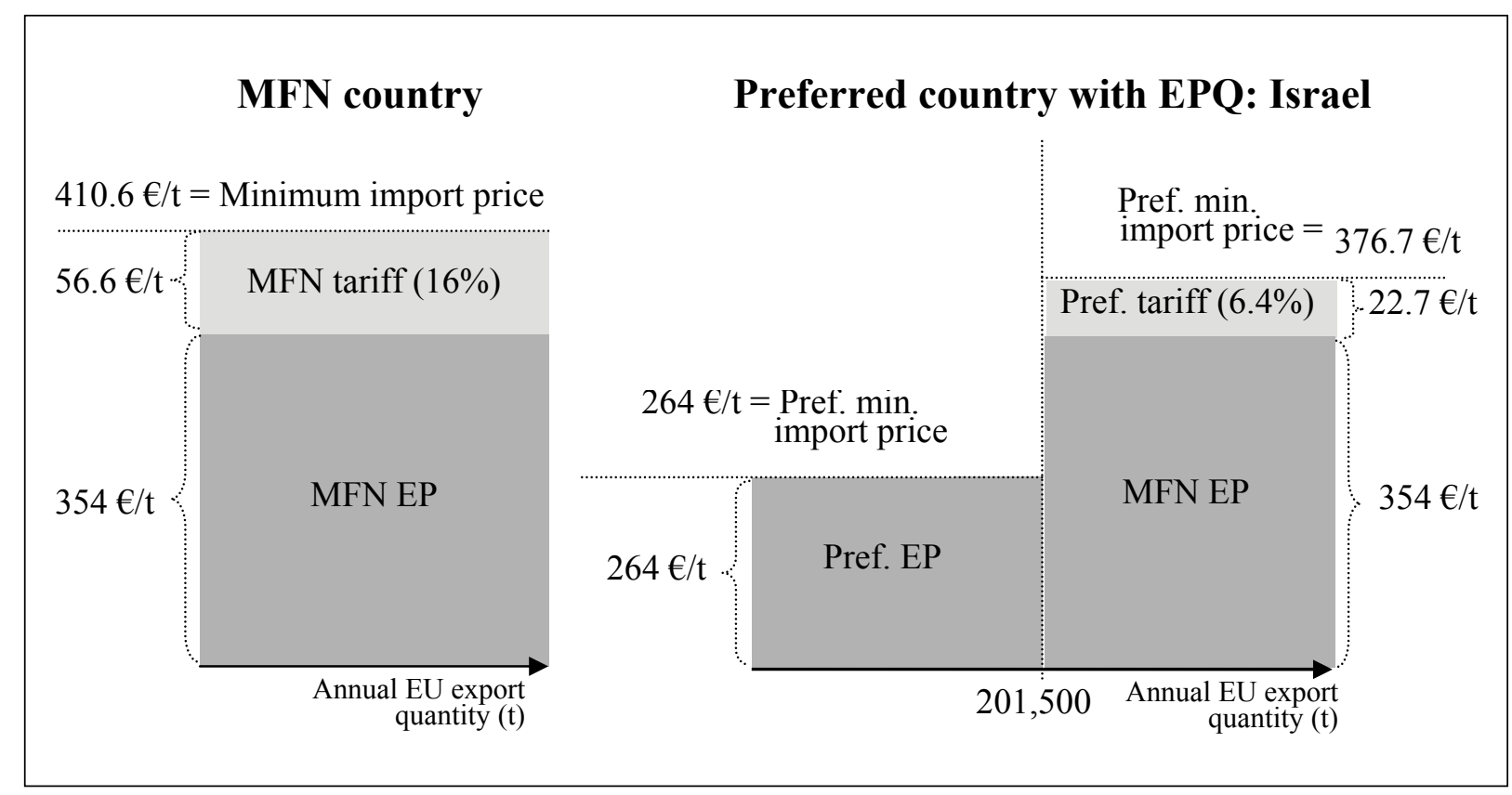

Figure 1: EPS market access conditions for oranges for a MFN country compared to a preferred country (Israel)

Sources: European Commission (2007), own calculations.

wholesale markets in all EU Member States. The daily SIVs are calculated as a weighted average of collected wholesale market prices, less a marketing and transportation margin and applied tariffs. ${ }^{10}$ Exporters have three options to declare fruits and vegetables which are subject to the EPS. The first is the SIV method, whereby the product is declared based on the product-specific SIV as surveyed by the EC on the respective import date. This method is easy to apply for the importer and does not lead to specific tariffs being charged if the SIV is higher than the EP. Alternative methods apply when products are declared at values indicated on invoices. These methods are used when there is an incentive for the importer to apply an alternative method, either because the SIV is below the EP, resulting in additional specific tariffs; or far above the EP, resulting in high ad valorem tariffs being charged. In such cases, the EU's import charges can be based on the free on board (f.o.b.) invoice price adjusted for insurance and freight costs and thus the actual cost insurance freight (c.i.f.) price (second method). The third option is customs clearance according to the deductive method, whereby import duties are charged in compliance with the effective selling price of the shipment, which has to be proven by invoice.

The EPS can be circumvented (both legally and illegally), so that some product is finally sold at prices below the EP (García-Álvarez-Coque, 2002). According to information from importers, illegal circumvention (e.g. based on false invoicing) is more prevalent in smallscale trading, particularly between related trading partners. Storage can offer a means of legal

\footnotetext{
${ }^{10}$ Details of the calculation of the SIV are provided by Regulation 3223/94 (OJ 1994, L337/66).
} 
circumvention, as storable products can be imported at any time while customs clearance is delayed until some later date when the SIV is above the EP. Once cleared at a favourable SIV, the product can be sold later on EU markets at any price (Cioffi and del' Aquila, 2004).

\section{$3 \quad$ Previous studies}

Various authors have analysed the functioning, effects and especially degree of protectiveness of the highly complex EPS and its predecessor the RPS.

Swinbank and Ritson (1995) analyse the influence of the RPS by determining the number of countervailing charges applied in the period 1988-1994 based on SIV data. The study covers all fruits and vegetables subject to the RPS for all major exporting countries. They find that the RPS has the most protective effects for lemons, with Turkey and Cyprus particularly affected. Overall, they identify Spain and the Canary Islands ${ }^{11}$ as the most affected exporters, accounting for about one-third of all cases of countervailing charges (Swinbank and Ritson, 1995, 346).

Analogously, Cioffi and del' Aquila (2004) analyse the effects of the EPS for apples, oranges and tomatoes based on the number of days on which the SIV was below the EP. They point out that the time distribution of these events in relation to the marketing season of each product has to be taken into account, in particular for highly storable products such as apples, in order to assess the protectiveness of the EPS correctly. The analysis is conducted for the major exporting countries in the period 1995-2000. They find that the EPS has low relevance for imports of apples and oranges, but has a relatively strong influence on tomatoes. In addition, they show that the incidence of SIVs below the EP for apples originating in the southern hemisphere countries of South Africa, Chile, New Zealand and Argentina is concentrated in October and November, which falls outside the main export period for these countries (March to September). They attribute such episodes when SIVs fall below the EP outside the main export season to residual quantities of stored apples (Cioffi and del' Aquila, 2004, 175).

Several recent case studies have investigated the relevance of the EPS for individual SMC and specific fruits and vegetables. Chemnitz and Grethe (2005) find that the EPS is of high importance for tomato imports from Morocco. The EU import price which is measured as the SIV is below the MFN EP in $71 \%$ of the observations for tomatoes originating in Morocco in the period 2000-2003. As a result, the preferential entry price is heavily utilised and monthly

\footnotetext{
${ }^{11}$ Although Spain and the Canary Islands entered the EU in 1986, they had to comply with the reference price system indirectly through a system of offer prices until 1993.
} 
Moroccan tomato export quantities are almost equal to the size of the respective entry price quota in the period 2000-2004. This 'fine tuning' is accomplished by a public Moroccan export control and coordination authority which coordinates and monitors Moroccan tomato exports.

García-Álvarez-Coque et al. (2007) analyse different policy scenarios for the liberalisation of the EU import regime for fresh tomatoes based on a comparative static partial equilibrium model that accounts for the EU-25, Morocco and the rest of the world (ROW) as major suppliers. They find that eliminating the EPS would have serious consequences for EU tomato producers, reducing sales by $20 \%$ in some periods of the year, whereas Morocco and the ROW would benefit. In addition, prices could decrease by up to $10 \%$ in the first quarter of each year. Trade effects resulting from liberalisation of the EPS would also be largest in this period.

In their analysis of the EU import regime for oranges, Goetz and Grethe (2007a) show that the EPS is of low relevance for orange exports from SMC. In particular, the SIV is about $70 \%$ higher on average than the applied, preferential EP for Moroccan oranges in the period 19952004. The SIV of Moroccan oranges is only lower than the EP in $7 \%$ of all observations, implying that Morocco does not profit from its preferential entry price for oranges. This is supported by analysis of Morocco's orange quota filling rate, which includes the preferential entry price quota as well as a preferential tariff rate quota. Since 1997, Morocco's orange quota filling rate has been below 50\%.

Martinez-Gomez (2007) finds that the value resulting from the preferential entry price for exports of Moroccan clementines to the EU accounts for about $25 \%$ of the total value of preferences, with the remaining $75 \%$ attributed to preferential ad valorem tariff reductions.

López and Muñiz (2007) develop a method to measure the impact of different options for tariff cuts under the Doha Round of the WTO on market access for products covered by the EPS. For lemons, cucumbers and tomatoes, they find that reducing the EP by the same amount as the MTE can generate much larger reductions in expected duties than maintaining it constant at current levels. The authors point out that this effect is sensitive to the difference between the actual import price and the EP.

In summary, all recent studies on the restrictiveness of the EPS cover only a single product/country of origin combination or a subset of products/countries of origin. None analyses the effectiveness of the EPS in general. Results on single products/countries of origin are heterogeneous. 


\section{Specification of indicators to analyse the effectiveness of the EPS}

In this study, the relevance of the EPS for the import price of each of the 15 selected types of fruits and vegetables, and for the primary exporting countries, is individually investigated. This section specifies, empirically illustrates and discusses limitations of the utilized indicators.

We define the relative difference between the SIV and the respective EP as GAP as follows:

$$
G A P_{i j t}=\frac{\left(S I V_{i j t}-E P_{i j t}\right)}{E P_{i j t}}
$$

with $\mathrm{i}=$ kind of product, $\mathrm{j}=$ country of origin and $\mathrm{t}=$ time. Since preferential EPs are granted to just some countries, $E P_{i j t}$ depends not only on the kind of product but also the country of origin. Besides, $E P_{i j t}$ varies seasonally for some fruits and vegetables. If $G A P_{i j t}>0$, the import price is higher than the EP, and if $G A P_{i j t}<0$, it is lower.

Several characteristics of the distribution of $G A P_{i j t}$ can be identified which are related to the relevance of the EPS. Import price observations with $G A P_{i j t}<0$ indicate that there exists an export supply below the EP. The higher the share of observations with $G A P_{i j t}<0$, the higher the export supply at prices below the EP. In such cases, the EPS is relevant.

Assuming that circumvention of the EPS is only possible to some degree, and/or that circumvention involves additional costs (e.g. for storage), a high share of observations with $G A P_{i j t}<0$ indicates that abolishing the EP would result in an increase of imports at prices below the EP. The stronger the degree of circumvention and/or the lower the cost of circumvention, the less the EPS restricts the existing export supply below the EP, and the lower the effect of abolishing the EP would be.

This can be illustrated by two examples, oranges and tomatoes originating in Morocco. Case studies show that the EPS is of low relevance for EU orange imports originating in Morocco (Goetz and Grethe, 2007). In contrast, the EPS is highly relevant for imports of tomatoes originating in Morocco (Chemnitz and Grethe, 2005; García-Álvarez-Coque et al., 2007). Figure 2 compares histograms for the distributions of $G A P_{i j t}$ for these two cases in the period 1997-2005. 
The figure shows that $G A P_{i j t}>0$ for all observations for oranges, whereas $G A P_{i j t}<0$ for a substantial share $(21 \%)$ of observations for tomatoes. Thus, the export supply for oranges originating in Morocco is exclusively above the EP, whereas tomatoes exported by Morocco are also supplied at prices below the EP.

Thus, we define the share of observations with $G A P_{i j t}<0$ in all observations of $G A P_{i j t}$ as the first indicator of our analysis of the relevance of the EPS:

$$
\text { neg.GAP } P_{i j}=\left(\text { number of observations } G A P_{i j t} \text { with } G A P_{i j t}<0\right)
$$

/ (number of observations $G A P_{i j t}$ )

with $\mathrm{i}=$ kind of product, $\mathrm{j}=$ country of origin and $\mathrm{t}=$ time. This is correlated with the importance of the EPS. The smaller neg.GAP $i j$, the less relevant the EP for the import price for product $\mathrm{i}$

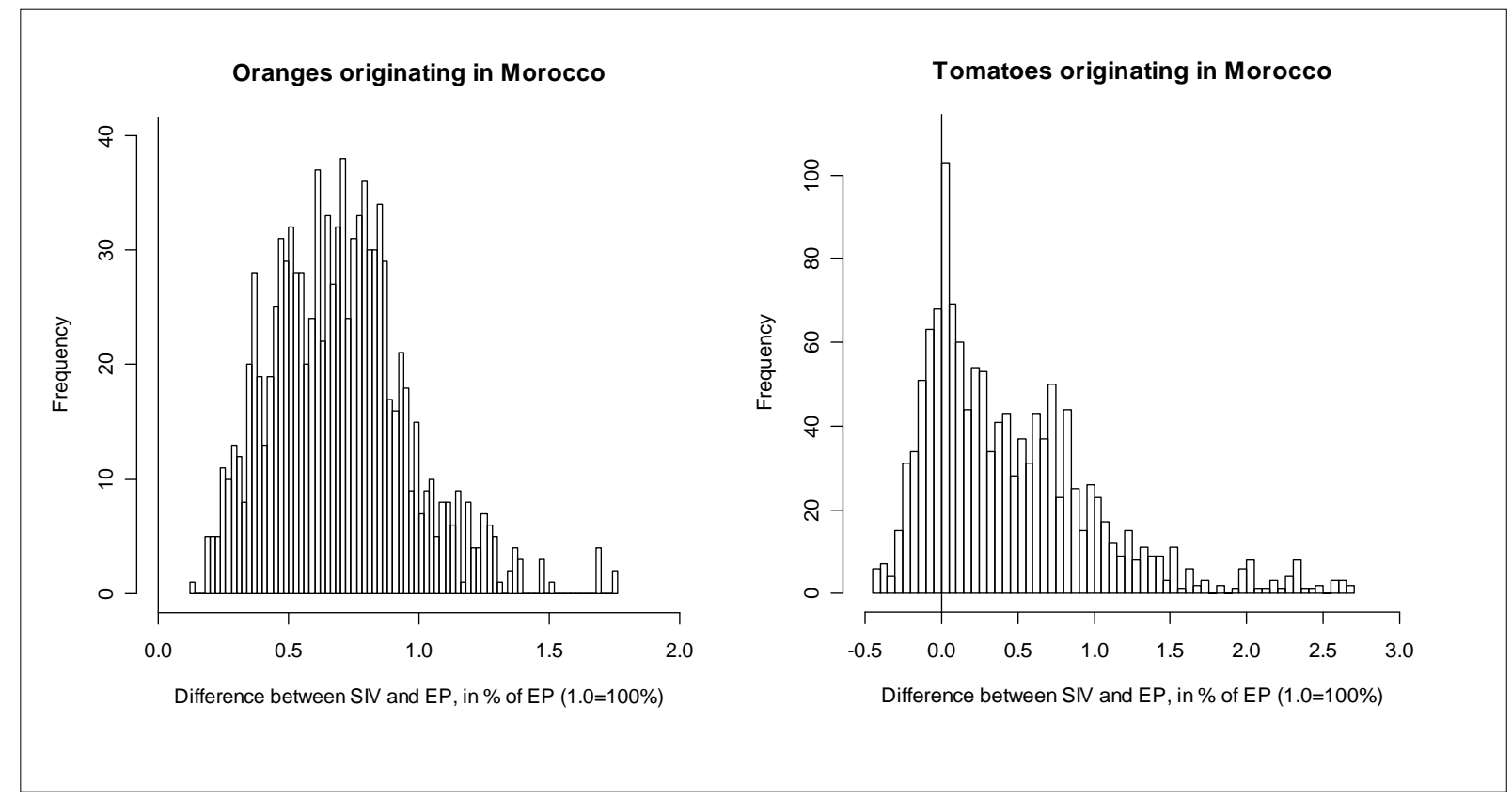

Figure 2: Histograms of $G A P_{i j t}$ for oranges and tomatoes originating in Morocco

Sources: European Commission (2005a, 2007), own calculations.

exported by country j. Conversely, the largerneg.GAP $P_{i j}$, the higher the influence of the EPS on the EU import price. As explained above, this requires SIV to be below the EP within the actual import season of the product. A similar variable is used in previous studies on the effectiveness of the EPS and RPS (see Cioffi and dell' Aquila (2004) and Swinbank and Ritson (1995), respectively). 
One drawback of neg.GAP $P_{i j}$ as an indicator for the relevance of the EPS is that it is confined to the effects of the EPS on observations with $G A P_{i j t}<0$ and does not cover the influence of the EPS on observations with $G A P_{i j t}>0$. Therefore, we derive a second indicator from the assumption, which is supported by anecdotal evidence, that exporters often supply their product at the lowest possible price while complying with the EP, thereby utilising their competitive cost advantage only to such a degree that additional specific tariffs are avoided. In other words, exporters could supply at lower prices but do not do so in order to avoid triggering specific tariffs. This implies a concentration of observations with $G A P_{i j t}>0$ slightly above the EP. Here, the EP is relevant for exporters and has a significant influence on the price of the export supply. Hence, if the EP were abolished, export supply at prices below the EP would increase. Conversely, the EPS has no influence on observations with $G A P_{i j t}>0$ with SIV being significantly higher than the EP. The degree of accumulation of observations with $G A P_{i j t}>0$ slightly above the EP can be measured by the quantile with $\mathrm{p}=0.05$ of the distribution of $G A P_{i j t}$ with $G A P_{i j t}>0$. The quantile with $\mathrm{p}=0.05$ measures the highest $G A P_{i j t}$ value in the set of observations that belong to the bottom $5 \%$ of the distribution of observations with $G A P_{i j t}>0$. The lower the value of the 0.05 -quantile, the more observations accumulate slightly above EP. This indicator explicitly addresses the influence of the EPS on import price observations with $G A P_{i j t}>0$.

As an example, it becomes directly evident from Figure 2, that observations with $G A P_{i j t}>0$ concentrate slightly above the EP for tomatoes, whereas for oranges the value of $G A P_{i j t}$ is significantly higher than the EP with the minimum value of $G A P_{i j t}$ amounting to 0.13 . The 0.05 quantile is 0.03 for tomatoes and 0.31 for oranges. In other words, the smallest $5 \%$ of the observations with $G A P_{i j t}>0$ exceed the EP by at most $3 \%$ for tomatoes compared with 31\% for oranges. This suggests that the EPS is much more effective for tomatoes from Morocco than for oranges from Morocco, confirming the case study results cited above. 
Thus, the degree of concentration of observations with $G A P_{i j t}$ around the EP measured by the 0.05 quantile of the distribution of $G A P_{i j t}$ with $G A P_{i j t}>0$ serves as the second indicator in our analysis. Since the variance of $G A P_{i j t}$ may vary by product and country of origin, and the 0.05 quantiles of distributions with differing variance are not exactly comparable, the 0.05 quantile is standardised by the standard deviation. In addition, large values are weighted less by taking logarithms, as the effectiveness of the EPS is only proportional to the 0.05 quantile within a certain interval:

$$
Q_{0.05 i j}^{*}=\ln \left(\frac{Q_{0.05 i j}}{s d\left(G A P_{i j}\right)}\right)
$$

The less $G A P_{i j t}$ is concentrated around the EP, the larger $Q_{0.05 i j}^{*}$ and the lower the influence of the EPS on the EU import price. For oranges and tomatoes originating in Morocco, $Q_{0.05 i j}^{*}$ equals 11.83 and 0.54 , respectively. However, the converse case has to be interpreted with care, as an accumulation of prices around the EP could also be caused by other factors, as the following example illustrates. Figure 3 shows the histogram of the EU import price for pineapples, measured as the unit value (UV). UVs are surveyed by the EC on a biweekly basis for fruits and vegetables which are not subject to the EPS (European Commission, 2006). We transform the UV according to

$$
U V_{i t}^{*}=\frac{U V_{i t}-\min \left(U V_{i}\right)}{\min \left(U V_{i}\right)},
$$

with $\mathrm{i}=$ product and $\mathrm{t}=$ time. Thus, $U V_{i t}^{*}$ differs from $S I V_{i j t}^{*}$ in that it does not describe the difference to $E P_{i j t}$ but rather to the minimum $U V_{i}$.

Figure 3 shows that the distribution of $U V_{i t}^{*}$ for pineapples exhibits an accumulation close to its minimum value with $Q_{0.05}^{*}=2.97$, even though an EP for pineapples does not exist. In this case, the accumulation is not caused by the EPS. Instead, it could be associated with strong price competition, if the sum of production and marketing costs is similar to the minimum $U V_{i}$ for many suppliers. ${ }^{12}$ Therefore, a low value of $Q_{0.05 i j}^{*}$ in combination with a particularly low value of neg.GAP ${ }_{i j}$ may but does not necessarily indicate that the EPS is

\footnotetext{
${ }^{12}$ Also, Deaton and Laroque (1989) find that price distributions of storable products tend to be truncated on the left.
} 
relevant. In such cases, the importance of the EPS cannot be determined unambiguously based on these indicators alone.

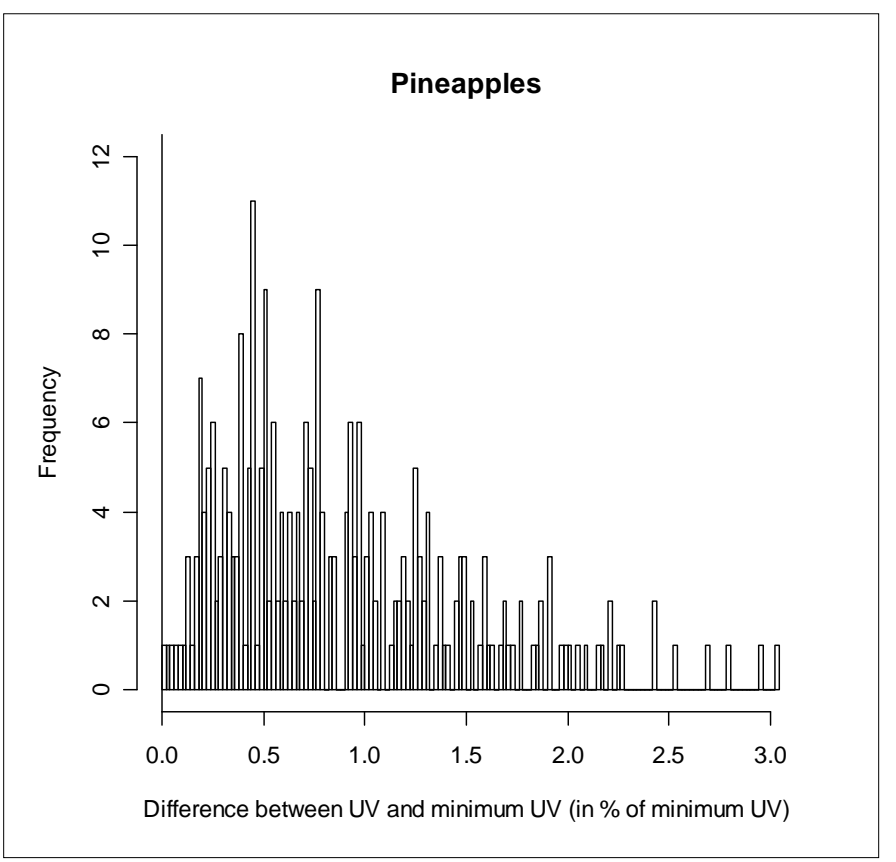

Figure 3: Histogram of $U V_{i t}^{*}$ for pineapple

Sources: European Commission (2006), own calculations.

The possible combinations of $Q_{0.05 i j}^{*}$ and $n e g . G A P_{i j}$ can be categorised (Figure 4). Quadrant I represents cases in which neg.GAP $P_{i j}$ is high and $Q_{0.05 i j}^{*}$ is low, indicating that a relatively large export supply at prices below the EP exists, with the export supply above the EP concentrated slightly above the EP level. This implies that the EPS does influence the EU import price. In contrast, quadrant IV comprises combinations of a small value for neg.GAP $i j$ and a large value for $Q_{0.05 i j}^{*}$. In this case, there is no large export market segment below the EP, and market supply is not concentrated strongly at prices just above the EP. This suggests that the EPS is of relatively low relevance for the EU import price. A combination in quadrant II implies that the export market supply below the EP is small but that market supply above the EP accumulates around the EP. Here, the EPS could be important, but not necessarily so, as explained above.

Combinations of large values of both neg.GAP $P_{i j}$ and $Q_{0,05 i j}^{*}$ in quadrant III imply that market supply at prices below the EP exist, but that supply prices above the EP are not concentrated just above the EP. This could indicate a segmented market consisting of a low-quality segment with a price level below the EP as well as a high-quality segment with a price level 
far above the $\mathrm{EP}^{13}$. Alternatively, observations in quadrant III could be explained by a high degree of circumvention of the system. In such cases, the EPS is relevant for the EU import price.

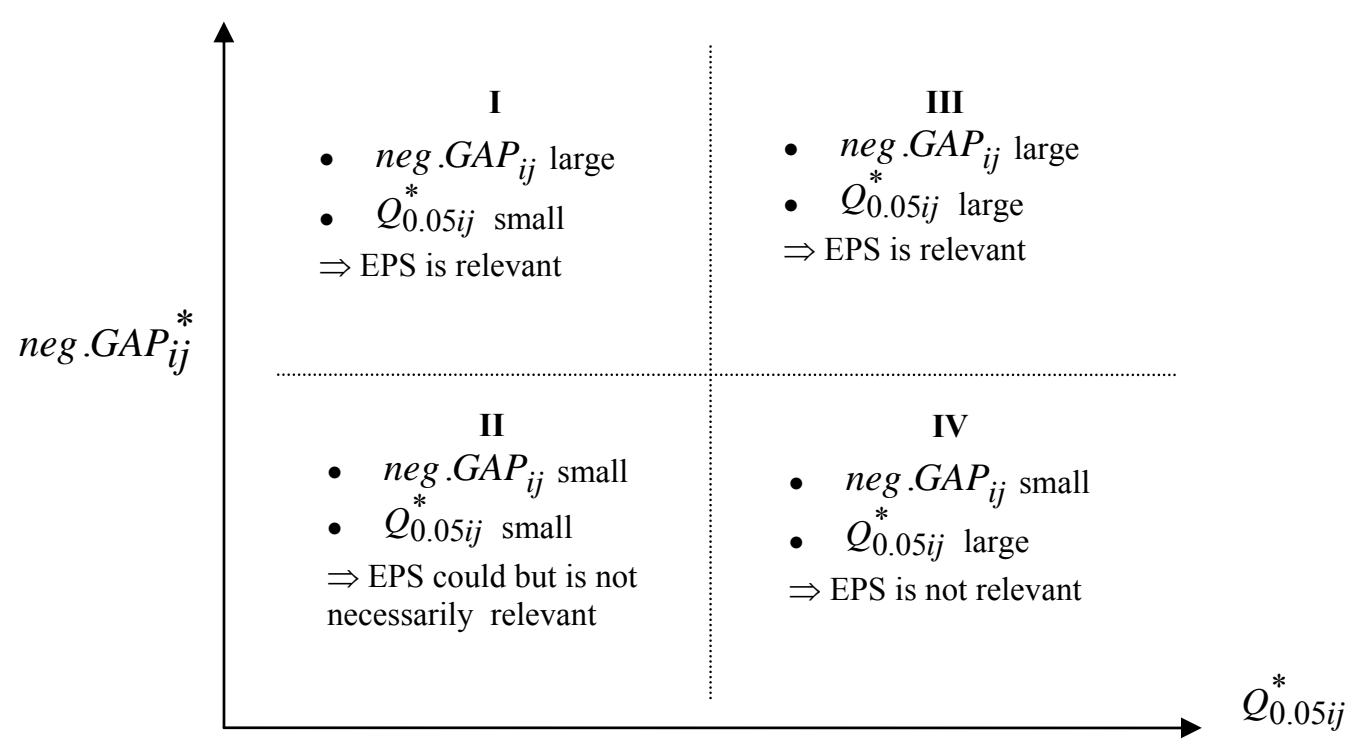

Figure 4: Classes of combinations of the two indicators of the effectiveness of the EPS

It should be pointed out that the two indicators $Q_{0.05 i j}^{*}$ and neg.GAP $P_{i j}$ complement each other, but are theoretically not necessarily related. For example, if the EP is highly relevant and a country's exports to the EU are strongly organised and managed well in order to comply with the EPS by supplying products at a price at least as high as the EP, the value of neg.GAP $P_{i j}$ as well as $Q_{0.05 i j}^{*}$ might be low. In this case, the effectiveness of the EPS is high, although neg.GAP $i j$ is low. Thus, neg.GAP $i j$ alone would not correctly determine the effectiveness of the EPS. Instead, the high relevance of EPS would become evident in a low value of ${ }_{0.05 i j}^{*}$. The remainder of this section aims to further justify the indicators selected for measuring the relevance of the EPS. We describe other measures correlated to the effectiveness of the EPS and difficulties that would arise if applied in the context of this study.

The skewness coefficient ${ }^{14}$ is a further distribution moment which can reflect the impact of the EPS. For example, the skewness of the distribution of GAP values for oranges from Morocco, for which the EPS is of low importance, is rather low at 0.62 , but is relatively high

\footnotetext{
${ }^{13}$ The idea of a twofold segmentation of the EU fruits and vegetables market can also be found in Cioffi and dell' Aquila (2004, 179).

${ }^{14}$ Skewness is a measure for the asymmetry of a probability distribution. A positive skew indicates that the right tail of the distribution is longer than the left tail, whereas a negative skew indicates that the left tail of the distribution is longer than the right tail. The measure of skewness used here is $S=E(X-\mu)^{3} / \sigma^{3}$ with $\eta$ the mean values and $\sigma$ the standard deviation of $\mathrm{f}(\mathrm{x})$.
} 
at 1.19 for tomatoes originating in Morocco, for which the EPS is highly relevant. This represents an additional hint that the EPS is highly effective for tomatoes from Morocco, as the asymmetric distribution with the relatively short left tail is probably caused by traders avoiding selling below the entry price. However, skewness is also strongly influenced by accidental extreme values, which are typical for fruit and vegetable data. Figure 5 shows A)

the histogram and normal density function and B) the qq-plot ${ }^{15}$ of the distribution of $G A P_{i j t}$ for apples from South Africa, which is characterised by a large number of extreme values and a skewness coefficient of 2.04. Yet, as the graphs directly show, the influence of the EPS is low since observations with $G A P_{i j t}>0$ neither accumulate slightly above the EP, nor is there a high share of observations with $G A P_{i j t}<0$. In contrast, skewness is rather low for lemons originating in Argentina at 0.77 (Figure 6), although the distribution of $G A P_{i j t}$ is characterised by a high share of negative observations and an accumulation of observations

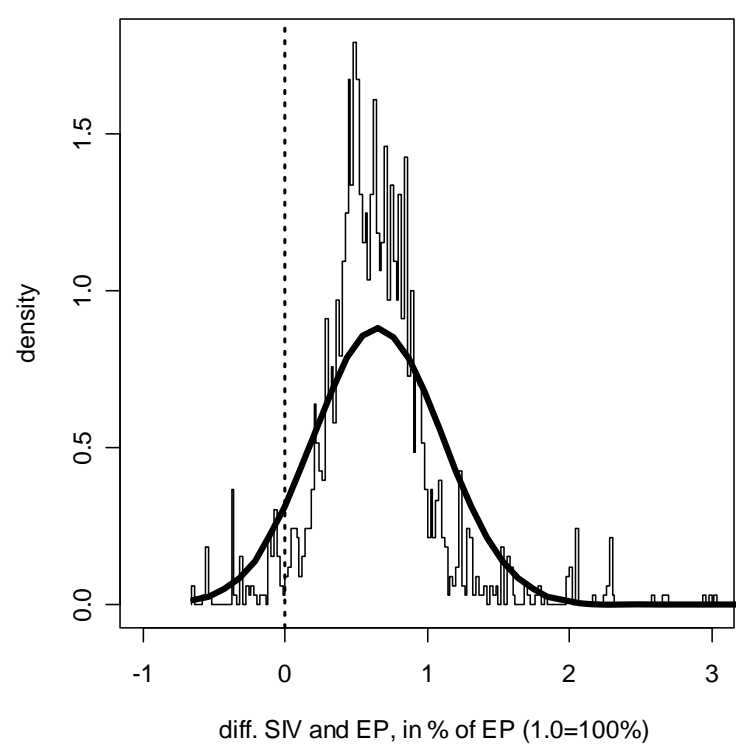

B

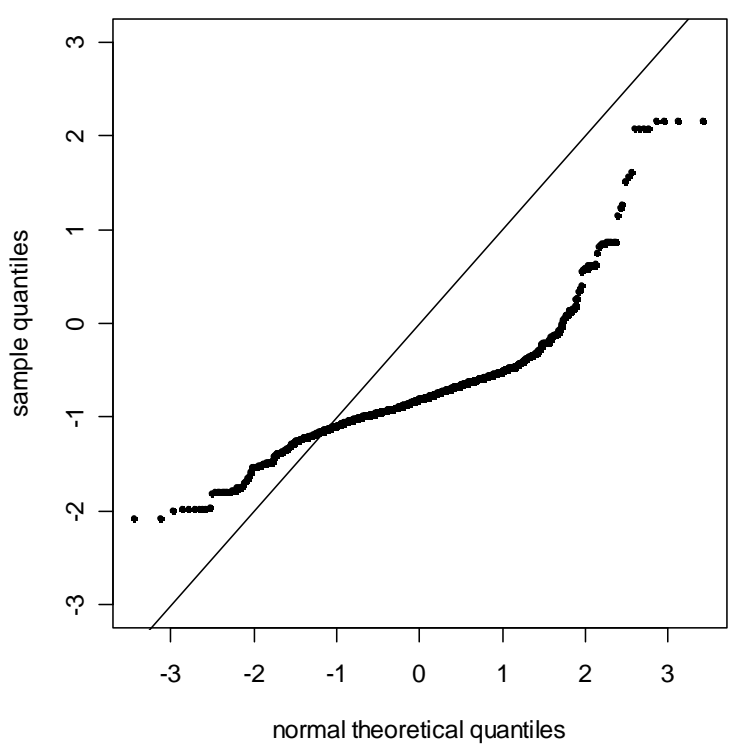

Figure 5: $G A P_{i j t}$ apples from South Africa - A) histogram and normal density function, B) QQ-plot $G A P_{i j t}$

Sources: European Commission (2005a, 2007), own calculations.

\footnotetext{
${ }^{15}$ A quantile-quantile (qq) plot is a tool for comparing two distributions. In our application, the empirical distribution is compared to a normal distribution. If these two distributions are equal, their quantiles are equal, implying that the empirical quantile values are on the diagonal line.
} 
with $G A P_{i j t}>0$ slightly above the EP. In the latter case, the low value of skewness is caused by a high share of negative observations which increase the symmetry of the distribution of $G A P_{i j t}$. Therefore, a robust estimate of skewness that excludes extreme values from the dataset, would improve results only in some cases but not all. Thus, we do not consider skewness as an indicator in this study.

Furthermore, for our analysis we do not assume either that $G A P_{i j t}$ would be normally distributed in the absence of an EP, or that the EP generates a truncation of the distribution, as López and Muñiz (2007) do, for two reasons. First, due to the existence of observations of $G A P_{i j t}$ with $G A P_{i j t}<0$, distributions of $G A P_{i j t}$ which are influenced by the EP are not necessarily represented by a truncated distribution. This becomes particularly evident from Figure 6 which presents the histogram (A) and the corresponding qq-plot (B) of the distribution of $G A P_{i j t}$ for lemons originating in Argentina with $36 \%$ of $G A P_{i j t}<0$.

Second, the assumption that SIV is normally distributed seems inadequate in general. As shown above, price distributions may be truncated. Furthermore, price distributions may be two peaked, as shown in Figure 7 A) for artichokes originating in Egypt.
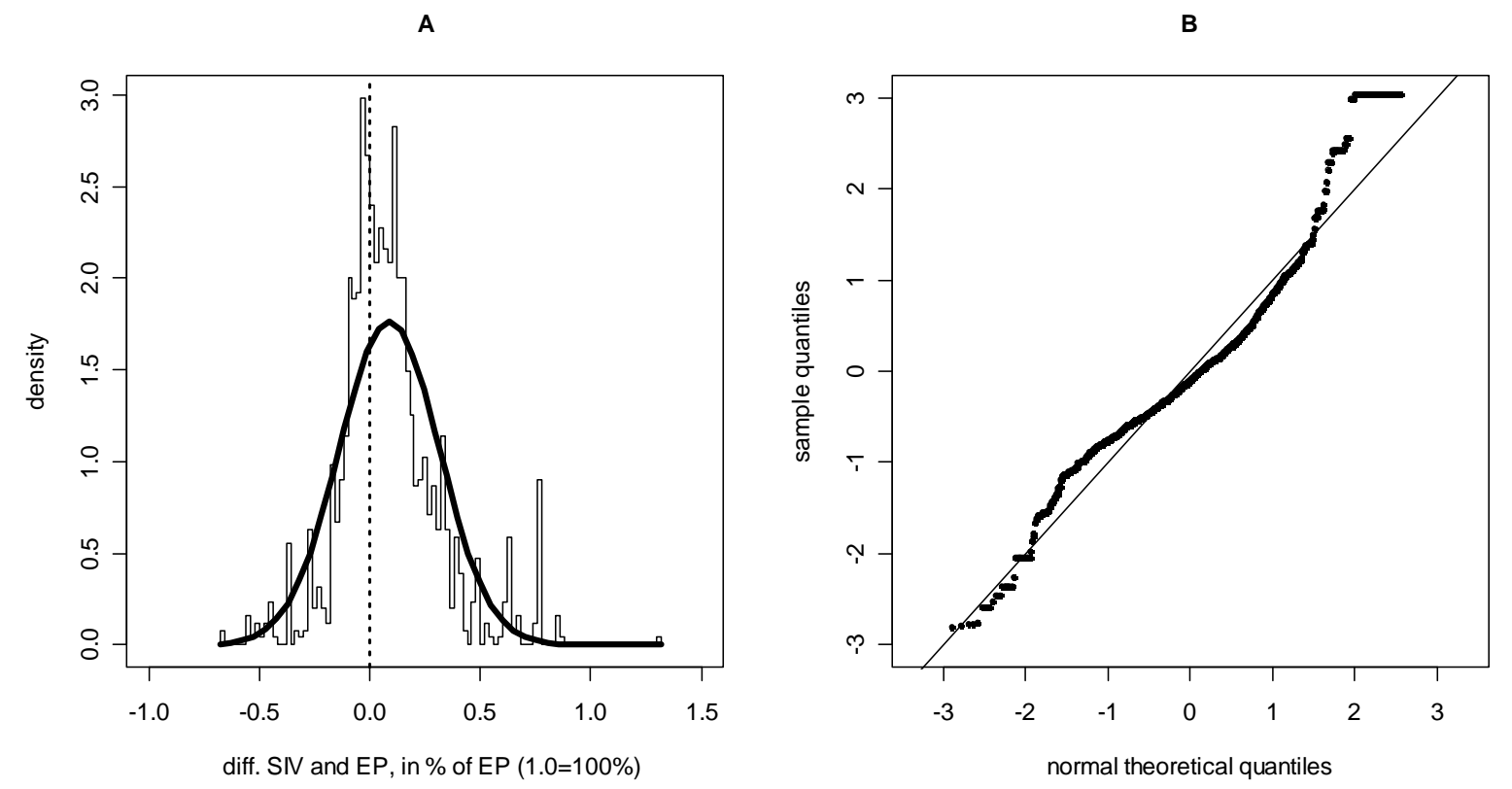

Figure 6: $G A P_{i j t}$ lemons from Argentina - A) histogram and density function, B) QQplot $G A P_{i j t}$

Sources: European Commission (2005a, 2007), own calculations. 
A

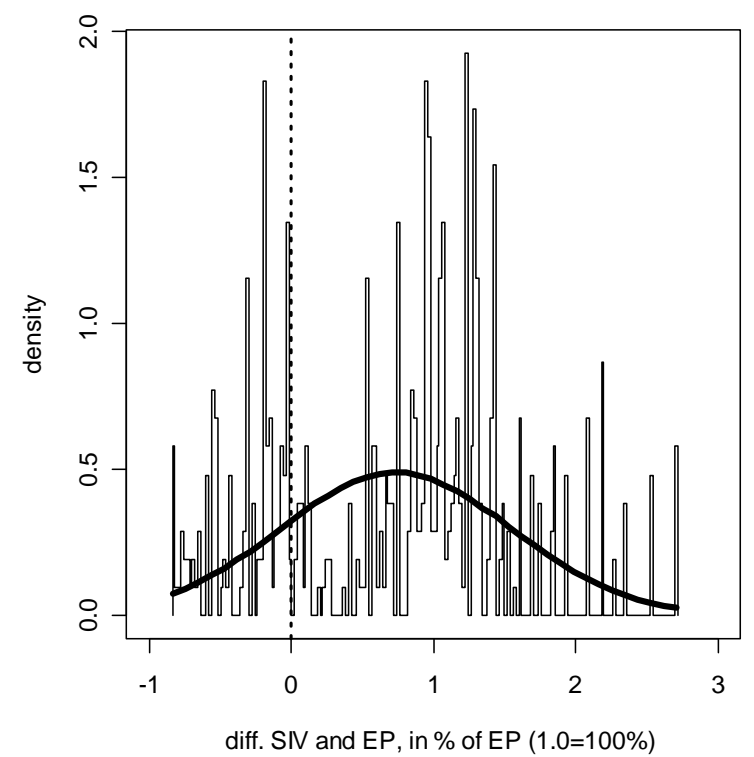

B

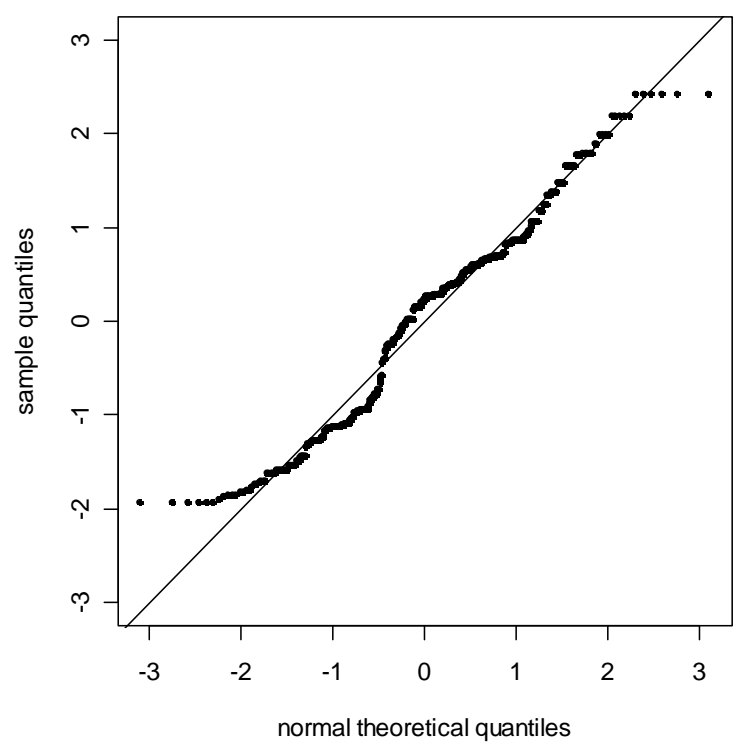

Figure 7: $G A P_{i j t}$ artichokes from Egypt - A) histogram and normal density function, B) QQ-plot

Sources: European Commission (2005a, 2007), own calculations.

\section{$5 \quad$ Empirical results}

The indicators neg.GAP $P_{i j}$ and $Q_{0.05 i j}^{*}$ derived above are calculated for 81 country- and product-specific distributions of $G A P_{i j t}$, each consisting of between 65 and 2,678 observations ${ }^{16}$.

We conduct a cluster analysis with the aim to attribute country- and product-specific imports of fresh fruits and vegetables into classes which differ in the relevance of the EPS.

Although neg.GAP ${ }_{i j}$ and $Q_{0.05 i j}^{*}$ exhibit substantial correlation (correlation coefficient $=-0.59$, which is significantly different from zero at $\mathrm{p}=0.01$ ), both indicators are used as variables in the cluster analysis for reasons given in Section 4.

The cluster analysis is conducted in several steps. We first identify any outliers (here, "plums from Turkey") using the Single-Linkage method and remove them from the dataset. Then, the optimal number of clusters and the respective cluster means are identified by the Ward method, which serves as a starting partition in the consequent application of the K-Means

\footnotetext{
${ }^{16}$ The number of available observations of SIVs for a product of a particular exporting country varies depending on the number of days the product is traded on EU wholesale markets. Moreover, series of observations of up to two years length are excluded from individual datasets due to data inconsistencies. Altogether, we utilise about 57,000 observations of SIV in the time period 1995-2005.
} 
method to determine the elements of each cluster. Although Scree test results indicate that the optimal number of clusters is three, we allow four clusters in the K-Means method. Since objects in cluster 1 are distinctively different from all other objects, these could be treated as outliers. If the Scree test is conducted for the dataset excluding the objects in cluster 1, then three clusters are optimal. Therefore, we choose the four-cluster result from the Ward method as the starting partition for the K-Means method, which identifies the optimal four-cluster solution for 80 objects.

Several criteria suggest that the obtained four-cluster solution is of high quality. F-values are smaller than 1 for both variables in each cluster, indicating that the clusters are very homogeneous (Table 2). Further, eta $=0.93$ on average implies that the two variables neg.GAP ${ }_{i j}$ and $Q_{0.05 i j}^{*}$ are significantly different and that the within-cluster variance is low. In addition, eta ${ }^{2}=0.86$ shows that $86 \%$ of the variance of neg.GAP $P_{i j}$ and $Q_{0.05 i j}^{*}$ can be attributed to differences between clusters on average. The stability of the cluster solution is high. Crosstabulation indicates that 74 objects, corresponding to $92.5 \%$ of the total, are classified congruently by the Ward and the K-means methods. In addition, the kappa number is equal to 0.90 .

Results of the cluster analysis are presented in Table 2 and in the cluster plot (Figure 8). The cluster plot is organized in the same dimensions as Figure 4 above: the vertical axis displays the share of negative observations in its original dimension, while the horizontal axis displays the size of the 0.05 quantile in its normalised, logarithmised and z-standardised form. Table 3 additionally presents detailed results for all objects.

Table 2: Cluster characteristics

\begin{tabular}{|c|c|c|c|c|c|c|c|c|}
\hline & \multicolumn{2}{|c|}{$\begin{array}{c}\text { Cluster 1 } \\
\mathrm{n}=8(10 \%)\end{array}$} & \multicolumn{2}{|c|}{$\begin{array}{c}\text { Cluster 2 } \\
\mathrm{n}=21(26 \%)\end{array}$} & \multicolumn{2}{|c|}{$\begin{array}{c}\text { Cluster } 3 \\
\mathrm{n}=26(33 \%)\end{array}$} & \multicolumn{2}{|c|}{$\begin{array}{c}\text { Cluster } 4 \\
\mathrm{n}=25(31 \%)\end{array}$} \\
\hline & $\begin{array}{c}\text { neg.GAP } \\
\text { (stand.) }\end{array}$ & $\begin{array}{l}Q_{0,05 i j}^{*} \\
\text { (stand.) }\end{array}$ & $\begin{array}{c}\text { neg.GAP } \\
\text { (stand.) }\end{array}$ & $\begin{array}{l}Q_{0,05 i j}^{*} \\
\text { (stand.) }\end{array}$ & $\begin{array}{c}\text { neg.GAP } \\
\text { (stand.) }\end{array}$ & $\begin{array}{l}Q_{0,05 i j}^{*} \\
\text { (stand.) }\end{array}$ & $\begin{array}{c}\text { neg.GAP } P_{i j} \\
\text { (stand.) }\end{array}$ & $\begin{array}{l}Q_{0,05 i j}^{*} \\
\text { (stand.) }\end{array}$ \\
\hline F-value & 0.15 & 0.65 & 0.19 & 0.28 & 0.02 & 0.10 & 0.01 & 0.15 \\
\hline $\begin{array}{l}\text { t-value } \\
\text { (mean) }\end{array}$ & 2.65 & -1.06 & 0.31 & -1.04 & -0.47 & 0.10 & -0.61 & 1.11 \\
\hline $\begin{array}{l}\text { Relevance } \\
\text { EPS }\end{array}$ & & & & & & & & low \\
\hline
\end{tabular}




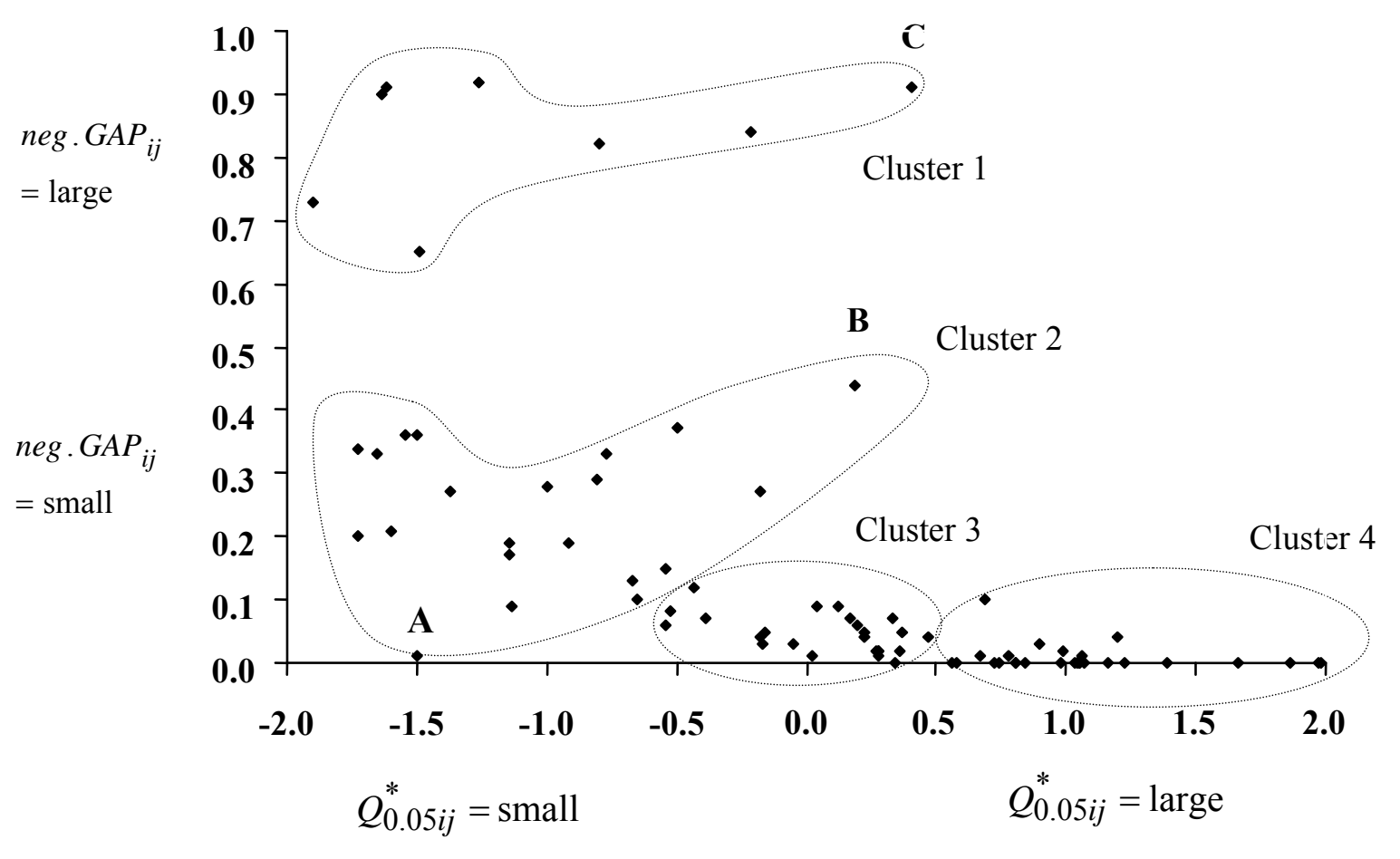

\section{Figure 8: Cluster plot}

Cluster 1 consists of eight $(10 \%)$ of the eighty objects, which are characterised by an extremely high value of neg.GAP $P_{i j}$, varying between 0.65 and 0.92 , while $Q_{0.05 i j}^{*}$ varies over a broad range between -1.90 and 0.41 . T-values for cluster 1 indicate that neg.GAP $P_{i j}$ is higher and $Q_{0.05 i j}^{*}$ substantially lower than on average.

Products that are characterised by a significantly lower, yet still high, value of neg.GAP ${ }_{i j}$ for most products (between 0.09 and 0.44 except for one case (point A)), and a low value of $Q_{0.05 i j}^{*}$ (between -1.73 and 0.19 ) belong to cluster 2 . Like cluster 1 , the t-value is higher and lower than on average for neg.GAP $P_{i j}$ and $Q_{0.05 i j}^{*}$, respectively. Cluster 2 comprises 21 objects accounting for $26 \%$ of all objects.

Objects assigned to cluster 4 are distinguished by a very low value of neg.GAP $P_{i j}$ (at most 0.1 ) and a high value of $Q_{0.05 i j}^{*}$ (at least 0.67 ). In addition, objects in cluster 3 are characterised by a rather low value of neg.GAP $P_{i j}(<12 \%)$ and high value of $Q_{0.05 i j}^{*}(<0.47)$, which are higher and lower than the values of objects of cluster 4 on average, respectively. For both clusters 3 
and 4 , neg.GAP $i j$ is lower and $Q_{0.05 i j}^{*}$ higher than average. Cluster 3 and cluster 4 are composed of 26 and 25 objects accounting for $33 \%$ and $31 \%$ of all objects, respectively.

Thus, the 4 identified clusters are not congruent with the 4 quadrants in Figure 4.

Cluster results suggest that the EPS is of highest relevance for objects in cluster 1, which display a very high share of negative observations for all objects and a strong accumulation of SIVs close to the EP for most products. Furthermore, for objects belonging to cluster 2 the EPS is relevant, although to a lesser extent. The share of negative observations is lower than for cluster 1 , but still at $9 \%$ or more for all but one product. In addition, SIVs are concentrated closely above the EP for most products in cluster 2. Thus, clusters 1 and 2 can by and large be attributed to quadrant I in Figure 4. The relevance of the EPS is lower for objects in cluster 3, and lowest of all for all objects attributed to cluster 4 . The share of negative observations is very low for both clusters, and only for some products in cluster 3 is there some concentration of SIVs near the EP level. Clusters 3 and 4 match with quadrant IV in Figure 4.

In the following, three objects depicted in Figure 8 are discussed more in detail. Oranges originating in the US (A) are characterised by a particularly low value for neg.GAP $P_{i j}$ of 0.01 as well as for $Q_{0.05}^{*}$. In other words, this object is characterised by an extremely low share of observations with $G A P_{i j t}<0$, but a strong accumulation of observations with $G A P_{i j t}>0$ closely above the EP. Therefore, this object could be attributed to quadrant II in Figure 4, for which the EPS could be, but is not necessarily of high relevance. Importers point out that the observed accumulation of observations close to the EP for oranges originating in the US is not caused by the EPS. In general, oranges exported by the US are highly priced and therefore their share in the EU market is very low.

Two objects - clementines originating in Turkey (B) and plums originating in Bulgaria (C) are characterised by high values of neg.GAP $P_{i j}$ and concurrently relatively high values of $Q_{0.05}^{*}$. These objects might correspond to objects belonging to quadrant III in Figure 4, which may indicate that market supply is segmented in a low-quality segment with a price level below the EP, and a high-quality segment with a price level far above the EP. Indeed, importers confirm that there are two kinds of clementines of different quality exported by Turkey which are characterised by large differences in price levels. For plums, by contrast, importers attribute the apparent existence of two market segments to annual price differences for plums. The amount of plums harvested in the EU varies considerably from year to year, implying large annual price differences. 
The affiliation of individual fruits and vegetables is with some exceptions heterogeneous throughout countries of origin (Table 3). For example, the EPS is of low importance for the major apple exporters to the EU such as Argentina, New Zealand and South Africa, but relevant for minor exporters such as China, Turkey, Poland and Uruguay. Regarding pears, the EPS is only relevant for exports from China. ${ }^{17}$ In addition, the EPS is of high relevance for the major tomato suppliers (Morocco and Turkey), but of low importance for Israel and Tunisia.

To draw some more general conclusions with regard to the relevance of the EPS for particular kinds of fruits and vegetables, country-specific results for each product are weighted by their respective share in the total quantity of EU imports during the period covered by the EPS (Table 3). For example, the countries of origin for apples that are attributed to clusters 3 and 4 account for $59 \%$ and $38 \%$ of total EU apple imports, respectively. This aggregation shows that the EPS is most relevant for the import of artichokes, courgettes, cucumbers, lemons, plums and tomatoes (dominant shares in clusters 1 and 2); significantly lower for apples, clementines and pears (dominant shares in cluster 3); and least relevant for apricots, mandarins, oranges, peaches and nectarines and table grapes (dominant shares in cluster 4). For their part, apples are easily stored, offering broad opportunities to circumvent the EPS (which is particularly the case for apples originating in countries in the Southern Hemisphere). Therefore, it can be expected that the removal of the EPS for apples would only have a very limited effect on the EU market.

Furthermore, to assess the relevance of the EPS for individual export countries, the incidence of clusters is aggregated per country over all products. The group of countries which are repeatedly attributed to clusters 1 and 2 and thus for which the EPS is of high relevance comprises Turkey (5 out of 11 products), the eastern European countries of Bulgaria, Poland, Romania and Hungary before EU accession (8 out of 11), the neighbouring eastern European countries of Bosnia-Herzegovina, Serbia-Montenegro and Macedonia (1 out of 1 each), Morocco (3 out of 6), South Africa (2 out of 4) and China (2 out of 2).

In contrast, the EPS is of low relevance for Israel (4 out of 5 objects are clearly assigned to clusters 3 and 4), the US ( 3 out of 3), and Jordan, Canada and New Zealand ( 2 out of 2 each). The results also suggest that the influence of the EPS on the SMC (with the exception of Cyprus) is mixed, with the exception of mandarins and table grapes, which are attributed to cluster 4 for all SMC. For example, the EPS has a higher influence on tomato exports from Morocco and Turkey than from Israel or Tunisia; and greater impact on orange exports from

\footnotetext{
${ }^{17}$ For a detailed analysis of the relevance of the EPS for fruits and vegetables originating in China, see Goetz and Grethe (2007b).
} 
Table 3: Cluster analysis of results

\begin{tabular}{|c|c|c|c|c|c|}
\hline & neg.GAP ${ }_{i j}$ & 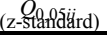 & $\begin{array}{l}\text { Number of } \\
\text { observations }\end{array}$ & $\begin{array}{l}\text { Share in total } \\
\text { extra-EU import } \\
\text { ent }\end{array}$ & Cluster \\
\hline Mandarins & \multicolumn{5}{|c|}{ EPS of lowest relevance $(\mathrm{a}:<0.94$; b: cluster $4:<0.94)$} \\
\hline Cyprus & 0.00 & 1.98 & 219 & 0.06 & 4 \\
\hline Israel & 0.00 & & 514 & 0.16 & 4 \\
\hline Jamaica & 0.00 & 0.81 & 492 & $<0.01$ & 4 \\
\hline Morocco & 0.01 & 1.06 & 395 & 0.07 & 4 \\
\hline Pakistan & 0.02 & 0.99 & 97 & $<0.01$ & 4 \\
\hline Turkey & 0.00 & 1.66 & 819 & 0.63 & 4 \\
\hline Oranges & \multicolumn{5}{|c|}{ EPS of lowest relevance $(a:<0.94 ;$ b: cluster $2:<0.02$, cluster $3: 0.25$, cluster $4: 0.67$} \\
\hline Cyprus & 0.01 & 0.02 & 502 & 0.03 & 3 \\
\hline Egypt & 0.05 & -0.16 & 669 & 0.09 & 3 \\
\hline Israel & 0.00 & 1.39 & 834 & 0.21 & 4 \\
\hline Morocco & 0.00 & 1.23 & 1035 & 0.46 & 4 \\
\hline South Africa & 0.37 & -0.50 & 220 & 0.01 & 2 \\
\hline Tunisia & 0.03 & -0.17 & 762 & 0.07 & 3 \\
\hline Turkey & 0.08 & -0.52 & 1016 & 0.06 & 3 \\
\hline USA & 0.01 & -1.50 & 191 & $\leq 0.01$ & 2 \\
\hline Peaches/Nectarines & \multicolumn{5}{|c|}{ EPS of lowest relevance (a: $0.71 ;$ b: cluster $3: 0.06$, cluster $4: 0.65$ ) } \\
\hline Israel & 0.09 & 0.12 & 65 & 0.06 & 3 \\
\hline Turkey & 0.00 & 0.84 & 485 & 0.65 & 4 \\
\hline Pears & \multicolumn{5}{|c|}{ EPS of lower relevance (a: $<0.94 ;$ b: cluster $2: 0.02$, cluster $3:<0.88$, cluster $4:<0.04)$} \\
\hline Argentina & 0.07 & & 923 & 0.43 & 3 \\
\hline Chile & 0.07 & 0.33 & 796 & 0.17 & 3 \\
\hline China & 0.33 & -1.65 & 799 & 0.02 & 2 \\
\hline Hungary & 0.02 & 0.36 & 559 & $<0.01$ & 3 \\
\hline New Zealand & 0.00 & 0.81 & 136 & $<0.01$ & 4 \\
\hline South Africa & 0.02 & 0.28 & 1243 & 0.27 & 3 \\
\hline Turkey & 0.00 & 1.03 & 1124 & 0.03 & 4 \\
\hline Plums & \multicolumn{5}{|c|}{ EPS of highest relevance (a: 0.86 ; b: cluster 1: 0.71 , cluster $4: 0.15$ ) } \\
\hline Bosnia-Herzegovina & 0.82 & -0.80 & 128 & 0.01 & 1 \\
\hline Bulgaria & 0.91 & 0.41 & 123 & 0.03 & 1 \\
\hline Hungary & 0.73 & -1.90 & 388 & 0.44 & 1 \\
\hline Israel & 0.03 & 0.90 & 494 & 0.15 & 4 \\
\hline Poland & 0.90 & -1.64 & 134 & 0.05 & 1 \\
\hline Romania & 0.65 & -1.49 & 349 & 0.15 & 1 \\
\hline Serbia-Montenegro & 0.92 & -1.26 & 144 & 0.03 & 1 \\
\hline Table grapes & \multicolumn{5}{|c|}{ EPS of lowest relevance (a: $<0.75 ;$ b: cluster $2:<0.01$, cluster $4: 0.73$ ) } \\
\hline Cyprus & 0.04 & 0.22 & 159 & 0.02 & 3 \\
\hline Egypt & 0.00 & 0.72 & 141 & 0.01 & 4 \\
\hline Hungary & 0.17 & -1.14 & 309 & $<0.01$ & 2 \\
\hline Israel & 0.00 & 1.07 & 317 & 0.01 & 4 \\
\hline Turkey & 0.00 & 0.74 & 756 & 0.40 & 4 \\
\hline USA & 0.00 & 1.97 & 598 & 0.31 & 4 \\
\hline Tomatoes & \multicolumn{5}{|c|}{ EPS of higher relevance (a: $0.98 ;$ b: cluster $1: 0.01$, cluster $2: 0.91$, cluster $3: 0.08$ ) } \\
\hline Israel & 0.06 & -0.54 & 520 & 0.06 & 3 \\
\hline Macedonia & 0.84 & -0.21 & 268 & 0.01 & 1 \\
\hline Morocco & 0.21 & -1.60 & 1325 & 0.83 & 2 \\
\hline Poland & 0.36 & -1.50 & 181 & 0.01 & 2 \\
\hline Tunisia & 0.12 & -0.43 & 651 & 0.01 & 3 \\
\hline Turkey & 0.27 & -1.37 & 1593 & 0.06 & 2 \\
\hline
\end{tabular}

\begin{tabular}{|c|c|c|c|c|c|}
\hline \multirow[b]{2}{*}{ Apples } & neg. $G A P_{i j}$ & 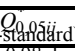 & $\begin{array}{l}\text { Cumber of } \\
\text { servation }\end{array}$ & $\begin{array}{ll}\operatorname{areint} \\
\text { a-EU in }\end{array}$ & Cluster \\
\hline & \multicolumn{5}{|c|}{ 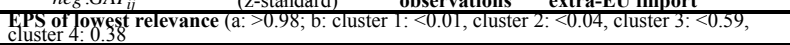 } \\
\hline Argentina & 0.09 & 0.04 & 1275 & 0.10 & 3 \\
\hline Australia & 0.00 & 0.98 & 714 & 0.01 & 4 \\
\hline Brazil & 0.05 & 0.37 & 1179 & 0.07 & 3 \\
\hline Canada & 0.00 & 1.05 & 1543 & 0.01 & 4 \\
\hline Chile & 0.05 & 0.22 & 1412 & 0.20 & 3 \\
\hline China & 0.10 & -0.65 & 1493 & 0.02 & 2 \\
\hline New Zealand & 0.04 & 1.20 & 1315 & 0.30 & 4 \\
\hline Poland & 0.91 & -1.62 & 813 & $<0.01$ & 1 \\
\hline South Africa & 0.04 & 0.47 & 1648 & 0.21 & 3 \\
\hline South Korea & 0.02 & 0.28 & 340 & $<0.01$ & 3 \\
\hline Turkey & 0.20 & -1.73 & 337 & $<0.01$ & 2 \\
\hline Uruguay & 0.13 & -0.67 & 788 & $<0.01$ & 2 \\
\hline USA & 0.01 & & 2212 & 0.06 & 4 \\
\hline Apricots & \multicolumn{5}{|c|}{ EPS of lowest relevance (a: 0.87 ; b: cluster $3: 0.26$, cluster $4: 0.61$ ) } \\
\hline Hungary & 0.10 & 0.69 & 130 & 0.26 & 3 \\
\hline Turkey & 0.00 & 1.16 & 323 & 0.61 & 4 \\
\hline Artichokes & \multicolumn{5}{|c|}{ EPS of higher relevance (a: 0.96 ; b: cluster $2: 0.96$ ) } \\
\hline Egypt & 0.27 & -0.18 & 519 & 0.96 & 2 \\
\hline Cherries & \multicolumn{5}{|c|}{ EPS of lowest relevance (a: $<0.83 ;$ b: cluster $2: 0.01$, cluster $3:<0.13$. cluster $4: 0.72)$} \\
\hline Bulgaria & 0.19 & $\frac{-1.14}{1.14}$ & 160 & 0.01 & 2 \\
\hline Canada & 0.00 & 1.05 & 1543 & 0.02 & 4 \\
\hline Hungary & 0.06 & 0.20 & 154 & 0.12 & 3 \\
\hline Iran & 0.03 & -0.05 & 175 & $<0.01$ & 3 \\
\hline Turkey & 0.01 & 0.78 & 440 & 0.60 & 4 \\
\hline USA & & 1.04 & 466 & 0.10 & 4 \\
\hline Clementines & \multicolumn{5}{|c|}{ EPS of lower relevance (a: $0.99 ;$ b: cluster $2: 0.01$, cluster $3: 0.98$ ) } \\
\hline Turkey & 0.44 & 0.19 & 356 & 0.01 & 2 \\
\hline Morocco & 0.01 & 0.28 & 799 & 0.98 & 3 \\
\hline Courgettes & \multicolumn{5}{|c|}{ EPS of lower relevance (a: $0.97 ;$ b: cluster $3: 0.11 ;$ Morocco: 0.86} \\
\hline Jordan & 0.00 & 0.56 & 119 & 0.01 & 3 \\
\hline Morocco & 0.09 & -1.13 & 979 & 0.86 & 2 \\
\hline Turkey & 0.04 & & 2204 & 0.10 & 3 \\
\hline Cucumbers & \multicolumn{5}{|c|}{ EPS of lower relevance (a: $0.67 ; \mathrm{b}$ : cluster $2: 0.21$, cluster $3: 0.45$ ) } \\
\hline Bulgaria & 0.29 & -0.81 & 344 & 0.11 & 2 \\
\hline Egypt & 0.00 & 0.34 & 205 & 0.01 & 3 \\
\hline Jordan & 0.00 & 0.58 & 571 & 0.06 & 3 \\
\hline Morocco & 0.28 & -1.00 & 385 & 0.10 & 2 \\
\hline Turkey & 0.07 & -0.39 & 1788 & 0.38 & 3 \\
\hline Lemons & \multicolumn{5}{|c|}{ EPS of higher relevance $(\mathrm{a}:<0.97$; b: cluster $2: 0.96$, cluster $3:<0.01)$} \\
\hline Argentina & 0.36 & & 1273 & 0.66 & 2 \\
\hline Cyprus & 0.02 & 0.27 & 789 & $<0.01$ & 3 \\
\hline South Africa & 0.19 & -0.92 & 1254 & 0.09 & 2 \\
\hline Turkey & 0.15 & -0.54 & 1253 & 0.15 & 2 \\
\hline Uruguay & 0.33 & -0.77 & 812 & 0.05 & 2 \\
\hline Zimbabwe & 0.34 & & 313 & $<0.01$ & 2 \\
\hline
\end{tabular}

a: The sum of import shares of all countries of origin in total extra-EU imports for the respective product in the time period for which the EPS applies. 
Egypt, Tunisia and Turkey than from Israel or Morocco. It is striking that the EPS is of high relevance for Moroccan exports of courgettes, cucumbers and tomatoes, for which Morocco enjoys preferential EPs. Overall, out of 38 SMC objects, the EPS is of high relevance for 8 objects ( $21 \%$ in cluster 4$)$, and of low if any relevance for 30 objects ( $79 \%$ in clusters 3 and 4).

\section{Future developments that could impact the effectiveness of the EPS}

Several future developments may influence the effectiveness of the EPS. Most importantly, the EPS will be eroded for three reasons. First, the EPS is fixed in nominal terms, which means that it is devalued each year due to inflation. Second, the EU is seeking to conclude regional trade agreements (RTAs) with many countries and is increasingly including agricultural products in these RTAs. Current negotiations include a potential agreement with the MERCOSUR countries and further liberalisation with the SMC as part of the Barcelona Process. Due to improved market access for fresh fruit and vegetables caused by tariff or entry price reductions agreed upon as part of RTAs, the difference between EU prices and international prices will decline, further decreasing the relevance of the EPS. Third, the EU import regime for fruit and vegetables will be subject to any agreement on agriculture that may be reached in the Doha Round of trade negotiations in the WTO. Various aspects play a role in how such an agreement could influence the EPS; the following paragraphs try to anticipate how the results could look like.

A banded approach for tariff reductions has been agreed in the Doha Round and the first question therefore concerns which tariff band fruit and vegetables would fall into. For products which are subject to the EPS, ad valorem equivalents (AVEs) have to be established in order to determine tariff reductions. As AVEs notified to the WTO are not yet available, those in Table 4 are calculated as the ad valorem tariff plus the MTE as a percentage of the respective import unit value (IUV) derived from Eurostat (various issues) external trade data. Potential reduction rates are based on the EU proposal (European Commission, 2005b).

A second question is how tariff reductions would influence entry prices. During the implementation period of the Uruguay Round Agreement, entry prices were reduced by the same amount of $€$ per ton as the respective specific tariffs. As entry prices were higher than the specific tariffs, their relative reduction was below the $20 \%$ reduction rate which was applied to specific tariffs. As a result, the higher the specific tariff in relation to the entry price was, the more entry prices were reduced in relative terms. Whether the EU will apply this approach again is an open question and subject to negotiation. 
A third question is to what extent the EU is able and willing to declare tariff lines for fresh fruit and vegetables as "sensitive". The consequences are still unclear owing to the enormous differences in the current proposals with respect to the share of tariff lines which should be eligible for this category (1-8\%), as well as the still-missing agreement on the size of tariff rate quotas (TRQs), which should be opened for these products as well as in and above TRQ tariff reduction rates.

Table 4 provides an initial, very rough assessment of how future entry prices and specific

Table 4: Potential development of AVEs and EPs after the conclusion of the Doha Round

\begin{tabular}{|c|c|c|c|c|c|c|c|c|c|}
\hline & $\begin{array}{l}\text { IUV } \\
1999- \\
2001 \\
(€ / t)\end{array}$ & $\begin{array}{c}\text { Ad val. } \\
\text { tariff (\%) }\end{array}$ & $\begin{array}{c}\text { Base } \\
\text { MTE } \\
(€ / \mathbf{t})\end{array}$ & $\begin{array}{c}\text { Max. } \\
\text { total } \\
\text { AVE } \\
(\in / \mathbf{t})\end{array}$ & $\begin{array}{c}\text { Base EP } \\
(€ / \mathbf{t})\end{array}$ & $\begin{array}{l}\text { Potential } \\
\text { red. rate } \\
\quad(E \mathbf{E})\end{array}$ & $\begin{array}{c}\text { Final } \\
\text { MTE } \\
(€ / \mathbf{t})\end{array}$ & $\begin{array}{c}\text { Final EP } \\
(€ / \mathbf{t})\end{array}$ & $\begin{array}{l}\text { Reduction } \\
\text { of EP }\end{array}$ \\
\hline Tomatoes & 766 & $8.8-14.4$ & 298 & $53 \%$ & $526-1,126$ & $40 \%$ & 179 & $407-1,007$ & $11-23 \%$ \\
\hline Cucumbers & 747 & $12.8-16.0$ & 378 & $67 \%$ & $481-1,105$ & $50 \%$ & 189 & $292-916$ & $17-39 \%$ \\
\hline Artichokes & 1,279 & 10.4 & 229 & $28 \%$ & $654-826$ & $35 \%$ & 149 & 574-746 & $10-12 \%$ \\
\hline Courgettes & 1,033 & 12.8 & 152 & $28 \%$ & $413-692$ & $35 \%$ & 99 & $360-639$ & $8-13 \%$ \\
\hline Oranges & 454 & $3.2-16.0$ & 71 & $32 \%$ & 354 & $40 \%$ & 43 & 326 & $8 \%$ \\
\hline $\begin{array}{l}\text { Clementines/ } \\
\text { mandarins }\end{array}$ & 691 & 16.0 & 106 & $31 \%$ & $286-649$ & $40 \%$ & 64 & $244-607$ & $7-15 \%$ \\
\hline Lemons & 640 & 6.4 & 256 & $46 \%$ & $462-558$ & $40 \%$ & 154 & $360-456$ & $18-22 \%$ \\
\hline Table grapes & 1,471 & $8.0-17.6$ & 96 & $24 \%$ & $476-546$ & $35 \%$ & 62 & $442-512$ & $6-7 \%$ \\
\hline Apples & 757 & $4.8-11.2$ & 238 & $43 \%$ & $457-568$ & $40 \%$ & 143 & $362-473$ & $17-21 \%$ \\
\hline Pears & 735 & $4.0-10.4$ & 238 & $43 \%$ & $388-510$ & $40 \%$ & 143 & $293-415$ & $19-25 \%$ \\
\hline Apricots & 1,431 & 20.0 & 227 & $36 \%$ & $771-1,071$ & $40 \%$ & 136 & $680-980$ & $8-12 \%$ \\
\hline Cherries & 1,619 & 12.0 & 274 & $29 \%$ & $916-1,494$ & $35 \%$ & 178 & $820-1,398$ & $6-10 \%$ \\
\hline $\begin{array}{l}\text { Peaches/ } \\
\text { nectarines }\end{array}$ & 1,601 & 17.6 & 130 & $26 \%$ & $600-883$ & $35 \%$ & 85 & $555-838$ & $5-8 \%$ \\
\hline Plums & 1,111 & $6.4-12.0$ & 103 & $21 \%$ & 696 & $35 \%$ & 67 & 660 & $5 \%$ \\
\hline
\end{tabular}

Sources: European Commission (2005b, 2007), Eurostat (various issues), own calculations.

tariffs could look if the respective products were not declared sensitive and if the EU were to apply the Uruguay Round approach to the reduction of entry prices.

Table 4 shows that AVEs vary between $21 \%$ and $67 \%$, resulting in potential reduction rates between 35\% and 50\% for specific and ad valorem tariffs. Applying the resulting reduction of MTEs to the entry prices reduces them by between $5 \%$ and $39 \%$. These reductions will cause the effectiveness of the EPS to decline strongly.

In contrast to these three factors that tend to erode the effectiveness of the EPS, the improvement of transport and marketing infrastructure in many developing countries may result in lower EU import prices, which would in turn enhance the importance of the EPS.

If developing countries manage to reduce transport costs substantially by establishing freight routes with high trade volumes and large vessels, highly efficient ports, and a competitive 
shipping services industry, the cost-competitiveness of their fresh fruit and vegetable supply would improve and they could increasingly serve lower-price EU market segments, potentially supplying products below the EP. However, we would expect the effects eroding the EPS to outweigh the potential improvement in marketing and transport infrastructure in developing countries in the short run.

\section{$7 \quad$ Conclusions}

The results of this analysis suggest that the relevance of the EPS is heterogeneous among products and among countries of origin for most kind of fruits and vegetables. Thus, an adequate assessment of the importance of the EPS requires not only a product-specific but also a country-specific analysis.

With respect to product-specific results, we find that the effectiveness of the EPS is highest for artichokes, courgettes, cucumbers, lemons, plums and tomatoes. The influence of the EPS on apples, clementines and pears is lower, and the EPS is of lowest relevance for apricots, mandarins, oranges, peaches and nectarines and table grapes.

With respect to country-specific results, we find that the EPS is of particular relevance for fruit and vegetable exports from the EU's neighbours such as Morocco, Turkey and Eastern Europe. These countries would benefit most if the EPS were removed. In contrast, the EPS is of minor importance for exports from far-away countries with high transport costs such as Canada, Israel, New Zealand and the US, with the exception of China and South Africa. Results suggest that abolishing the EPS would enable the latter two countries to utilise their competitive cost advantage more fully.

We also find that the EPS is of high relevance for Moroccan exports of courgettes, cucumbers and tomatoes, despite the fact that Morocco enjoys preferential EPs. This implies that Morocco exhausts the preferential EPs for these products.

However, the EPS is of little relevance for developing countries other than the EU's direct southern neighbours today. Since LDCs are not covered by the EPS anyhow as part of the EBA initiative, the EPS is of no relevance for Sub Saharan Africa except for South Africa. Furthermore, exports from Latin American countries (Brazil, Argentina, Chile and Uruguay) are mostly attributed to cluster 3, thus the EPS is of minor importance. This may also be due to substantial sea transport costs for these countries, with transport in a refrigerated container amounting to e.g. $165 \$ / \mathrm{t}$ for Brazil, $175 \$ / \mathrm{t}$ for Argentina and 250 \$/t for Chile. ${ }^{18}$

\footnotetext{
${ }^{18}$ These data were provided by the private sector.
} 
Overall, in $36 \%$ of the analysed country-specific and product-specific cases we find the EPS to be of relatively high relevance. In contrast, the EPS is of rather low, if any, relevance for $64 \%$ of the investigated cases. Any further reduction of EPs as part of the negotiation process of RTAs or a potential conclusion of the Doha Round will lower the relevance of the EPS even further.

In cases in which the EPS is determined to be highly relevant, it can be expected that the removal of the EPS would result in an increase of exports to the EU at prices below the EP. However, this effect depends on the degree to which the EPS is currently circumvented and the costs involved. Therefore, particularly for apples originating in the Southern Hemisphere countries, the EPS might be of even lower relevance than the results of our cluster analysis suggest.

Our results are in line with the findings of García-Álvarez-Coque et al. (2007) and MartinezGomez (2007) regarding Moroccan exports of tomatoes and clementines. In addition, our results conform with those of Cioffi and del' Aquila (2004) for apples, oranges and tomatoes. However, our findings only partially conform with those of López and Muñiz (2007), since we analyse the relevance of the EPS not only in product-specific but also country-specific terms, which reveals substantial differences in the relevance of the EPS for countries exporting cucumbers and tomatoes to the EU.

Generalising the results of this analysis for the whole EU fruit and vegetable trade, it is necessary to take into account that the analysis has been conducted based on EU wholesale market prices ${ }^{19}$, even though the majority of the fruit and vegetable trade is conducted directly by exporters to retailers and not via the wholesale market in several EU countries. For example, the share of the fruit and vegetable trade via wholesale markets is only about $20 \%$ in Germany, and is even lower in the $\mathrm{UK}^{20}$, compared with shares of about $65 \%$ in Spain and Italy, and even higher in France (Gibbon, 2003). Prices of products traded directly can differ significantly from products traded via wholesale markets. For example, importers estimate that fresh fruit and vegetable prices on wholesale markets are on average about $10-20 \%$ higher than prices of directly traded products in Germany. This would limit the scope for traders to apply the deductive method or the fob invoice method for customs clearance in case of a low SIV which reflects wholesale market prices.

\footnotetext{
${ }^{19}$ Exceptions are prices gathered in the UK, Netherlands and Finland, which are requested directly from the importers, as the fresh fruit and vegetable trade via the wholesale market has very low importance. In Greece, these data are collected from the customs authority.

${ }^{20}$ Information provided by ZMP, Germany.
} 
German importers $^{21}$ explicitly confirm the results of this study. They emphasise that the EPS is indeed relevant for products assigned to clusters 1 and 2 in our analysis. Regarding cluster 3 products, they confirm that the EPS has some influence on clementines, but has rather low relevance for apples and pears. They point out that the EPS is of no relevance for products attributed to cluster 4 , i.e. apricots, mandarins, oranges, peaches and nectarines and table grapes.

For any simulation modelling of trade liberalisation for fruits and vegetables between the SMC and the EU, we conclude that there is little value in modelling the effects of the EPS for cluster 4 products, i.e. exports of apricots, cherries, mandarins, nectarines and peaches and table grapes by Turkey; mandarins and oranges by Morocco; mandarins, oranges, plums and table grapes by Israel; and table grapes by Egypt, for which the EPS is indeed a paper tiger. Rather, it seems promising to concentrate on cluster 2 cases, for which the EPS constitutes a powerful market barrier.

Finally, we note that the EPS is a complex system and, compared to a tariff, its effectiveness is not transparent. Clearly it is in contradiction with the spirit of the WTO rules on market access for agricultural products which prohibit non-tariff barriers. Its administration, further development and administration by importing companies involve transaction costs, for example for storage in order to avoid customs clearance when the SIV is below the EP. In light of the redundancy of the EPS for many products and origins found here, which is likely to increase as the EPS is eroded by bilateral and multilateral trade liberalisation, its abolition would be an important step in the direction of a more liberal and transparent trading regime.

\section{References}

Bunte, F., 2005. Liberalizing EU Imports for Fruits and Vegetables. Contributed paper, XI ${ }^{\text {th }}$ Congress of European Association of Agricultural Economists, Copenhagen. August, 24-27.

Gibbon, P., 2003. Value-chain Governance. Public Regulation and Entry Barriers in the Global Fresh Fruit and Vegetable Chain into the EU. Development Policy Review. 21(5-6), 615-625.

Chemnitz, C. and H. Grethe, 2005. EU Trade Preferences for Moroccan Tomato Exports Who Benefits? Contributed paper, $\mathrm{XI}^{\text {th }}$ Congress of European Association of Agricultural Economists, Copenhagen. August, 24-27.

\footnotetext{
${ }^{21}$ Results of the cluster analysis were discussed in detail with three German fruit and vegetable importers.
} 
Cioffi, A. and C. dell'Aquila, 2004. The Effects of Trade Policies for Fresh Fruit and Vegetables of the European Union. Food Policy 29, 169-185.

Deaton, A. and G. Laroque, 1992. On the Behaviour of Commodity Prices. The Review of Economic Studies, 59 (1): 1-23.

Diop, N. and S. M. Jaffee, 2005. Fruits and Vegetables: Global Trade and Competition in Fresh and Processed Product Markets. In: Aksoy. M. A. and J. C. Beghin. Global Agricultural Trade and Developing Countries. World Bank, 237-257.

European Commission, 2005a. Standard Import Values. Unpublished.

European Commission, 2005b. Making Hong Kong a Success: Europe's Contribution. Brussels, 28 October.

European Commission, 2006. Unit Values. Unpublished.

European Commission, 2007. TARIC.

European Union, various issues. Official Journal of the European Communities (OJ).

Eurostat, various issues. External Trade Data.

García-Álvarez-Coque, J. M., 2002. Agricultural Trade and the Barcelona Process: Is Full Liberalization Possible? European Review of Agricultural Economics 29(3), 339-422.

García Álvarez-Coque, J. M. and J. M. Jordán Galduf, 2007. Agro-food Trade and the EuroMediterranean Agreements, Contributed paper, 1. Mediterranean Conference on Agrofood Social Scientists (103rd EAAE Seminar), Barcelona, Spain, April 23-25.

Goetz, L. and H. Grethe, 2007a. The EU Import System for Oranges: Much Ado about Nothing? Journal of International Agricultural Trade and Development 3(1).

Goetz, L. and Grethe, H., 2007b. Does the Entry Price System Restrict Fresh Fruit and Vegetable Exports from China to the EU? Contributed paper presented at the International Agricultural Trade Research Consortium (IATRC) Summer Symposium, July 8-9, Beijing, China.

Grethe, H. and S. Tangermann, 1999. The EU Import Regime for Fresh Fruit and Vegetables after Implementation of the Results of the Uruguay Round. Diskussionsbeitrag 9901. Institut für Agrarökonomie. Georg-August-Universität Göttingen.

López, J. A. and I. A. Muñiz, 2007. Measuring Domestic Implications of Tariff Cuts under EU Entry Price Regime, Contributed paper, 1. Mediterranean Conference on Agrofood Social Scientists (103rd EAAE Seminar), Barcelona, Spain, April 23-25.

Martin, E. and H. de Gorter, 1999. The Agreement on Agriculture and the CAP: The Reform of the Fruit and Vegetable Import Regime, Contributed paper, AAEA Annual Meeting, Nashville, Tennessee, August 8-11. 
Martinez-Gomez, V., 2007. Assessing Euro-Med Trade Preferences: The Case of Entry Price Reduction, Contributed paper, 1. Mediterranean Conference on Agro-food Social Scientists (103rd EAAE Seminar), Barcelona, Spain, April 23-25.

Swinbank, A. and C. Ritson, 1995. The Impact of the GATT Agreement on EU Fruit and Vegetable Policy. Food Policy 20, 339-357.

UN (2008): UN Comtrade Database, www.comtrade.un.org, accessed May 18, 2008.

Williams, E. and C. Ritson, 1987. The Impact of the EEC's Reference Price System on the Marketing of Fruit and Vegetables in the U.K., Report No. 31, Department of Agricultural and Food Marketing, University of Newcastle upon Tyne. 
5 Does the Entry Price System Restrict Fresh Fruit and Vegetable Exports from China to the EU?

jointly with Harald Grethe 


\title{
Does the Entry Price System Restrict Fresh Fruit and Vegetable Exports from China to the EU?
}

\author{
Linde Götz $z^{a}$ and Harald Grethe ${ }^{b}$ \\ Contributed paper at the 2007 IATRC Summer Symposium in Beijing, China, 8-9 July 2007 \\ ${ }^{a}$ Georg-August-University of Göttingen (1goetz@gwdg.de) \\ ${ }^{\mathrm{b}}$ Humboldt-University of Berlin (harald.grethe@agrar.hu-berlin.de)
}

\section{Introduction}

China has become a major exporter of fresh fruits and vegetables in recent years. Between 2002 and 2006, China's fresh fruit and vegetable exports rose continuously, more than doubling in value to reach nearly $\$ 5$ billion US in 2006 . The net trade position for fresh fruits and vegetables has also come close to doubling during this period, reaching $\$ 3.5$ billion US. Although the European Union (EU) is not a major destination market for fresh fruit and vegetable exports from China, some products, such as apples and pears, are being exported to the EU at an increasing rate. These products, however, are subject to EU most favored nation (MFN) import barriers, as China has no preferential trade agreement with the EU.

The EU protects EU growers of 15 fruits and vegetables against international competition through ad valorem tariffs of up to $20 \%$, and the entry-price system (EPS) aims to restrict imports below the product-specific, politically-designated entry price (EP) level.

Various authors have analyzed the mechanism and the effects of the highly complex and opaque EPS. In particular, the EPS is compared to its predecessor, the reference price system (RPS) (Swinbank and Ritson, 1995; Grethe and Tangermann, 1999; Martin and de Gorter, 1999; Cioffi and del' Aquila, 2004). These studies found it difficult to assess the effectiveness of the EPS in general, since its effectiveness strongly depends on specific market conditions of the fruits and vegetables concerned. This conclusion is supported by individual case studies: Chemnitz and Grethe (2005) found that the EPS effectively restricts Moroccan tomato exports below the relevant EP to the EU, whereas Götz and Grethe (2007) show that the EPS is of low relevance for orange exports from Mediterranean countries.

The objective of this paper is to explore the relevance of the EPS for Chinese fruit and vegetable exports to the EU. Section 2 gives a short overview of the Chinese fresh fruit and vegetable trade. Section 3 explains the EP system, and Section 4 presents and discusses two indicators to assess the system's effectiveness. Section 5 reports results of a general analysis on the effectiveness of the EPS for fruits and vegetables from various origins based on a data 
set of Standard Import Values (SIVs), which are surveyed by the European Commission (EC) for each product and exporting country individually. Subsequently, Section 5 provides a more complete analysis of the restrictiveness of the EPS for Chinese exports of apples and pears, the only fresh fruits subject to the EPS and exported to the EU. Finally, Section 6 draws conclusions and gives an outlook on the future development of fresh fruit and vegetable exports from China to the EU.

\section{Chinese Fresh Fruit and Vegetable Trade}

Figure 1 displays China's fresh fruit and vegetable trade from 2002 to 2006 . For vegetables as well as fruits, China was a clear net exporter over this period - net exports rose continuously to reach $\$ 3.5$ billion US by 2006 .

Figure 1: China's Fresh Fruit and Vegetable Trade (2002-2006, bill. US\$)

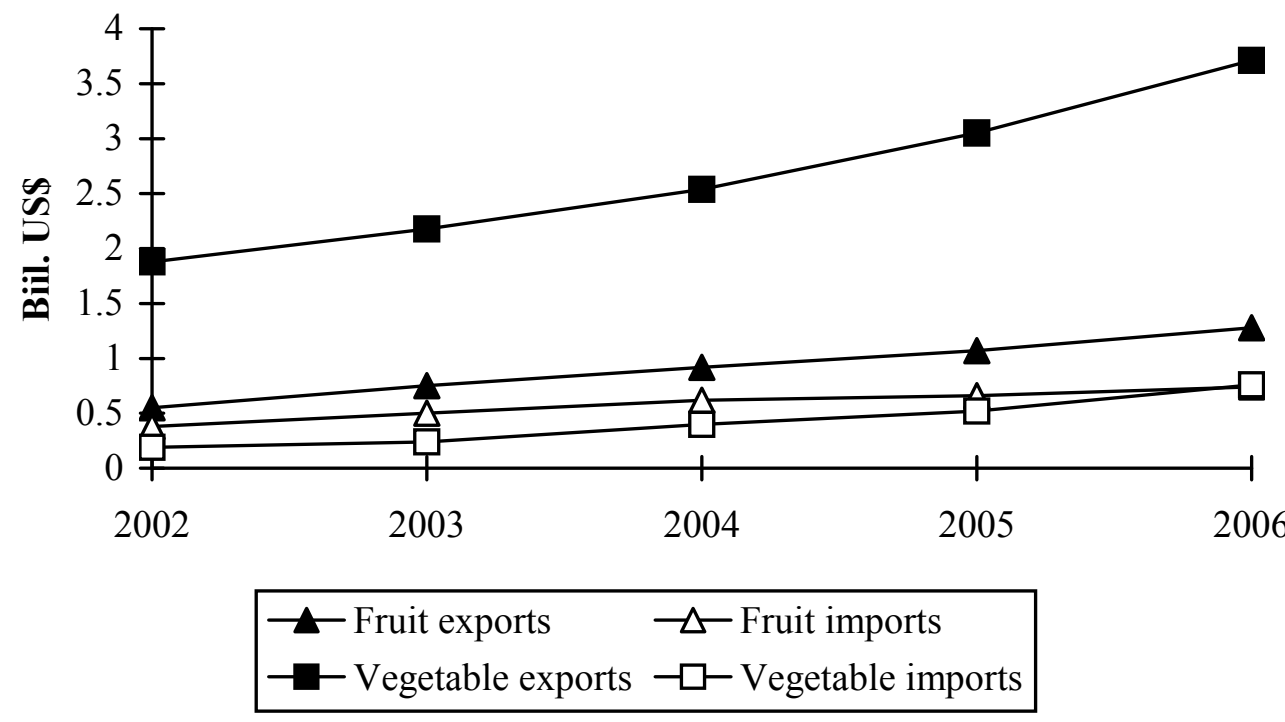

Source: FAO (2007), Eurostat (2007), own calculations.

The EU market is not a major destination for Chinese exports of fresh fruits and vegetables that are covered by the EPS. However, for apples and pears, Chinese exports to the EU have increased significantly over recent years (Figures 2 and 3).

From 1995 to 2000, China had essentially balanced trade for apples; however, after 2000, China became a strong net exporter of apples, with exports approaching one million tonnes in 2005. The share of apples exported to the EU has risen from zero in the mid-1990s to more than $5 \%$ in recent years. Figure 2 displays a sharp decline in the EU share in 2005, but market observers report that this is an inaccurate representation, explaining the decline as a result of 
incomplete official trade statistics. These observers argue that Chinese exports of apples to the EU actually increased in 2005 to reach more than 80,000 tonnes. The EU has recently implemented a licensing system for apple imports to monitor trade flows more closely. ${ }^{22}$

Figure 2: China's Apple Trade (1995-2005, mill. tonnes)

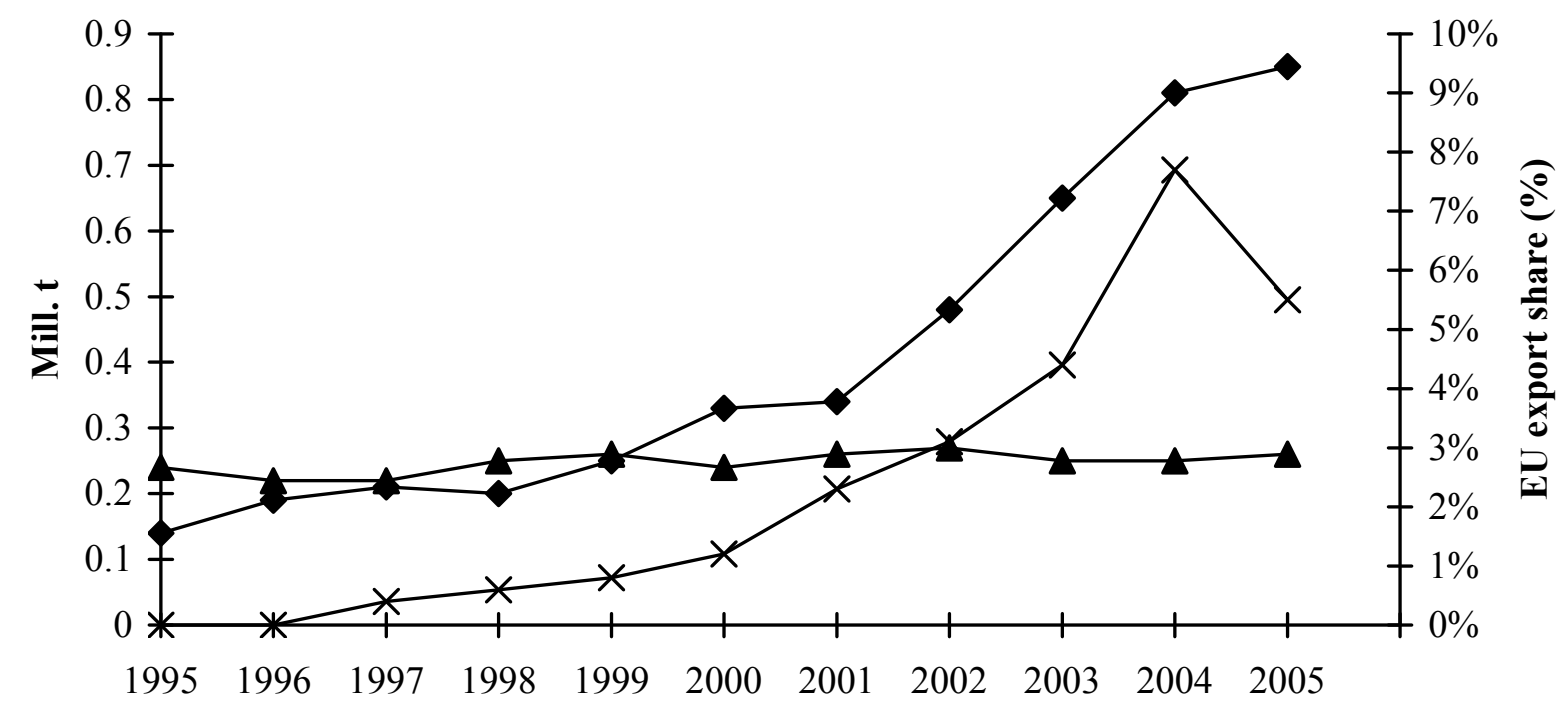

$\neg$ Imports $\multimap-$ Exports $\rightarrow \leftarrow$ EU export share

Source: FAO (2007), Eurostat (2007), own calculations.

Figure 3: China's Pear Trade (1995-2005, mill. tonnes)

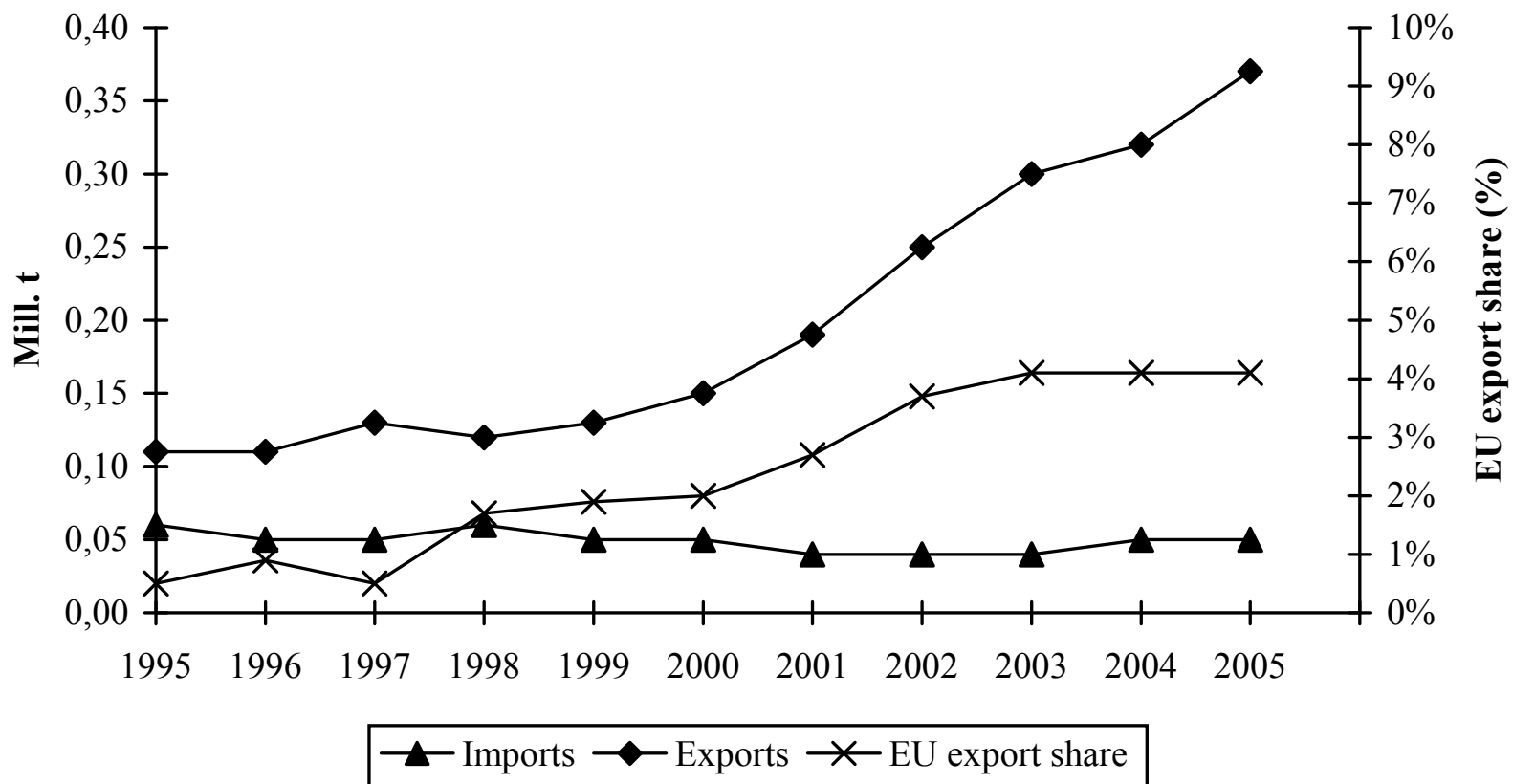

Source: FAO (2007), Eurostat (2007), own calculations.

22 Regulation 179/2006 (OJ 2006, L29/26). 
For pears, Chinese net exports have increased significantly in recent years, totaling more than 300,000 tonnes in 2005. The EU share of Chinese exports has increased to 4\% since 2003.

\section{The Import Regime of the EU for Fresh Fruits and Vegetables}

The EU protects EU growers of 15 selected fruits and vegetables against international competition by means of ad valorem tariffs up to $20 \%$ and through the EPS (Table 1). The EPS aims to restrict imports below the product-specific, politically-designated EP level. If the EP is undercut, an additional specific tariff is levied, varying proportionally to the difference between the product's actual import price and the EP. If the EP is undercut by $8 \%$ or more, the maximum specific tariff (i.e., the maximum tariff equivalent (MTE) ${ }^{23}$ ) is charged at an amount up to $80 \%$ of the EP. The EPS became effective on July 1, 1995, displacing the RPS.

Table 1: Basic Elements of the EPS

\begin{tabular}{|l|l|l|l|l|l|}
\hline & $\begin{array}{l}\text { Ad valorem } \\
\text { tariff } \\
(\%)\end{array}$ & $\begin{array}{l}\text { EP } \\
\text { Level } \\
(€ / \text { t) }\end{array}$ & $\begin{array}{l}\text { Period of } \\
\text { application }\end{array}$ & $\begin{array}{l}\text { Specific tariff } \\
\text { MTE } \\
(€ / \text { t })\end{array}$ & in \% of EP \\
\hline $\begin{array}{l}\text { Apples } \\
\text { Apricots }\end{array}$ & $4.8-11.2$ & $457-568$ & $01.01 .-31.12$. & 238 & $41.9-52.1$ \\
Artichokes & 10.0 & $771-1,071$ & $01.06 .-31.07$. & 227 & $21.2-29.4$ \\
Cherries & 12.0 & $654-826$ & $01.11 .-30.06$. & 229 & $27.7-35.0$ \\
Clementines & 16.0 & $916-1,494$ & $21.05 .-10.08$. & 274 & $18.3-29.9$ \\
Courgettes & 12.8 & 649 & $01.11 .-28.02$. & 106 & 16.3 \\
Cucumbers & $12.8-16.0$ & $413-692$ & $01.01 .-31.12$. & 152 & $22.0-36.8$ \\
Lemons & 6.4 & $461-1,105$ & $01.01 .-31.12$. & 378 & $34.2-78.6$ \\
Mandarins & 16.0 & 286 & $01.01 .-31.12$. & 256 & $45.9-55.4$ \\
Oranges & $3.2-16.0$ & 354 & $01.11 .-28.02$. & 106 & 37.1 \\
Peaches/ & 17.6 & $600-883$ & $11.06 .-30.09$. & 130 & 20.1 \\
$\begin{array}{l}\text { Nectarines } \\
\text { Pears }\end{array}$ & $4.0-10.4$ & $388-510$ & $01.07 .-30.04$. & 238 & $14.7-21.7$ \\
Plums & $6.4-12.0$ & 696 & $11.06 .-30.09$. & 103 & $46.7-61.3$ \\
Table & $8.0-17.6$ & $476-546$ & $21.07 .-20.11$. & 96 & 14.8 \\
Grapes & $8.8-14.4$ & $526-1,126$ & $01.01 .-31.12$. & 298 & $17.6-20.2$ \\
Tomatoes & 596 & $26.5-56.7$ \\
\hline
\end{tabular}

Source: European Commission (2007), own calculations.

One difficulty of monitoring compliance with the EPS is that a large share of fruit and vegetable imports in the EU is paid on commission, meaning that the import price is not determined until the product is sold in the EU import market. Therefore, the EC calculates a

\footnotetext{
${ }^{23}$ The designation "maximum tariff equivalent" stems from the Uruguay Round of the GATT, in which the MTE was established as the tariffied equivalent of the former reference price system.
} 
synthetic import price, the SIV. Fruit and vegetable prices - surveyed for each product and export country individually - are collected from representative fruit and vegetable wholesale markets in all EU member countries. The daily SIVs are calculated as the weighted average of collected wholesale market prices, less a marketing and transportation margin and custom duties. $^{24}$

During customs clearance, exporters have three options when declaring their fruits and vegetables that are subject to the EPS. According to the SIV method, the produce is declared based on the product-specific SIV as surveyed by the EC on the respective import date. This method is easy to apply for the importer and does not result in specific tariffs charges if the SIV is higher than the EP. Two reasons, however, may establish an incentive for the importer to apply an alternative method. First, the SIV may be below the EP, resulting in additional specific tariffs. Second, the SIV may be far above the EP, resulting in high ad valorem tariffs. In these two cases, products can be declared for the value of the produce as indicated by an invoice (invoice method). If the invoice method is used, the import charges are based on the f.o.b. invoice price adjusted for insurance and freight costs and thus the actual c.i.f. price. A third option is customs clearance by the deductive method, which is based on the final selling price of the shipment to be proven by invoice.

The EPS offers opportunities to legally and illegally circumvent paying specific tariffs, although the produce is finally sold at prices below the EP (García-Álvarez-Coque, 2002). According to information from importers, illegal circumvention is more prevalent in smallscale trading, particularly between related trading partners. Legal circumvention involves storing produce in the EU: stored products can be imported at any time and declared for customs clearance when the SIV is above the EP. Once cleared at a favourable SIV, the product can be sold in EU markets at any price.

\section{Indicators for Analyzing the Restrictiveness of the System}

In this study, the relevance of the EPS for the import price of each product and origin is investigated based on the distribution of the SIV relative to the EP.

We define the relative difference between the SIV and the respective EP as GAP as follows:

24 Details of the calculation of the SIV are set down in Regulation 3223/94 (OJ 1994, L337/66). 
(1) $G A P_{i j t}=\frac{\left(S I V_{i j t}-E P_{i j t}\right)}{E P_{i j t}}$

where $i=$ kind of produce, $j=$ country of origin, and $t=$ time. Thus, $G A P_{i j t}$ represents the relative difference between $S I V_{i j t}$ and $E P_{i j t}$. $E P_{i j t}$ depends not only on the kind of produce, but also on the country of origin since preferential EPs are granted to some countries. Besides, $E P_{i j t}$ varies seasonally for some fruits and vegetables. If $G A P_{i j t}>0$, the import price is higher than the EP, and if $G A P_{i j t}<0$, it is lower.

Several characteristics of the distribution of $G A P_{i j t}$ can be identified that are related to the relevance of the EPS. First, observations with $G A P_{i j t}<0$ indicate that there exists an export supply below the EP. The higher the share of observations with $G A P_{i j t}<0$ in all observations of SIV, the higher the export supply at prices below the EP. In this case, the EPS is relevant.

Assuming that circumvention of the EPS is only possible to some degree, and/or that circumvention involves additional costs (e.g. for storage), a high share of observations with $G A P_{i j t}<0$ indicates that abolishing the EP would result in an increase of export supply at prices below the EP. The stronger the degree of circumvention and/or the lower the cost of circumvention, the less the EPS restricts the existing export supply below the EP, and the lower the effect of abolishing the EP would be.

The share of observations with negative $G A P_{i j t}$ as an indicator for the relevance of the EPS is confined to the effects of the EPS on observations with $G A P_{i j t}<0$ and does not cover the influence of the EPS on observations with $G A P_{i j t}>0$.

The second indicator is derived from the assumption, supported by anecdotal evidence, that exporters may supply their produce at the lowest possible price while complying with the EP, thereby utilizing their competitive cost advantage and avoiding additional specific tariffs. This would be expressed in an accumulation of observations with $G A P_{i j t}>0$ closely above the EP. Here, the EP is relevant for exporters and has a significant influence on the price of the export supply. If the EP was abolished, export supply at prices below the EP would increase. Conversely, the EPS has no influence on observations with $G A P_{i j t}>0$ with SIV being 
significantly higher than the EP. The degree of accumulation of observations with $G A P_{i j t}>0$ slightly above the EP can be measured by the quantile with $\mathrm{p}=0.05$ of the distribution of $G A P_{i j t}$ with $G A P_{i j t}>0$. The quantile with $\mathrm{p}=0.05$ measures the highest $G A P_{i j t}$ value in the set of observations that belong to the bottom $5 \%$ of the distribution of observations with $G A P_{i j t}>0$. The lower the value of the 0.05 -quantile, the more observations accumulate slightly above the EP. This indicator explicitly addresses the influence of the EPS on import price observations with $G A P_{i j t}>0$.

The two indicators explained above are illustrated by the following two examples: oranges and tomatoes originating in Morocco. Goetz and Grethe (2007) show that the EPS is of low relevance for EU orange imports originating in Morocco. In contrast, the EPS is highly relevant for tomato imports originating in Morocco (Chemnitz and Grethe, 2005; GarcíaÁlvarez-Coque et al., 2007). Figure 4 opposes histograms for the distributions of $G A P_{i j t}$ of these two cases from 1997 to 2005.

\section{Figure 4: Histograms of ${ }^{G A P_{i j t}}$ for Moroccan Orange and Tomato Exports}

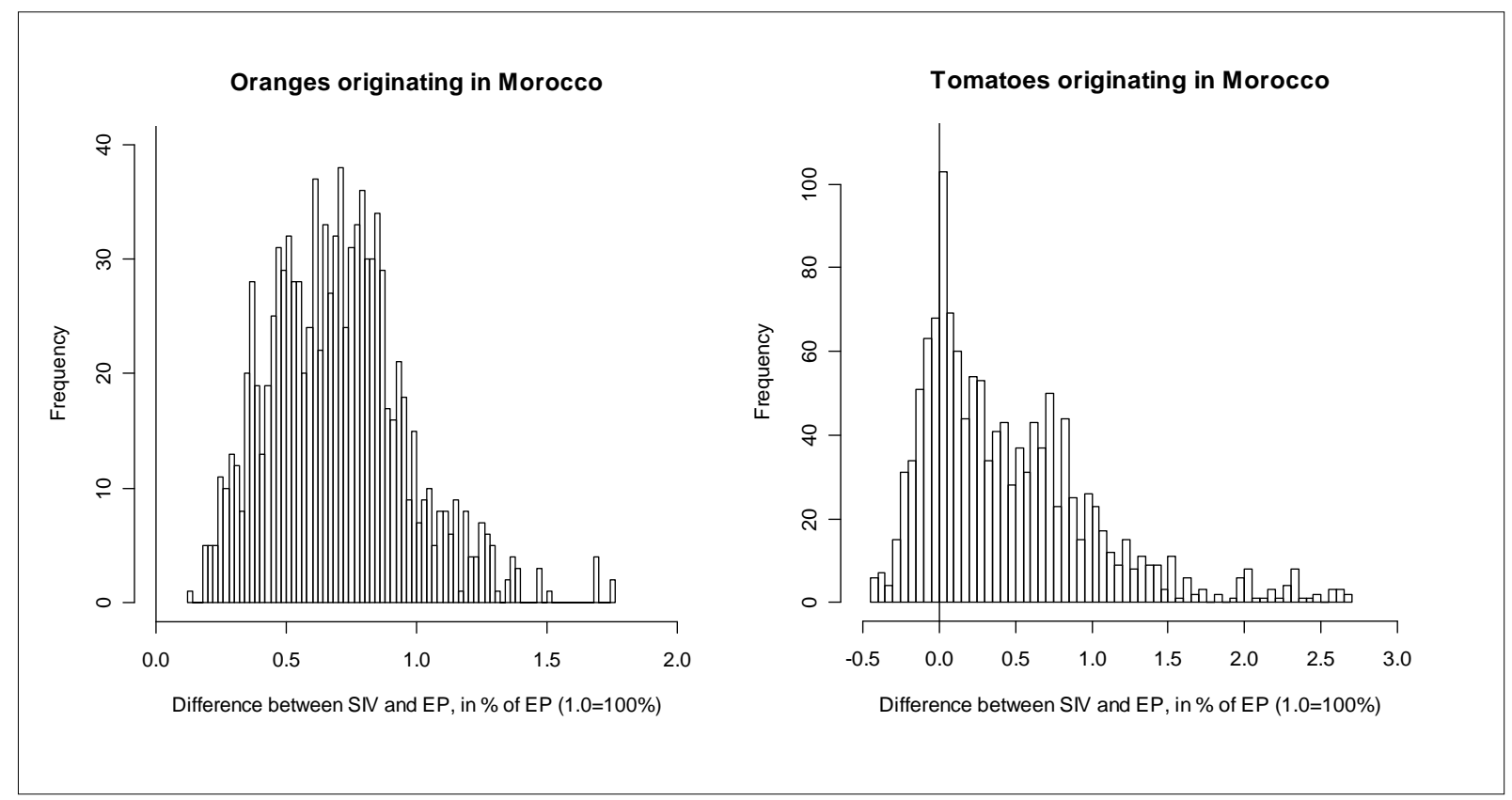

Source: Own calculations based on European Commission (2006).

It is evident that $G A P_{i j t}>0$ for all observations of oranges, whereas $G A P_{i j t}<0$ for a substantial share $(21 \%)$ of observations of tomatoes. Thus, export supply for oranges originating in 
Morocco can be observed exclusively above the EP, whereas tomatoes exported by Morocco are supplied at prices both above and below the EP. Further, for tomatoes, observations of $G A P_{i j t}$ when $G A P_{i j t}>0$ accumulate closely above the EP, whereas observations of $G A P_{i j t}$ for oranges are significantly higher than the EP with the minimum value of $G A P_{i j t}$ set at 0.13 . The 0.05 -quantile is 0.03 for tomatoes and 0.31 for oranges. In other words, $5 \%$ of observations with $G A P_{i j t}>0$ exceed the EP by no more than $3 \%$ for tomatoes and $31 \%$ for oranges.

Therefore, we measure the relevance of the EPS by two indicators in this study:

1) The share of observations with $G A P_{i j t}<0$ of all observations $G A P_{i j t}$, which can be defined as

(2) neg.GAP $P_{i j}=$ (number of observations $G A P_{i j t}$ with $\left.G A P_{i j t}<0\right) /$ (number of observations $\left.G A P_{i j t}\right)$

where $i=$ kind of produce, $j=$ country of origin, and $t=$ time (correlated with the importance of the EPS). The smaller neg.GAP $i j$, the less relevant is the EP for the import price for produce $i$ exported by country $j$. Conversely, the larger neg.GAP $P_{i j}$, the higher the influence of the EPS on the EU import price. A similar variable was used in previous studies on the effectiveness of the EPS and RPS by Cioffi and dell' Aquila (2004) and Swinbank and Ritson (1995), respectively.

2) This indicator is supplemented by a new indicator, which measures the degree of accumulation of observations with $G A P_{i j t}$ closely above the EP by the 0.05 -quantile of the distribution of $G A P_{i j t}$ when $G A P_{i j t}>0$. Since the variance of $G A P_{i j t}$ may change by type of produce and country of origin - and due to the fact that the 0.05 -quantile of distributions with differing variance are not exactly comparable - the 0.05 -quantile is standardized by the standard deviation. In addition, large values are given less weight by creating a logarithm of the 0.05 -quantile because the efficiency of the EPS is proportional to the 0.05 -quantile within a certain interval only:

$$
Q_{0.05 i j}^{*}=\ln \left(\frac{Q_{0.05 i j}}{s d\left(G A P_{i j}\right)}\right) .
$$


The less $G A P_{i j t}$ accumulates closely above the EP, the larger $Q_{0.05 i j}^{*}$ and the lower the influence of the EPS on the EU import price. For oranges and tomatoes originating in Morocco, $Q_{0.05}^{*}$ equals 11.83 and 0.54 , respectively. Yet, the converse case has to be interpreted with care since an accumulation of prices closely above the EP could also be caused by other factors, as illustrated by the following example. Figure 5 shows the histogram of the EU import price for pineapple, measured by unit value (UV). UVs are surveyed by the EC on a biweekly basis for fruits and vegetables that are not subject to the EPS. We transform UV according to

$$
U V_{i t}^{*}=\frac{U V_{i t}-\min \left(U V_{i}\right)}{\min \left(U V_{i}\right)},
$$

where $i=$ produce and $t=$ time. Thus, $U V_{i t}^{*}$ differs from $G A P_{i j t}$ in that it does not describe the difference to $E P_{i j t}$ but to the minimum $U V_{i}$.

\section{Figure 5: Histogram of ${ }^{U V_{i t}^{*}}$ for Pineapple}

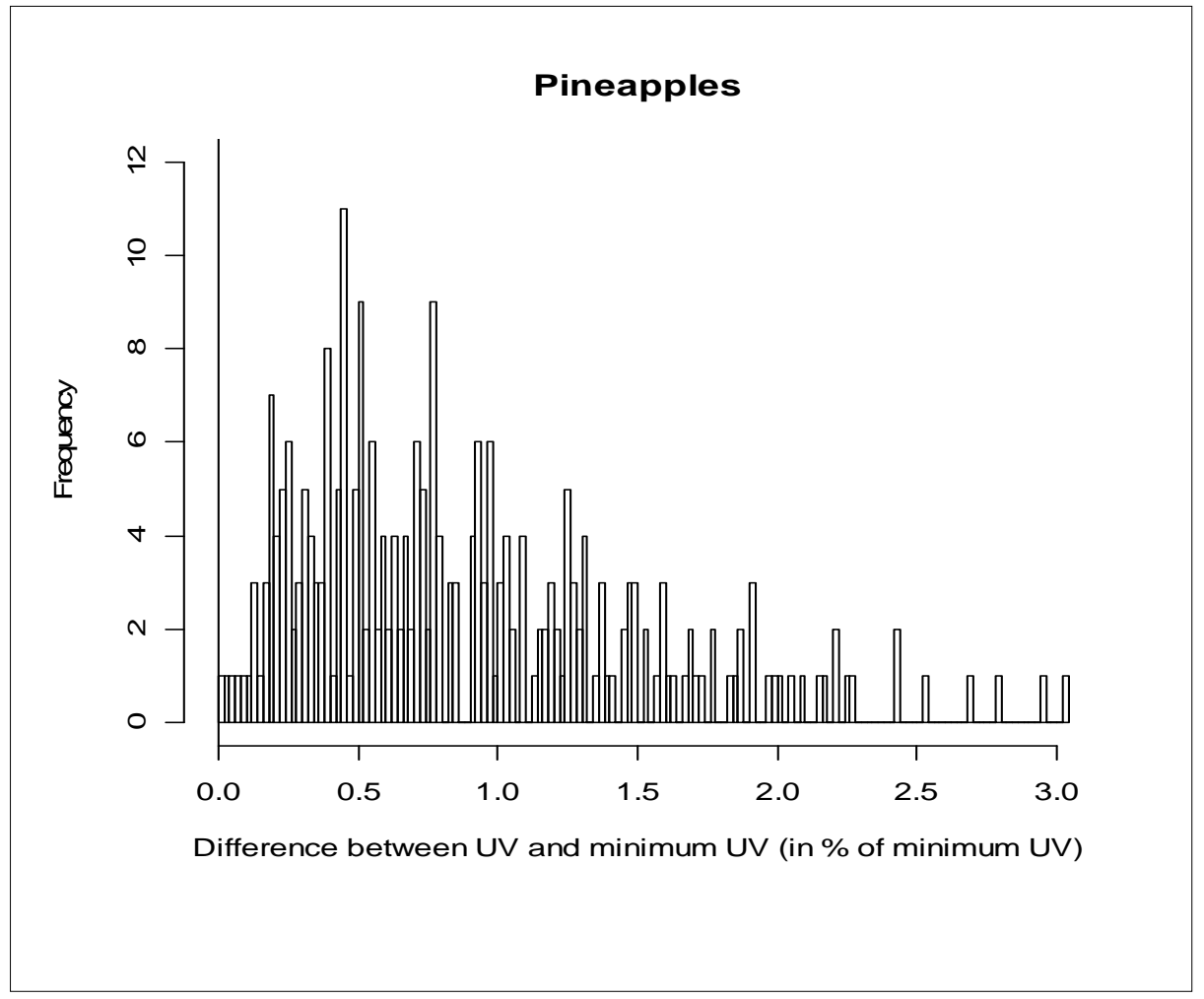

Source: Own calculations based on European Commission (2006). 
It becomes evident that the distribution of $U V_{i t}^{*}$ for pineapples exhibits an accumulation close to its minimum value with $Q_{0.05}^{*}$ equal to 2.97, even though an EP for pineapples does not exist. In this case, the accumulation is not caused by the EPS. Instead, the accumulation could be associated with a strong price competition if the sum of production and marketing costs is similar to the minimum $U V_{i}$ for many producers. Therefore, a low value of $Q_{0.05 i j}^{*}$ in combination with a particularly low value of neg.GAP $P_{i j}$ may, but does not necessarily, indicate a relevant EPS. In those cases, the importance of the EPS cannot be determined unambiguously based on these indicators alone.

\section{Analysis of Effectiveness of the EPS}

\section{1 General Analysis for Fruit and Vegetable Imports of the EU}

The indicators derived above, neg.GAP $i j$ and $Q_{0.05 i j}^{*}$, are calculated for 81 country and product specific distributions of $G A P_{i j t}$, each consisting of between 65 and 2,678 observations. The number of available observations of SIVs for a product of a particular exporting country varies depending on the number of days the produce is traded on EU wholesale markets. For this analysis, we utilize about 57,000 observations of SIVs from 1995 to 2005. Both indicators are used as variables in a cluster analysis, although the details of the analysis are not presented in this paper. Instead, we present the overall results in Figure 6 and consider the clusters in which Chinese exports of apples and pears are positioned.

Figure 6 is organized in the dimensions of the two indicators described above: The vertical axis displays the share of negative observations in its original dimension, and the horizontal axis displays the size of the 0.05 -quantile in its normalized, logarithmized, and z-standardized form. Cluster 1 is comprised of products with extremely high shares of negative observations between $65 \%$ and $92 \%$ and a high degree of accumulation of positive SIVs close to the EP. For this cluster, which consists mainly of plums from Central European countries, the EP system has a significant effect on EU import prices. Cluster 3 and Cluster 4 (to an even greater degree) display a very low share of negative observations of less than $12 \%$ and little or no accumulation of positive SIVs close to the EP. For products in these clusters, the EPS has minimal effectiveness. 
Figure 6: Results of Cluster Analysis (All Observations, 19952005)

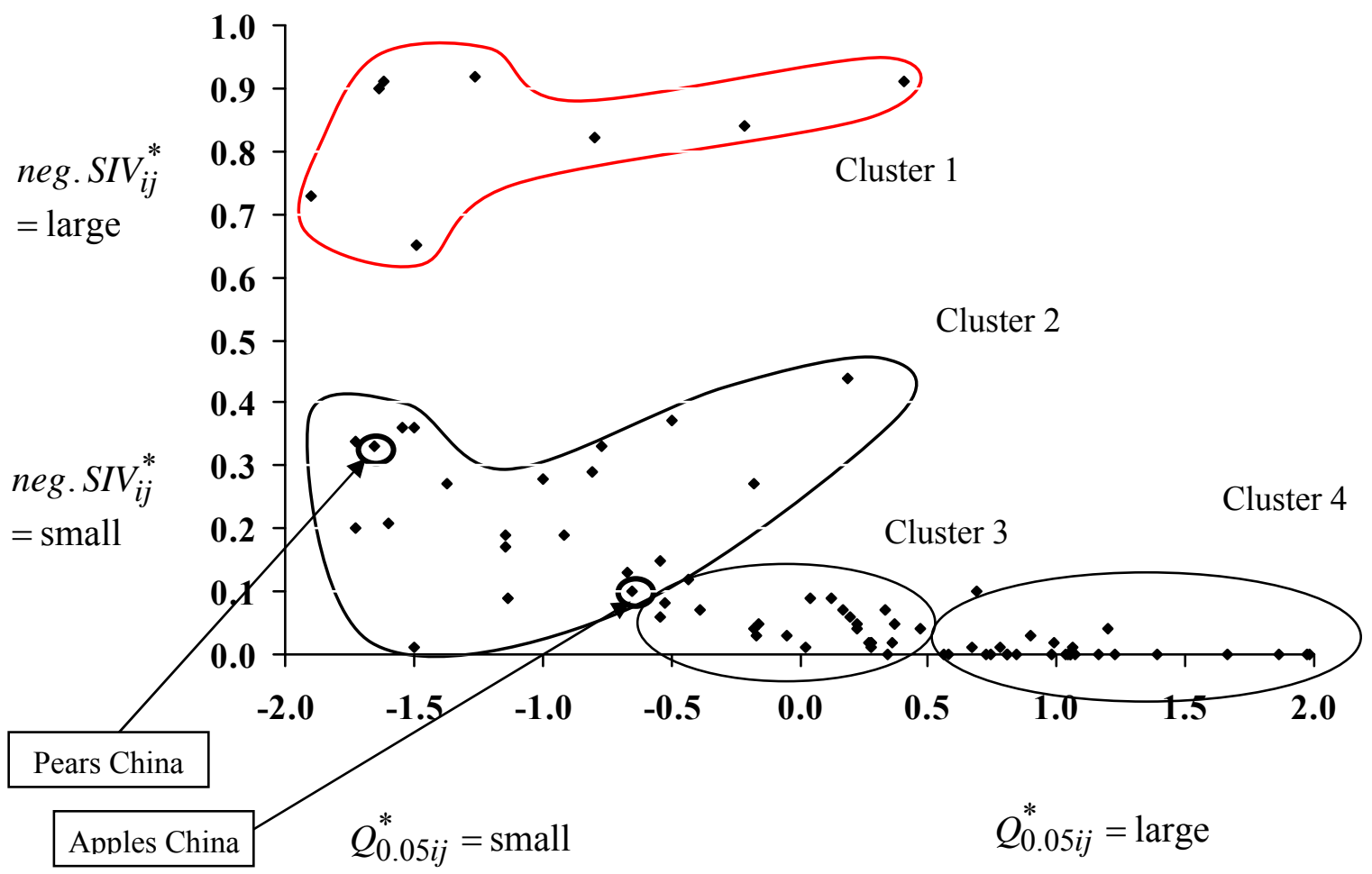

Source: Own calculations.

Cluster 2, which includes both apple and pear imports from China, is a relatively heterogeneous cluster. For most elements, there is a significant share of negative observations of up to $44 \%$ and a high degree of accumulation of positive SIVs closely above the EP. For these products as well, the EP system has an effect on the EU import price, although to a differing extent.

Figure 6 clearly demonstrates that for pears from China, the share of negative observations is higher than for apples from China (33\% compared to $10 \%)$ and the size of the 0.05 -quantile is lower, hinting at a higher effectiveness of the system for pears than for apples.

\section{2 Specific Analysis for Apples and Pears from China}

Figure 7 shows histograms for the distribution of apples and pears from China over all years available, making it clear that the share of negative observations is higher for pears and that the accumulation of SIVs just above the EP is also higher. 
It is important to keep in mind that both Figure 7 and the cluster analysis presented in Figure 6 are based on the distribution of SIVs for the period 1997 to 2005 as a whole and do not differentiate according to the time dimension. Thus, it is not possible to draw conclusions as to whether the system has become more or less restrictive over recent years. The remainder of this section is devoted to the analysis of the development of the distribution of SIVs for Chinese apple and pear exports to the EU over time.

Figure 8 displays the level of SIVs and the EP for apples from 1997 to spring 2006, and Table 2 displays distribution measures.

\section{Figure 7: Histograms for Apples and Pears from China (1997- 2005)}
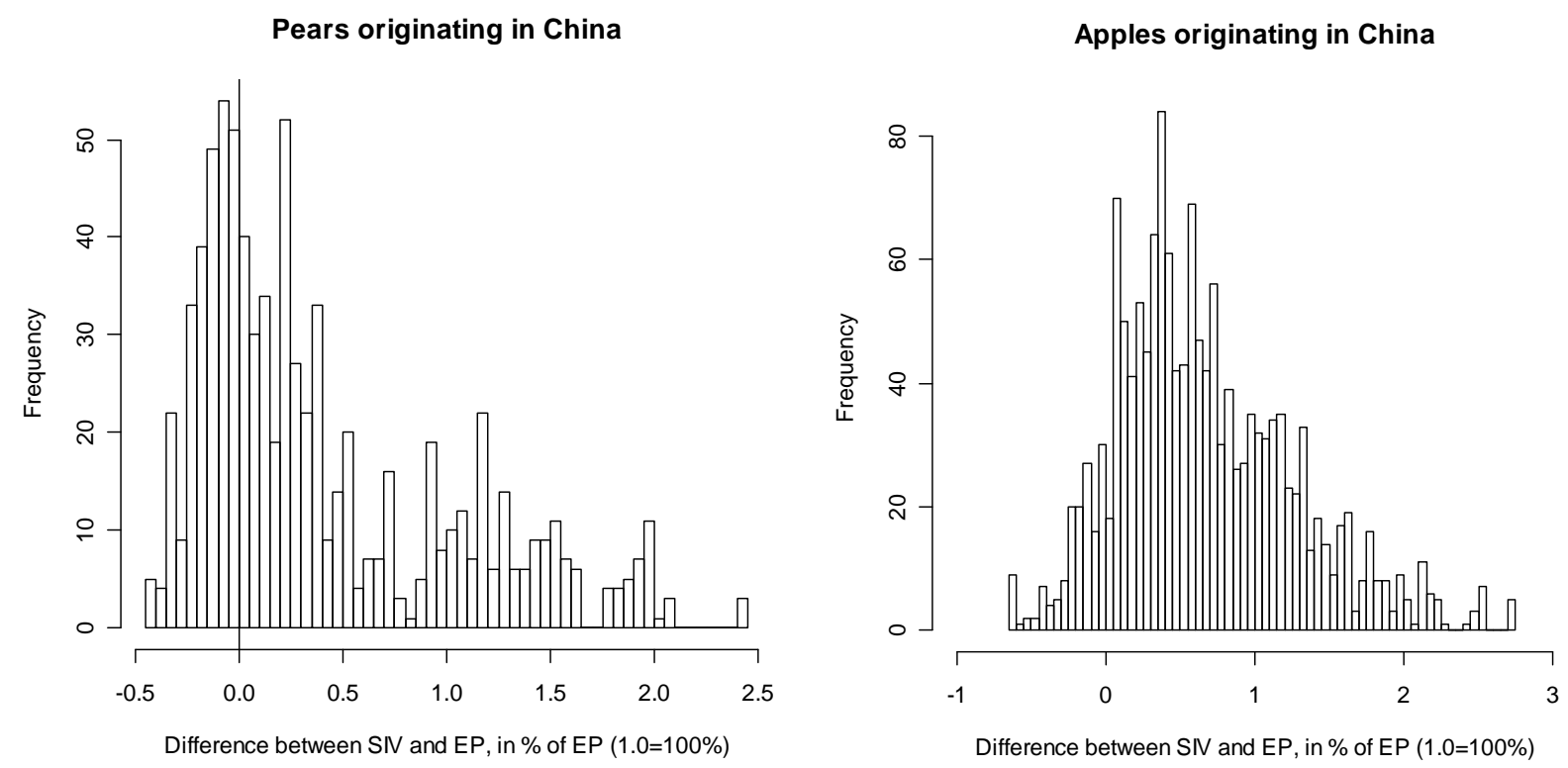

Source: Own calculations based on European Commission (2006).

The SIV distribution for apples from China is well above the EP level until 2003, but in 2002 it began declining from a level of $129 \%$ above the EP on average to about $20 \%$ above the EP by 2005 . Accordingly, the share of negative observations rose to $27 \%$.

Looking at skewness, we expect that the closer the mean of the distribution gets to the EP, the more right-skewed the distribution will be, indicating a truncating effect caused by the EPS; this would imply a negative correlation between skewness and mean of the distribution. However, this hypothesis was not confirmed here.

The decreasing average SIV level, the increasing share of negative observations, and the declining size of the 0.05-quantile all support the conclusion that the EPS has become more relevant for Chinese apple exports to the EU in recent years. This conclusion is supported by 
interviews with EU importers, who report that it has become more difficult in recent years to escape tariffs under the EPS and that the storage of apples until a favourable SIV appears is a widespread practice.

\section{Figure 8: Standard Import Values of EU Apple Imports from China $(1997-2006, € / 100 \mathrm{~kg})$}

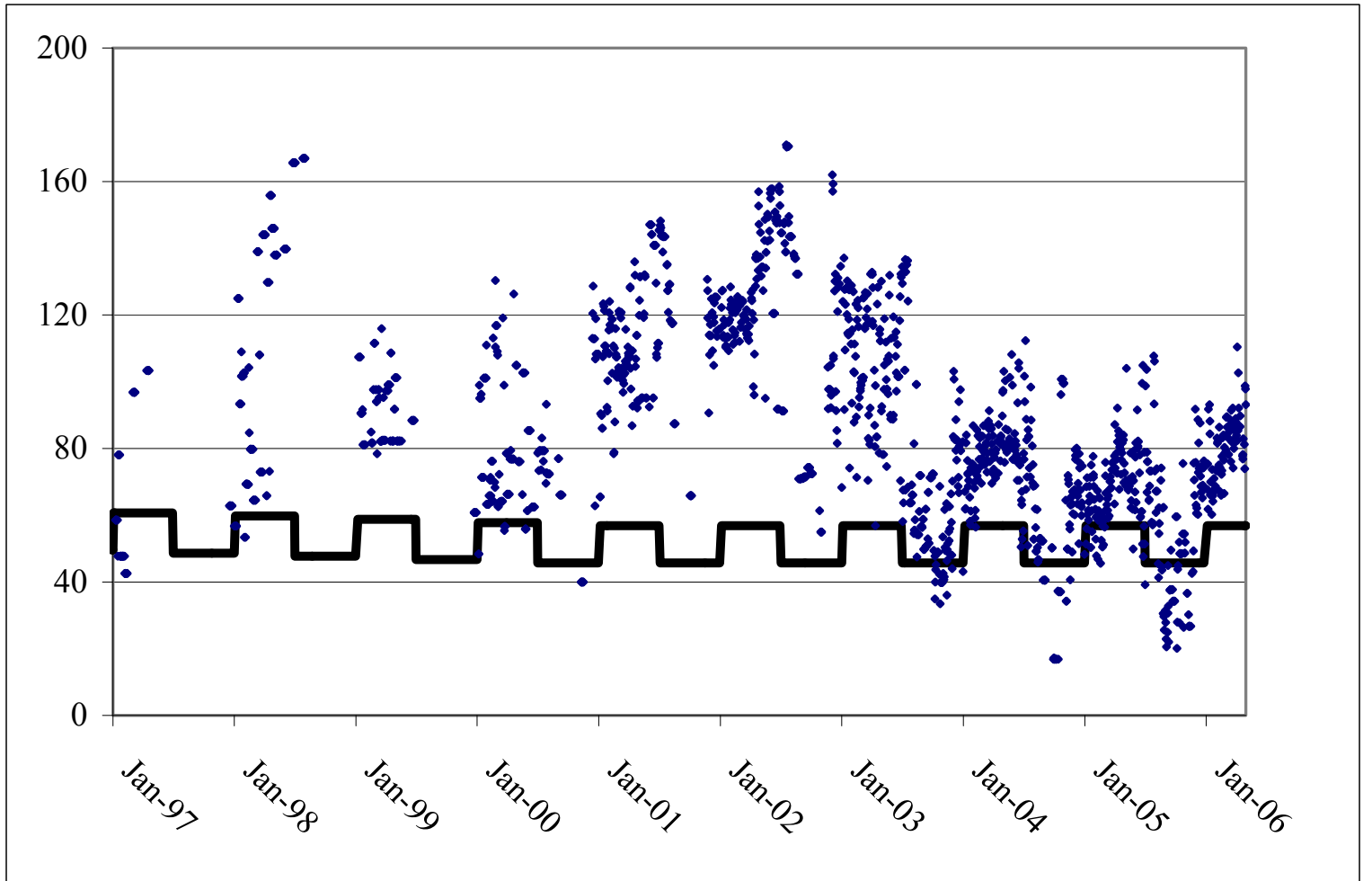

Source: European Commission (2006), own modifications.

Table 2: Distribution Measures for SIVs of Apples from China (1999-2005)

\begin{tabular}{|c|c|c|c|c|c|c|c|c|}
\hline & 1999 & 2000 & 2001 & 2002 & 2003 & 2004 & 2005 & $\begin{array}{l}\text { Corr. } \\
\text { mean } \\
2005)\end{array}$ \\
\hline Mean & 0.53 & 0.48 & 1.17 & 1.29 & 0.67 & 0.35 & 0.20 & \\
\hline Neg. obs. & 0.00 & 0.10 & 0.00 & 0.00 & 0.07 & 0.12 & 0.27 & \\
\hline 0.05 quantile & 18.15 & 2.01 & 10.58 & 10.09 & 1.82 & 2.81 & 1.93 & \\
\hline Skewness & 0.69 & 0.80 & 0.39 & 0.51 & 0.34 & -0.14 & 0.34 & $28.2 \%$ \\
\hline $\begin{array}{l}\text { Observations } \\
\text { Share of neg. } \\
\text { observations }\end{array}$ & 87 & 159 & 178 & 212 & 247 & 231 & 237 & \\
\hline$<92 \%$ of EP & 0.0 & 0.5 & 0 & 0 & 0.65 & 0.89 & 0.76 & \\
\hline
\end{tabular}

Source: Own calculations.

Table 2 also reports the share of cases where the SIV is less than $92 \%$ of the EP when the SIV is below the EP ("negative observations"); this share varies between $50 \%$ and $89 \%$. If 
importers would clear their products in such cases according to the SIV method, they would have to pay a specific tariff of about $40-50 € / 100 \mathrm{~kg}$ (see Table 1), which would almost double the price of Chinese apples on the EU market. Importers report, however, that the full specific tariff (MTE) is very rarely charged, as importers typically wait for a more favourable SIV before customs clearance.

Figure 9 compares the development of SIVs to the average Chinese export UV for apples and to the price level for apples in the EU in order to explore reasons for the declining SIV level.

Figure 9: Development of Apple Prices (1997-2005, €/100kg)

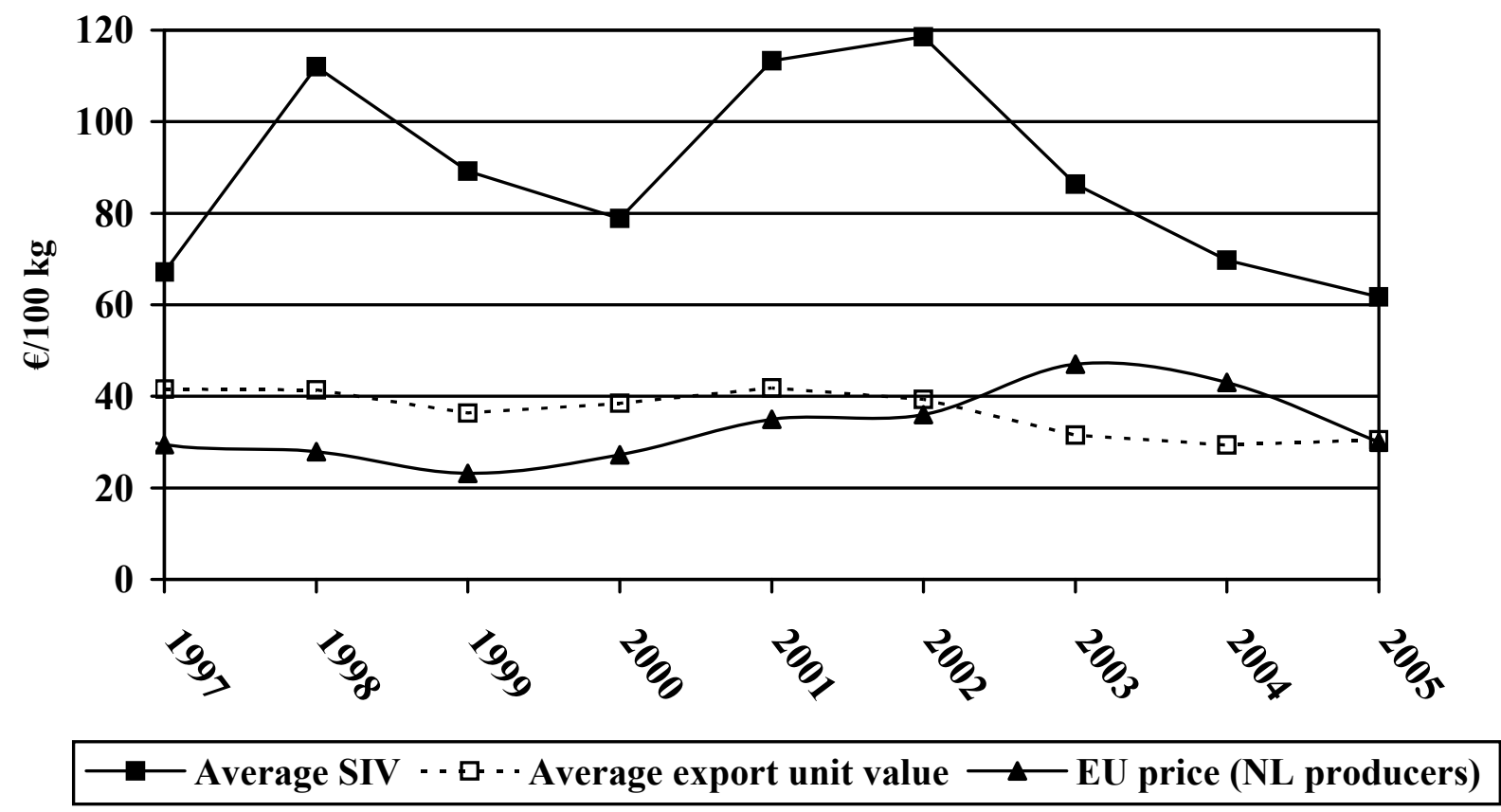

Source: European Commission (2006), FAO (2007).

The domestic EU price (producer price in the Netherlands, the main import country for Chinese apples) was relatively constant between 2002 and 2005 and, therefore, cannot explain the strong decline in the average Chinese SIV. Also, the average export UV of Chinese apples has been declining much less than the SIV on the European market. This indicates that there are more specific reasons underlying the price decline for apples traded to the EU, such as Chinese marketing strategy or changes in transportation costs; however, these possibilities were not confirmed by importers, who report fairly constant transportation costs over recent years.

Figure 10 displays the level of SIVs and the EP for pears from 1998 to spring 2006, and Table 3 displays distribution measures. 
The SIV distribution for pears from China was well above the EP level until 2002, but in 2000 it began declining from a level of $104 \%$ above the EP on average to about $20 \%$ above the EP by 2005 . Accordingly, the share of negative observations rose to $46 \%$ in 2005 . The 0.05 -

\section{Figure 10: Standard Import Values of EU Pear Imports from China (1997-2006, $€ / 100 \mathrm{~kg})$}

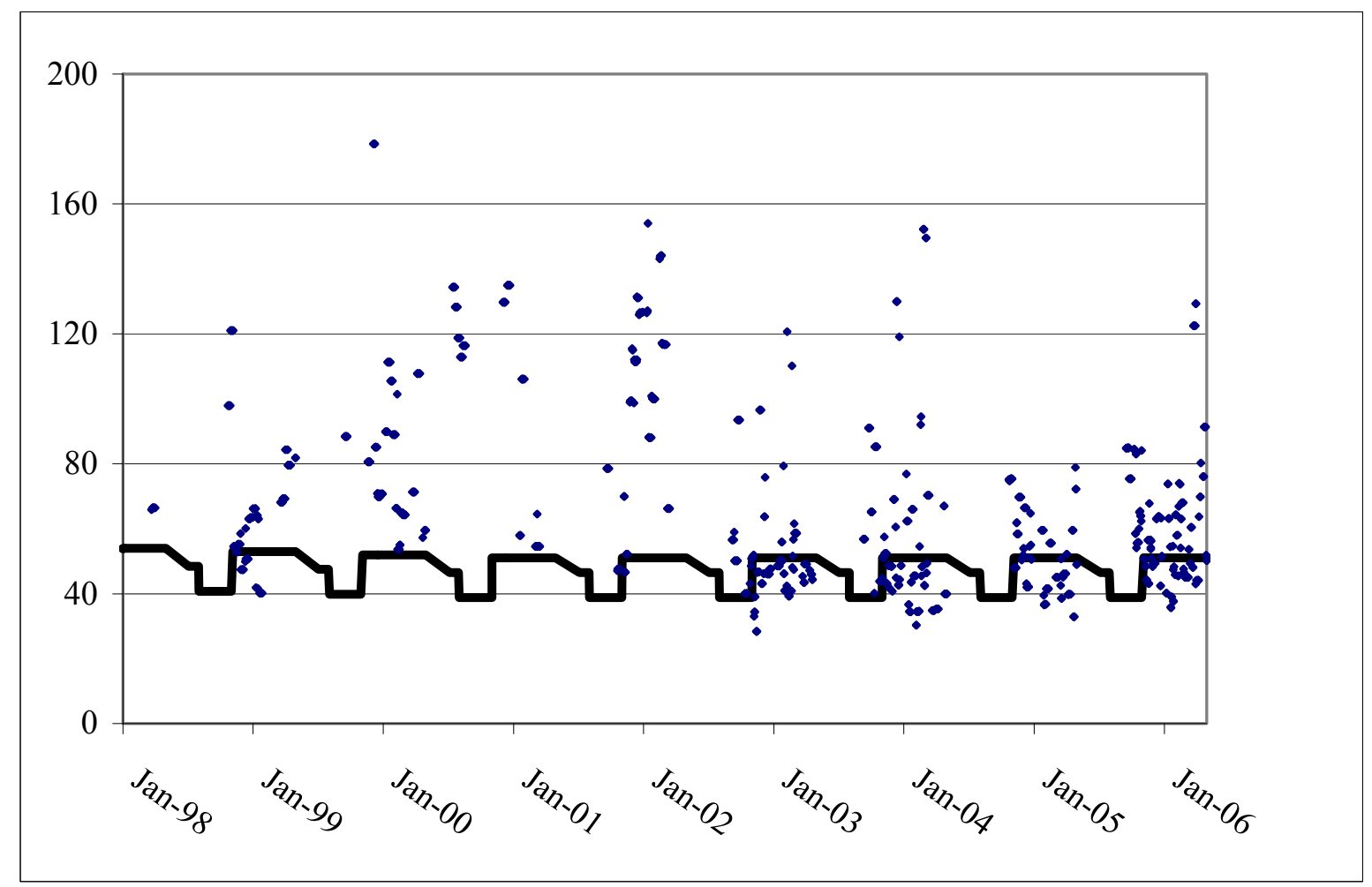

Source: European Commission (2006), own modifications.

\section{Table 3: Distribution Measures for SIVs of Pears from China (1999-2005)}

\begin{tabular}{|c|c|c|c|c|c|c|c|c|c|}
\hline & 1998 & 1999 & 2000 & 2001 & 2002 & 2003 & 2004 & 2005 & $\begin{array}{l}\text { Corr. with mean } \\
(2000-2005)\end{array}$ \\
\hline Mean & 0.34 & 0.50 & 1.04 & 0.70 & 0.52 & 0.21 & 0.16 & 0.20 & \\
\hline $\begin{array}{l}\text { Neg. obs. } \\
0.05\end{array}$ & 0.30 & 0.12 & 0.00 & 0.05 & 0.29 & 0.52 & 0.53 & 0.46 & \\
\hline quantile & 0.46 & 4.01 & 0.85 & 0.42 & 0.61 & 0.20 & 1.05 & 0.65 & \\
\hline Skewness & 1.59 & 1.80 & -0.02 & 0.02 & 0.48 & 1.50 & 1.84 & 1.06 & $-88.2 \%$ \\
\hline $\begin{array}{l}\text { Observatio } \\
\text { ns }\end{array}$ & 53 & 64 & 95 & 65 & 99 & 120 & 108 & 116 & \\
\hline $\begin{array}{l}\text { Share of } \\
\text { neg. } \\
\text { observatio } \\
\text { ns }<92 \% \\
\text { of EP }\end{array}$ & 0.38 & 1.0 & 0.0 & 1.0 & 0.86 & 0.56 & 0.79 & 0.72 & \\
\hline
\end{tabular}

Source: Own calculations.

quantile is low throughout. The strong negative correlation between skewness and mean of the distribution shows that the distribution becomes more right-skewed the lower the mean is, 
indicating a truncating effect caused by the EPS. In conclusion, the decreasing average SIV level, the increasing share of negative observations, and the increasing right-skewness all support the conclusion that the EPS has become more effective for Chinese pear exports to the EU in recent years.

The share of cases where the SIV is less than $92 \%$ of the EP in total cases with SIV $<$ EP is between $38 \%$ and $100 \%$.

To investigate reasons for the declining SIV level, Figure 11 compares the development of SIVs to the average Chinese export UV for pears and to the price level for pears in the EU.

\section{Figure 11: Development of Pear Prices (1997-2005, €/100kg)}

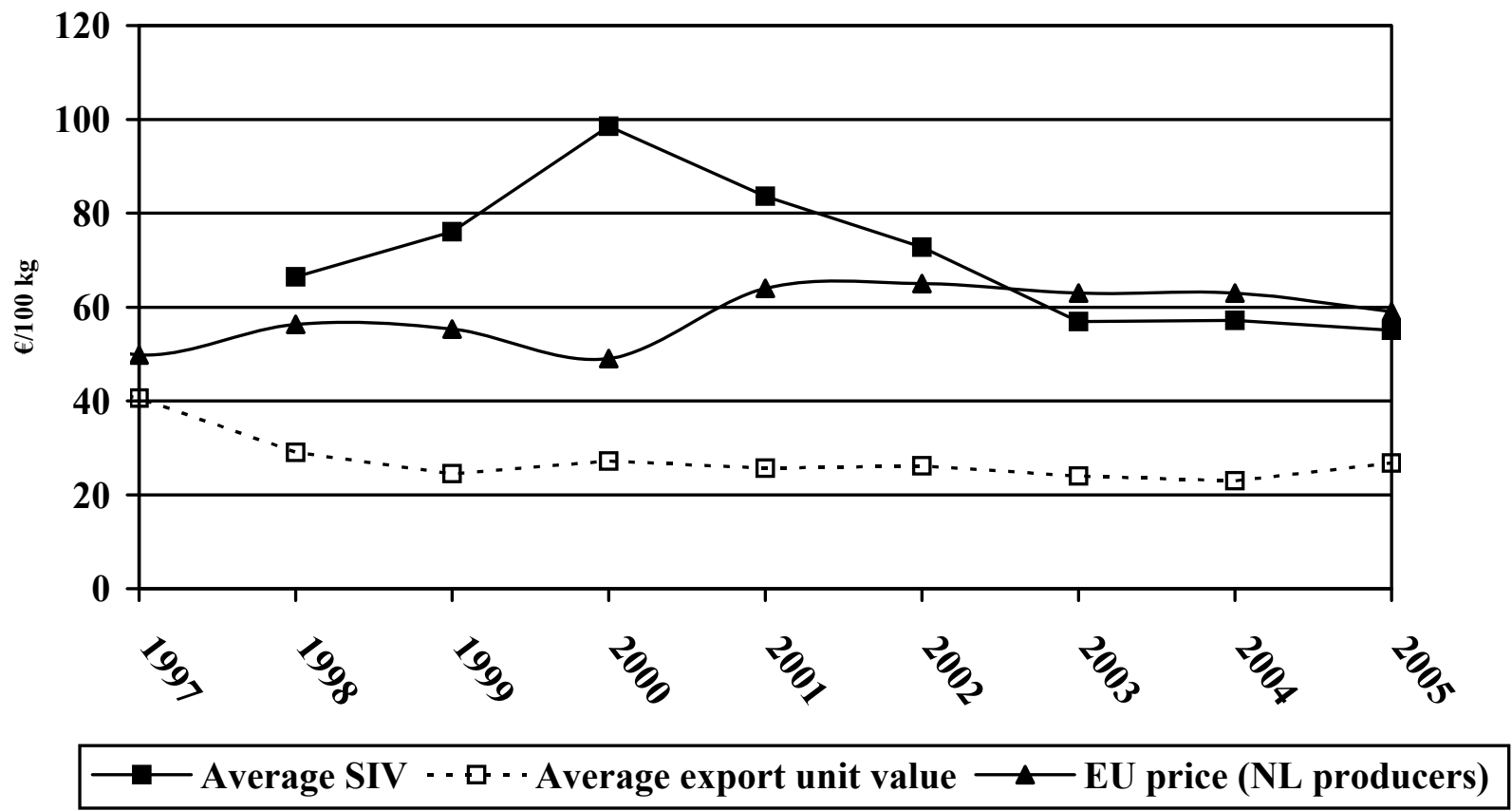

Source: European Commission (2006), FAO (2007).

As was the case for apples, the strongly declining SIV for pears from China on the EU market is not found in conjunction with a declining EU price or a declining general export UV of Chinese pears.

\section{Conclusions and Outlook}

Our results indicate that the EPS restricts exports of apples and, even more so, of pears to the EU. In addition, the restrictiveness of the EPS has increased in recent years, as the price level of Chinese exports has come closer to the EP.

This contrasts with exports from all other relevant exporters of apples (New Zealand, South Africa, Chile, Brazil, Argentina) and pears (Argentina, Chile, South Africa) to the EU, which 
exclusively fall into Clusters 3 and 4 (see Figure 6); thus, the EPS is of low relevance. Looking at fresh fruit and vegetable exports to the EU in general, China and South Africa are the only countries other than North African and Eastern European countries for which the EPS is highly relevant.

How can the declining SIV of Chinese apples on the EU market and the increasing market share be explained? Next to potential cost advantages in production, transportation costs seem to play a role. Traders report that the cost to ship a 20-ton container from China to the EU is about $2500 €$, in contrast to a container from Chile that would cost $4500 €$. This results in a significant price difference, equivalent to about $17 \%$ of the average Chinese SIVs for apples and pears in 2005. Some traders also report that they expect Chinese traders to ship less quantity to the EU in the future as low selling prices on the EU market, together with specific tariffs, have resulted in occasional losses for Chinese traders in recent years.

The future development of Chinese apple and pear exports to the EU will depend strongly on domestic market conditions in China. Chinese net exports of apples accounted for only $2.4 \%$ of total production - for pears this share was $2.8 \%$ (FAOSTAT, 2007). Thus, small relative changes in the Chinese consumption pattern could affect exports significantly. In fact, Lardy (2007) showed that the strong GDP growth rates in China - about $10 \%$ over the last three decades - have translated only to a limited extent into household consumption due to high investment and private saving rates. If the share of disposable income in the Chinese GDP increases, this may induce much higher domestic consumption of fresh fruits and vegetables and thus reduce the export potential. Such a development would make the EPS less relevant in protecting the EU market.

Finally, a potential conclusion of the Doha Round might result in significant tariff reduction rates that would also apply to the specific tariffs which are part of the EPS. In implementing the results of the Uruguay Round, the EU reduced entry prices by the same monetary amount as specific tariffs - an approach that could be repeated and would thus further diminish the relevance of the EPS (Grethe, 2005: 28-29).

\section{References}

Chemnitz, C. and H. Grethe (2005), EU Trade Preferences for Moroccan Tomato Exports Who Benefits? In: $\mathrm{XI}^{\text {th }}$ Congress. European Association of Agricultural Economists. The Future of Rural Europe in the Global Agri-Food System. Copenhagen. 24-27 August (CD). 
Cioffi, A. and C. dell' Aquila (2004), The Effects of Trade Policies for Fresh Fruit and Vegetables of the European Union. Food Policy 29: 169-185.

European Commission (2006), Standard Import Values. Unpublished.

European Commission (2007), TARIC.

EUROSTAT (2007), External Trade Data. Internet database.

FAOATAT (2007). Internet database.

García-Álvarez-Coque, J. M. (2002), Agricultural Trade and the Barcelona Process: Is full Liberalization Possible? European Review of Agricultural Economics 29(3): 339-422.

Garcia Alvarez-Coque, J. M., Martinez-Gomez, V. and M. Villanueva (2007), F \& V Trade Model to Assess Euro-Med Agreements. An Application to the Fresh Tomato Market. Contributed paper at the Mediterranean Conference on Agro-Food Social Scientists (103rd EAAE Seminar), April 23-25, Barcelona, Spain.

Goetz, L. and H. Grethe. (2007), The EU Import System for Oranges: Much Ado about Nothing? Journal of International Agricultural Trade and Development 3(1).

Grethe, H. and S. Tangermann (1999), The EU Import regime for Fresh Fruit and Vegetables after Implementation of the Results of the Uruguay Round. Diskussionsbeitrag 9901. Institut für Agrarökonomie. Georg-August-Universität Göttingen.

Grethe, H. (2005), EU Agricultural Trade Preferences for North Africa and the Near East and the EU Import Regime for Fresh Fruit and Vegetables. Paper prepared for the FAO Regional Trade Workshop Recent Development in the WTO Negotiations on Agriculture and in Regional Trade Agreements and their Implications for Trade, Agriculture and Food Security in the Near East Countries", Cairo 15th to 17th November.

Lardy, N. (2007), China's Consumption Driven Growth Path. Plenary paper at the IATRC Conference "China's Agricultural Trade: Issues and Prospects", July 8-9, Beijing.

Martin, E. and H. de Gorter (1999), The Agreement on Agriculture and the CAP: The Reform of the Fruit and Vegetable Import System. Cornell.

Swinbank, A. and C. Ritson (1995), The Impact of the GATT Agreement on EU Fruit and Vegetable Policy. Food Policy 20: 339-357. 
6 Vertical Price Transmission in the International Fresh Fruit and Vegetable Supply Chain: Israeli Grapefruit Exports to the EU after Export Market Liberalization

jointly with Stephan von Cramon-Taubadel and Yael Kachel 


\title{
Vertical Price Transmission in the International Fresh Fruit and Vegetable \\ Supply Chain: Israeli Grapefruit Exports to the EU \\ after Export Market Liberalization
}

\author{
Linde Götz ${ }^{\mathrm{a}}$, Stephan von Cramon-Taubadel ${ }^{\mathrm{b}}$ and Yael Kachel ${ }^{\mathrm{c}}$
}

\begin{abstract}
${ }^{a}$ Leibniz-Institute of Agricultural Development in Central and Eastern Europe (IAMO), Halle/Saale, Germany ${ }^{25}$
${ }^{\mathbf{b}}$ Department of Agricultural Economics and Rural Development, University of Göttingen, Germany

${ }^{\mathrm{c}}$ Department of Agricultural Economics and Management, The Hebrew University of Jerusalem, Israel
\end{abstract}

\begin{abstract}
:
This paper studies vertical price transmission between Israel and the EU in the imperfectly competitive Israeli citrus export sector, which emerged after the former parastatal marketing board was liberalised in 1991. We identify positive asymmetry in price transmission, implying that profits of the Israeli exporters increase at the expense of grapefruit growers, and argue that this is in evidence of Israeli citrus exporters exerting market power vis-à-vis Israeli citrus growers.

This study is unique in investigating vertical price transmission in the international supply chain for fresh fruits and vegetables (FFV). International FFV trade is especially susceptible to the abuse of market power since transparency regarding the determination of the grower price is extremely low.

In our model approach we explicitly account for possible changes in exporters' pricing behaviour in the post-liberalization period. The analysis finds that exporters transmitted changes in the EU import market to Israeli growers asymmetrically in the volatile phase directly after liberalization, but symmetrically in the calm phase thereafter. Further, results suggest the measured asymmetry in price transmission to be economically significant. Overall, our study demonstrates that liberalization improved the efficiency of Israel's international citrus marketing channel, although this took time and was probably accelerated by government market intervention.
\end{abstract}

\section{Introduction}

International FFV trade is especially susceptible to the abuse of market power. FFV export sectors are often characterized by low competition. Also, transparency how the grower price is determined is extremely low. In particular, business in the international FFV supply chain is characterized by oral contracts. Typically, growers supply their produce to exporting companies on consignment and are thus not provided with information on the grower price until after the produce has been sold in the export market. Prices achieved in the export market are also influenced by the quality of the produce at the point of time of arrival in the export market which is determined by on-site inspection which is out of the growers' control. For small farmers, particularly in developing countries, to profit from the increasing

\footnotetext{
25 This work was mainly done when Linde Götz was a PhD student at the Department of Agricultural Economics and Rural Development, University of Göttingen, Germany.
} 
international trade in FFV it is decisive that they are well integrated into the supply chain and benefit adequately from the profits achieved from international FFV trade.

This study is unique in investigating vertical price transmission in the international supply chain for fresh fruits and vegetables $(\mathrm{FFV})^{26}$. To cast light on the issue of market power we study vertical price transmission in international grapefruit trade from import markets in the EU to growers in Israel.

It is often hypothesised that imperfect competition will manifest itself in asymmetric price transmission (MEYER AND VON CRAMON-TAUBADEL, 2004; RAPSOMANIKIS ET AL., 2006). In most cases, it is predicted that market power will lead to positive asymmetric price transmission meaning that e.g. margin-squeezing decreases in output prices will be transmitted faster and more completely than margin-stretching price changes ${ }^{27}$.

We test for asymmetric price transmission (APT) in the export chain for Israeli grapefruits as evidence of imperfect competition in the Israeli FFV export sector. Israeli grapefruit exports provide a case study that is well suited to isolating the link between market power and APT. First, as described in the following section, exports are in the hands of a few firms so imperfect competition is possible and might be reflected in APT. Second, since the grower price of the Israeli grapefruits exported to the EU is determined ex-post only after the products are sold in the export market, and FFV products are highly perishable, several other factors that might cause APT such as adjustment and menu costs, caused by adjusting a firm's prices to a change in the price or quantity of inputs or outputs and inflation, can be disregarded. Furthermore, asymmetry in price transmission can not result from market intervention by the EU since the EU entry price system does not apply to grapefruits ${ }^{28}$. Third, the post-liberalisation period that we study includes two important developments that may have changed exporters' pricing behaviour. These developments are the enforcement of the minimum price agreement in 1994/95, and a substantial increase in sea transport costs in the 1990 s by up to $60 \%$.

To take advantage of the opportunities offered by the Israel/EU grapefruit export case, we use weekly, firm-specific data of the three largest Israeli citrus exporters on grapefruit from $1991 / 92$ to $1999 / 00$ to test for APT between grower prices in Israel and import prices in

\footnotetext{
${ }^{26}$ In contrast, previous studies on asymmetric price transmission in the fresh fruits and vegetables sector confine to the analysis of price transmission within the national marketing channel (e.g. WARD, 1982, PICK, KARRENBROCK AND CARMAN, 1990, Brooker, EASTWOOd, CARVER and Gray 1997, Willett, Hansmire AND Bernard, 1997, GIRAPUNTHONG, VANSICKLE AND RENWICK, 2003).

${ }^{27}$ There is a lack of theoretical models explicitly linking the exercise of market power to specific forms of APT (Meyer AND VON Cramon-TAubadel, 2004). MCCorriston Et Al. (1998), MCCorriston ET AL. (2001), WELDEGEBRIEL (2004) and LLOYD et al. (2006) develop models of vertical price transmission in the presence of market power and non-constant returns to scale. However, these models explore implications for long run elasticities of price transmission, and not for APT.

${ }^{28}$ For an overview on the EU entry price system see GOETZ AND GRETHE, 2007.
} 
France, and for possible structural changes in the nature of any APT that we find over the course of the 1990s.

LlOYd ET AL. (2006) and LLOYD AND MORGAN (2007) point out that asymmetric price adjustment might result from an increase in marketing costs inducing a rise in the price spread even in a competitive market environment. In this study we observe relatively increasing marketing costs caused by the decline in the French import price during the underlying time period. Yet, we explicitly account for this by allowing for structural breaks in the cointegration regressions. Furthermore, the Israeli government's market intervention by the enforcement of the minimum price agreement aimed to protect growers against the abuse of market power by Israeli exporters. This provides strong evidence that market power has actually been exerted by the exporters in the first years after liberalization implying asymmetry in price transmission.

Our results suggest that two of the three Israeli exporters transmitted changes in the French import market to Israeli growers asymmetrically in the heterogeneous, volatile price phase directly after liberalization but symmetric in the more homogeneous, calm phase some years later. Further, we find the measured asymmetry in price transmission to be economically significant. In particular, the growers' losses amounted up to $4.0 \%$ of growers' total revenues in one season.

This rest of this paper is structured as follows. Section two gives some information on the liberalization of the Israeli citrus export sector. Section 3 explains characteristic features of the data set and how they are accounted for in the empirical specification. The methodological concepts are explained in section 4 and empirical model results are presented in section 5 . Chapter 6 concludes und provides directions for future research.

\section{Liberalization of the Israeli parastatal marketing board}

Prior to 1991, Israeli fresh citrus fruits were exported exclusively by the parastatal Citrus Marketing Board of Israel (CMBI). The goal of liberalizing the Israeli citrus export sector was to increase the citrus growers' income and to strengthen the efficiency of the Israeli citrus export marketing channel by establishing competition between the exporting companies. The CMBI's citrus export activities were mainly taken over by four large companies. In the first 10 years after liberalization, these companies accounted for over $90 \%$ of all Israeli citrus exports. In contrast, Israel's citrus production was polypolistic with about 630 citrus growers accounting for roughly $80 \%$ of the citrus growing area. 
Tnuport, the largest grapefruit exporter in the nineties, and Mehadrin had own packing stations and provided packing services before liberalization. After liberalization Tnuport and Mehadrin started to engage in providing citrus export services also. Mehadrin also owns citrus plantations and thus only partially buys citrus fruits from individual citrus growers. Agrexco, a company which had an export monopoly for fruit (other than citrus) and vegetables, started to engage in the export of citrus fruits after liberalization of the citrus sector. The fourth largest citrus exporter is Pardess, a cooperative of citrus growers.

The restricted number of exporters provides only limited opportunities for the citrus growers to choose between exporters, giving leeway to the exporters to exert market power vis-à-vis the Israeli citrus growers by paying a lower grower price. In addition, the consignment system of the former monopoly has been maintained. This induced the government, in 1993/94, to intervene in the newly liberalized market by establishing a minimum price agreement for oranges to protect growers against the abuse of market power by exporting companies. According to this agreement, exporters qualified for a government subsidy if they signed a written, standardized contract with growers, guaranteeing a minimum grower price and stating the timetable of payments and conditions triggering additional payments to the growers. The minimum price agreement was extended to include grapefruits in most of export season 1994/95 and part of 1995/96 (KACHEL, 2003).

Government export marketing boards in the agricultural sector have been reformed or even abolished particularly in developing countries. Yet, the expected income gains to farmers did not accrue in many cases. For example, MATHER AND GREENBERG (2001) analyze the effects of privatization of the citrus marketing board of South Africa in 1994 where new exporters entered the market in 1996. They find that liberalization has shifted market power from the former export monopoly and cooperative packing stations to privately-owned large citrus enterprises. WILCOX AND ABBOTT (2004) use a conjectural variations approach and find evidence of market power in the post-liberalized coca bean market exerted by exporters and processors over growers in the Ivory Coast. For the cashew nut export sector in Mozambique MCMiLlan ET AL. (2002) find that the largest share of the benefits from removal of the export tax was captured by traders and little was attributed to the farmers. In their model of a concentrated developed country food market, SEXTON ET AL. (2007) show that even relatively small deviations from perfect competition can imply that the majority of the benefits from trade liberalization accrue to the marketing companies and not to farmers.

This study aims to investigate whether the newly established companies in the Israeli citrus export sector have exerted market power over the citrus growers by asymmetric price 
transmission implying short-run additional revenues to the exporters and losses to the citrus growers.

\section{Dataset and critical issues}

The analysis is based on weekly ${ }^{29}$ grower price data reported by each of the three largest Israeli grapefruit exporting firms (Tnuport, Mehadrin and Agrexco), and the corresponding French import price for red 'Sunrise' grapefruits in the seasons 1991/92 to 1999/00 (Figure 1). Over the study period, Tnuport was Israel's largest red grapefruit exporter with a market share of $38 \%$, followed by Mehadrin (28\%) and Agrexco (26\%). The EU is Israel's primary export market for grapefruits. Between 1991 and 2000, the EU accounted for $75 \%$ to $90 \%$ of total Israeli red grapefruit exports, and France alone accounted for between 20\% and 40\% (C.L.A.M.). The Israeli firm-level grower prices for red grapefruits for export and the

Figure 1: Firm-level Israeli grower prices (gp) for the three largest Israeli exporting companies and the French import price 1991/92 to 1999/00 (real NIS/t)

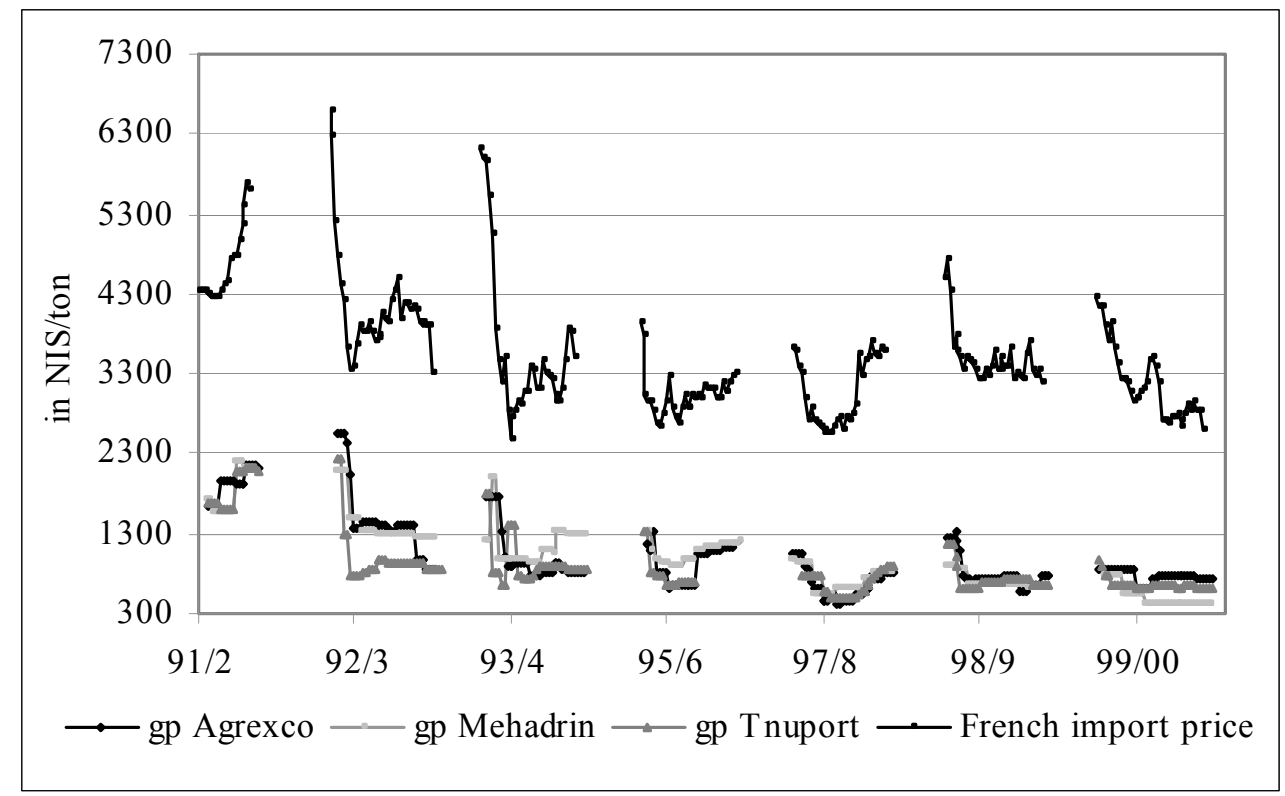

Source: Citrus Growers' Association of Israel, CMBI

corresponding French import prices are weighted averages ${ }^{30}$ of the prices for different fruit sizes. The Israeli grower prices and the French import prices are stated in New Israeli Shekel (NIS) per ton and deflated with the Israeli monthly consumer price index $(2000=100$; CBS

\footnotetext{
${ }^{29}$ BROOKER ET AL. (1997) point out that due to the perishability of fresh fruits and vegetables and the high volatility of produce supply, the planning horizon in the fresh produce marketing channel is short and pricing strategies can change several times per month. Therefore, at least weekly data is required to adequately capture price transmission in the fruits and vegetable sector.

${ }^{30}$ The Israeli grower prices as well as the French import prices are weighted with a standard size distribution, not accounting for differences in the actual size distribution exported.
} 
Israel). The data set is balanced by including only those weeks for which grower price data is available for all three exporters, and contains altogether seven seasons with a total of 205 observations. In the context of this study weekly data is sufficient to fully capture price transmission since fresh grapefruits are delivered from Israel to France once a week by ship during the harvest season.

We identify three empirical particularities which are explicitly accounted for in our estimation approach:

1. It is likely that the pricing behaviour of the citrus exporting companies changed in the postliberalization period.

The French grapefruit import prices decreased significantly over the period of this analysis. From Table 1 it becomes evident that the mean French import price weighted by the total export quantity of the Israeli exporters in season 1991/92 fell by 30\% from $4547 \mathrm{NIS} /$ ton to $3165 \mathrm{NIS} /$ ton in season 1999/00. All exporters will have attempted to pass decreased French import prices on to the growers, but firm-specific strategies and the scope for passing this on may have varied depending inter alia on each firm's market power.

Further, exporters might have adjusted their long-run pricing strategy following the minimum price agreement imposed by the government particularly in 1994/95 which signalled that the government was willing and able to intervene in response to what were perceived as unfair pricing practices by the exporting firms.

Table 1: Weighted Mean French import price for grapefruits, by season (in NIS/t)

\begin{tabular}{|c|c|c|c|c|c|c|c|}
\hline Season & $1991 / 92$ & $1992 / 93$ & $1993 / 94$ & $1995 / 96$ & $1997 / 98$ & $1998 / 99$ & $1999 / 00$ \\
\hline $\begin{array}{c}\text { Mean French } \\
\text { import price }\end{array}$ & 4547 & 4135 & 3579 & 3028 & 3076 & 3483 & 3165 \\
\hline
\end{tabular}

The data indicate that the homogeneity of grower prices increased over time, which may be evidence of increasing competition. In particular, the difference between the maximum and minimum of the grower price (price spread) of the three major exporters decreases significantly during the nineties (Figure 2). The mean spread of the three grower prices amounts to $400 \mathrm{NIS} / \mathrm{t}$ in season $91 / 92$ to $95 / 96$ and reduces to $180 \mathrm{NIS} / \mathrm{t}$ in seasons $97 / 98$ to 99/00. This indicates that grower price volatility decreased, suggesting that exporters' pricing behaviour changed between 95/96 and 97/98.

We account for these possible changes by testing for structural breaks in the cointegration regressions. In addition, and based on the results of these tests, we distinguish a 
heterogeneous, volatile phase in 91/92, 92/93, 93/94 and 95/96 from a more homogeneous, stable phase in 97/98, 98/99 and 99/00, and estimate separate ECMs for these two phases (referred to as SUBSET 1 and SUBSET 2 in the following).

Figure 2: Spread of the weekly grower prices of Agrexco, Mehadrin and Tnuport (in NIS/t)

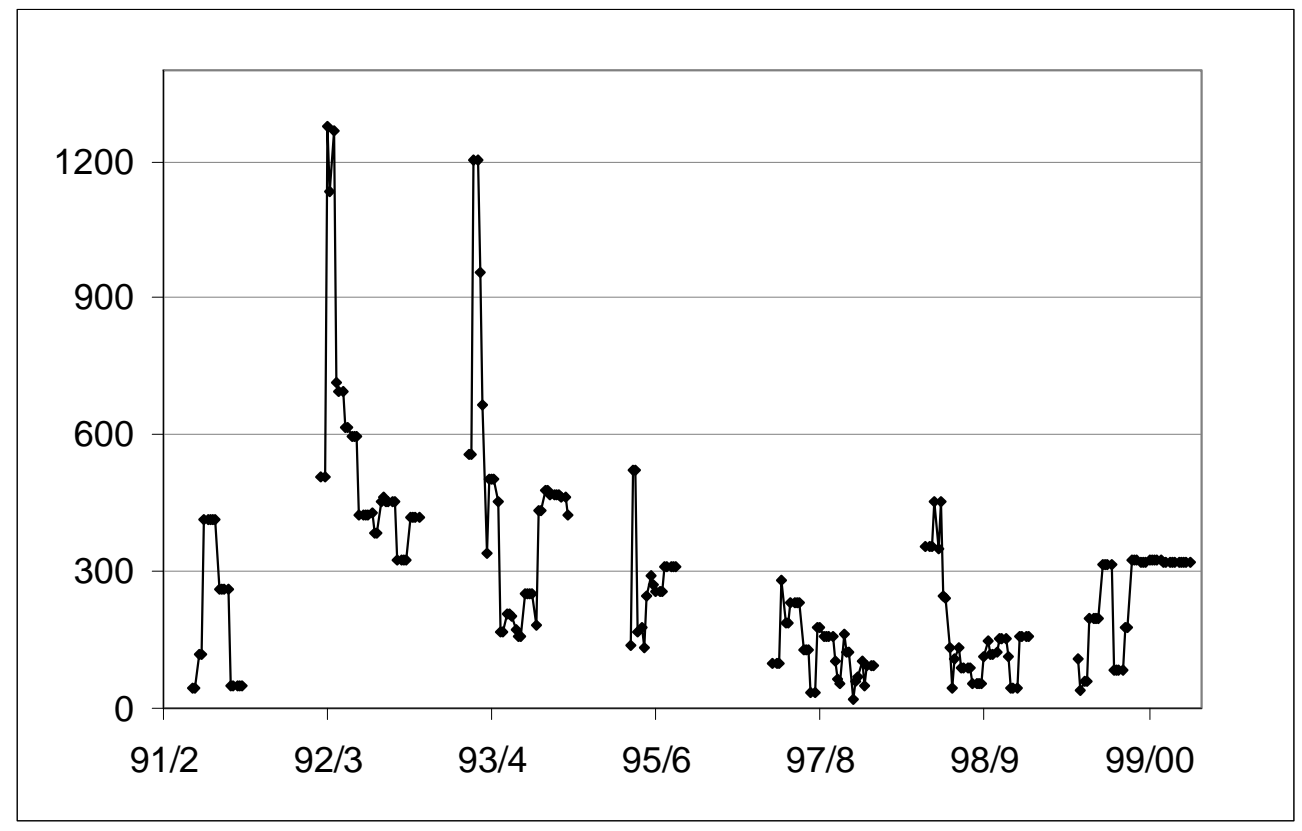

Source: own calculations

2. The data set is characterized by gaps resulting from seasonal interruptions in grapefruit production and trade. This implies that for the first observations in each season, no or only incomplete information on the preceding observations is available, so that a complete set of lagged variables cannot be created. How many observations are lost in this manner depends on the chosen lag specification. WARD (1982) introduces additional dummy variables for those observations for which lags are missing in his model to ensure that each observation can be included in the estimation. We take the alternative course of omitting observations for which the required lags cannot be constructed. Our approach leads to a loss of degrees of freedom whereas Ward's approach may lead to estimation bias. Given the often very large differences in our data between the first observations of one season (see Figures 1 and 2), we are more concerned about bias than losing degrees of freedom.

3. We account for the lag between the week in which the grower price is recorded, and the week in which the corresponding French import price is determined. The grower price represents the value of the produce at the point of time of its delivery to the packing station, while the French import price is determined at the harbour in Marseille. According to the consignment system, the grower price is determined ex post, i.e. after the produce is sold in the French import market. The minimum time lag between those two points in the transport 
chain is 7 to 9 days. Since delays may occur at several points, this lag is stochastic. Simplifying, we assume a transport lag of two weeks for all models ${ }^{31}$.

\section{Methods}

\subsection{Identifying asymmetry in price transmission}

To estimate the ECM we follow the Engle and Granger (1987) two-step approach which requires the time series to be cointegrated. First, the long-run equilibrium relationship between the Israeli grower price $p_{i t}$ and the French import price $p_{j t}$ for Israeli grapefruits is estimated as

(1) $p_{i t}=\alpha_{0}+\alpha_{1} * p_{j t}+v_{t}$ with $\mathrm{t}=1, \ldots, \mathrm{T}$.

The data are in logarithms, so $\alpha_{1}$ corresponds to the price transmission elasticity, indicating the percentage price change in $p_{i t}$ if $p_{j t}$ changes by $1 \%$. If prices changes are transmitted completely, then $\alpha_{1}=1$. If there is no price transmission, $\alpha_{1}$ is not significantly different form zero. The residual vector $v_{t}$ represents the short-run deviations from this long-run equilibrium. The actual grower price may be higher or lower than its long-run equilibrium value in any given period, thus $v_{t}$ might be greater or smaller than zero, respectively. The estimated residuals are lagged by one period and enter the ECM as the error correction term $(\mathrm{ECT})$ where $E C T_{t}=p_{i t-1}-\alpha_{0}-\alpha_{1} * p_{j t-1}$ :

(2) $\Delta p_{i t}=\sum_{n=1}^{K} \beta_{1 n} \Delta p_{j t-n+1}+\sum_{m=1}^{L} \beta_{2 m} \Delta p_{i t-m}+\phi E C T_{t}+\varepsilon_{t}$

In this model, $\sum_{n=1}^{K} \beta_{1 n} \Delta p_{j t-n+1}$ captures contemporaneous and previous change effects of $p_{j t}$ on $p_{i t}$ up to lag period $\mathrm{K}, \sum_{m=1}^{L} \beta_{2 m} \Delta p_{i t-m+1}$ accounts for autocorrelation up to order $\mathrm{L}$ and $E C T_{t}=p_{i t-1}-\alpha_{0}-\alpha_{1} * p_{j t-1}$ reflects error correction. $\phi$ indicates the speed at which shortrun deviations from the long-run equilibrium in the previous period are corrected, and is sometimes referred to as the speed of adjustment parameter.

To allow for asymmetry in price transmission, contemporaneous and lagged effects caused by price increases are distinguished from those caused by price decreases by splitting the respective variables in positive and negative components in the ECM. The ECT is included as

\footnotetext{
${ }^{31}$ We estimated the model for lags of 1 to 3 weeks, but coefficients did not differ substantially.
} 
a split variable as well. $\mathrm{ECT}^{+}$contains the positive, and $\mathrm{ECT}^{-}$the negative lagged residuals of the long-run equilibrium regression given by equation (1). Thus, positive and negative error correction behaviour can be identified separately:

$$
\Delta p_{i t}=\sum_{n_{1}=1}^{K_{1}} \beta_{1 n_{1}}^{+} D_{1 t}^{+} \Delta p_{j t-n_{1}+1}+\sum_{n_{2}=1}^{K_{2}} \beta_{1 n_{2}}^{-} D_{1 t}^{-} \Delta p_{j t-n_{2}+1}+\sum_{m=1}^{L} \beta_{2 m} \Delta p_{i t-m}+\phi_{1} D_{2 t}^{+} E C T_{t}+\phi_{2} D_{2 t}^{-} E C T_{t}+\varepsilon_{t}
$$

with $D_{1 t}^{+}=1$ if $\Delta p_{j t-n_{1}+1}>0$ and 0 otherwise, $D_{1 t}^{-}=1$ if $\Delta p_{j t-n_{2}+1}<0$ and 0 otherwise,

$$
D_{2 t}^{+}=1 \text { if } E C T_{t}>0 \text { and } 0 \text { otherwise, and } D_{2 t}^{-}=1 \text { if } E C T_{t}<0 \text { and } 0 \text { otherwise. }
$$

This model structure enables differing number of lags for the positive and negative short-run effects to be included. Asymmetry in price transmission is present if the null hypothesis that the estimated coefficients of the respective positive and negative variable are equal is rejected by a F-test.

Meyer AND VON CRAMON-TAUBADEL (2004) point out the importance of supplementing the statistical detection of asymmetric price transmission by analyzing its economic implications and relevance. Based on the results of estimating equation (3), we estimate the revenue that Israeli grapefruit growers have foregone as a result of asymmetric price transmission in the study period.

\subsection{Tests for structural breaks in a cointegration regression}

Standard tests for cointegration (e.g. the residual-based ENGLE AND GRANGER (1987) test) require that the cointegrating vector is time-invariant. If the cointegrating vector changes during the sample period, the results of these tests might be misleading (GREGORY AND HANSEN, 1996). In GREGORY AND HANSEN's (1996) cointegration test, the null hypothesis of no cointegration is tested against the alternative hypothesis of cointegration allowing for the presence of a structural break at an unknown point of time as indicated by the following three model frameworks:

a) level shift

(4) $p_{i t}=\alpha_{01} * \varphi_{t \tau}^{1}+\alpha_{02} * \varphi_{t \tau}^{2}+\alpha_{1} * p_{j t}+v_{t}$

with $\varphi_{t \tau}^{1}=1$ if $t \leq[n \tau], \varphi_{t \tau}^{1}=0$ if $t>[n \tau]$, where $\tau \in(0,1)$

$$
\varphi_{t \tau}^{2}=0 \text { if } t \leq[n \tau], \varphi_{t \tau}^{2}=1 \text { if } t>[n \tau] \text {, where } \tau \in(0,1)
$$

b) level shift with trend

(5) $p_{i t}=\alpha_{01} * \varphi_{t \tau}^{1}+\alpha_{02} * \varphi_{t \tau}^{2}+\alpha_{1} * p_{j t}+\alpha_{2} * t+v_{t}$

c) regime shift

(6) $p_{i t}=\alpha_{01} * \varphi_{t \tau}^{1}+\alpha_{02} * \varphi_{t \tau}^{2}+\alpha_{11} * \varphi_{t \tau}^{1} * p_{j t}+\alpha_{12} * \varphi_{t \tau}^{2} * p_{j t} * \varphi_{t \tau}+v_{t}$.

In this test, the residuals of the individual cointegration regressions in (4)-(6) for all possible breakpoints are tested for the existence of a unit root by an Augmented Dickey Fuller (ADF) 
test $^{32}$. If the standard ADF test does not reject the null hypothesis of no cointegration, but the ADF statistic of the GREGORY-HANSEN test does, this is interpreted as evidence of a structural break in the cointegration regression. The point of time of the structural break corresponds to the break point of the cointegration regression for which the ADF statistic is lowest. Critical values are non-standard and are tabulated in GREGORY AND HANSEN (1996). This approach has been applied by BAKUCS AND FERTÖ (2006), GUILlOTREAU, GREL AND SiMiONI (2005) and TIFFIN AND DAWSON (2000) in previous studies of price transmission ${ }^{33}$. GREGORY AND HANSEN (1996) point out explicitly that this test is not a test for the existence of a regime shift, but rather a test for cointegration which allows for the existence of a regime shift.

\section{Empirical Results}

\subsection{Price transmission analysis}

We start our analysis with determining the order of integration of the data series by the ADF test and the KPSS test of KWIATOWSKI ET AL. (1992). We find the French import price $\left(p_{j t}\right)$ to be $\mathrm{I}(0)$ according to the ADF test, but I(1) according to the KPSS test. The Israeli grower price series for all three exporters are I(1) according to the ADF as well as the KPSS.

We utilize the residual-based test by ENGLE AND GRANGER (1987) to test for cointegration of the French import price $\left(p_{j t}\right)$ with the Israeli grower price $\left(p_{i t}\right)$ of each of the three exporters.

The consignment system strongly suggests that the Israeli grower price is the dependent variable and the French import price the independent variable. The results in Table 2 indicate cointegration between the Israeli grower price and the French import price for Agrexco (5\% significance level) only.

Table 2: Results of the residuals-based test for cointegration of $y$ and $x$ for the disaggregated data sets

\begin{tabular}{|c|c|c|}
\hline \multirow{2}{*}{ Agrexco } & \multicolumn{2}{|c|}{$\operatorname{ADF}\left(H_{0}: \mathrm{x}\right.$ and $\mathrm{y}$ are not cointegrated $)$} \\
\cline { 2 - 3 } & Test-statistic & Conclusion \\
\hline Mehadrin & $|-3.922|>|-3.37|(5 \%)$ & $\begin{array}{c}\text { reject } H_{0} \text { at the } 5 \% \text { level; } \\
\text { variables are cointegrated }\end{array}$ \\
\hline Tnuport & $|-3.172|<|-3.37|(5 \%)$ & $\begin{array}{c}\text { cannot reject } H_{0} ; \text { variables are } \\
\text { not cointegrated }\end{array}$ \\
not cointegrated
\end{tabular}

\footnotetext{
${ }^{32}$ This procedure is followed for all model frameworks in (4) to (6). Estimates and their standard errors are compared and additional information, if available, is utilized to select the model framework which fits best.

${ }^{33}$ In a multivariate setting, BARASSI AND GOSHRAY (2007) detect an unknown break-point by employing a testing procedure proposed by BARASSI AND TAYLOR (2004) for a change in the cointegration rank.
} 
The failure to find cointegration for the other firms may be due to structural breaks as outlined above. Hence, we next test for cointegration allowing for the existence of a structural break using the GREgORY-HANSEN test. For Agrexco, Mehadrin and Tnuport a regime shift as given by (6) is identified at the 1\% level of significance on March 1993, week 11 (observation 42), October 1997, week 42 (observation 103) and October 1992, week 41 (observation 19), respectively (Figure 3). It is striking that the structural break is earliest for Tnuport, the exporter with the largest market share and thus probably the largest degree of market power. The identified break-points of the cointegration regressions for Agrexco, Mehadrin and Tnuport are accounted for in the estimation of the cointegration residuals, which enter the ECM as ECT terms.

Figure 3: ADF-values obtained by the Gregory-Hansen test for different break-points of the disaggregated grower price for Agrexco, Mehadrin and Tnuport

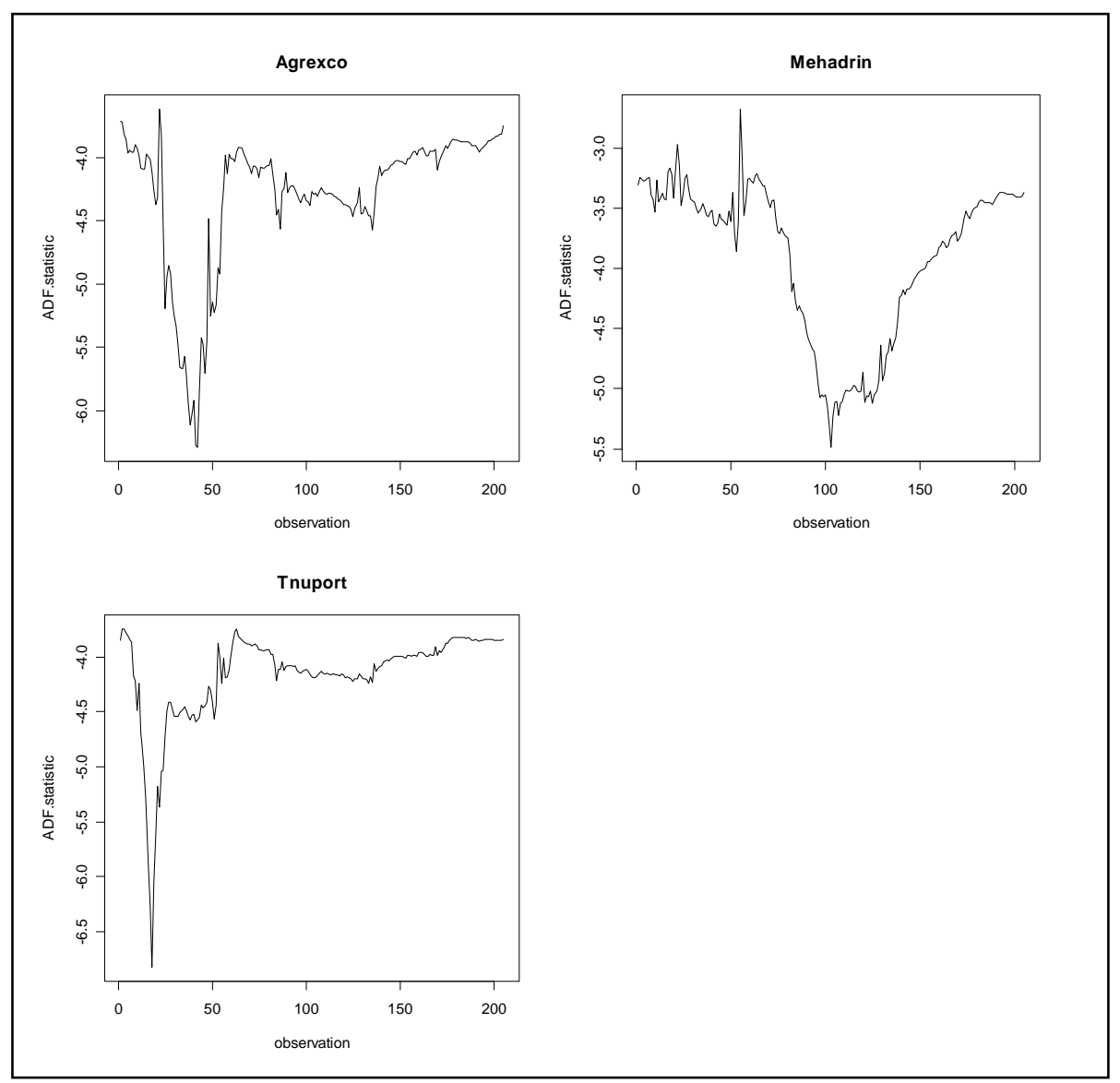

The estimated coefficients of the long-run equilibrium regression according to equation (6) for each exporter are presented in Table 3. In all cases $\alpha_{11}$ is higher than $\alpha_{12} . \alpha_{12}$ is by far lowest for Tnuport, the largest exporter with the potentially largest market power. This decrease in the slope coefficient may be attributed to the decrease in the French import price resulting in relatively higher fixed costs and reducing the share of the Israeli grower price in the French import price. 
The residuals of this cointegration regression enter the ECM as the ECT term as indicated by equation (2).

The ECM (equation) is estimated for each of the three exporters individually based on the COMPLETE data set comprising observations of all 7 marketing seasons accounting for the specified break point in the cointegration regression (Table 4).

Table 3: Estimated coefficients of the cointegration regression for the three exporters

\begin{tabular}{|c|c|c|c|c|}
\hline Coefficient & $\alpha_{01}$ & $\alpha_{11}$ & $\alpha_{02}$ & $\alpha_{12}$ \\
\hline Agrexco & -261.29 & 0.456 & -184.11 & 0.295 \\
\hline Mehadrin & -27.054 & 0.378 & -54.74 & 0.258 \\
\hline Tnuport & -1157.0 & 0.577 & 287.0 & 0.138 \\
\hline
\end{tabular}

Lag-lengths $\mathrm{K}_{1}$ and $\mathrm{K}_{2}$ are chosen according to the Bayesian Information Criteria (BIC). Laglength L accounts for autocorrelation, which is detected by the Breusch-Godfrey test. If the Breusch-Pagan test identifies the presence of heterogeneity, White's heteroscedasticity consistent standard error is estimated based on the heteroscedasticity corrected covariance matrix.

For the COMPLETE data series, the F-test confirms that the estimates of $\phi_{1}$ and $\phi_{2}$ for Agrexco are significantly different at the $1 \%$ significance level, suggesting strong asymmetry in the error correcting behavior. The identified asymmetry is of the kind that is beneficial to exporters but reduces growers' revenues. For example, when the import price falls, implying that the grower price lies above its long-run equilibrium level and squeezing Agrexco's margin, the grower price is reduced by $42.4 \%$ of this "error" in the next week. If, on the other hand, the import price increases, thus the grower price falls below its long-run equilibrium level and Agrexco's margin is stretched, the grower price does increase only by $8.3 \%$ in the next week. Though, results for the COMPLETE data series further suggest price transmission to be symmetric for Mehadrin and Tnuport since the estimated values for $\phi_{1}$ and $\phi_{2}$ for Mehadrin and Tnuport are found to be not significantly different. In addition, the observed contemporaneous price transmission is symmetric for Tnuport.

To test whether the exporters' price transmission behaviour may have changed, we estimate separate ECMs for the phase with heterogeneous grower prices in the first years after liberalization (SUBSET 1) and the subsequent phase with more homogeneous grower prices (SUBSET 2). Again, the break points in the individual cointegration regressions are accounted for. 
Table 4: Estimated ECM coefficients based on disaggregated data for the complete data set and data subsets

(Theoretical F-values are given for the $5 \%$ significance level; * indicates $1 \%$ significance level)

\begin{tabular}{|c|c|c|c|c|c|c|c|c|c|c|c|c|c|c|c|c|c|c|}
\hline \multirow[b]{3}{*}{ Coef./ test stat. } & \multicolumn{6}{|c|}{ COMPLETE } & \multicolumn{6}{|c|}{ SUBSET 1} & \multicolumn{6}{|c|}{ SUBSET 2} \\
\hline & \multicolumn{2}{|c|}{ Agrexco } & \multicolumn{2}{|c|}{ Mehadrin } & \multicolumn{2}{|c|}{ Tnuport } & \multicolumn{2}{|c|}{ Agrexco } & \multicolumn{2}{|c|}{ Mehadrin } & \multicolumn{2}{|c|}{ Tnuport } & \multicolumn{2}{|c|}{ Agrexco } & \multicolumn{2}{|c|}{ Mehadrin } & \multicolumn{2}{|c|}{ Tnuport } \\
\hline & $\begin{array}{l}\text { Estim. } \\
\text { value }\end{array}$ & $\begin{array}{l}\text { stand. } \\
\text { error } \\
(\mathrm{t}- \\
\text { value })\end{array}$ & $\begin{array}{l}\text { Estim. } \\
\text { value }\end{array}$ & $\begin{array}{c}\text { stand. } \\
\text { error } \\
(\mathrm{t}- \\
\text { value })\end{array}$ & $\begin{array}{l}\text { Estim. } \\
\text { value }\end{array}$ & $\begin{array}{c}\text { stand. } \\
\text { error } \\
(\mathrm{t}- \\
\text { value })\end{array}$ & $\begin{array}{l}\text { Estim. } \\
\text { value }\end{array}$ & $\begin{array}{l}\text { stand. } \\
\text { error } \\
(\mathrm{t}- \\
\text { value })\end{array}$ & $\begin{array}{l}\text { Estim. } \\
\text { value }\end{array}$ & $\begin{array}{l}\text { stand. } \\
\text { error } \\
(\mathrm{t}- \\
\text { value })\end{array}$ & $\begin{array}{l}\text { Estim. } \\
\text { value }\end{array}$ & $\begin{array}{c}\text { stand. } \\
\text { error } \\
(\mathrm{t}- \\
\text { value })\end{array}$ & $\begin{array}{l}\text { Estim. } \\
\text { value }\end{array}$ & $\begin{array}{c}\text { stand. } \\
\text { error } \\
(\mathrm{t}- \\
\text { value })\end{array}$ & $\begin{array}{l}\text { Estim. } \\
\text { value }\end{array}$ & $\begin{array}{l}\text { stand. } \\
\text { error } \\
(\mathrm{t}- \\
\text { value })\end{array}$ & $\begin{array}{l}\text { Estim. } \\
\text { value }\end{array}$ & $\begin{array}{c}\text { stand. } \\
\text { error } \\
(\mathrm{t}- \\
\text { value })\end{array}$ \\
\hline$\beta_{11}^{+}$ & $\mathrm{Na}$ & $\begin{array}{l}\mathrm{Na} \\
\mathrm{Na}\end{array}$ & $\mathrm{Na}$ & $\begin{array}{l}\mathrm{Na} \\
\mathrm{Na}\end{array}$ & 0.083 & $\begin{array}{c}0.045 \\
(1.861)\end{array}$ & 0.189 & $\begin{array}{c}0.069 \\
(2.742)\end{array}$ & 0.002 & $\begin{array}{c}0.138 \\
(0.017)\end{array}$ & $\mathrm{Na}$ & $\begin{array}{l}\mathrm{Na} \\
\mathrm{Na}\end{array}$ & $\mathrm{Na}$ & $\begin{array}{l}\mathrm{Na} \\
\mathrm{Na}\end{array}$ & $\mathrm{Na}$ & $\begin{array}{l}\mathrm{Na} \\
\mathrm{Na}\end{array}$ & 0.007 & $\begin{array}{c}0.044 \\
(0.157)\end{array}$ \\
\hline$\beta_{11}^{-}$ & $\mathrm{Na}$ & $\begin{array}{l}\mathrm{Na} \\
\mathrm{Na}\end{array}$ & $\mathrm{Na}$ & $\begin{array}{l}\mathrm{Na} \\
\mathrm{Na}\end{array}$ & 0.170 & $\begin{array}{c}0.121 \\
(1.400)\end{array}$ & 0.051 & $\begin{array}{c}0.085 \\
(0.603)\end{array}$ & 0.145 & $\begin{array}{c}0.078 \\
(1.871)\end{array}$ & $\mathrm{Na}$ & $\begin{array}{l}\mathrm{Na} \\
\mathrm{Na}\end{array}$ & $\mathrm{Na}$ & $\begin{array}{l}\mathrm{Na} \\
\mathrm{Na}\end{array}$ & $\mathrm{Na}$ & $\begin{array}{l}\mathrm{Na} \\
\mathrm{Na}\end{array}$ & 0.137 & $\begin{array}{c}0.137 \\
(0.038)\end{array}$ \\
\hline$\beta_{21}$ & 0.116 & $\begin{array}{c}0.078 \\
(1.486)\end{array}$ & $\mathrm{Na}$ & $\begin{array}{l}\mathrm{Na} \\
\mathrm{Na}\end{array}$ & $\mathrm{Na}$ & $\begin{array}{l}\mathrm{Na} \\
\mathrm{Na}\end{array}$ & $\mathrm{Na}$ & $\begin{array}{l}\mathrm{Na} \\
\mathrm{Na}\end{array}$ & $\mathrm{Na}$ & $\begin{array}{l}\mathrm{Na} \\
\mathrm{Na}\end{array}$ & $\mathrm{Na}$ & $\begin{array}{l}\mathrm{Na} \\
\mathrm{Na}\end{array}$ & 0.058 & $\begin{array}{c}0.076 \\
(0.755)\end{array}$ & $\mathrm{Na}$ & $\begin{array}{l}\mathrm{Na} \\
\mathrm{Na}\end{array}$ & 0.219 & $\begin{array}{c}0.096 \\
(2.286)\end{array}$ \\
\hline$\phi_{1}$ & -0.424 & $\begin{array}{c}0.105 \\
(-4.04)\end{array}$ & -0.062 & $\begin{array}{l}0.100 \\
(-0.62)\end{array}$ & -0.131 & $\begin{array}{l}0.078 \\
(-1.69)\end{array}$ & -0.438 & $\begin{array}{c}0.121 \\
(-3.63)\end{array}$ & -0.034 & $\begin{array}{c}0.087 \\
(-0.40)\end{array}$ & -0.180 & $\begin{array}{l}0.076 \\
(-2.38)\end{array}$ & -0.408 & $\begin{array}{c}0.184 \\
(-2.24)\end{array}$ & -0.012 & $\begin{array}{c}0.070 \\
(-0.17)\end{array}$ & 0.025 & $\begin{array}{c}0.084 \\
(0.297)\end{array}$ \\
\hline$\phi_{2}$ & -0.083 & $\begin{array}{c}0.035 \\
(-2.34)\end{array}$ & 0.032 & $\begin{array}{c}0.170 \\
(0.188)\end{array}$ & -0.014 & $\begin{array}{c}0.107 \\
(-0.13)\end{array}$ & -0.009 & $\begin{array}{l}0.089 \\
(-0.10)\end{array}$ & -0.061 & $\begin{array}{l}-0.061 \\
(-0.60)\end{array}$ & 0.258 & $\begin{array}{c}0.208 \\
(1.244)\end{array}$ & -0.106 & $\begin{array}{l}-0.047 \\
(-2.27)\end{array}$ & -0.061 & $\begin{array}{c}0.074 \\
(0.822)\end{array}$ & -0.063 & $\begin{array}{c}0.038 \\
(-0.16)\end{array}$ \\
\hline $\begin{array}{c}\text { Breusch-Godfrey } \\
\text { test } \\
\text { (p-value) }\end{array}$ & \multicolumn{2}{|c|}{0.101} & \multicolumn{2}{|c|}{0.959} & \multicolumn{2}{|c|}{0.528} & \multicolumn{2}{|c|}{0.053} & \multicolumn{2}{|c|}{0.801} & \multicolumn{2}{|c|}{0.443} & \multicolumn{2}{|c|}{0.069} & \multicolumn{2}{|c|}{0.981} & \multicolumn{2}{|c|}{0.266} \\
\hline $\begin{array}{l}\text { Breusch-Pagan test } \\
\text { (p-value) }\end{array}$ & \multicolumn{2}{|c|}{$<0.001$} & \multicolumn{2}{|c|}{$<0.001$} & \multicolumn{2}{|c|}{$<0.001$} & \multicolumn{2}{|c|}{0.006} & \multicolumn{2}{|c|}{0.019} & \multicolumn{2}{|c|}{0.329} & \multicolumn{2}{|c|}{0.005} & \multicolumn{2}{|c|}{0.371} & \multicolumn{2}{|c|}{0.163} \\
\hline $\begin{array}{c}\text { Empirical \& } \\
\text { theoretical F-value } \\
\text { (sym. contempor. } \\
\text { price transm.) } \\
\beta_{11}^{+}=\beta_{11}^{-}\end{array}$ & \multicolumn{2}{|c|}{$\mathrm{Na}$} & \multicolumn{2}{|c|}{$\mathrm{Na}$} & \multicolumn{2}{|c|}{$0.619<3.889$} & 1.476 & 3.939 & $0.714<$ & 3.939 & $\mathrm{~N}$ & & $\mathrm{~N}$ & & $\mathrm{~N}$ & & 3.918 & 3.938 \\
\hline $\begin{array}{c}\text { Empirical \& } \\
\text { theoretical F-value } \\
\text { (sym. error } \\
\text { correcting behav.) } \\
\phi_{1}=\phi_{2}\end{array}$ & 11.913 & $6.765^{*}$ & 1.352 & 3.889 & 1.127 & 3.889 & 6.728 & 3.939 & $0.714<$ & $3.939_{\mathrm{c}}$ & $3.940>$ & 3.939 & $1.942<$ & 3.934 & $0.513<$ & 3.935 & $0.827<$ & 3.938 \\
\hline
\end{tabular}


We find asymmetry in the error correcting behaviour for Agrexco and Tnuport in SUBSET 1. In particular, deviations from the long-run equilibrium are corrected faster if the grower price is above its long-run equilibrium level, but deviations are corrected slower if the grower price is below its equilibrium level.

In the case of Tnuport the estimated coefficient for $\phi_{2}$ is positive. This would indicate that if the grower price is below its equilibrium level, price adjustment implies that the grower price drops even more below its equilibrium level. Yet, this coefficient is not significantly different from zero.

Though, our results suggest that price transmission of Agrexco and Tnuport is symmetric in SUBSET 2. For Mehadrin, price transmission is found to be symmetric in SUBSET 1 as well as in SUBSET 2.

\subsection{Welfare implications}

The calculation of the welfare implications of asymmetric price transmission in the Israeli grapefruit export chain is confined to seasons 1991/92, 1992/93, 1993/94 and 1995/96 since asymmetry is found in SUBSET 1 only.

The estimated coefficients of the asymmetric ECM are utilized to calculate the grower price $p_{i t}^{a s}$ based on the specified type of asymmetric price transmission. The grower price in period $\mathrm{t}+1\left(p_{i(t+1)}^{a s}\right)$ is equal to the grower price in the previous period $\mathrm{t}\left(p_{i t}^{a s}\right)$ plus the changes in the grower price in period $\mathrm{t}+1$ :

$$
\text { (7) } \begin{aligned}
p_{i(t+1)}^{a s}=p_{i t}^{a s}+\sum_{n_{1}=1}^{K_{1}} \beta_{1 n_{1}}^{+} D_{1(t+1)}^{+} \Delta p_{j(t+1)-n_{1}+1} & +\sum_{n_{2}=1}^{K_{2}} \beta_{1 n_{2}}^{-} D_{1(t+1)}^{-} \Delta p_{j(t+1)-n_{2}+1}+\sum_{m=1}^{L} \beta_{2 m} \Delta p_{i(t+1)-m} \\
& +\phi_{1} D_{2(t+1)}^{+} E C T_{(t+1)}+\phi_{2} D_{2(t+1)}^{-} E C T_{(t+1)}
\end{aligned}
$$

For Agrexco we have $K_{1}=K_{2}=L=1$ and for Tnuport $K_{1}=K_{2}=L=0$. For Tnuport we assume $\phi_{2}=0$ in the estimation of $p_{i(t+1)}^{a s}$ since the estimated coefficient for $\phi_{2}$ is positive and not statistically significant (more details are given in the previous section).

To calculate the grower price $\left(p_{i(t+1)}^{s}\right)$ under the assumption of symmetric price transmission, we assume that the speed of adjustment for positive and negative price changes is equal $\left(\phi_{1}=\phi_{2}\right)$. The estimated coefficient for $\phi_{1}$, which exceeds $\phi_{2}$, is utilized for Agrexco and Tnuport, on the assumption that if such rapid transmission is possible in one direction, equally rapid transmission should be possible in the other as well. The quantitative effect of price asymmetry $\left(q e^{a s}\right.$ ) for one season with $\mathrm{t}=\mathrm{v}$ and $\mathrm{t}=\mathrm{w}$ corresponding to the beginning and the end of a season, respectively, equals: 
(8) $q e^{a s}=\sum_{t=v}^{t=w}\left(p_{i t}^{s}-p_{i t}^{a s}\right) * q_{i t}$

with $q_{i t}$ equal to the amount of products exported at time period $t$.

The estimated values for the growers' losses are presented in Table 5. For Agrexco, the seasonal losses vary between about 5,000 NIS and 330,000 NIS, corresponding to between $0.17 \%$ of seasonal revenues in $1995 / 96$ and $3.95 \%$ of seasonal revenues in 1992/93. For Tnuport the seasonal losses add up to between about 52,000 NIS and 580,000 NIS. The losses account for between $0.36 \%$ and $3.50 \%$ of the seasonal revenues and are highest in season 1991/92.

As growers' profits are presumably only a small proportion of their total revenues, the loss in grower profits due to asymmetry is likely to be quite important.

Table 5: Growers' losses due to asymmetry in price transmission

\begin{tabular}{|c|c|c|c|c|c|}
\hline & $\begin{array}{c}\text { Growers' } \\
\text { losses }\end{array}$ & $\mathbf{1 9 9 1 / 9 2}$ & $\mathbf{1 9 9 2 / 9 3}$ & $\mathbf{1 9 9 3 / 9 4}$ & $\mathbf{1 9 9 5 / 9 6}$ \\
\hline \multirow{2}{*}{ Agrexco } & in NIS & 17,157 & 331,530 & 23,649 & 5,237 \\
\cline { 2 - 6 } & $\begin{array}{c}\text { in \% of } \\
\text { revenue }\end{array}$ & $0.421 \%$ & $3.945 \%$ & $0.359 \%$ & $0.167 \%$ \\
\hline \multirow{2}{*}{ Tnuport } & in NIS & 579,620 & 55,060 & 158,376 & 52,164 \\
\cline { 2 - 6 } & $\begin{array}{c}\text { in \% of } \\
\text { revenue }\end{array}$ & $3.496 \%$ & $0.358 \%$ & $1.480 \%$ & $1.553 \%$ \\
\hline
\end{tabular}

\section{Conclusions}

The analyses of price transmission based on firm-specific grower price data suggests that price transmission behaviour of Israelis citrus exporters changed in the post-liberalization period after 1991. We attribute those changes to two external factors, i.e. the government market intervention in favour of the citrus growers, and the substantial decrease in the French import price. The latter has reduced the scope of the Israeli exporters to capture an extra margin. More precisely, this has decreased the difference between the grapefruit growers' reservation price and the maximum import price at which EU importers are willing to buy. This implies that the difference between the three exporters' grower prices has decreased and exporters stop to transmit prices asymmetrically. 
In our model approach we distinguish a period with more volatile grower prices from a phase with more homogeneous pricing. We find that the two Israeli exporters Agrexco and Tnuport have transmitted grapefruit price changes in the EU import market asymmetrically to Israeli citrus growers in the phase with heterogeneous pricing in the first years after liberalization, whereas Mehadrin has transmitted prices symmetrically. Mehadrin might have less motivation for exerting market power over the citrus growers since it partially retains the citrus produce from its own citrus plantations.

However, our results suggest that price transmission of all three exporters was symmetric in the subsequent phase (second half of the 1990s) characterized by more homogeneous pricing. Thus, the efficiency of Israel's international citrus marketing channel improved in the aftermath of liberalization. It is highly probable that the government's imposition of a minimum price agreement on the grapefruit sector effective in the seasons 1994/95 and partially $95 / 96$ at least contributed to this development.

The identified asymmetry was beneficial to exporters and damaging to growers by increasing and decreasing profits, respectively. This supports the assumption that the detected asymmetry in price transmission is caused by the abuse of market power by the exporters.

We also find that the specified asymmetry in price transmission is economically significant providing further evidence that the observed asymmetry in price transmission was caused by Israeli exporters exerting market power over Israeli citrus growers. Our results indicate that growers' seasonal losses resulting from asymmetric price transmission amounted to as much as $4.0 \%$ and $3.9 \%$ of citrus growers' total revenues delivering to Agrexco and Tnuport, respectively, and hence presumably a much larger share of their profits.

The findings of this study are in line with the results of former studies on the effects of a market liberalization confirming that there is a high risk that market power is exerted by the newly established export companies.

As an area for future research, price transmission in the international FFV supply chain, particularly between export prices in markets of developed countries and grower prices obtained by small farmers in developing countries under different supply chain governance structures should be investigated. As pointed out above, although asymmetry in price transmission might result from a bundle of different causes, in the context of international trade in FFV grower prices are generally determined ex-post due to the consignment system, thus all causes of asymmetric price transmission related to menu and adjustment costs are not relevant. Therefore, positive asymmetry in price transmission identified in this context may be interpreted as evidence of market power. 
This kind of data analysis faces particular challenges regarding data requirements which have to be taken into account to avoid measurement error:

First, we used an aggregated price as the EU import price for grapefruits. Of course, different exporters might achieve different prices for their produce in the same market, particularly since the quality of fresh produce is very vulnerable and is determined by e.g. maturity of the fruits at the point of time of picking or time elapsed to move the produce from the farm gate to the ship. Therefore, the higher the variability in product quality of different growers of one country of a particular kind of product, the higher are the distortions resulting from utilizing aggregated import prices. This might vary between countries and also depend on the degree of vulnerability of the produce. Thus, analyses on products originating in countries which exhibit low variability of quality should be preferred.

Also, to exactly measure the weekly average export price achieved by an exporter for grapefruits, export price data for all markets the exporter delivered to would be required. Yet, this analysis is based on import price data of the EU market (France) only. The more diverse the export markets a particular kind of product of a country is exported to, the more data is required to exactly measure the average export price achieved by exporters. Therefore, data requirements for exporters of a country concentrating on one or a few export markets are lower and thus more suitable for this kind of analysis.

Finally, frequency of the data set has to be chosen adequately, depending e.g. on how often fresh products are delivered from one country to a particular country's market. High frequency price data might be gathered in a telephone survey on the primary importers of this product of one country.

\section{References}

Aguiar, D. And J. Santana (2002): Asymmetry in Farm to Retail Price Transmission: Evidence from Brazil, in: Agribusiness, Vol. 18(1): 37-48.

BAKUCS, L.Z. AND I. FerTÖ (2005): Marketing Margins and Price Transmission on the Hungarian Pork Market, in: Brosig, S. AND H. HockMANN (eds.): How effective is the Invisible Hand? Agricultural and Food Markets in Central and Eastern Europe. Studies on the Agricultural and Food Sector in Central and Eastern Europe, IAMO, Vol. 31: 134-149.

Banerjee, A., J. Dolado, J. Galbraith AND D. Hendry (1993): Co-integration, Error Correction, and the Econometric Analysis of Non-Stationary Data, Oxford University Press, Oxford.

BARASSI, M.R. AND A.M.R. TAYLOR (2004): A test for Change in the Cointegrating Rank (mimeo, Birmingham: University of Birmigham, 2004). 
BArassi, M.R. AND A. Ghoshray (2007): Structural Change and Long-run Relationships between US and EU Wheat Export Prices, Journal of Agricultural Economics, Vol. 58(1): 7690 .

Brooker, J., D. EAstwood, B. CARVER And M. Gray (1997): Fresh Vegetable Price Linkage between Grower/Shippers, Wholesalers, and Retailers, in: Journal of Food Distribution Research, Vol.28 (1): 54-61.

Central Bureau of Statistics Israel (CBS): Price Indices-Shipping, http://www.cbs.gov.il/sidfilee.cgi

C.L.A.M.: Les Exportacions d'Agrumes du Bassin Mediterraneen, various years.

VON CRAMON-TAUBADEL, S. (1998): Estimating asymmetric price transmission with the error correction representation: An application to the German pork market, in: European Review of Agricultural Economics, Vol. 25: 1-18.

von Cramon-Taubadel, S., J.P. Loy And J. Meyer (2006): The Impact of Cross-Sectional Data Aggregation on the Measurement of Vertical Price Transmission: An Experiment with German Food Prices, in: Agribusiness, Vol. 22 (4): 1-18.

DiCKEY, D.A. AND W.A. FULLER (1981): Likelihood ratio statistics for autoregressive time series with a unit root, in: Econometrica, Vol 49(4): 1057-1072.

ENGLE, R.F. AND C.W.J. GRANGER (1987): Cointegration and error correction: Representation, estimation and testing, in: Econometrica, Vol. 49: 251-276.

Goetz, L. AND H. GReTHE (2007): The Relevance of the EU Entry Price System for Imports of Fresh Fruits and Vegetables, IATRC Working Paper 07-03.

Girapunthong, N., J. VAnSickle And A. Renwick, (2003): Price Asymmetry in the United States Fresh Tomato Market, in: Journal of Food Distribution Research, Vol.34 (3): 51-59.

GRANGER, C.W.J. AND A.A. WeISs (1983): Time Series Analysis of Error-Correction Models, in: Studies in Econometrics, Time Series, and Multivariate Statistics, New York, Academic Press: 255-278.

GREGORY, A.W. AND B.E. HANSEN (1996): Residual-based tests for cointegration in models with regime shifts, in: Journal of Econometrics, Vol. 70: 99-126.

Guillotreau, P., L. Le Gre And M. Simioni (2005): Price-Cost Margins and Structural Change: Sub-Contracting within the Salmon Marekting Chain, Review of Development Economics, Vol. 9(4): 581-597.

Hamilton, J. (1994): Time Series Analysis, Princeton University Press, Princeton, New Jersey.

HouCK, J.P. (1977): An Approach to specifying and estimating nonreversible Functions, American Journal of Agricultural Economics, Vol. 59: 570-572.

KaCHEL, Y. (2003): The Influence of Industry Structure on Performance: The Case of the Israeli Citrus Industry, PhD Thesis, Hebrew University of Jerusalem, Department of Agricultural Economics, Israel.

KwiatKowski, D., P.C.P. Phillips, P. Schmidt And Y. ShIn (1992): Testing the Null Hypothesis of Stationarity against the Alternative of a Unit Root, in: Journal of Econometrics, Vol 54: 159-178.

Lloyd T., S. McCorriston, C. Morgan And A. Rayer (2006): Food scares, market power and price transmission: the UK BSE crisis, European Review of Agricultural Economics, Vol. 33(2): 119-147. 
Lloyd, T. AND W. Morgan (2007): Market Power in UK Food Retailing, EuroChoices 6(3): $22-29$.

MAther, C. AND S. GReEnBerg (2003): Market Liberalisation in Post-Apartheid South Africa: the Restructuring of Citrus Exports after Deregulation, Journal of Southern African Studies, Vol. 29(2): 393-412.

McCorriston, S., C.W. Morgan And A.J. Rayner (1998): Processing Technology, Market Power and Price Transmission, Journal of Agricultural Economics, Vol. 49(2): 185-201.

McCorriston, S., C.W. Morgan AND A.J. RAYner (2001): Price transmission: the interaction between market power and returns to scale, European Review of Agricultural Economics, Vol. 28(2): 143-159.

MCMillan, M., D. RODRIK, K.H.Welch (2002): When economic reform goes wrong: cashews in Mozambique. NBER Working Paper 9117, NBER, Cambridge, M.A.

MEYer, J. AND VON S. CRAMON-TAUBADEl (2004): Asymmetric price transmission: A survey, in: Journal of Agricultural Economics, Vol. 55: 581-611.

Parrott, S., D. Eastwood AND J. Brooker (2001): Testing for Symmetry in Price Transmission: An Extension of the Shiller Lag Structure with an Application to Fresh Tomatoes, in: Journal of Agribusiness, Vol. 19(1): 35-49.

Pesaran, M.H., Y. ShIN AND R. SMith (2001): Bounds Testing Approaches to the Analysis of Level Relationships, in: Journal of Applied Econometrics, Vol. 16: 289-326.

Pick, D., J. KARRENBRock And H. CARMAN (1990): Price Asymmetry and Marketing Margin Behaviour: An Example for California-Arizona Citrus, in: Agribusiness, Vol. 6(1): 75-84.

RAPSOMANikis, G., D. HAllam AND P. CONFORTI (2006): Market integration and price transmission in selected food and cash crop markets of developing countries: review and applications, in: SARRIS, A. AND D. HALlAM: Agricultural Commodity Markets and Trade, Edward Elgar, Cheltenham, UK: 187-217.

SeXton, R.J., I. Sheldon, S. McCorriston AND H. WANG (2007): Agricultural trade liberalization and economic development: the role of downstream market power, Agricultural Economics, Vol. 36: 253-270.

TIFFIN, R. AND P.J. DAWSON (2000): Structural breaks, cointegration and the farm-retail price spread for lamb, Applied Economics, Vol. 32: 1281-1286.

WARD, R.W. (1982): Asymmetry in Retail, Wholesale, and Shipping Point Pricing for Fresh Vegetables, in: American Journal of Agricultural Economics, Vol. 64(2): 205-212.

Weldegebriel, H. (2004): Imperfect Price Transmission: Is Market Power Really to Blame?, Journal of Agricultural Economics, Vol. 55(1): 101-114.

Wilcox, M.D. And ABbotT, P.C. (2004): Market Power and Structural Adjustment: The Case of West African Cocoa Market Liberalization, Selected Paper AAEA Annual Meeting, Denver, Colorado, August 1-4, USA.

Willett, L., M. HANSMIRE AND J. Bernard (1997): Asymmetric Price Response Behaviour of Red Delicious Apples, in: Agribusiness, Vol. 13(6): 649-658. 
7 Threshold Adjustment and/or Threshold Cointegration? An Application to the German Apple Market

jointly with Stephan von Cramon-Taubadel and Emma Stephens 


\title{
Threshold adjustment and/or threshold cointegration?
}

\section{An application to the German apple market}

\author{
Linde Goetz*, Stephan von Cramon-Taubadel* and Emma Stephens** \\ *Department of Agricultural Economics and Rural Development, University of Goettingen, Germany \\ lgoetz@uni-goettingen.de, scramon@uni-goettingen.de \\ ** Pitzer College, USA \\ emma stephens@pitzer.edu
}

We are grateful to Heribert Tintinger of the Bundesanstalt für Landwirtschaft und Ernaehrung (Bonn) for making data on apple trade on German wholesale markets available. Linde Goetz gratefully acknowledges financial support by the Schaumann-Stiftung. Work leading to this paper took place while Stephan von Cramon was a Fulbright Scholar visiting the Department of Applied Economics and Management of Cornell University, where Christopher Barrett provided many important ideas and suggestions. The usual disclaimer applies.

\begin{abstract}
We propose a three-step procedure to estimate a regime-dependent vector error correction model (VECM). In this model, not only the short-run adjustment process towards equilibrium is non-linear, as in threshold VECM and Markov switching VECM frameworks, but the longrun equilibrium relationship itself can also display threshold-type non-linearity. The proposed approach is unique in explicitly testing the null hypothesis of linear cointegration against the alternative of threshold cointegration based on the Gonzalo and Pitarakis (2006) test. The model is applied to apple price data on wholesale markets in Hamburg and Munich, using the share of domestic apples in total wholesale trade as the threshold variable. We identify four price transmission regimes characterized by different equilibrium relationships and short-run adjustment processes. This proposed approach is particularly suitable for capturing irregular seasonal threshold effects in price transmission typical for fresh fruits and vegetables.
\end{abstract}

\section{Introduction}

Applications of the threshold vector error correction model (TVECM) to analyze price transmission assume that prices are linked by a constant long-run equilibrium relationship, while allowing for threshold or switching effects in the short-run adjustment process towards this equilibrium. The TVECM (e.g. Goodwin and Piggott, 2001; Meyer, 2004; Serra, Gil and Goodwin, 2006; Balcombe, Bailey and Brooks, 2007) distinguishes between regimes depending on whether the deviation of prices from their long-run equilibrium, in other words the error correction term (ECT), is above or below a threshold value. For example, if the ECT exceeds a specific threshold which is determined by the size of the transaction costs, then more rapid adjustment to the constant long-run equilibrium is expected than if the ECT is smaller than the threshold value, in which case adjustment might even cease altogether. In the Markov-switching VECM (e.g. Bruemmer et al., 2008), shifts between different adjustment regimes are triggered by unobservable state variables. Both models maintain the hypothesis of a linear long-run equilibrium relationship. This may not always be justifiable. For example, if 
product qualities or the direction of trade between two markets changes, then the long-run relationship between the prices on these markets may change as well. Failing to account for non-linearity in the long-run relationship can lead to misleading estimates of this relationship and the adjustment processes that lead to it.

In this paper we propose a three-step procedure to estimate a regime-dependent VECM. In this model, not only the short-run adjustment process towards equilibrium, but also the longrun equilibrium relationship itself can display threshold-type non-linearity, as a function of the size of a stationary variable with respect to a threshold value. The proposed approach is unique in explicitly testing the null hypothesis of linear cointegration against the alternative of threshold cointegration based on a test proposed by Gonzalo and Pitarakis (2006). As Gonzalo and Pitarakis (2006) point out, the use of the term 'threshold cointegration' in connection with threshold VECMs is misleading because in a threshold VECM it is actually the adjustment or error correction that is subject to threshold effects, while the cointegration itself (i.e. the longrun relationship) is assumed to be constant and linear.

We apply this procedure to data on daily apple prices on wholesale markets in Hamburg and Munich. Due to substantial seasonal variation in supply quantities, prices and price differences, we hypothesize that the equilibrium relationship between prices in Hamburg and Munich is subject to threshold effects, with the share of German as opposed to imported apples in total wholesale trade acting as the threshold variable.

We proceed as follows. Chapter 2 contains a literature review; chapter 3 presents the Gonzalo and Pitarakis (2006) test and a three step procedure based on this test to study threshold cointegration in a regime-specific VECM. Chapter 4 describes the seasonal characteristics of supply and price determination on wholesale apple markets in Hamburg and Munich. Estimation and results are presented in chapter 5, and chapter 6 concludes.

\section{Literature review}

The notion that price series and the relationships between them can display structural breaks and other types of non-linear behaviour has received considerable attention in the recent literature $^{34}$. While most studies focus on non-linear adjustment to constant, linear long-run relationships between prices, some also account for structural breaks in long-run equilibrium relationships. Baffes and Gardner (2003) consider a structural break in their analysis of the impact of policy reforms on the transmission of world price changes to domestic markets for

\footnotetext{
${ }^{34}$ WANG AND TOMEK (2008) discuss the relationship between structural breaks and unit root tests in agricutural price data.
} 
31 price pairs. Their test for a structural break at a known point in time is based on the null hypothesis that the nominal rate of protection in the pre-reform period differs significantly from that in the post-period. In cases in which the null hypothesis is accepted, the sample is split into two sub-samples for which separate VECMs are estimated.

Dercon (1995) allows for two known break points due to market liberalisation and war in a cointegration regression by including two dummy variables tied to the slope coefficient. Cointegration is confirmed by the Engle-Granger residual-based test, and the sample is split into three sub-samples for which individual VECMs are estimated. Bakucs and Fertö (2006), Goetz and von Cramon-Taubadel (2006), Guillotreau, Grel and Simioni (2005) and Tiffin and Dawson (2000) all employ the Gregory-Hansen test (1996) ${ }^{35}$ to test for an unknown breakpoint in cointegration regressions of price transmission. Bakucs and Fertö (2006) identify a break in the intercept and a linear trend in the long-run equilibrium regression, and use this to derive a corresponding ECT term for inclusion in the subsequent estimation of an ECM for Hungarian pork prices. In Goetz and von Cramon-Taubadel (2006), breaks are found in the intercept as well as the slope coefficient of the cointegration regression and are attributed to a substantial increase in transport costs. Based on these results, the authors estimate separate ECMs for a volatile and a calm price phase on the market in question (Israeli grapefruit exports to the EU). Similarly, Guillotreau, Grel and Simioni (2005) identify a break in the intercept as well as the slope coefficient of the cointegration regression between the Norwegian export price for fresh salmon and the retail price in supermarkets. They attribute this break to a shift in product forms concurrent with the creation of new marketing organizations. Corresponding separate ECMs are estimated by the Engle and Granger twostep procedure. Finally, Tiffin and Dawson (2000) detect a structural break in the cointegration regression between producer and retail prices in the UK. They attribute this break to a change in the subsidization policy on this market, and include a corresponding dummy variable in the unrestricted VECM estimated by the Johansen (1988) procedure.

Sanjuan and Dawson (2003) analyze vertical price transmission in the UK market for beef, lamb and pork between 1986 and 2000, accounting for the influence of the BSE crisis in 1996. They analyze the long-run equilibrium relationship using the cointegration procedure

\footnotetext{
${ }^{35}$ The GREGORY-HANSEN (1996) test is conducted within the framework of the ENGLE AND GRANGER residualbased cointegration test. The null hypothesis of no cointegration is tested against the alternative of a more general type of cointegration in which the cointegration regression is allowed to change at a single unknown point of time. The regime shift can occur regarding 1) the level, 2) the level with a time trend 3) the level as well as the slope of the cointegration regression. The test proceeds as follows: First, the type of regime shift is specified. The resulting model is then estimated for all possible breakpoints and the residuals are tested for the existence of a unit root by an ADF-test. The true structural break corresponds to the cointegration regression with the break point for which the residuals do not have a unit root and the null hypothesis of no cointegration can be rejected.
} 
proposed by Johansen, Mosconi and Nielsen $(2000)^{36}$ and confirm the existence of a structural break for beef but not for lamb or pork.

Barassi and Ghoshray (2007) account for a possible policy-induced structural break in price transmission between EU and US wheat export prices. They employ a testing procedure by Barassi and Taylor (2004) for a change in the cointegration rank with an unknown breakpoint, treating the time of the structural change as endogenous. One break-point corresponding to the 1992 reform of the EU's Common Agricultural Policy (CAP) is identified in the cointegration rank. The sample is therefore split into two sub-samples, and cointegration is tested by the Johansen procedure in each sub-sample individually. Results suggest that there was no long-run relationship between EU and US wheat export prices prior to the CAP reform, but that such a relationship does exist in the period thereafter.

The approach we follow in this paper differs from all of these approaches in that we do not test for a structural break in the long-run price transmission relationship but rather for threshold-type non-linearity in this relationship using a test developed by Gonzalo and Pitarakis (2006). As outlined below, this type of non-linearity allows the long-run relationship to move back and forth between regimes as a function of a threshold variable, rather than hypothesising a one-off break in this relationship. This is an appealing model in settings, such as the one explored below (spatial trade in apples), in which price transmission is hypothesised to be seasonal, but the timing and duration of seasons differs from year to year depending on weather and harvests in the regions that are linked by trade. In such settings, the use of seasonal dummy variables to account for seasonal variation in the equilibrium relationship (e.g. Chavas and Mehta, 2004) might not be sufficiently flexible.

\section{Methods}

\subsection{Test on threshold effects in cointegration}

Gonzalo and Pitarakis (2006) propose a test of the null hypothesis of linear cointegration:

$$
y_{t}=\boldsymbol{\beta}^{\prime} \mathbf{x}_{t}+u_{t}
$$

against the alternative hypothesis of cointegration with threshold effects:

(2) $y_{t}=\boldsymbol{\beta}^{\prime} \mathbf{x}_{t}+\lambda^{\prime} \mathbf{x}_{t} I\left(q_{t-d}>\gamma\right)+u_{t}$

with $\mathbf{x}_{t}=\mathbf{x}_{t-1}+\mathbf{v}_{t}$,

\footnotetext{
${ }^{36}$ This test is a generalization of the JOHANSEN (1988) test for cointegration which allows for up to two structural breaks in the cointegration regression at pre-specified points of time. The main difference to the JOHANSEN (1988) test is that different critical values apply.
} 
where $u_{t}$ and $v_{t}$ are scalar and p-vector valued stationary disturbance terms respectively, $q_{t-d}$ with $d \geq 1$ is a stationary threshold variable lagged by d periods, and $I\left(q_{t-d}>\gamma\right)$ is an indicator function that equals one if $q_{t-d}>\gamma$, and zero otherwise.

Gonzalo and Pitarakis (2006) propose a supLM test based on the following statistic:

$$
L M_{T}(\gamma)=\frac{1}{\tilde{\sigma}_{0}^{2}} \mathbf{u}^{\prime} \mathbf{M} \mathbf{X}_{\gamma}\left(\mathbf{X}_{\gamma}^{\prime} \mathbf{M} \mathbf{X}_{\gamma}\right)^{-1} \mathbf{X}_{\gamma}^{\prime} \mathbf{M u}
$$

where $\mathbf{M}=\mathbf{I}-\mathbf{X}\left(\mathbf{X}^{\prime} \mathbf{X}\right)^{-\mathbf{1}} \mathbf{X}^{\prime}, \mathbf{X}$ stacks all values of $\mathbf{x}_{t}$ in the linear model (1), and ${ }^{\mathbf{X}_{\gamma}}$ stacks the values of $\mathbf{x}_{t}$ corresponding to the criterion $q_{t}>\gamma$ in the non-linear model (2). T is the length of the full sample, $\mathrm{u}$ is the residual, and $\tilde{\sigma}_{0}^{2}$ is the residual variance of the linear model (1).

The LM test statistic $L M_{T}(\gamma)$ is calculated for all possible values of the threshold variable $q_{t}$. A trimming parameter is employed to ensure a minimum number of observations on each side of the threshold. The supLM test statistic is given by

$$
\sup L M=\sup _{\gamma \in \Gamma} L M_{T}(\lambda)
$$

Gonzalo and Pitarakis (2006) explore the behaviour of this statistic in Monte Carlo experiments under a variety of assumptions regarding the covariance between $\mathrm{v}$ and $\mathrm{u}$ and the endogeneity of the threshold variable q. They find that critical values are robust to changes in these assumptions and closely resemble critical values tabulated by Andrews (1993).

\subsection{A three-step procedure for estimating the threshold cointegration model}

We propose the following three-step procedure to estimate a regime-specific VECM which includes non-linearities not only in the short-run and equilibrium adjustment process but also in the long-run equilibrium relationship between prices in question.

First, since the test for threshold cointegration by Gonzalo and Pitarakis (2006) requires that the time series data be integrated of order 1 , we determine the order of integration of the data series by conducting unit root tests.

Second, we test the null hypothesis of linear cointegration

$$
y_{t}=\alpha_{0}+\alpha_{1} * x_{t}+u_{t}
$$

against the alternative hypothesis of threshold cointegration: 
(6)

$$
y_{t}=\left(\alpha_{0}+\alpha_{1}{ }^{*} x_{t}\right)+\left(\lambda_{0}+\lambda_{1} * x_{t}\right) I\left(q_{t-d}>\gamma\right)+u_{t}
$$

utilizing the supLM test proposed by Gonzalo and Pitarakis (2006).

Third, we estimate an unrestricted, regime-specific ECM by including dummy variables defined by the indicator function $I\left(q_{t-d}>\gamma\right)$ corresponding to the threshold determined by the supLM test. This ECM takes the form:

$$
\Delta y_{t}=\beta_{0}+\delta_{0} * I\left(q_{t-d}>\gamma\right)+\sum_{m=1}^{K}\left(\beta_{1 m} \Delta x_{t-m+1}+\delta_{1 m} \Delta x_{t-m+1} * I\left(q_{t-d}>\gamma\right)\right)
$$

$$
+\sum_{n=1}^{L}\left(\beta_{2 n} \Delta y_{t-n}+\delta_{2 m} * \Delta y_{t-n} * I\left(q_{t-d}>\gamma\right)\right)+\beta_{3} * y_{t-1}+\delta_{3} * y_{t-1} * I\left(q_{t-d}>\gamma\right)+\beta_{4} * x_{t-1}+\delta_{4} * x_{t-1} * I\left(q_{t-d}>\gamma\right)+\varepsilon_{t}
$$

The regime-dependent cointegration vector can be retrieved from equation (7) as:

(8) $\alpha_{0}=-\left(\beta_{0}+\delta_{0} * I\left(q_{t-d}>\gamma\right)\right) /\left(\beta_{3}+\delta_{3} * I\left(q_{t-d}>\gamma\right)\right.$ and

(9) $\alpha_{1}=-\left(\beta_{4}+\delta_{4} * I\left(q_{t-d}>\gamma\right)\right) /\left(\beta_{3}+\delta_{3} * I\left(q_{t-d}>\gamma\right)\right.$.

\section{Application and data: the German wholesale markets for apples}

The procedure outlined above is applied to spatial price transmission between wholesale prices for apples in Hamburg and Munich, Germany. The wholesale apple markets in Hamburg and Munich are the largest in Germany, together accounting for $42 \%$ of all apples traded on the five largest German wholesale markets between 2003 and $2006^{37}$. We utilize 942 daily ${ }^{38}$ prices for German apples on wholesale markets in Munich and Hamburg between 2003 and $2006^{39}$ (Figure 1).

About $60 \%$ of the apples produced in Germany are grown in the two largest apple growing areas: Niederelbe $(8,840 \mathrm{ha})$, which is close (roughly $50 \mathrm{~km}$ ) to the wholesale market in Hamburg; and Bodenseegebiet (7,000 ha), which is somewhat less proximate to the wholesale market in Munich (roughly $250 \mathrm{~km}$ ). German apples are stored in large warehouses and can be supplied year-round by growers to wholesale markets. However, the supply of German apples on the wholesale markets in Hamburg and Munich is characterized by substantial seasonal variation in 1) quantities, 2) prices and 3) price differences.

\footnotetext{
${ }^{37}$ The other large wholesale markets are in Berlin, Cologne and Frankfurt.

${ }^{38}$ High frequency data is decisive for investigating fresh fruit and vegetables due to the perishability and seasonality of these products.

${ }^{39}$ The apple prices are trade volume-weighted averages of the prices of different varieties of apples.
} 
Figure 1: Prices of German apples on wholesale markets in Hamburg and Munich, 2003-2006

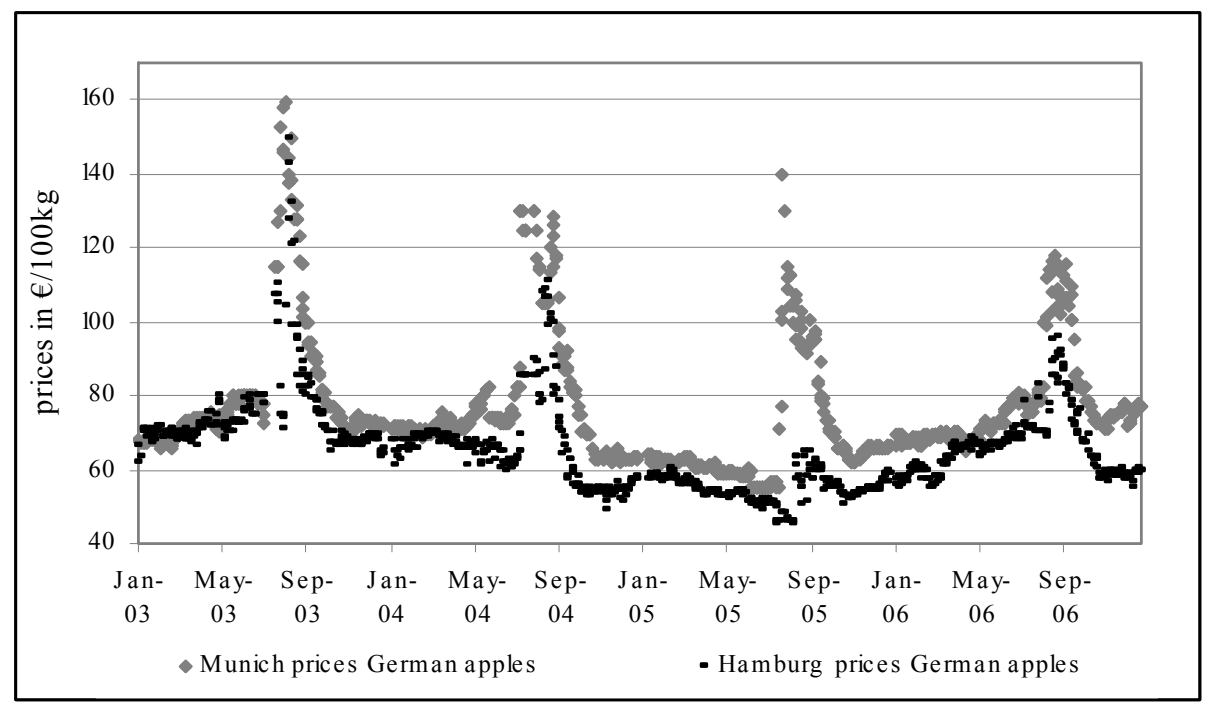

Data source: BLE

First, the daily share of German apples in all apples traded on the wholesale markets in Hamburg and Munich varies seasonally between 1\% and 60\% (Figure 2). In addition to German apples, imports from Italy provide another ,domestic' (i.e. intra-EU) source of apples that is roughly synchronised with German supply and accounts for up to $66 \%$ of all the apples traded on wholesale markets. Apple supply from these northern hemisphere countries is continuously high during the winter months, and decreases in spring until summer. At this time, the supply of apples originating in southern hemisphere countries (Argentina, Brazil, Chile, New Zealand, South Africa and Uruguay) increases, peaking at up to $90 \%$ of daily wholesale apple trade in early summer. When newly harvested German

Figure 2: Prices and share of apples originating in Germany and southern hemisphere (SH) countries represented by New Zealand of all apples traded in Hamburg and Munich

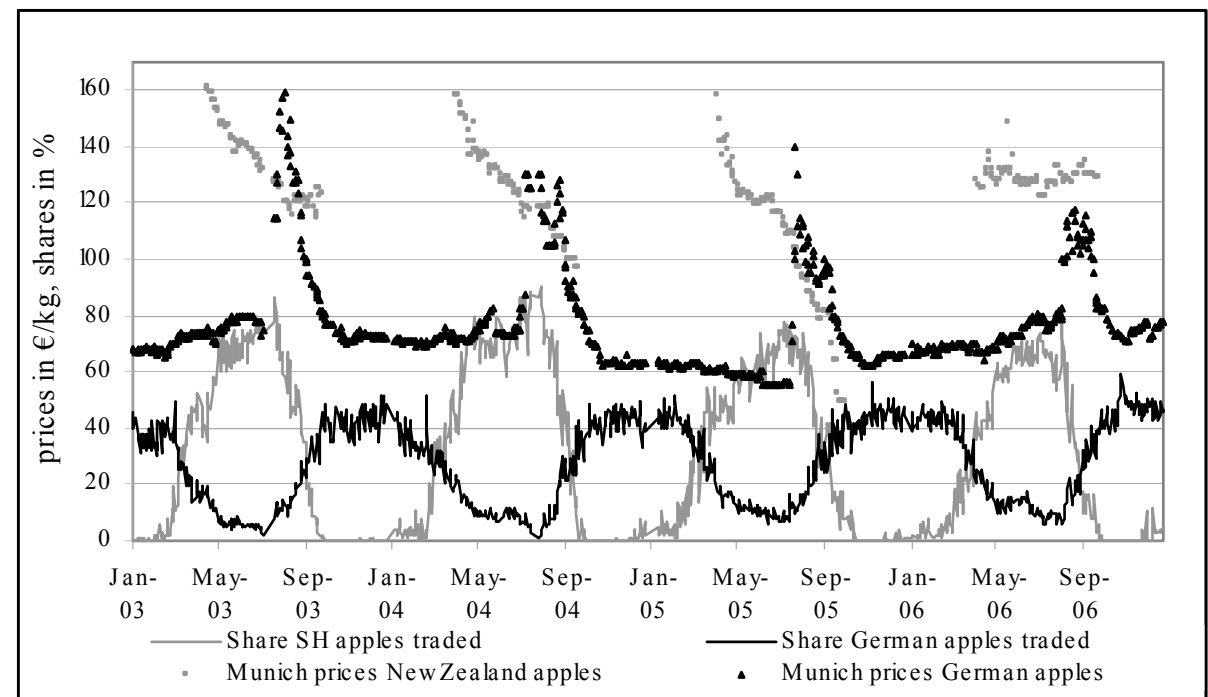

Data source: BLE 
and Italian apples enter the market in late summer, the share of German apples traded increases steadily and the share of southern hemisphere apples drops sharply until they are driven out of the market in the fall. In the course of an average year, apples grown in Germany, Italy and southern hemisphere countries account for roughly $90 \%$ of all apples traded on wholesale markets in Hamburg and Munich.

Second, the price of German apples is highest when newly harvested apples become available in late summer. Thereafter, prices drop continuously during the fall harvest, and remain almost constant during winter until spring when apples are sold from storage. In late spring, when apples from southern hemisphere countries reach a substantial market share, German apple prices slightly increase or decrease depending on the quantity and quality of southern hemisphere apples supplied. Similarly, prices of southern hemisphere apples are highest at the beginning of their season in spring, when they enter the market as newly harvested produce. At this time the price of southern hemisphere apples may exceed the price of German stored apples by up to $100 \%$. Thereafter, prices of southern hemisphere apples drop continuously until the end of the season in fall.

Third, prices differ between wholesale markets in Germany. Figure 1 illustrates that the price level is higher in Munich than in Hamburg. The average difference amounts to $14 \%$, but it varies, being relatively low and stable in the winter/spring months, and higher and more variable in late summer, when the share of German apples traded is low and newly harvested apples enter the market (Figure 3). Traders report that the Munich market demands higher

Figure 3: Price difference between apple prices in Hamburg and Munich (in \% of Hamburg price) and share of German apples in total daily trade

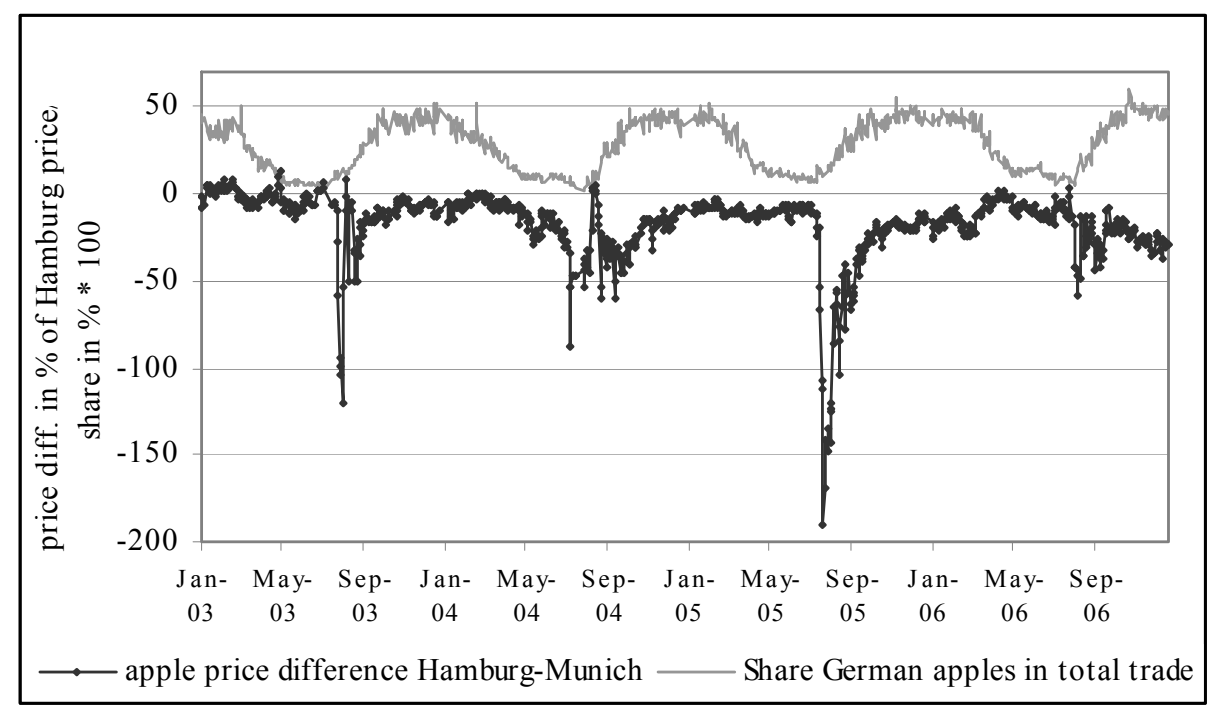

Data source: BLE; own calculations 
quality than Hamburg, which explains the higher average prices in Munich. This is especially apparent in August/September when the first new-harvest domestic apples appear on the market and command premium prices. Furthermore, the closer proximity of the Hamburg market to the nearest production region in Germany leads to a lower transport cost component in apples prices there. Traders report that transport costs from the growing area to the wholesale market account for between $4 \%-7 \%$ of the wholesale price in Hamburg compared with $6 \%-9 \%$ in Munich.

Based on this description of the markets, we hypothesise that price transmission between the wholesale apples markets in Hamburg and Munich will be seasonally regime-dependent depending on whether these markets are mainly supplied from domestic or imported sources. However, an important characteristic of the seasonal pattern of apple prices and quantities is that it is irregular, caused by random variations in weather and the timing and quality of harvests in Germany and elsewhere. This irregular seasonality is typical for fresh fruits and vegetables markets (see e.g. Rodríguez and Hernàndez, 2005). For example, the German apple season (defined as the date on which the share of German apples in total trade increases to over $10 \%$ for the first time in a year) started as early as July 22 in 2003 and July 14 in 2005, and as late as August 17 in 2004 and August 7 in 2006. Similarly, the beginning of the southern hemisphere apple season varies between January and March. Related to these fluctuations, the variety and quality composition of the domestic and imported apples traded in Hamburg and Munich can vary considerably from year to year.

For this reason, a modelling approach based on seasonal dummy variables would be too inflexible. Instead, we hypothesize that the equilibrium price relationship between wholesale prices in Hamburg and Munich is subject to threshold effects, with the share of German apples in total wholesale trade acting as the threshold variable. This specification allows for seasonal regime shifts to occur at different times from year to year, depending on the timing and volume of the German harvest.

\section{Empirical Results}

The results of the ADF test (Dickey-Fuller, 1981) and the KPSS test (Kwiatowski et al., 1992) suggest that the wholesale apple prices in Hamburg $\left({ }_{G E R}^{H}\right)$ and Munich $\left({ }^{p_{G E R}^{M}}\right)$ (about 930 observations each) are I(1). Also, the Johansen test and residual based test on cointegration indicate that there is cointegration over the whole sample ${ }^{40}$.

\footnotetext{
${ }^{40}$ Results are available by the authors upon request.
} 
Next, we conduct the Gonzalo and Pitarakis (2006) test for threshold cointegration between $p_{G E R}^{H}$ and $p_{G E R}^{M}$ for model (I) $p_{G E R}^{H}=f\left(p_{G E R}^{M}\right)$ with $p_{G E R}^{H}$ as the dependent and $p_{G E R}^{M}$ as the independent variable and model (II) $p_{G E R}^{M}=f\left(p_{G E R}^{H}\right)$ with the converse structure.

The daily share of apples produced in Germany in total wholesale trade in Hamburg and Munich is used as the threshold variable. Since this variable fluctuates from day to day, we smooth it by calculating the central moving average of the nearest 12 observations for each observation $^{41}$ (see figure 5). In this way we avoid repeated, 'back and forth' regime changes that would otherwise occur in periods in which the variable is close to its threshold value. The LM-test statistic in (3) is estimated for all observed values of the threshold variable, with the trimming parameter is set to 0.08 to ensure that each regime contains at least $8 \%$ of all observations. Figure 4 presents the estimated value of the LM-test statistic and the corresponding value of the threshold variable for models I (panel a) and II (panel b). For model I, the value of the LM-test statistic is highest for the threshold values 0.105 and 0.399 , corresponding to $\mathrm{LM}=45.20$ ( $\mathrm{p}$-value $<0.01$ ) and $\mathrm{LM}=50.41$ ( $\mathrm{p}$-value $<0.01$ ), respectively ${ }^{42}$. For model II, the LM-test statistic is highest for the threshold values 0.121 and 0.335 , corresponding to $\mathrm{LM}=48.69$ ( $\mathrm{p}$-value $<0.01$ ) and $\mathrm{LM}=21.99$ ( $\mathrm{p}$-value $<0.01$ ), respectively.

Figure 4: Values of the Gonzalo-Pitarakis test statistic

a) Model I $\left(p^{H}=f\left(p^{M}\right)\right)$

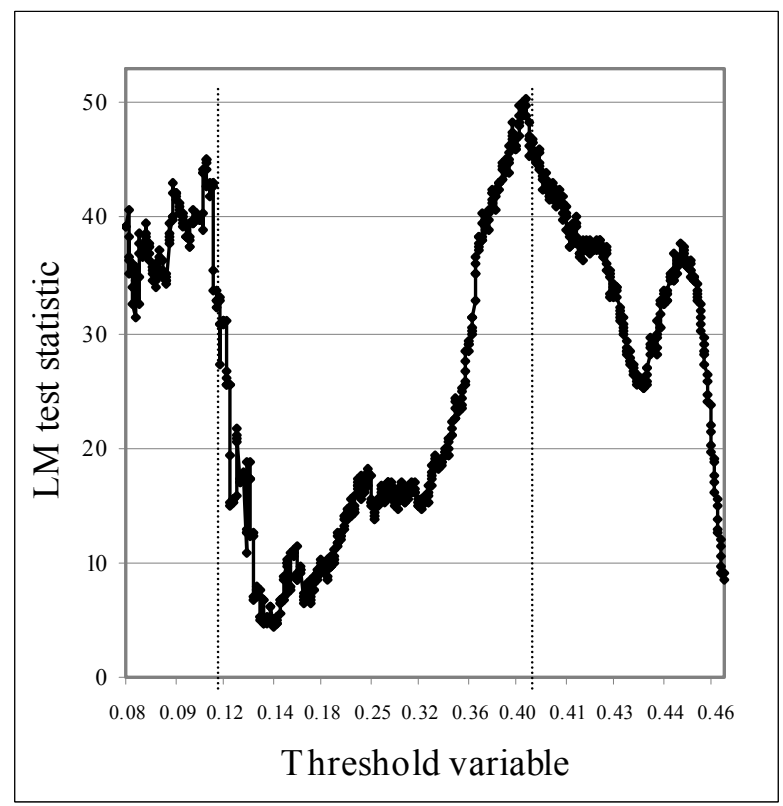

Source: own calculations b) Model II ( $p_{G E R}^{M}=f\left(p_{G E R}^{H}\right)$

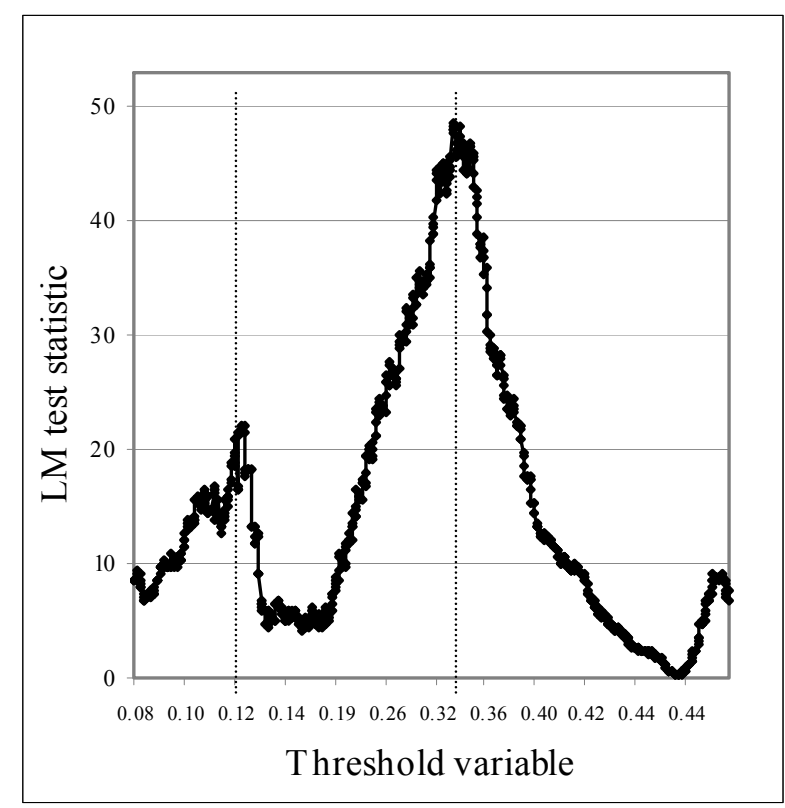

\footnotetext{
${ }^{41} 2$ to 20 -component central moving averages were employed. Shorter moving averages do not eliminate the problem of 'back and forth' regime switches in the neighbourhood of the threshold value, while results are qualitatively very similar for moving averages of 12 components and more.

42 The p-values are taken from ANDREWS (1993) table I. For a trimming parameter of 0.10 and $\mathrm{p}=2$, the corresponding critical values are $12.27(\mathrm{p}$-value $=0.05)$ and $16.04(\mathrm{p}$-value $=0.01)$.
} 
Since the LM statistic displays two distinct peaks, we assume that there are two significant thresholds and correspondingly three long-run equilibria in the cointegration relationship between apple prices in Munich and Hamburg. To this end, three dummy variables are included in the model: SMALLER is defined by the indicator function $I\left(q_{t-d}<0.121\right)$; BETWEEN is redefined by $I\left(0.121<q_{t-d}<0.335\right)$; and LARGER is defined by $I\left(0.335<q_{t-d}\right)$. Furthermore, we note that the BETWEEN regime occurs twice each year; once during the transition from LARGER to SMALLER (from spring to early summer) as the share of German apples is falling; and once during the transition from SMALLER to LARGER (from late summer to fall) as the share of German apples is increasing. These two transitions represent very different market conditions: In the former, newer southern hemisphere apples progressively replace older stored apples from the last domestic crop; in the latter, the new domestic crop replaces imported southern hemisphere apples. To account for this, we divide BETWEEN into BETWEEN1 (spring) and BETWEEN2 (fall) with appropriate dummy variables. Figure 5 illustrates the mapping of observations into the four resulting regimes.

In the following, to shorten the presentation, we carry out the subsequent analysis using threshold values for model II (0.121 and 0.335) alone; results based on threshold values from model I (available on request) are qualitatively similar.

The presence of cointegration between the Hamburg and Munich prices in each of these four regimes is tested using both a residual-based (ADF) test and the Johansen trace-test (Table 1).

Figure 5: Attribution of the observations of the Munich apple price to the four regimes based on thresholds retrieved from the GONZALO-PITARAKIS (2006)

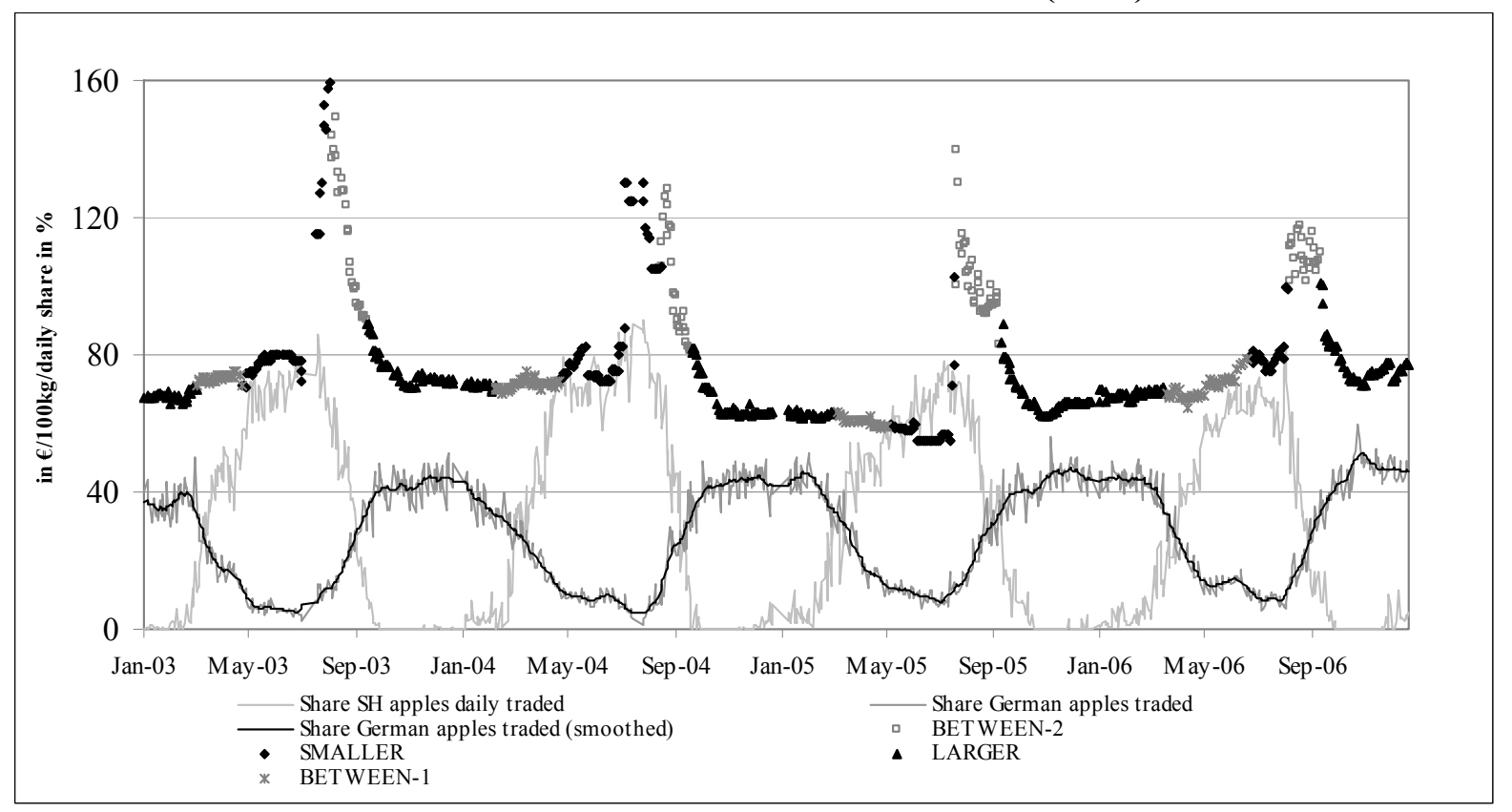

Source: own calculations 
The results unambiguously point to cointegration in all regimes except BETWEEN1 (spring), where the results of the cointegrating ADF test only points to cointegration when Munich prices are regressed on Hamburg prices. Table 1 also shows unweighted mean and standard error of the price difference between the Munich and the Hamburg market for each regime.

The price difference and standard error are by far highest in regime BETWEEN2 (fall), followed by the regime SMALLER. The price difference and standard error is lowest for the regimes LARGER and BETWEEN1 (spring).

In the next step we estimate the unrestricted regime-dependent ECM with four regimes according to (7) in models I and II.

Table 1: Results test on cointegration and price volatility of the 4 regimes (Residual based test without intercept and trend), model II limits

\begin{tabular}{|c|c|c|c|c|}
\hline $\begin{array}{l}\text { Dummy variable } \\
\text { Number of obsv. } \\
\text { Threshold limits }\end{array}$ & $\begin{array}{c}\begin{array}{c}\text { BETWEEN1 } \\
\text { (spring) }\end{array} \\
185 \text { obsv. } \\
0.121 \leq q_{t} \leq 0.335 ;\end{array}$ & $\begin{array}{c}\text { SMALLER } \\
\text { (summer) } \\
214 \text { obsv. } \\
q_{t}<0.121\end{array}$ & $\begin{array}{c}\text { BETWEEN2 } \\
\text { (fall) } \\
111 \text { obsv. } \\
0.121 \leq q_{t} \leq 0.335 ;\end{array}$ & $\begin{array}{c}\text { LARGER } \\
\text { (winter) } \\
424 \text { obsv. } \\
q_{t}>0.335\end{array}$ \\
\hline \multicolumn{5}{|l|}{ Test on cointegration } \\
\hline $\begin{array}{l}\text { a) Residual based test } \\
\text { ADF t-value, } \\
\text { [number of lags], } \\
\text { (p-value) } \\
\text { Model I } \\
\ln \left(p_{G E R}^{H}\right)=f\left(\ln \left(p_{G E R}^{M}\right.\right. \\
\text { Model II } \\
\ln \left(p_{G E R}^{M}\right)=f\left(\ln \left(p_{G E R}^{H}\right.\right.\end{array}$ & $\begin{array}{l}-2.34,[2 \text { lags }] \\
(>0.1) \\
-3.892,[0 \mathrm{lag}] \\
(<0.01)\end{array}$ & $\begin{array}{l}4.999,[0 \mathrm{lag}] \\
(<0.01) \\
-3.892,[0 \mathrm{lag}] \\
(<0.01)\end{array}$ & $\begin{array}{l}\begin{array}{l}2.998,[0 \mathrm{lag}] \\
(<0.05) \\
\\
3.949,[1 \mathrm{lag}] \\
(<0.01)\end{array}\end{array}$ & $\begin{array}{l}-3.265,[1 \mathrm{lag}] \\
(<0.05) \\
-4.557,[0 \mathrm{lag}] \\
(<0.01)\end{array}$ \\
\hline $\begin{array}{l}\text { b) Johansen trace } t \text {. } \\
\mathrm{LR}^{\text {trace }} \text { zero versus } \\
\text { one coint. rel., lags } \\
\text { (p-value) }\end{array}$ & $\begin{array}{l}11.62,[2 \text { lags }] \\
(>0.1)\end{array}$ & $\begin{array}{l}25.39,[2 \text { lags }] \\
(<0.01)\end{array}$ & $\begin{array}{l}24.76,[2 \text { lags }] \\
(<0.01)\end{array}$ & $\begin{array}{l}25.63,[2 \text { lags] } \\
(<0.05)\end{array}$ \\
\hline \multicolumn{5}{|l|}{ Price difference } \\
\hline $\begin{array}{l}\text { Mean (standard error) } \\
\left|p_{G E R}^{M}-p_{G E R}^{H}\right|\end{array}$ & $4.266(2.445)$ & $12.266(14.435)$ & 30.105 (16.309) & $9.175(5.341)$ \\
\hline
\end{tabular}

Source: own calculations

Our hypothesis of a regime-dependent model in which the long-run relationship (and correspondingly the adjustment process) displays threshold behaviour is supported by the results of the likelihood-ratio test. In this test, the value of the log-likelihood function of the regime-specific ECM with 4 regimes according to (7) (unrestricted model) is compared to that of an ECM over all observations without distinguishing between regimes (restricted model). 
The null hypothesis that the restricted model is superior to the unrestricted model is clearly rejected at low p-values in model frameworks I as well as II (Table 2).

Table 2: Likelihood ratio test results

\begin{tabular}{|c|c|c|}
\hline & $\begin{array}{c}\text { Model I } \\
\left(p^{H}=f\left(p^{M}\right)\right)\end{array}$ & $\begin{array}{c}\text { Model II } \\
\left(p_{\text {GER }}^{M}=f\left(p_{G E R}^{H}\right)\right.\end{array}$ \\
\hline LR-test statistic & 42.524 & 56.835 \\
\hline Degrees of freedom & 15 & 15 \\
\hline$p$-value & 0.0002 & $<0.0001$ \\
\hline
\end{tabular}

Source: own calculations

Table 3 presents the estimates for the long-run price transmission elasticity and the speed of adjustment for the regimes SMALLER, BETWEEN2 and LARGER, for which the data series were identified as cointegrated. The t-values account for autocorrelation and heteroscedasticity in model I and for heteroscedasticity only in model $\mathrm{II}^{43}$.

Results indicate that the price transmission elasticity varies significantly between regimes and model frameworks. The coefficient corresponding to the speed of adjustment to the long-run equilibrium has the correct negative sign and is statistically significant in all cases with the exception of the regime SMALLER in model framework II. This indicates that the price relationship is unidirectional in the regime SMALLER, with the Hamburg price error correcting, whereas the Munich market is dominating the price. In the other cases the price relationship is bi-directional and error correcting behaviour is identified for both markets. Furthermore, results for both models suggest that deviations from the long-run equilibrium are corrected fasted in regime BETWEEN2 in fall and slowest in regime LARGER during winter. The speed of adjustment is also quite high in the regime SMALLER in model I. Results obtained for the full data set (COMPLETE) suggest that the price relationship is unidirectional and that the Hamburg price only error corrects whereas the Munich market dominates the price.

\footnotetext{
${ }^{43}$ Detailed ECM estimation results are available by the authors on request.
} 
Table 3: Estimates for the long-run price transmission elasticity and the speed of adjustment for the 4 regimes and the full sample

\begin{tabular}{|c|c|c|c|c|c|}
\hline \multirow[b]{2}{*}{$\begin{array}{l}\text { Dummy } \\
\text { variable }\end{array}$} & \multirow[b]{2}{*}{ Parameter } & \multicolumn{2}{|c|}{$\begin{array}{c}\text { Model I } \\
\left(\ln \left(p_{G E R}^{H}\right)=f\left(\ln \left(p_{G E R}^{M}\right)\right)\right)\end{array}$} & \multicolumn{2}{|c|}{$\begin{array}{c}\text { Model II } \\
\left(\ln \left(p_{G E R}^{M}\right)=f\left(\ln \left(p_{G E R}^{H}\right)\right)\right)\end{array}$} \\
\hline & & Estimate & t-value & Estimate & t-value \\
\hline \multirow{2}{*}{$\begin{array}{l}\text { SMALLER } \\
\text { (summer) }\end{array}$} & Price transmission elasticity & 0.911 & & 1.087 & \\
\hline & Speed of adjustment & -0.118 & -2.077 & 0.034 & 0.870 \\
\hline \multirow{2}{*}{$\begin{array}{l}\text { BETWEEN2 } \\
\text { (fall) }\end{array}$} & Price transmission elasticity & 1.340 & & 0.225 & \\
\hline & Speed of adjustment & -0.123 & -2.510 & -0.117 & -2.985 \\
\hline \multirow{2}{*}{$\begin{array}{l}\text { LARGER } \\
\text { (winter) }\end{array}$} & Price transmission elasticity & 0.056 & & 0.348 & \\
\hline & Speed of adjustment & -0.044 & -3.645 & -0.080 & -4.054 \\
\hline \multirow{2}{*}{ COMPLETE } & Price transmission elasticity & 0.638 & & 0.495 & \\
\hline & Speed of adjustment & -0.072 & -3.131 & -0.023 & -1.470 \\
\hline
\end{tabular}

Source: own calculations

Taking into account the time period, market condition and error-correcting behaviour, the four regimes can be characterized as follows:

Regime SMALLER (summer): Corresponds to the market conditions in May/JuneJuly/August, when the remainder of the stored apples of the previous harvest and the first apples of the new harvest are supplied to the market. This is the only regime in which the price relationship is unidirectional with the Munich price not error correcting and thus dominating the Hamburg price. In contrast, the Hamburg price error corrects at relatively high speed. This may be attributed to the harvest season starting earlier in the southern parts of Germany implying that new apples are first sold on the Munich market. Thus, the initial price level for the new harvest is set on the Munich market and is transmitted to the Hamburg market. Price differences between the Hamburg and the Munich market are relatively high giving leeway to profitable arbitrage opportunities implying strong market integration.

Regime BETWEEN2 (fall): This regime matches with the time period July/AugustSeptember, when the daily traded share of newly harvested, apples grown in Germany increases implying that prices of German apples and the apple price level in general declines, inducing apple supply of southern hemisphere countries to vanish. Deviations from its longrun equilibrium are corrected fastest in this regime in both models compared to the other regimes. 
The intense integration of markets with the compared to the other regimes highest speed of adjustment to the long-run equilibrium may be traced back to the highest mean difference between prices in Munich and Hamburg in this regime.

Traders confirm that large amounts of apples traded between northern and southern Germany in this time period. For example, substantial amounts of special varieties of apples (Boskop, Cox Orange), which are particularly grown in the northern part of Germany, are sold to the market in southern Germany to be stored in warehouses. Also, if the harvest is good in one and bad in the other area, e.g. due to hail or bad weather during bloom, producers the area with the bad harvest will buy apples from the other region to fill warehouses.

Regime LARGER (winter): Relates to the market conditions prevailing during September to March, when almost exclusively German and Italian apples stored in the regional warehouses are supplied to the wholesale markets. Prices in both markets do error correct, but the speed of adjustment is lowest compared to the other regimes. Yet, the speed of adjustment of the market in Munich is higher than of the market in Hamburg. This low speed of adjustment to the long-run equilibrium might be attributed to the relatively low mean price difference between the wholesale market in Hamburg and Munich limiting profitable interregional trade and implying a low degree of market integration.

Regime BETWEEN1 (spring): Is in accordance with the time period March-April/June, when the share of stored German apples sold declines and apple warehouses are cleared, whereas the share of newly harvested apples grown in southern hemisphere countries increases. Cointegration between the prices of the Hamburg and Munich market can not be confirmed unambiguously, indicating that a long-run equilibrium relationship does not exist. In this regime price differences between Hamburg and Munich are lowest, reducing the margin for profits resulting from interregional trade. This might explain why cointegration can not be identified clearly. In addition, since apples have been stored for quite some time at this point of time, once they are taken out of the warehouse, the apples perish very fast which is a further factor restricting interregional trade in this regime.

\section{Conclusions and discussion}

In this paper we propose a three-step procedure to estimate a regime-dependent VECM accounting for threshold effects not only in the short-run adjustment towards the long-run 
equilibrium but in the long-run equilibrium relationship as well. This type of non-linearity allows the long-run equilibrium relationship to move back and forth between regimes as a function of the size of an exogenous threshold variable with respect to a threshold value, rather than hypothesizing a one-off break in this relationship. This model seems to be particularly suitable in settings of irregular seasonal price transmission, typical for fresh fruits and vegetables, in which the use of seasonal dummy variables to account for seasonal variation in the equilibrium relationship might not be sufficiently flexible. The proposed price transmission model estimation strategy is unique in utilizing the test by Gonzalo and Pitarakis (2006) on the hypothesis of linear versus threshold cointegration.

In our application to the German wholesale market for apples we find clear evidence of threshold cointegration with the share of German apples traded in total wholesale market trade serving as the threshold variable. We identify two thresholds in the cointegration regression and distinguish four price transmission regimes which are characterized by different equilibrium relationships as well as short-run adjustment processes towards this equilibrium. Our econometric results fit well with the actions on the German apple market.

This research will be extended to further enlighten the connection between the size of the price difference between the markets in Hamburg and Munich and the degree of market integration. Actual costs of transporting apples from one market to the other will be gathered and be compared to the size of price differences in each regime.

In addition, the factors inducing differences in price transmission elasticity implying nonlinear cointegration will be further investigated. In this study the risk of successfully selling apples in another market probably plays a major role whereas variation in transport costs is of minor importance.

Further, the price responses in one market to a price shock in the other market for each regime could be analyzed by impulse-response functions.

The model could be extended and regard for threshold effects induced by the ECT term, as in the threshold VECMs, also. Yet, this faces the problem that with increasing number of regimes in a model, the number of observations entering into the estimation of the parameters of a regime decreases.

\section{References}

Andrews, D. (1993): Tests for parameter instability and structural change with unknown change point, Econometrica, Vol. 61: 821-856. 
Baffes, J. and B. Gardner (2003): The Transmission of World Commodity Prices to Domestic Markets Under Policy Reforms in Developing Countries, Policy Reform, Vol. 6(3): 159-180.

Bakucs, L.Z. and I. Fertö (2005): Marketing Margins and Price Transmission on the Hungarian Pork Market, in: Brosig, S. and H. Hockmann (eds.): How effective is the Invisible Hand? Agricultural and Food Markets in Central and Eastern Europe. Studies on the Agricultural and Food Sector in Central and Eastern Europe, IAMO, Vol. 31: 134-149.

Balcombe, K., Bailey, A. and J. Brooks (2007): Threshold Effects in Price Transmission: The Case of Brazilian Wheat, Maize and Soya Prices, American Journal of Agricultural Economics 89(2): 308-323.

Bruemmer, B., S. von Cramon-Taubadel, S. and S. Zorya (forthcoming): A Markov-switching vector error correction model of vertical price transmission between wheat and flour in Ukraine, European Review of Agricultural Economics.

Balke, N.S. and T.S. Fomby (1997): Threshold Cointegration, International Economic Review 38: $627-645$.

Barassi, M.R. and A.M.R. Taylor (2004): A test for Change in the Cointegrating Rank (mimeo, Birmingham: University of Birmigham, 2004).

Barassi, M.R. and A. Ghoshray (2007): Structural Change and Long-run Relationships between US and EU Wheat Export Prices, Journal of Agricultural Economics, Vol. 58(1): 7690 .

Candelon, B. and H. Lütkepohl (2001): On the Reliability of Chow Type Tests for Parameter Constancy in Multivariate Dynamic Models, Economic Letters, Vol. (73): 155-160.

Chavas, J.-P. and A. Mehta (2004): Price Dynamics in a Vertical Sector: The Case of Butter, American Journal f Agricultural Economics, Vol. 86(4): 1078-1093.

Bundesanstalt für Landwirtschaft und Ernährung (BLE): Observation wholesale markets 2003-2005, unpublished. 
Dercon, S. (1995): On Market Integration and Liberalisation: Methods and Application to Ethiopia, Journal of Development Studies, Vol. 32(1): 112-143.

Dickey, D.A. and W.A. Fuller (1984): Likelihood ration statistics for autoregressive time series with a unit root, Econometrica, Vol. 49: 1057-1072.

Goetz, L. and von S. Cramon-Taubadel (2006): Asymmetric Price Transmission in the Israeli Citrus Export Sector in the Aftermath of Liberalization, Contributed Paper presented at the "1. Mediterranean Conference of Agro-Food Social Scientists”, April 23-25, Barcelona, Spain.

Gonzalo, J. and T. Lee (1998): Pitfalls in testing for long run relationships, Journal of Econometrics, Vol. 86: 129-154.

Gonzalo, J. and J. Pitarakis (2006): Threshold Effects in Cointegrating Relationships, Oxford Bulletin of Economics and Statistics, 68 (Supplement): 813-833.

Goodwin, B.K. and N. Piggott (2001): Spatial market integration in the presence of threshold effects, American Journal of Agricultural Economics 83: 302-317.

Gregory, A.W. and B.E. Hansen (1996): Residual-based Tests for Cointegration in Models with Regime Shifts, Journal of Econometrics, Vol. 70: 99-126.

Guillotreau, P., Le Gre, L. and M. Simioni (2005): Price-Cost Margins and Structural Change: Sub-Contracting within the Salmon Marekting Chain, Review of Development Economics, Vol. 9(4): 581-597.

Hansen, B.E. and B. Seo (2002): Testing for two-regime threshold cointegration in vector error correction models, Journal of Econometrics, Vol. 110: 293-318.

Hansen, G. (1996): Residual-based tests for cointegration in models with regime shifts, Journal of Econometrics, Vol. 70: 99-126. 
Johansen, S. (1988): Statistical Analysis of Cointegration Vectors, Journal of Economic Dynamics and Control 12 (June-Sept. 1988): 215-238.

Kennedy, P. (2003): A Guide to Econometrics, $5^{\text {th }}$ Edition, Blackwell Publishers.

Kwiatowski, D., Phillips, P., Schmidt, P. and Y. Shin (1992): Testing the Null Hypothesis of Stationarity against the Alternative of a Unit Root, Journal of Econometrics, Vol. 54: 159178.

Johansen, S., Mosconi, R. and B. Nielsen (2000): Cointegration analysis in the presence of structural breaks in the deterministic trend, Econometrics Journal, Vol. 3: 216-249.

Lo, M.C. and E. Zivot (2001): Threshold cointegration and non-linear adjustment to the law of one price, Macroeconomic Dynamics, Vol. 5: 533-576.

Meyer, J. (2004): Measuring market integration in the presence of transaction costs - a threshold vector error correction approach, Agricultural Economics, Vol. 31: 327-334.

Rodríguez, G.M. and J.J.C. Hernàndez (2005): Modelling weekly Canary tomato exports, Agricultural Economics, Vol. 33: 255-267.

Serra, T., Gil, J.M. and B.K. Goodwin (2006): Local polynomial fitting and spatial price relationships: price transmission in EU pork markets, European Review of Agricultural Economics 33(3): 415-436.

Sanjuan, A. and P.J. Dawson (2003): Price transmission, BSE and structural breaks in the UK meat sector, European Review of Agricultural Economics, Vol. 30(2): 155-172.

Tiffin, R. and P.J. Dawson (2000): Structural breaks, cointegration and the farm-retail price spread for lamb, Applied Economics, Vol. 32: 1281-1286.

Wang, D. and W. Tomek (2007): Commodity Prices and Unit Root Tests, American Journal of Agricultural Economics, Vol. 89(4): 873-889. 


\section{Discussion of Results and Ideas for Future Research}

This chapter summarizes our main findings and discusses some of their limitations. Strategies on how to overcome some of these problems and possible extensions for future research are laid out. I start with some general comments on data analysis with fresh fruit and vegetable data and then go through the research papers.

Data analysis based on fresh fruit and vegetable data faces specific challenges. The particularities of fresh fruit and vegetable data have to be taken into account explicitly to avoid distorted results. In our research on the effectiveness of the EPS, we have specified indicators which account for the frequent occurrence of extreme values in fresh fruit and vegetable data. Also, we have developed a special procedure of how to consider the discontinuity of the grapefruit price data in estimating price transmission models. This implies a significant amount of additional work since statistical programmes for time series analysis (e.g. JMULTI) or time series procedures available in statistical programmes cannot be used; instead, models and statistical tests have to be programmed. Further, we have suggested a procedure to estimate a regime-specific vector error correction model, suitable for capturing irregular seasonal threshold effects in price transmission which are typical for fresh fruits and vegetables.

\section{A) The EU Import Regime for Oranges-Much Ado about Nothing?}

In the paper "The EU Import Regime for Oranges-Much Ado about Nothing?" we have shown that the EU import system for oranges was not decisive for the decline of orange exports of the MED, particularly Morocco and Israel, to the EU.

Hence, factors beyond EU trade policy must have caused this development. For example, market distance and product variety are of particular importance for the decline of Israeli orange exports to Germany. German importers appreciate the high flexibility of orange imports from Spain. Due to Spain's proximity to the market, Spanish produce is packed directly in nets in Spain and transported by truck to retailers' distribution centers in Germany within two days. In contrast, Israeli produce is first packed in cardboard boxes in Israel, which are transported by ship within four days to Marseille (France). The produce is then carried by truck to packing stations in Germany where it is repacked in nets before it is brought to supermarkets. Of course, the resulting transportation costs are lower for Spanish produce. Besides, Shamouti is the orange variety which still dominates Israeli orange production. In Spain, new orange varieties were introduced, e.g. the Navel varieties. German consumers 
prefer Navel over Shamouti oranges, but Israeli orange producers have failed to adapt to this change in consumer preferences in time.

In future research the significance of the EU internal agricultural policy for fresh fruits and vegetables as well as structural policy for the increase in EU orange market share of Spanish produce could be investigated. We suspect that these policy measures have substantially contributed to the changes in the composition of the EU market supply for oranges. In particular, EU orange production is protected internally by processing aid and withdrawal compensation. Also, operational programs of producer organizations for improvement of product quality and market promotion activities are financially supported. Restructuring aids are granted to modernize marketing structure and to grub up old orange groves. Additional funds are provided by the EU Cohesion Fund, e.g. for enhancement of transport infrastructure.

\section{B) The EU Entry Price System for Fresh Fruits and Vegetables - Paper Tiger or}

\section{Powerful Market Barrier?"}

In the paper "The EU Entry Price System for Fresh Fruits and Vegetables - Paper Tiger or Powerful Market Barrier?" we have shown that the effectiveness of the EPS differs substantially across products and across countries of origin for most of the 15 relevant fruits and vegetables.

In cases in which the EPS is determined to be highly relevant, it can be expected that the removal of the EPS would result in an increase of exports to the EU at prices below the entry price. This effect, however, depends on the degree to which the EPS is currently circumvented and the costs involved.

The EPS can be circumvented (both legally and illegally), so that some products are effectively sold at prices below the entry price (GARCíA-ÁlvAREZ-COQUE, 2002). According to information from importers, illegal circumvention (e.g. by false invoicing) is more prevalent in small-scale trading, particularly between related trading partners. Storage can offer a means of legal circumvention, as storable products can be imported at any time while customs clearance is delayed until some later date when the SIV is above the entry price. Once cleared at a favourable SIV, the product can be sold later on EU markets at any price (CIOFFI AND DEL' AQUILA, 2004). Therefore, particularly for apples originating in countries of the southern hemisphere, the EPS might be of even lower relevance than the results of our cluster analysis suggest.

In order to generalise the results of this analysis to the whole EU fruit and vegetable trade, it is necessary to take into account that the analysis has been conducted based on EU wholesale 
market prices ${ }^{44}$, even though the majority of the fruit and vegetable trade in several EU countries is conducted directly by exporters to retailers and not via the wholesale market. For example, the share of the fruit and vegetable trade via wholesale markets is only about $20 \%$ in Germany, and is even lower in the UK, compared with shares of about $65 \%$ in Spain and Italy, and even higher shares in France (GIBBON, 2003). Prices of products traded directly can differ significantly from products traded via wholesale markets. For instance, importers estimate that fresh fruit and vegetable prices on wholesale markets are on average about 10$20 \%$ higher than prices of directly traded products in Germany. This limits the scope for traders to apply the deductive method or the fob invoice method for customs clearance in case of a low SIV which reflects wholesale market prices and might imply that the effectiveness for some products is to some degree higher than suggested by our results.

Interestingly, German importers explicitly confirm the overall results of this study. They emphasize that the EPS is indeed relevant for products assigned to clusters one and two in our analysis. Regarding cluster three products, they confirm that the EPS has some influence on clementines, but has rather low relevance for apples and pears. They point out that the EPS is of no relevance for products attributed to cluster four, i.e. apricots, mandarins, oranges, peaches and nectarines and table grapes. In the case of oranges originating in the US, importers stress that the observed accumulation of observations close to the entry price can not be caused by the EPS. They emphasize that in general, oranges exported by the US are highly priced and therefore their share in the EU market is very low.

In future research, the relationship between the wholesale market prices and prices which prevails in the direct trader-retailer relationship in Germany could be investigated. German traders claim that the SIV, calculated by the EC based on wholesale market prices in all EU member states, which serves as basis for customs clearance according the SIV method, is often quite different from the actual price which prevails in the direct importer-retailer relationship. This implies additional adjustment costs for the trade companies. Results of this research, which requires price data of the direct trade between importers and retailers, could support a policy recommendation postulating that calculations of the SIVs should be based on importer-retailer data for Germany or even all EU member countries, as it is already done in UK, the Netherlands and Finland.

\footnotetext{
${ }^{44}$ Exceptions are prices gathered in the UK, Netherlands and Finland, which are requested directly from the importers, as the fresh fruit and vegetable trade via the wholesale market has very low importance. In Greece, these data are collected from the customs authority.
} 


\section{C) Does the Entry Price System Restrict Fresh Fruit and Vegetable Exports from China}

to the EU?

In the paper "Does the Entry Price System Restrict Fresh Fruit and Vegetable Exports from China to the EU?" it became evident that the restrictiveness of the EPS for Chinese exports to the EU has increased in recent years for pears and even more for apples.

Investigating how the restrictiveness of the EPS developed over time might help to understand the causing factors. Yet, its applicability remains limited by the number of observations available for each year. The fewer observations are available to represent a product and country of origin specific distribution of the import price, the more caution is in order when interpreting the results, since incidental extreme values' influence on the outcome increases, which might imply misleading results.

Further, the study confirms that skewness is only limitedly suitable as an indicator for the effectiveness of the EPS, as it was argued in the previous study (GOETZ AND GRETHE, 2007a). Skewness of the price distribution could also result form product storage. The influence of storage on the price distribution is studied by DEATON AND LAROQUE (1992) within the rational expectations competitive storage model. They find that storage increases skewness, i.e. lack of symmetry, and kurtosis, i.e. tallness or flatness, of the price distribution. The product is bought and stored when the price is low, and it is sold when the price is high, in other words when the price is lower and higher, respectively, than the cut-off price at which a unit of the product stored until the next period would lead to zero expected profits. This implies that lower and higher prices are observed less often and thus the left tail and the right tail of the distribution are reduced (DEATON AND LAROQUE, 1992: 13). The effect on the prices above the cut-off price is influenced by the incidence of stockouts. The less often the product is sold out and product inventories are available, the larger is the effect of storage on the right side of the distribution. Yet, DEATON AND LAROQUE (1992) argue that although the price distribution might become truncated on the left-hand side, this does not happen to the right hand side since bad harvests always occur in some years implying stockouts at some points of the year leading to extremely high product prices similar to the case without storage. The authors point out that the storage effect on skewness and kurtosis is the larger, the more convex the inverse demand function is, as e.g. in the case of an isoelastic demand function. In contrast, the storage effect is lower in the case of a linear inverse demand function.

However, the price distributions investigated in this and the previous study are influenced by storage only to a limited degree due to high perishability. Exceptions are apples and pears which can be stored almost the whole year around by refrigeration under controlled 
atmosphere. In these cases skewness of the price distribution could be influenced by the effects of product inventories and thus can not be solely traced back to the effectiveness of the entry price system. In these cases it is important that the effectiveness of the EPS is estimated based on several indicators.

\section{D) Vertical Price Transmission in the International Fresh Fruit and Vegetable Supply}

\section{Chain: Israeli Grapefruit Exports to the EU after Export Market Liberalization}

Results derived from our analysis in the paper "Asymmetric Price Transmission in the Israeli Citrus Export Sector in the Aftermath of Liberalization" suggest that exporters have ceased from asymmetrically transmitting price changes in the EU export markets to the Israeli growers. This development might have been triggered by the governmental market intervention in 1994/1995.

The interpretation of the results has to take into account the following data issues as sources for distortions and limitations of the model approach.

First, to exactly measure the weekly average export price achieved by an exporter for grapefruits, export price data for all markets the exporter delivered to would be required. Yet, this analysis is based on import price data of the EU market (France) as a proxy for an exporter's average export price. Further, we use an aggregated price as the EU import price for grapefruits. Of course, different exporters might achieve different prices for their produce in the same market, particularly since the quality of fresh produce is very vulnerable and is determined by e.g. maturity of the fruits at the point of time of picking or time elapsed to move the produce from the farm gate to the ship. These sources of measurement error might imply that our results are distorted to some degree.

Second, all price data is stated in NIS/ton and deflated with the Israeli monthly consumer price index $(2000=100$; CBS Israel). In addition, the French import prices are transformed in NIS/ton by weekly exchange rates. Since the daily price data is transformed by a weekly exchange rate and even a monthly consumer price index, this might affect the structure of the data series and possibly influence results.

Third, since grapefruits are harvested from October to May only, the data series are discontinuous which has to be accounted for in the model approach. In this study we have excluded all observations from the data set for which the required information on previous periods is not available. In particular, if the model contains the change in the grower price lagged up to one period, then the first two observations of each season are left out from the 
analysis. WARD (1982) deals with the discontinuity of the data in a different way. He, instead, introduces additional dummy variables in the model ensuring that each observation is included in the estimation of only those variables for which the required information on the previous observations is present. Ward's method utilizes more of the available data than our approach. Yet, we suspect that in the context of the grapefruit data which exhibits extremely high prices at the beginning of a season, our method might perform better. It would be interesting to also estimate our model following Ward's approach and compare results.

In this study we interpret the detected asymmetry in price transmission as being caused by market power of the Israeli exporters vis-á-vis the Israeli growers. We argue that other causes of asymmetry in price transmission are not relevant in our context since the grower price is determined ex-post. This is confirmed by the identified positive price transmission indicating that exporters have increased their profits temporarily, while growers experienced losses. This argument could be further substantiated by providing additional evidence that the exporters have indeed exercised market power. As pointed out by MEYER AND VON CRAMONTAUBADEL (2004), the number of firms and concentration ratios do not capture this behaviour.

According to the structure-conduct performance approach market power can be detected by the analysis of the relationship between profitability measured by the price-cost margin and firm concentration. Following the new industrial organization literature the degree of market power could be identified by estimating the deviation of industry behaviour from competitive conduct. Also, market power could be identified in extensions of the model of GARDENER (1975) on marketing margins which also account for the influence of market power (e.g. SCHROETER AND AZZAM, 1991; RichARDS ET AL., 1998)

In the context of our study, all three approaches require data on marketing costs, in particular sea transport costs, of the Israeli exporters. However, this data is not available; even the yearly data on shipping costs give the development of sea transport costs in general, whereas sea transport of citrus is a special kind of transport in reefer containers. Thus, these costs might differ substantially from general sea transport costs.

Even the test of the existence of market power proposed by LLOYD ET AL. (2006) relies on the availability of marketing cost data. LLOYD ET AL. (2006) focus on sources of a change of the retail-farm price margin. They propose that a change in the farm-retail price spread may be induced only by a change in marketing or other regulatory costs in a perfectly competitive industry. In contrast, if oligopoly and/or oligopsony power prevails, the retail-farm margin may also be influenced by exogenous shocks caused by farm supply or retail demand. 


\section{E) Threshold Adjustment and/or Threshold Cointegration? An Application to the}

\section{German Apple Market}

In the paper "Threshold Adjustment and/or Threshold Cointegration? An Application to the German Apple Market" we have developed a three-step procedure to estimate a regimespecific VECM accounting for threshold effects in the cointegration regression. This type of non-linearity allows the long-run equilibrium relationship to move back and forth between regimes as a function of the size of an exogenous threshold variable with respect to a threshold value.

In our application to the Munich and Hamburg wholesale market for apples we find clear evidence of threshold cointegration with regard to the share of German apples traded on the market. We identify two thresholds and distinguish four regimes corresponding to four different market conditions alternating prevailing throughout a year.

This model could be extended and also regard threshold effects induced by the ECT term, as in the threshold VECMs. Yet, this faces the problem that with increasing number of regimes in a model, the number of observations entering into the estimation of the parameters of a regime decreases. In the context of measuring price transmission in the apple wholesale markets in Germany, transport costs are, as pointed out before, quite low. Thus disregarding threshold effects in the error correction term might have only minor effect on the model estimates.

In future research, the factors inducing differencing in price transmission elasticity and thus implying non-linear cointegration should be investigated. In the context of this study particularly the risk of successfully selling apples in another market might play a major role.

\section{References}

Cioffi, A. AND C. DELL'Aquila (2004): The Effects of Trade Policies for Fresh Fruit and Vegetables of the European Union, Food Policy, Vol. 29: 169-185.

Gardener, B. L. (1975): The Farm-Retail Price Spread in a Competitive Industry, American Journal of Agricultural Economics, Vol. 57(3): 399-409.

GARCíA-Álvarez-CoQue, J. M. (2002): Agricultural Trade and the Barcelona Process: Is Full Liberalization Possible? European Review of Agricultural Economics, 29(3): 339-422.

GibBon, P. (2003): Value-chain Governance. Public Regulation and Entry Barriers in the Global Fresh Fruit and Vegetable Chain into the EU, Development Policy Review, 21(5-6): 615-625.

Goetz, L. AND H. GRethe (2007a): The Relevance of the EU Entry Price System for Imports of Fresh Fruits and Vegetables, IATRC Working Paper 07-0. 
Lloyd, T.; S. McCorriston; C.W. Morgan AND A.J. RAYNer (2006): Food scares, market power and price transmission: the UK BSE crisis, European Review of Agricultural Economics, Vol. 33(2): 119-147.

Meyer, J. And S. von Cramon-Taubadel (2004): Asymmetric Price Transmission: A Survey, Journal of Agricultural Economics, Vol. 55: 581-611.

Richards, T.J.; PAtTerson, P.M. AND P.V. IsPelen (1998): Modeling Fresh Tomato Marketing Margins: Econometrics and Neural Networks, Agricultural and Resource Economics Review, Vol. 27(2): 186-199.

Schroeter, J. AND A. AzZAM (1991): Marketing Margins, Market Power and Price Uncertainty, American Journal of Agricultural Economics, Vol. 73(4): 990-999.

WARD, R.W. (1982): Asymmetry in Retail, Wholesale, and Shipping Point Pricing for Fresh Vegetables, in: American Journal of Agricultural Economics, Vol. 64(2): 205-212. 


\section{Unresolved Issues in Price Transmission Analysis}

In the following I outline some major unresolved issues in price transmission analysis. I start with three topics relevant in spatial price transmission analysis which is followed by two issues important for vertical price transmission. Finally, I present two subjects which concern spatial as well as vertical price transmission.

\section{A) Issues in Spatial Price Transmission}

Determinants of Spatial Price Transmission

Existing models of spatial price transmission are based on a model of spatial price equilibrium (e.g. TAKAYAMA AND JUdGE, 1971) which assumes for reasons of simplicity that a spatial price equilibrium is established by trade flows between these markets. Clearly, there are additional factors e.g. access to market information and existence of communication and transport facilities between two markets which contribute to prices in different markets moving in parallel. In particular, this might imply that producers and consumers shift their business from one market to another in space, which may not show up as trade at all. Thus, prices in different markets might be cointegrated or even in a spatial market equilibrium without physical trade flows observed. This is the motivation for BARRETT's (2001) distinction between spatial market equilibrium (price-based) and market integration (flowbased). Two markets are in spatial equilibrium if their prices differ exactly (at most) by the amount of transaction costs involved moving goods from one to the other market according the strong (weak) form the Law of one Price. Markets are called spatially integrated (segmented) if trade between the market occurs (is not observed). FACKLER AND GOODWIN (2001) point out that the determinants of spatial price integration have not yet been investigated comprehensively.

To properly identify market integration and equilibrium, in other words to estimate the influence of trade flows compared to the other non-trade flow factors, not only price data but also transaction cost data, in particular transport costs, and data on actual trade flows is required (e.g. BARRETT, 1996). Yet, this data is rarely available and often biased proxies have to be used instead (BARRETT, 2001; VAN CAMPENHOUT, 2007). Therefore, there is a strong need to improve the availability of this data by public authorities. Alternatively, comprehensive data material collected as primary data could serve as the data base for price transmission analysis, which is done by e.g. MABAYA (2003), AKER (2007) and AMIKUZUNO (2007) and STEPHENS ET AL. (forthcoming). 
In particular, AKER (2007) investigates market integration in cereal markets in Niger during the food crises in 2005. A threshold autoregressive model is estimated utilizing spatial transaction costs which are calculated based on a panel survey of traders, farmers and transporters containing detailed data on e.g. transport costs, gas prices and road quality. Also, information on the dispersion of cell phones is accounted for in the model approach. Results suggest that cell phones can reduce transaction costs and price dispersion, though this effect might not occur until all markets and hence all market actors have cell phone coverage (pg. $37)^{45}$.

STEPHENS ET AL. (forthcoming) develop a switching error correction model allowing for nonlinear cointegration which aims to distinguish the price transmission regime resulting from actual trade flows between markets from the price transmission regime resulting from more indirect mechanisms in non-trading periods. They apply this model to primary data on tomato markets in Zimbabwe containing data not only on prices but also on trade flows. They find that the regime specific long-run relationships in the presence of trade flows and without trade flows are quite different. Also, they identify adjustment towards the long-run equilibrium without trade flow between markets observed. Even, their results suggest that the adjustment of the margins towards the long-run equilibrium is faster in the non-trade than in the trade period.

MCNEW AND FACKLER (1997) find that the relationship between economic concepts of the law of one price, market integration and the statistical concept of cointegration is complex (pg. 205). In particular, they point out that prices in well-integrated efficient markets need not be cointegrated, which makes it difficult to give estimates retrieved from cointegration based models a clear economic interpretation. They demand that measures of spatial market integration should be derived from an economic model of spatial price determination.

In a recent paper, FACKLER AND TASTAN (2008) propose three measures of market integration which are directly deduced from the Takayama-Judge model of spatial price determination. The measures are defined based on the price transmission ratio corresponding to the degree to which an excess demand shock generated in one location is transmitted to another location. The price transmission ratio lies between zero (no transmission) and one (full transmission), supposed that transport supply is elastic, implying that price shocks are not fully transmitted because transport rates are influenced by shipment quantities.

\footnotetext{
${ }^{45}$ In Jensen's (2007) study on the effects of information technology in the South Indian fisheries sector he also studies the Low of one price. He finds that prior to the introduction of cell phones the Law of one price is violated in $54-60 \%$ of the investigated market price pairs, which reduces to between $3-8 \%$ in the aftermath of cell phone introduction.
} 
Two measures refer to the degree of integration between pairs of locations, i.e. the expected price transmission ratio and the frequency with which two locations are part of the same trading network. The third measure corresponds to the degree of integration in a whole set of markets which is determined by the expected number of isolated markets.

The advantage of these measures is that they measure market integration which may be caused by direct as well as indirect trade between the markets. Thus, two markets might be identified as well integrated even without direct trade flows between these markets but if both markets trade with a third location.

In summary, to shed more light on the determinants of spatial market integration and efficiency, price transmission analysis should be based on primary data gathered in a survey confining not only to price data. Comprehensive survey data should be gathered on cases which allow isolating the influence of one particular determinant, e.g. the influence of cell phones, the effects of a market information system or the impact of improved transport facilities. This could be achieved by e.g. comparing price transmission before and after the respective change. In addition, there is a need to develop further measures for market integration which are derived from economic models of spatial price determination.

Distributional assumptions of spatial price transmission models accounting for transaction costs

Disregarding the existence of transaction costs in price transmission models has been seen as one of the primary factors limiting validity of the results (FACKLER AND GOODWIN, 2001). The more sophisticated price transmission models as e.g. the parity bounds model (BAULCH, 1997) or the threshold error correction model (e.g. BALKE AND FOMBY, 1997) explicitly accounts for transaction costs. Yet, this model is criticized regarding its underlying distributional assumptions.

In the parity bounds model a lower and an upper parity bound are defined as the confidence interval around extrapolated transfer costs. Three regimes are distinguished depending on whether the price difference between two markets is equal to the transaction costs i.e. lies within the parity bounds (regime 1), is higher (regime 2) or smaller (regime 3) than the transaction costs.

Regime 1 is represented by a constant corresponding to the transaction costs and a normally distributed error term. For price differences higher than transaction costs (regime 2), it is assumed that the error term is half normally distributed and truncated from below zero, since the probability of observing large deviations from the transaction costs is lower than for 
smaller deviations. The same distribution is assumed to prevail in regime 3 when the price difference is smaller than transaction costs. Yet, VAN CAMPENHOUT (2007) claims that this assumption for regime 3 is not realistic since it can be expected that if price differences are smaller than transaction costs, large and small deviations from transaction costs have the same probability of occurrence.

However, I think that VAN CAMPENHOUT's distinction in the distributional assumption is related to the underlying economic theory of a spatial equilibrium. If it is assumed that the spatial price differences always tend to be exactly as high as transaction costs of trade between two markets (strong form of the Law of one Price), then the assumption of the halfnormal distribution prevailing in regime 3 seems to be adequate. If instead it is supposed that the weak form of the Law of one Price applies, meaning that a spatial equilibrium exists if price differences are equal or lower than transaction costs, then the assumption of an equal distribution of observations of this regime seems to be better.

Here, I see some analogy to the distinction between the equilibrium threshold autoregressive model (Equilibrium-TAR) and the equilibrium band threshold autoregressive model (BandTAR) introduced by BALKE AND FOMBY (1997). These two kinds of TAR models both account for the existence of costs to adjust to the long-run equilibrium, but differ in their dynamics of long-run equilibrium adjustment. In the equilibrium-TAR it is assumed that regardless if the price differential is smaller or larger than the adjustment costs, and thus the price differential lies inside or outside the threshold interval, equilibrium adjustment occurs towards the center of the threshold interval, i.e. the point of attraction. Yet, the speed of adjustment may differ if reversion begins from inside or outside the threshold boundary. I think that this model corresponds to the Strong Law of one Price since the equilibrium condition is defined by the price differential equal to the center of the threshold interval. In contrast, in the Band-TAR, for price differentials exceeding the threshold band, the point of attraction corresponds to the outer boundaries of the threshold band. Price differentials which lie within the threshold interval may but need not be attracted by the middle of the interval, thus a point of attraction may not even exist. Therefore, the Band-TAR corresponds to the Weak Law of One Price according to which two prices are in spatial equilibrium if the price differential does not exceed the equilibrium adjustment costs.

VAN CAMPENHOUT (2007) further demands that the distributional assumptions reflect that the distribution prevailing in a regime may be influenced by a trader's stock holding, which is called the leverage effect introduced by DEATON AND LAROQUE (1992). Accordingly, if the price is too low in one market, a trader might simply stop trading and put the products on 
stock. A strong leverage effect might imply that the strong form of the Law of One Price is more adequate and thus that the assumption of a half-normal distribution is realistic.

This shows that there is a need to systematically analyze the factors which determine if the weak or strong form of spatial market equilibrium applies and thus which distributional assumption is appropriate for the parity bounds model. For example, the leverage effect does of course not apply in the context of highly perishable fresh fruits and vegetables.

Similarly, there is the need to further investigate the adequacy of the underlying assumptions of other model types, e.g. the threshold vector error correction model.

There is a clear need to modify existing models such that the actual underlying distributions can be accounted for more adequately, or to utilize estimation methods which allow for more flexible underlying distributions.

Recently, BALCOMBE ET AL. (2007) have developed a generalized TAR-model which allows a running transition between an Equilibrium-TAR and a Band-TAR. They introduce additional parameters in the model so that the Equilibrium-TAR and the Band-TAR become special cases. In this model, the threshold interval within which the speed of adjustment differs, and the interval of attraction need not be identical. Prices might be attracted to the edge of the threshold interval but also to any other point within the interval. The threshold interval and the interval of attraction may fall apart when the transfer costs are composed of fixed and variable components. Then equilibrium adjustment may overshoot the threshold limit from without but within-threshold behavior may be observed within the full threshold band (pg. $312)$.

An example for a flexible estimation method is the nonparametric estimation of a threshold vector error correction model by SERRA ET AL. (2006).

For now it might be helpful to check the prevailing distributions in the data. If the actual distribution is strongly different from a model's distributional assumptions, a simpler model approach, e.g. neglecting transaction costs, might be more favorable.

\section{Selection of spatial price transmission models}

The available tool-kit to assess spatial price transmission comprises a bundle of different model approaches. Each model approach makes particular assumptions which influence and limit the model results and have to be accounted for in model selection (MEYER AND VON CRAMON-TAUBADEL, 2004).

For example, a spatial vector error correction model does not account for the influence of transaction costs on price transmission, which might imply that price transmission behavior is 
underestimated. It can be expected that the greater the neglected transaction costs, the more distorted the results may be. Therefore, it is essential that spatial price transmission studies on markets in Africa, which are often characterized by extremely high transaction costs, do not disregard transaction costs in the model approach (ABDULAI, 2006).

Yet, some limitations resulting from a particular model might not be directly evident. Therefore, results obtained from different price transmission models should be compared to draw meaningful conclusions as done by e.g. REZITI AND PANAGOPOULOS (2008). Though, a systematic and comprehensive investigation of the limitations of the different model approaches, as demanded by e.g. MEYER AND VON CRAMON-TAUBADEL (2004), which could be based on simulated as well as real-world data, which could help to develop criteria on model selection in price transmission analysis, is a still unresolved research issue. IHLE AND VON CRAMON-TAUBADEL (2008) compare a threshold cointegration and Markov switching vector error correction model based on simulated data.

\section{B) Topics in vertical price transmission}

\section{Vertical price transmission and market power}

Non-competitive market structure is one of the primary causes of asymmetry in price transmission proposed by the authors of vertical price transmission studies (MEYER AND VON CRAMON-TAUBADEL, 2004; RAPSOMANIKIS ET AL., 2006). However, there is a lack of theoretical models explicitly linking exercise of market power with asymmetry in price transmission, as well as a need for further empirical tests on the existence of this link (MEYER AND VON CRAMON-TAUBADEL, 2004).

A contribution to fill is gap is provided by KINNUCAN ET AL. (forthcoming). They develop a test which makes it possible to simultaneously test for asymmetry in the farm-retail price transmission and market power in the fresh strawberry market. They generalize the finite mixture model by SEXTON AND ZHANG (1996) and combine it with the imperfect competition model by SCHROETER AND AZZAM (1991) resulting in a two-regime pricing model which contains a conjectural elasticity parameter measuring the extend of monopsony power exercised by the retailer. The size of the conjectural elasticity parameter as well as the farmretail price relationship may vary between the regimes. This two-regime pricing model is estimated as a mixture model based on the expectation maximization algorithm giving the optimal mixing weights, indicating the probability that a price observation is in regime 1 or in regime 2, and the parameters of each price regime. This model is more general than the mixture model by SEXTON AND ZHANG (1996) since it does not suppose that 2 pricing regimes 
exist, but let the data determine whether a second pricing regime exists or not. Evidence that asymmetry in price transmission is indeed tied to market power is given if two regimes are identified, asymmetry in price transmission is detected in one regime but not in the other and concurrently the estimated conjectural elasticity parameter is statistically significant different from zero in the asymmetric but not in the symmetric price regime.

As an idea for future research, the link between price transmission and market power could be investigated empirically by applying the test for market power of LLOYD ET AL. (2006) combined with the measurement of vertical price transmission on retailer and grower price data for organically produced fruits and vegetables. LLOYD ET AL. (2006) focus on sources of a change of the retail-farm price margin. They propose that a change in the farm-retail price spread may be induced only by a change in marketing or other regulatory costs in a perfectly competitive industry. In contrast, if oligopoly and/or oligopsony power prevails, the retailfarm margin may also be influenced by exogenous shocks caused by farm supply or retail demand.

A promising case where one could test for the link between asymmetry in price transmission and market power, could be the market for organic vegetables. Demand and prices for organically produced vegetables increased substantially in 2006, which was probably triggered by the media reporting about results of Greenpeace's test on pesticide residues on conventionally grown products offered in German supermarkets. For example, sales of organically produced carrots and courgettes increased by $27 \%$ and $12 \%$ and prices by $17 \%$ and 47\% respectively, in 2006 compared to 2005 (ZMP, 2007). As a proxy for the unobservable marketing costs, unit labour costs in the retail sector could be used. An index of media coverage reporting on Greenpeace's measurements of pesticide residues could serve as a proxy for the demand-side shock.

Such a study could contribute to bridge the gap between the conjectured link between market power and asymmetry in price transmission by providing further empirical evidence.

\section{Data issues in vertical price transmission analysis}

In general, secondary data, which is in most cases aggregated data provided by statistical authorities and market research companies, is utilized in vertical price transmission analysis. It is assumed that the results derived from aggregated data are representative for individual behavior. Yet, VON CRAMON ET AL. (2006) show theoretically and empirically that price transmission behavior of individual agents derived from aggregated data is biased and suggests slower response than if derived from disaggregated data. 
Also, biases can result form an inaccurate data collection process which may influence the data and result in artificial asymmetry (MEYER AND VON CRAMON, 2004).

It is essential that theses sources of biases are taken into account for drawing inferences from the results. Even more, this should motivate to explicitly gather primary data for vertical price transmission analysis so that the analysis can be conducted based on disaggregated data and measures are estimated more precisely.

\section{C) Subjects in spatial and vertical price transmission}

Welfare effects of price transmission

Von Cramon-TAubadel (1998) and Goetz AND von Cramon-TAubadel (2008) estimate welfare implications of asymmetry in price transmission by calculating the losses experienced by the pork producers and citrus growers caused by lower producer and grower prices, respectively. Yet, to estimate welfare effects of asymmetric or low price transmission more completely, the effects on the whole economy have to be captured. Incomplete price transmission implies that the information carried by prices prevailing in a market for an economic agent is distorted which may result in inefficient market outcomes (RAPSOMANIKIS ET AL., 2006). For example, asymmetry in price transmission leading to lower grower prices for a particular product might imply that investments are relocated to another product or sector. Also, low market integration can have vast consequences for developing countries since this can influence the existence, extent and persistence of famines (VAN CAMPENHOUT, 2007).

Welfare effects of asymmetric or low price transmission for a sector or whole economy could be estimated by combining a price transmission model with a general or partial equilibrium model. For example, the welfare effects of asymmetry in price transmission would be equal to the difference in welfare in the case of asymmetric price transmission compared to symmetric price transmission. The challenge lies in the linkage of the price transmission model based on high-frequency, monthly or weekly data with a general or partial equilibrium model based on low-frequency, yearly data.

Similarly, price transmission models could be used to represent the price formation processes in a general or partial equilibrium model more adequately and thus to increase precision of the model results (RAPSOMANIKIS ET AL., 2006). In particular, insights in the dynamics of price transmission retrieved from a price transmission model could be utilized in a general or partial equilibrium model. SHARMA (2003) demonstrates the importance of precise measures of price 
transmission for equilibrium model outcomes and stresses its importance for further improving the quality of model results, particularly for small developing countries.

LISTERT AND ESPOSTI (2008) aim to make world prices for soft grain endogenous by connecting a vector error correction model with an EU aggregated model (AGMEMOD) composed of individual EU country models, which are in turn made up of individual commodity models. They proceed as follows. First, the VECM for soft wheat is estimated based on monthly price data for the EU key market (France) and the world market represented by the US market. This allows capturing short-run adjustments e.g. to seasonality. Next, the data observations and model estimates are transformed from monthly to yearly, which requires that the short-run dynamics are simplified. Third, the VECM based on yearly observations is included in the AGMEMOD model as the dynamic simultaneous price formation equation determining how the price for soft wheat is formed in the key market. This key price is transmitted to the other EU domestic markets according to the price transmission equation. Clearly, this is a promising area in which further research can be expected.

\section{Non-linear cointegration}

Most existing price transmission models are still based on the assumption of constant transaction costs, although transaction costs may not be constant over the period under study. For example, transport costs might be substantially higher during harvest season due to increased demand for transport services. Also, if the risks of trade increase, e.g. over flown roads during rain season, or due to war, transaction costs increase. Besides, transaction costs might change permanently due to a change in the transport or marketing infrastructure or due to a policy change.

Disregarding changes in the transaction costs might imply that meaningful conclusions can not be drawn. In chapter 7 we have reviewed existing VECM model approaches accounting for non-linearities in the long-run equilibrium relationship. We have further contributed to this literature by proposing a regime-specific VECM in which non-linearity depends on the size of a stationary threshold variable.

Though some other than VECM model frameworks have been developed recently to allow for non-linearity in transaction costs.

For example, VAN CAMPENHOUT (2007) includes a time trend in a symmetric self-exciting threshold autoregressive (SETAR) model, a threshold autoregressive (TAR) model where the transition (price change) depends on a lag of the process (lagged price in level) itself, to allow market integration to change over time. In this model the process of market integration is 
determined by transaction costs and the speed of price adjustment. The size of transaction costs is mainly the result of the costs and risks of trade between the markets whereas the speed of price adjustment is influenced by e.g. the quality of communication infrastructure between markets. The model accounts for transaction costs by distinguishing price adjustments (changes) smaller than a threshold determined by the size of transaction costs from price changes which exceed the threshold.

To allow for gradual changes in transaction costs and the adjustment parameter over time, a time trend is added in the threshold as well as in the adjustment parameter variable. Alternatively, to capture sudden changes in these parameters VAN CAMPENHOUT (2007) suggests including a dummy variable instead.

NEGASSA AND MyERS (2007) suggest an extension of the parity bounds model (PBM) to account for changing transaction costs. The standard PBM assumes that the probability of the distinguished regimes of spatial price equilibrium prevailing between two markets remains constant over time. NEGASSA AND MYERS (2007) modify the PBM to allow e.g. policy changes or investments in marketing infrastructure to have a gradual dynamic effect on trading regime probabilities (pg. 339). The regime probabilities may change over time by introducing a transition variable characterizing the time path of adjustment in regime probabilities in the joint probability density function as well as the likelihood function.

It can be expected that further more flexible model approaches capturing non-linearity in the long-run equilibrium relationship will be proposed in the future.

\section{References}

ABDULAI, A. (2006): Spatial integration and price transmission in agricultural commodity markets in sub-Saharan Africa, in: SARRIS, A. AND D. HALlAM (eds.): Agricultural Commodity Markets and Trade: New Approaches to Analyzing Market Structure and Instability, Edward Elgar, Cheltenham, USA.

AKer, J. (2007): Cereal Markets Performance during Food Crises: The Case of Niger in 2005. mimeo, http://papers.ssrn.com/sol3/papers.cfm?abstract_id=1004426

AMIKUZUNO. J. (2007): The Implication of Trade Liberalization Policy for Market Integration and Welfare in Ghana: An Experience with Tomato Markets, Paper presented at the DARE PhD Seminar, University of Goettingen, November 20, 2007.

BALKe, N.S. AND T.S. FomBY (1997): Threshold Cointegration, International Economic Review, Vol. 38(3): 627-645.

BAlcombe, K.; A. BAILEY AND J. BROOKS (2007): Threshold Effects in Price Transmission: The Case of Brazilian Wheat, Maize, and Soya Prices, American Journal of Agricultural Economics, Vol. 89(2): 308-323.

BARRETT, C. (2001): Measuring integration and efficiency in international agricultural markets, Review of Agricultural Economics, Vol. 23(1): 19-32. 
BAulch, B. (1997): Transfer Costs, Spatial Arbitrage and Testing for Food Market Integration, American Journal of Agricultural Economics, Vol. 79: 477-487.

VAn CAMPEnhout, B. (2007): Modelling trends in food market integration: Method and an application to Tanzanian markets, Food Policy, 32: 112-127.

VON CRAMON-TAUBADEL, S: (1998): Estimating asymmetric price transmission with the error correction representation: An application to the German pork market, European Review of Agricultural Economics, Vol. 25: 1-18.

VON CRAmon-TAubadel, S., J.P. Loy AND J. MeYer (2006): The Impact of Cross-Sectional Data Aggregation on the Measurement of Vertical Price Transmission: An Experiment with German Food Prices, in: Agribusiness, Vol. 22 (4): 1-18.

Deaton, A. AND G. LAROQue (1992): On the Behaviour of Commodity Prices, The Review of Economic Studies, 59 (1): 1-23.

FACKLER, P. AND B. GoOdwIN (2001): Spatial Price Analysis, in: Gardner, B. and G. Rausser (eds.): Handbook of Agricultural Economics, Vol. 1B: 971-1024.

FACKLER, P. AND H. TASTAN (2008): Estimating the Degree of Market Integration, American Journal of Agricultural Economics, Vol. 90(1): 69-85.

Goetz, L. And S. von Cramon-Taubadel (2008): Asymmetric Price Transmission in the Israeli Citrus Export Sector in the Aftermath of Liberalization, in: HeIßENHUBER, A., L. Kirner, S. Poechtrager AND K. SAlHOFER (2008): Conference proceedings of the GeWiSoLa $47^{\text {th }}$ Annual Conference "Agrar- und Ernaehrungswirtschaft im Umbruch", September 26-28, 2007, Munich, Germany.

Hansen, G. And B. Seo (2002): Testing for Two Regime Treshold Cointegration in Vector Error-Correction Models, Journal of Econometrics, Vol. 110: 293-318.

IHLE, R. AND S. VON CRAMON-TAUBADEL (2008): A comparison of threshold cointegration and Markov switching vector error correction models in price transmission analysis, Paper accepted for presentation at the 2008 NCCC-134 Conference on Applied Commodity Price Analysis, Forecasting and Market Risk Management, April 21-22, 2008, St. Louis, Missouri, USA.

Jensen, R. (2007): The Digital Provide: Information (Technology), Market Performance, and Welfare in the South Indian Fisheries Sector, The Quartely Journal of Economics, Vol. CXXII (3): 879-923.

LISTORTI, G. AND R. ESPOSTI (2008): Making the world market price endogenous within the AGMEMOD modeling framework: an econometric solution, Contributed paper, $107^{\text {th }}$ EAAE Seminar "Modelling Agricultural and Rural Development Policies", Sevilla, Spain, January 29-February 1, 2008.

KinnuCAn, H. ET AL. (forthcoming): Asymmetric Farm-Retail Price Transmission and Market Power: A New Test, mimeo.

MBAYA, E. (2003): Smallholder agricultural markets in Zimbabwe: Organization, spatial integration and equilibrium, $\mathrm{PhD}$ thesis, Cornell University.

Meyer, J. AND S. von Cramon-Taubadel (2004): Asymmetric Price Transmission: A Survey, Journal of Agricultural Economics, Vol. 55: 581-611.

Negassa, A. AND R. J. Myers (2007): Estimating Policy Effects on Spatial Market Efficiency: An Extension to the Parity Bounds Model, American Journal of Agricultural Economics, Vol. 89(2): 338-352. 
RAPsomanikis, G., D. Hallam AND P. CONFORTI (2006): Market integration and price transmission in selected food and cash crop markets of developing countries: review and applications, in: SARRIS, A. AND D. HALlAM (eds): Agricultural Commodity Markets and Trade: New Approaches to Analyzing Market Structure and Instability, Edward Elgar, Cheltenham, USA.

Sharma, S. (2003): The Transmission of World Price Signals: The Concept, Issues and some Evidence from Asian Cereal Markets, in: OECD: Agricultural Trade and Poverty: Making Policy Analysis Count, Paris.

Stephens, E.; E. Mabaya, S. von Cramon-Taubadel and C. Barrett (forthcoming): Spatial Market Dynamics and Trade Regimes.

TAKAYAMA, T. AND G. JUdGE (1971): Spatial and temporal price and allocation models. Amsterdam, North-Holland.

ZMP (2007): Ökomarkt-Jahrbuch : Verkaufspreise im ökologischen Landbau, Bonn. 